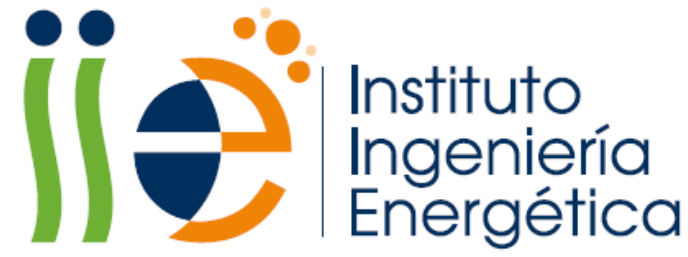

\title{
High capacity heat pump development for sanitary hot water production
}

\author{
PhD Thesis
}

Miquel Pitarch i Mocholí

\author{
Supervisors \\ Dr. D. José Gonzálvez Maciá \\ Dr. D. Emilio Navarro Peris
}

March 2017 

L'home viu d'emocions, no del seu currículum

Kilian Journet 



\section{Acknowledgments}

En primer lloc volia donar-li les gràcies als meus directors de tesis, José Gonzálvez i Emilio Navarro, perquè sense ells aquest treball no haguera sigut possible. Gràcies per donar-me l'oportunitat de treballar en el projecte Europeu NxtHPG, per tot el que m'heu ensenyat, pels bons consells i per les hores que hem passat analitzant els resultats o especulant sobre algun problema concret.

Gràcies als meus companys del IIE, sobretot a tots aquells que en alguna mesura han participat en aquest projecte, en especial a José Miguel, Carla, i Alex, amb qui he passat moltes hores barallant-nos amb sensors, vàlvules d'expansió i altres aparells del dimoni. També volia nomenar a Estefania, qui continuarà amb el treball d'aquesta tesi, i amb qui, juntament amb Emilio, hem passat unes quantes hores donant-li voltes i repensant els cicles termodinàmics.

Gràcies també als participants del projecte Europeu "Next Generation of Heat Pumps working with Natural fluids", de qui també he aprés moltes coses.

Des d'una perspectiva més personal, volia començar nomenant a aquells que varen començar amb mi aquesta aventura universitària, en especial a Ausiàs, i com no a Guillermo, a qui vaig conéixer en la cua per a la matrícula d'industrials, i que 10 anys després hem viscut tantíssimes coses junts.

To those guys who I met during my two years in Denmark and we became friends for life, the Xafaets: Andrea, Cristian and Niccolo.

Als meus amics d'infància, d'adolescència, edat adulta, i segur que vellesa, Irak, Gabi (Pollo), i com no Jorge (Puxi) amb qui he compartit tantes hores de confidències, moments bons i roïns, però sobretot reconfortants.

A Marinna, o meu sol do meio-dia, perquè el seu somriure ja m'alegra el dia, per tots els projectes que tenim i perquè amb ella sempre podré dir cueca.

Per últim volia donar-li les gràcies a la meua família. Als meus germans Gabi i José, qui m’ha fet tio de les xiquetes més boniques del món, Olga i Núria. A ma Mare, perquè és una lluitadora, però sobretot una somiadora, en part li dec a ella la meua forma de ser. Però si he de dedicar aquesta tesi a algú, és a ell, a l'home del somriure permanent, a qui li dec l'altra part de la meua forma de ser, a mon Pare. 



\section{Abstract}

Heat pumps have been identified as an efficient alternative to traditional boilers for the production of sanitary hot water (SHW). The high water temperature lift (usually from $10^{\circ} \mathrm{C}$ to $60^{\circ} \mathrm{C}$ ) involved in this application has conditioned the type of used solutions. On the one hand, transcritical cycles have been considered as one of the most suitable solutions to overcome the high water temperature lift. Nevertheless, the performance of the transcritical $\mathrm{CO}_{2}$ heat pump is quite dependent on the water inlet temperature, which in many cases is above $10^{\circ} \mathrm{C}$. Furthermore, performance highly depends on the rejection pressure, which needs to be controlled to work at the optimum point in any condition. On the other hand, for the subcritical systems, subcooling seems to be critical for the heat pump performance when working at high temperature lifts, but there is not any published work that optimizes subcooling in the SHW application for these systems. Therefore, the subcritical cycle should require a systematic study on the subcooling that optimizes COP depending on the external conditions, in the same way as it has been done for the rejection pressure in the transcritical cycle.

The aim of this thesis is to investigate the role of subcooling in the performance of a Propane water-to-water heat pump for SHW production, in the application of heat recovery from any water source. Two different approaches to overcome the high degree of subcooling were designed and built to test them in the laboratory:

1) Subcooling is made at the condenser: The active refrigerant charge of the system is controlled by a throttling valve. Subcooling is controlled independently at any external condition.

2) Subcooling is made in a separate heat exchanger, the subcooler. Subcooling is not controlled, it depends on the external condition and the heat transfer at the subcooler.

The heat pumps were tested at different water temperatures at the evaporator inlet $\left(10^{\circ} \mathrm{C}\right.$ to $\left.35^{\circ} \mathrm{C}\right)$ and condenser inlet $\left(10^{\circ} \mathrm{C}\right.$ to $\left.55^{\circ} \mathrm{C}\right)$, while the water production temperature was usually fixed to $60^{\circ} \mathrm{C}$. The obtained results have shown that COP depends strongly on subcooling. In the nominal condition $\left(20^{\circ} \mathrm{C} / 15^{\circ} \mathrm{C}\right.$ for the inlet/outlet water temperature at the evaporator and $10^{\circ} \mathrm{C} / 60^{\circ} \mathrm{C}$ for the inlet/outlet water temperature in the heat sink), the optimum subcooling was about $43 \mathrm{~K}$ with a heating COP of 5.61, which is about $31 \%$ higher than the same 
cycle working without subcooling. Furthermore, the system with subcooling has been proved experimentally as being capable of producing water up to $90^{\circ} \mathrm{C}$ and has shown a higher $\mathrm{COP}$ than some $\mathrm{CO}_{2}$ commercial products (catalog data reference). 


\section{Resum}

Les bombes de calor han estat identificades com una alternativa eficaç a les calderes tradicionals per a la producció d'aigua calenta sanitària (ACS). L'elevat salt de temperatura de l'aigua que normalment té lloc en aquesta aplicació (en general de $10^{\circ} \mathrm{C}$ a $60^{\circ} \mathrm{C}$ ) ha condicionat el tipus de solucions que s'utilitzen. Per una banda, els cicles transcrítics s'han considerat com una de les millors solucions per tal de treballar amb els elevats salts de temperatura de l'aigua. No obstant això, el rendiment de la bomba de calor transcrítica amb $\mathrm{CO}_{2}$ és bastant dependent de la temperatura d'entrada de l'aigua, que en molts casos està per damunt de $10^{\circ} \mathrm{C}$. A més, el rendiment depèn en gran mesura de la pressió de descarrega, la qual necessita ser controlada per tal de treballar en el punt òptim a qualsevol condició externa. Per altra banda, per als sistemes subcrítics, el sub-refredament sembla ser crític per al funcionament de la bomba de calor quan es treballa amb elevats salts de temperatura de l'aigua, però no hi ha cap treball publicat en el qual optimitzen el sub-refredament per a l'aplicació d'ACS en aquests sistemes. Per tant, els sistemes subcrítics requereixen d'un estudi sistemàtic per tal de buscar el subcooling òptim i maximitzar el COP en funció de les condicions externes, en la mateixa forma que s'ha fet per la pressió de descarrega en els cicles transcrítics.

L'objectiu d'aquesta tesi és investigar el paper del sub-refredament en el rendiment d'una bomba de calor treballant amb Propà per a la producció d'ACS, en l'aplicació de recuperació de calor de qualsevol font d'aigua (aigua-aigua). Dos enfocaments diferents per tal de superar l'alt grau de sub-refredament van ser dissenyats i construïts per posar-los a prova en el laboratori:

1) El sub-refredament es fa en el condensador: La càrrega activa de refrigerant del sistema es controla amb una vàlvula d'estrangulació. D'aquesta manera, el sub-refredament pot ser controlat de forma independent en qualsevol condició externa.

2) El sub-refredament es fa en un intercanviador de calor separat, el subrefredador. El sub-refredament no es controla, este depèn de la condició externa i de la transferència de calor al sub-refredador.

Les bombes de calor es van assajar a diferents temperatures de l'aigua a l'entrada de l'evaporador $\left(10^{\circ} \mathrm{C}\right.$ a $\left.35^{\circ} \mathrm{C}\right)$ i a l'entrada del condensador $\left(10^{\circ} \mathrm{C}\right.$ a $55^{\circ} \mathrm{C}$ ), mentre que la temperatura de producció d'aigua, normalment, es fixa a $60^{\circ} \mathrm{C}$. 
Els resultats obtinguts han demostrat que el COP depèn molt del sub-refredament. En les condicions nominals $\left(20^{\circ} \mathrm{C} / 15^{\circ} \mathrm{C}\right.$ per a la temperatura de l'aigua d'entrada/eixida a l'evaporador i $10^{\circ} \mathrm{C} / 60^{\circ} \mathrm{C}$ per a la temperatura de l'aigua d'entrada/eixida en el condensador), el sub-refredament òptim és aproximadament de $43 \mathrm{~K}$ amb un COP d'escalfament de 5,61, que és al voltant del $31 \%$ més alt que el mateix cicle treballant sense sub-refredament. A més, el sistema amb sub-refredament ha provat de forma experimental, que és capaç de produir aigua fins als $90^{\circ} \mathrm{C}$, i ha mostrat un COP més alt que alguns productes comercials que treballen amb $\mathrm{CO}_{2}$ (dades de referència del catàleg). 


\section{Resumen}

Las bombas de calor han sido identificadas como una alternativa eficaz a las calderas tradicionales para la producción de agua caliente sanitaria (ACS). El elevado salto de temperatura del agua que normalmente tiene lugar en esta aplicación (por lo general de $10^{\circ} \mathrm{C}$ a $60^{\circ} \mathrm{C}$ ) ha condicionado el tipo de soluciones que se utilizan. Por un lado, los ciclos transcríticos han sido considerados como una de las mejores soluciones para trabajar con los elevados saltos de temperatura del agua. Sin embargo, el rendimiento de la bomba de calor transcrítica con $\mathrm{CO}_{2}$ es bastante dependiente de la temperatura de entrada del agua, que en muchos casos está por encima de los $10^{\circ} \mathrm{C}$. Además, el rendimiento depende en gran medida de la presión de descarga, la cual necesita ser controlada con el fin de trabajar en el punto óptimo en cualquier condición externa. Por otra parte, para los sistemas subcríticos, el subenfriamiento parece ser crítico para el buen funcionamiento de la bomba de calor cuando se trabaja con elevados saltos de temperatura del agua, pero no hay ningún trabajo publicado en el que optimicen el subenfriamiento para la aplicación de ACS en estos sistemas. Por lo tanto, los sistemas subcríticos requieren de un estudio sistemático para buscar el subcooling óptimo y maximizar el COP en función de las condiciones externas, de la misma forma que se ha hecho para la presión de descarga en los ciclos transcríticos.

El objetivo de esta tesis es investigar el papel del subenfriamiento en el rendimiento de una bomba de calor trabajando con Propano para la producción de ACS, en la aplicación de recuperación de calor de cualquier fuente de agua (aguaagua). Dos enfoques diferentes para superar el alto grado de subenfriamiento fueron diseñados y construidos para ponerlos a prueba en el laboratorio:

1) El subenfriamiento se hace en el condensador: La carga activa de refrigerante del sistema se controla con una válvula de estrangulación. De esta manera, el subenfriamiento puede ser controlado de forma independiente a cualquier condición externa.

2) El subenfriamiento se hace en un intercambiador de calor separado, el subenfriadador. El subenfriamiento no se controla, este depende de la condición externa y de la transferencia de calor en el subenfriadador.

Las bombas de calor se ensayaron a diferentes temperaturas del agua a la entrada del evaporador $\left(10^{\circ} \mathrm{C}\right.$ a $\left.35^{\circ} \mathrm{C}\right)$ y entrada del condensador $\left(10^{\circ} \mathrm{C}\right.$ a $\left.55^{\circ} \mathrm{C}\right)$, 
mientras que la temperatura de producción de agua, normalmente, se fija a $60^{\circ} \mathrm{C}$. Los resultados obtenidos han demostrado que el COP depende mucho del subenfriamiento. En las condiciones nominales $\left(20^{\circ} \mathrm{C} / 15^{\circ} \mathrm{C}\right.$ para la temperatura del agua de entrada/salida en el evaporador y $10^{\circ} \mathrm{C} / 60^{\circ} \mathrm{C}$ para la temperatura del agua de entrada/salida en el condensador), el subenfriamiento óptimo fue aproximadamente de $43 \mathrm{~K}$ con un COP de calentamiento de 5,61, que es alrededor del 31\% más alto que el mismo ciclo trabajando sin subenfriamiento. Además, el sistema con subenfriamiento ha probado de forma experimental, que es capaz de producir agua hasta los $90^{\circ} \mathrm{C}$, y ha mostrado un COP más alto que algunos productos comerciales que trabajan con $\mathrm{CO}_{2}$ (datos de referencia del catálogo). 


\section{Contents}

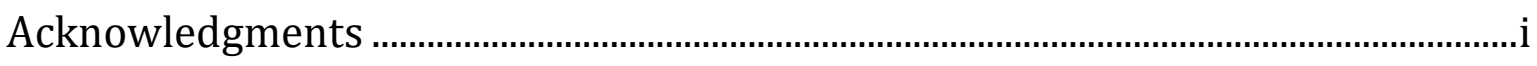

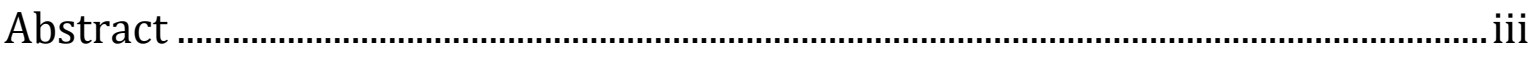

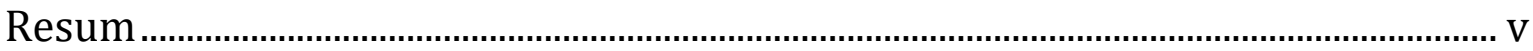

Resumen

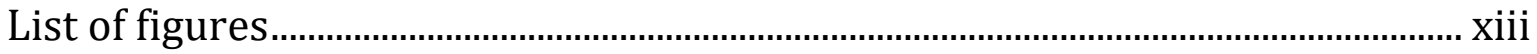

List of tables........................................................................................................

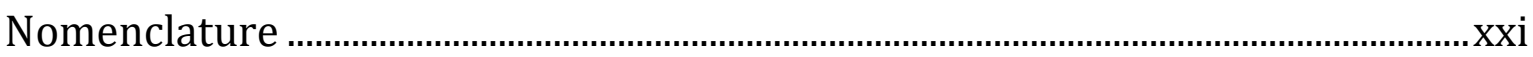

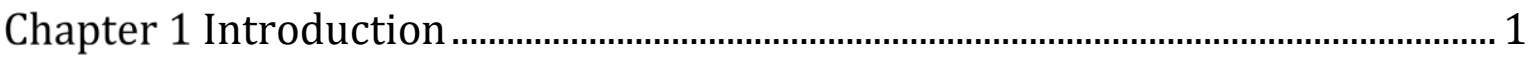

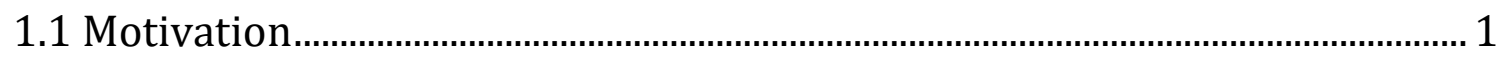

1.2 Conditions for the waste heat recovery and the SHW application ................ 4

1.2.1 Waste heat recovery ............................................................................................. 4

1.2.2 SHW application...................................................................................... 5

1.3 Natural refrigerants for the SHW application ................................................... 7

1.3.1 The transcritical $\mathrm{CO}_{2}$ cycle......................................................................... 8

1.3.2 Propane (R290) for the SHW application .................................................12

1.4 Objectives...........................................................................................................

Chapter 2 Theoretical analysis.......................................................................................19

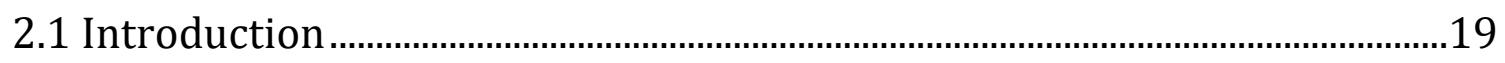

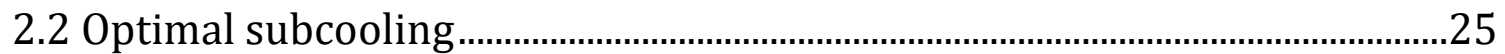

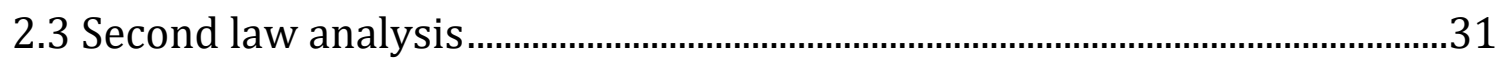

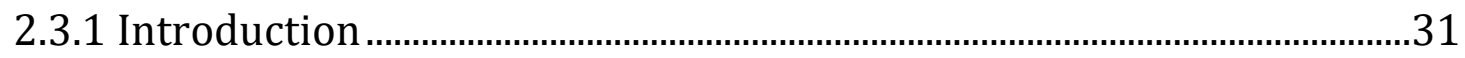

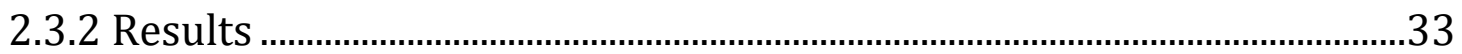

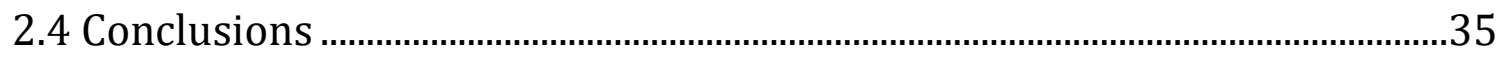

Chapter 3 Heat pump: concept and designs.................................................................37

3.1 Subcooling made in the condenser (SMC heat pump) …………………….......38

3.2 Subcooler in series with condenser (SMS heat pump) .....................................40 
3.3 Heat Pump prototype: the real implementation of the systems ...................41

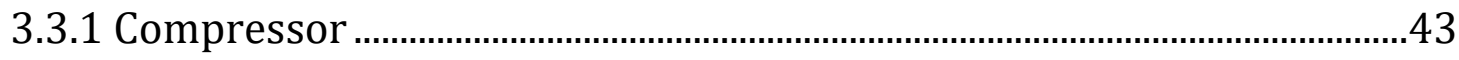

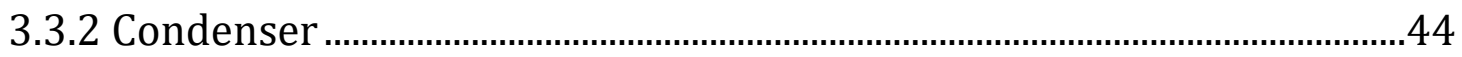

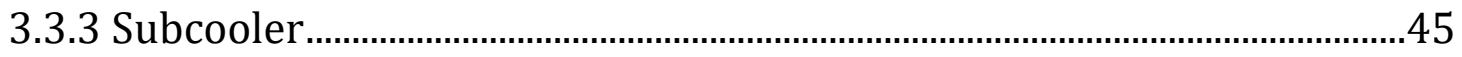

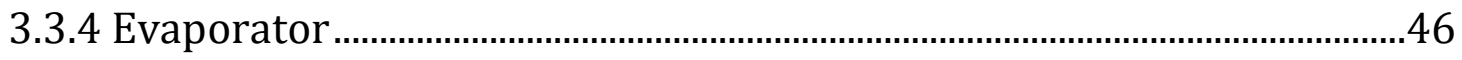

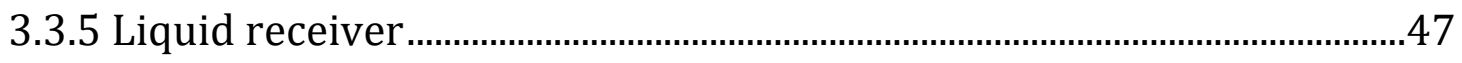

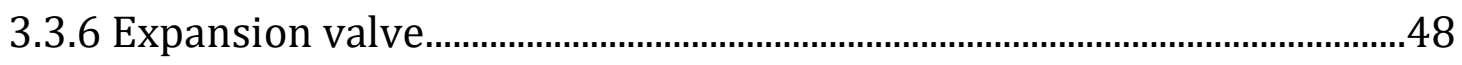

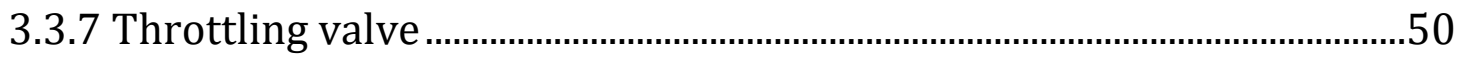

Chapter 4 Experimental setup and test conditions .................................................51

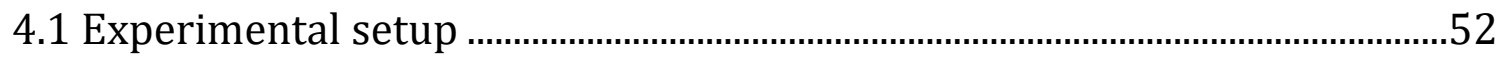

4.1.1 Water loop for the heat source (Evaporator) ...........................................54

4.1.2 Water loop for the heat sink (Condenser)..................................................55

4.1.3 Water/glycol loop and chiller working with R410A …............................56

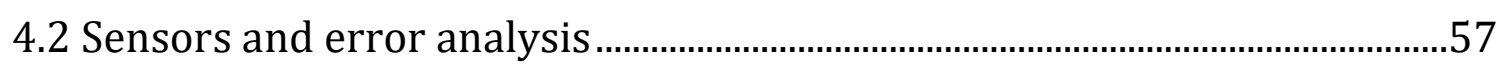

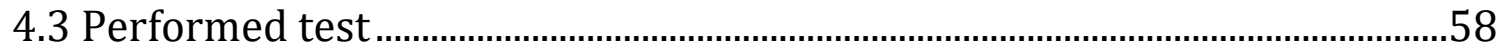

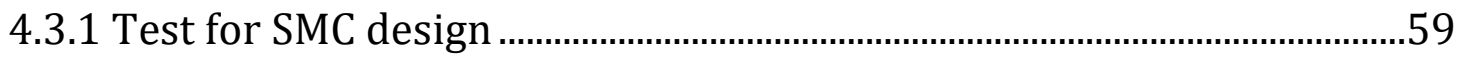

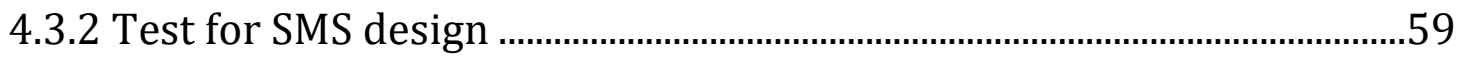

Chapter 5 Experimental results and discussion.........................................................63

5.1 Subcooling in the condenser: SMC design..........................................................63

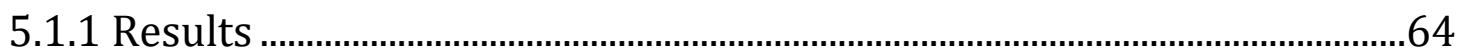

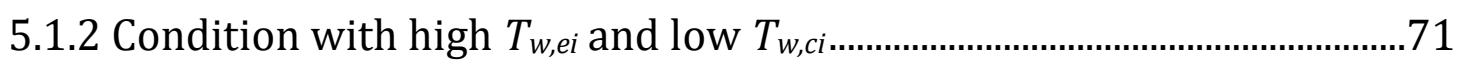

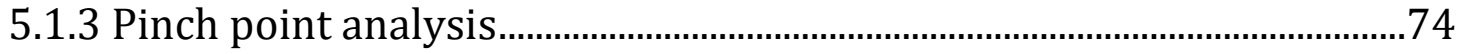

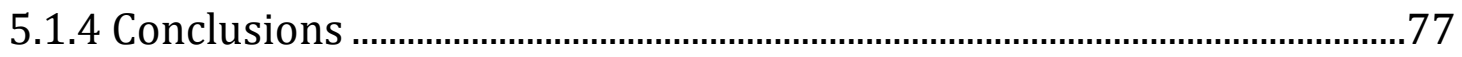

5.2 Subcooling in a separate heat exchanger: SMS design ...................................79

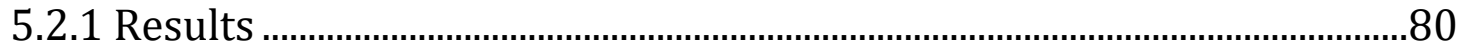

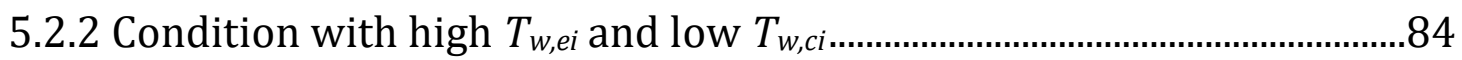

5.2.3 Comparison between the SMS (R290) and the reference $\mathrm{CO}_{2}$ heat pump

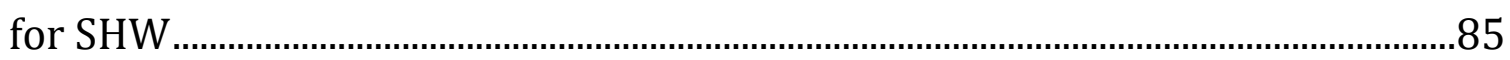

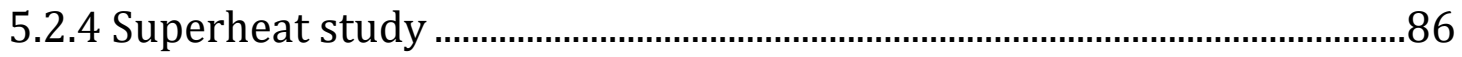

5.2.5 Thermography: Evaporator refrigerant distribution...............................88

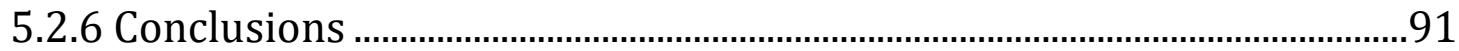


Chapter 6 Theoretical comparison between SMS and SMC

6.1 Model .94

6.1.1 Model validation: Subcooling made in the condenser (SMC). .94

6.1.2 Model adjustment to the heat pump with subcooler .96

6.2 Results .96

6.3 Conclusions 102

Chapter 7 General conclusions and future work 103

7.1 Conclusions 103

7.1.1 From the theoretical analysis 104

7.1.2 From the experimental results 104

7.2 Future work 106

7.2.1 Integration in a real system 106

7.2.2 Improvement of the heat pump design 107

References 109

Appendix A The importance of heat pump liquid receiver configuration on the impact during transient behavior.

A.1 Abstract.

A.2 Introduction

A.3 Experimental setup

A.3.1 Refrigerant cycle.

A.3.2 Liquid receiver design.

A.3.3 Test procedure

A.4 Results ...

A.4.1 Inlet elbow downwards.

A.4.2 Inlet elbow upwards

A.5 Conclusions.

Appendix B Results and error analysis.

B.1 Auxiliary consumption.

B.2 Uncertainty

B.3 Experimental results for the SMC design

B.4 Results for the SMS design 



\section{List of figures}

Figure 1.1: Sketch of a heat pump connected to the stratified storage system ............ 6

Figure 1.2: Sketch of a transcritical $\mathrm{CO}_{2}$ cycle with high-pressure control in the

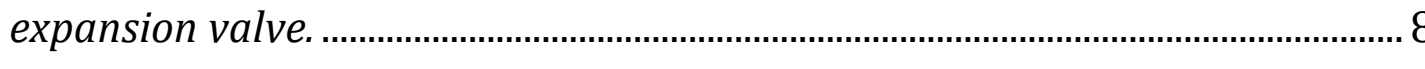

Figure 1.3: Illustration of the tight dependency between the rejection pressure, the pinch point and the $\mathrm{CO}_{2}$ outlet temperature from the gas cooler for a $\mathrm{CO}_{2}$ heat pump water heater.

Figure 1.4: COP dependency with water inlet temperature for different subcritical refrigerants without subcooling and the transcritical $\mathrm{CO}_{2}$ cycle working at the optimal rejection pressure. Water outlet temperature $60^{\circ} \mathrm{C}$. (Pitarch et al., 2014)

Figure 1.5: Sketch of a subcritical R290 cycle with superheat control in the expansion valve and working without subcooling.

Figure 1.6: Illustration of the tight dependency between the subcooling, the pinch point and the R290 outlet temperature from the condenser for an R290 subcritical heat pump water heater.

Figure 2.1: P-h diagram for propane cycles. 20

Figure 2.2: a) Heating COP as a function of subcooling and condensing temperature (Evaporating temperature $0^{\circ} \mathrm{C}$ ) b) Temperature limitation at the condenser

Figure 2.3: Temperature profile vs. normalized capacity, three subcoolings (infinite condenser assumption).

Figure 2.4: Temperature profile vs. normalized capacity (infinite condenser assumption) a) Water $10^{\circ} \mathrm{C}$ to $60^{\circ} \mathrm{C}$ b) Water $50^{\circ} \mathrm{C}$ to $60^{\circ} \mathrm{C}$

Figure 2.5: a) Heating COP as a function of subcooling b) Condensing temperature as function of subcooling (infinite condenser assumption).

Figure 2.6: Normalized heating COP as a function of the subcooling deviation from the subcooling with two pinch point a) R290 b) R134a c) R1234yf d) R32 $\left(\mathrm{T}_{\mathrm{sf}, \mathrm{out}}=60^{\circ} \mathrm{C}\right)$ 
Figure 2.7: Optimal subcooling as a function of temperature difference in the heat sink.

Figure 2.8: Optimal subcooling as a function of the temperature difference in the heat sink. Different scenarios are considered. The reference is: isentropic compression, $\mathrm{T}_{\mathrm{e}}=0^{\circ} \mathrm{C}, \mathrm{Sh}=10 \mathrm{~K}$

Figure 2.9: T-s diagram for Carnot and Lorenz cycles. Zero temperature difference between refrigerant and secundary fluid (DT $=0 \mathrm{~K}$ ).

Figure 2.10: COP of Lorenz variation with the temperature lift in the $\operatorname{sink}\left(\mathrm{T}_{\mathrm{sf}, \text { out }^{-}}\right.$ $\mathrm{T}_{\mathrm{s} f, \mathrm{in}}$.

Figure 2.11: Second law efficiency at different inlet and outlet secondary fluid temperatures a) $\mathrm{R} 290 \mathrm{~b}$ ) $\mathrm{R} 744\left(\mathrm{CO}_{2}\right.$ ) c) R1234yf d) $\mathrm{R} 32$ (infinite heat transfer area assumption). All cycles are working at the optimal subcooling or rejection pressure.

Figure 3.1: Heat Pump with subcooling at the condenser controlled by a throttling valve a) Scheme, b) P-h diagram.

Figure 3.2: Heat Pump subcooler in series with condenser a) Scheme, b) P-h diagram.

Figure 3.3: Scheme of the heat pump prototype to measure the SMS and SMC designs.

Figure 3.4: Photo of the heat pump prototype to measure the SMS and SMC designs.

Figure 3.5: a) Compressor efficiency b) Volumetric efficiency as a function of the pressure ratio

Figure 3.6: Heating Cop for a finite heat exchanger (IMST-ART) respect to the infinite heat transfer assumption (5.7, the theoretical maximum) as a function of the number of plates in the condenser. Nominal point, subcooling fixed to $43.4 \mathrm{~K}$ (propane)

Figure 3.7: a) Pressure drop on the water side at the subcooler as a function of the water flow rate. b) Scheme of Condenser+Subcooler of the SMS design with a case study estimation (with IMST-ART)

Figure 3.8: From the left to the right: Scheme of the liquid receiver with the level sensor, The AKS 100 level sensor, a picture of the liquid receiver with the level sensor installed

Figure 3.9: Pressure-enthalpy diagram for the propane cycle: a) Low subcooling,

b) High subcooling.. 
Figure 3.10: Picture of the throttling valves: EX5 and EXL 125/B1G and schematic of the control for the throttling valve: PID $\rightarrow$ EXD-U00 $\rightarrow$ EX5 50

Figure 4.1: Overview scheme of the Test Rig with sensors. .53

Figure 4.2: Scheme of the evaporator water loop with typical temperatures .54

Figure 4.3: Scheme of the evaporator water loop with representative temperatures .55

Figure 4.4: Picture of the evaporator and condenser water loop in the test rig.....56

Figure 4.5: Scheme and picture of the water/glycol loop and chiller working with R410A 57

Figure 5.1: Heat Pump with subcooling controlled by a throttling valve a) Scheme, b) P-h diagram. .64

Figure 5.2: COP heating vs. subcooling (Maximum uncertainty \pm 0.08 ) : a) $\mathrm{T}_{\mathrm{w}, \mathrm{ei}}=$ $10^{\circ} \mathrm{C}$ c) $\mathrm{T}_{\mathrm{w}, \mathrm{ei}}=20^{\circ} \mathrm{C}$ e) $\mathrm{T}_{\mathrm{w}, \mathrm{ei}}=30^{\circ} \mathrm{C}$. Heating capacity vs. subcooling (Maximum uncertainty $\pm 0.05 \mathrm{~kW}$ ): b) $\mathrm{T}_{\mathrm{w}, \mathrm{ei}}=10^{\circ} \mathrm{C}$ d) $\mathrm{T}_{\mathrm{w}, \mathrm{ei}}=20^{\circ} \mathrm{C}$ f) $\mathrm{T}_{\mathrm{w}, \mathrm{ei}}=$ $30^{\circ} \mathrm{C} .\left(\mathrm{T}_{\mathrm{w}, \mathrm{co}}=60^{\circ} \mathrm{C}\right)$. 65

Figure 5.3: a) Subcooling and refrigerant outlet temperature at the condenser vs. $\mathrm{T}_{\mathrm{w}, \mathrm{ci}}$ at the maximum COP point (optimal subcooling) b) Condensing temperature vs. subcooling $\left(\mathrm{T}_{\mathrm{w}, \mathrm{co}}=60^{\circ} \mathrm{C}\right)$. .68

Figure 5.4: Evaporating temperature vs. subcooling $\left(\mathrm{T}_{\mathrm{w}, \mathrm{co}}=60^{\circ} \mathrm{C}\right)$ .69

Figure 5.5: Refrigerant quality at evaporator inlet. 70

Figure 5.6: Discharge temperature as a function of the condensing pressure........71

Figure 5.7: Pressure-Enthalpy diagram a) $\mathrm{T}_{\mathrm{w}, e i}=30^{\circ} \mathrm{C}$; $\mathrm{T}_{\mathrm{w}, \mathrm{ci}}=30^{\circ} \mathrm{C}$ b) $\mathrm{T}_{\mathrm{w}, e i}=30^{\circ} \mathrm{C}$; $\mathrm{T}_{\mathrm{w}, \mathrm{ci}}=10^{\circ} \mathrm{C}$ 72

Figure 5.8: Experimental analysis a) Temperature profile vs. normalized capacity: Refrigerant R290 with different subcooling and the secondary fluid going from $30^{\circ} \mathrm{C}$ to $60^{\circ} \mathrm{C}$. b) Pinch point temperatures as a function of subcooling.

Figure 5.9: Heat Pump subcooler in series with condenser a) Scheme, b) P-h diagram.

Figure 5.10: a) Heating COP, b) Heating capacity vs. inlet water temperature to subcooler for different water inlet temperature to the evaporator $\left(\mathrm{T}_{\mathrm{w}, \text { co }}=\right.$ $\left.60^{\circ} \mathrm{C}\right)$ 
Figure 5.11: a) Heating COP, b) Condensing temperature vs. inlet water temperature to subcooler, with and without subcooling $\left(\mathrm{T}_{\mathrm{w}, \mathrm{co}}=60^{\circ} \mathrm{C}\right) \ldots . .81$

Figure 5.12: a) Subcooling and refrigerant temperature at subcooler outlet, b) Refrigerant quality at inlet evaporator vs. inlet water temperature to subcooler for different water inlet temperature to the evaporator $\left(\mathrm{T}_{\mathrm{w}, \mathrm{co}}=\right.$ $\left.60^{\circ} \mathrm{C}\right)$

Figure 5.13: Pressure-Enthalpy diagram for condition: $\mathrm{T}_{\mathrm{w}, \mathrm{ei}}=30^{\circ} \mathrm{C} ; \mathrm{T}_{\mathrm{w}, \mathrm{ci}}=10^{\circ} \mathrm{C}$,

a) SMC design b) SMS design

Figure 5.14: Heating COP as a function of a) $\mathrm{T}_{\mathrm{w}, \mathrm{ci}}$ with $\mathrm{T}_{\mathrm{w}, \mathrm{co}}=60^{\circ} \mathrm{C}$ b) $\mathrm{T}_{\mathrm{w}, \mathrm{co}}$ with $\mathrm{T}_{\mathrm{w}, \mathrm{ci}}=30^{\circ} \mathrm{C}$.

Figure 5.15: Improvement when reducing superheat from $10 \mathrm{~K}$ to $5 \mathrm{~K}$ a) Total improvement b) Improvement per K of superheat

Figure 5.16: Picture of the evaporator and location of the input/output ports for refrigerant and water.

Figure 5.17: Thermography of evaporator $\left.\left(\mathrm{T}_{\mathrm{w}, \mathrm{ei}}=25^{\circ} \mathrm{C} ; \mathrm{T}_{\mathrm{w}, \mathrm{ci}}=10^{\circ} \mathrm{C} ; \mathrm{T}_{\mathrm{w}, \mathrm{co}}=60^{\circ} \mathrm{C}\right) \mathrm{a}\right)$

Superheat of $6 \mathrm{~K} \mathrm{~b}$ ) Superheat of $10 \mathrm{~K} \mathrm{c}$ ) Superheat of $17 \mathrm{~K}$.

Figure 5.18: Thermography of evaporator $\left.\left(\mathrm{T}_{\mathrm{w}, \mathrm{ei}}=25^{\circ} \mathrm{C} ; \mathrm{T}_{\mathrm{w}, \mathrm{co}}=60^{\circ} \mathrm{C} ; \mathrm{Sh}=10 \mathrm{~K}\right) \mathrm{a}\right)$ $\mathrm{T}_{\mathrm{w}, \mathrm{ci}}=10^{\circ} \mathrm{C}$ b) $\left.\mathrm{T}_{\mathrm{w}, \mathrm{ci}}=15^{\circ} \mathrm{C} \mathrm{c}\right) \mathrm{T}_{\mathrm{w}, \mathrm{ci}}=30^{\circ} \mathrm{C}$ .90

Figure 6.1: Model validation; a) heating COP, b) condensing pressure. $\left(\mathrm{T}_{\mathrm{w}, \mathrm{ei}}=20^{\circ} \mathrm{C}\right)$

Figure 6.2: Results for two condenser height; a) heating COP, b) condensing pressure. $\left(\mathrm{T}_{\mathrm{w}, \mathrm{ei}}=20^{\circ} \mathrm{C}\right)$

Figure 6.3: Percentage of the area dedicated for subcooling as a function of subcooling and $\mathrm{T}_{\mathrm{w}, \mathrm{ci}}$ (SMCL and the fixed area for SMS). $\left(\mathrm{T}_{\mathrm{w}, \mathrm{ei}}=20^{\circ} \mathrm{C}\right) \ldots . . .98$

Figure 6.4: a) Heating COP and b) condensing pressure as a function of subcooling and condenser size $\left(\mathrm{T}_{\mathrm{w}, \mathrm{ci}}=30^{\circ} \mathrm{C}, \mathrm{T}_{\mathrm{w}, \mathrm{co}}=60^{\circ} \mathrm{C}\right.$ and $\left.\mathrm{T}_{\mathrm{w}, \mathrm{ei}}=20^{\circ} \mathrm{C}\right)$

Figure 6.5: a) Condenser-dedicated area as a function of condenser size, b) refrigerant and water temperature profile in the condenser $\left(\mathrm{T}_{\mathrm{w}, \mathrm{ci}}=30^{\circ} \mathrm{C}\right.$, $\mathrm{T}_{\mathrm{w}, \mathrm{co}}=60^{\circ} \mathrm{C}$ and $\mathrm{T}_{\mathrm{w}, \mathrm{ei}}=20^{\circ} \mathrm{C}$ ). 100

Figure 6.6: Heating COP as a function of subcooling for $\mathrm{T}_{\mathrm{w}, \mathrm{ei}}=30^{\circ} \mathrm{C}$ and $\mathrm{T}_{\mathrm{w}, \mathrm{ci}}=10^{\circ} \mathrm{C}$.

Figure 7.1: System layout of the heat pump with an additional recovery heat exchanger

Figure 7.2: Heat Pump with subcooling controlled by the expansion valve. 107 
Figure A. 1: a) Typical combinations of inlet and outlet ports. b) Type of connection to the unit (Corberán, 2010).

Figure A. 2: Subcooler in series with condenser a) Scheme, b) P-h diagram........120

Figure A. 3: Scheme of the LR, the liquid sensor and a detail of the two port configurations.

Figure A. 4: Transient behavior for inlet "elbow looking downwards" a) liquid level, b) Subcooling.

Figure A. 5: Transient behavior for "inlet elbow looking upwards" a) liquid level, b) Subcooling. 



\section{List of tables}

Table 2.1: Optimal subcooling and heating COP, and the degree of improvement respect the case without subcooling for different secondary fluid

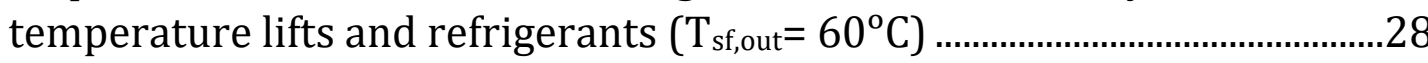

Table 3.1: Components of the HP system …………………............................................4

Table 4.1: Sensors and their uncertainty ………………………………………………....58

Table 4.2: Test matrix with a total number of 68 measured points.............................59

Table 4.3: Test matrix with a total number of 42 measured points. ${ }^{*}$ Water mass flow ratio between subcooler and condenser .....................................................60

Table 5.1: Heating COP increase for $\mathrm{T}_{\mathrm{w}, \mathrm{ci}}=10^{\circ} \mathrm{C}$ compared to $\mathrm{T}_{\mathrm{w}, \mathrm{ci}}=50^{\circ} \mathrm{C}$. .66

Table 5.2: Optimal subcooling and COP for the model (chapter 2) and experiments. The evaporating temperature in the model is considered $\mathrm{T}_{\text {evap }}=\mathrm{T}_{\mathrm{w}, \mathrm{ei}}-10$ (10 $\mathrm{K}$ of subcooling).

Table 5.3: Normalized $\mathrm{COP}_{h}$ at different $\mathrm{DT}_{\mathrm{a}}$ and $\mathrm{DT}_{\mathrm{b}}$ for different cases.

Experimental results .76

Table 5.4: $\mathrm{DT}_{\mathrm{a}}$ and $\mathrm{DT}_{\mathrm{b}}$ for different cases. Results with the software IMST-ART. $\left(\mathrm{T}_{\mathrm{w}, \mathrm{co}}=60^{\circ} \mathrm{C}\right)$

Table 5.5: SMS experimental results for different water temperature production $\left(\mathrm{T}_{\mathrm{w}, \mathrm{co}}\right) . \mathrm{T}_{\mathrm{w}, \mathrm{ci}}$ is fixed to $30^{\circ} \mathrm{C}$.

Table 5.6: Comparison of results at different Superheats 87

Table 6.1: SMC model validation at the optimum subcooling $\left(\mathrm{T}_{\mathrm{w}, \mathrm{ei}}=20^{\circ} \mathrm{C}\right)$. .95

Table 6.2: Experimental SMS and SMCL model comparison at optimal subcooling. $\left(\mathrm{T}_{\mathrm{w}, \mathrm{ei}}=20^{\circ} \mathrm{C}\right)$. .98

Table B. 1: Experimental results and uncertainties for the SMC design. 130

Table B. 2: Experimental results and uncertainties for the SMS design 134 



\section{Nomenclature}

$\begin{array}{ll}\text { COP } & \text { Coefficient of Performance, }[-] \\ c_{p} & \text { Specific heat capacity }\left[\mathrm{kJ} \mathrm{kg}^{-1} \mathrm{~K}^{-1}\right] \\ D T & \text { Temperature difference at pinch point }[\mathrm{K}] \\ h & \text { Specific enthalpy }\left[\mathrm{kJ} \mathrm{kg}^{-1}\right] \\ \dot{m} & \text { Mass flow rate }\left[\mathrm{kg} \mathrm{s}^{-1}\right] \\ p & \text { Pressure [bar] } \\ \dot{Q} & \text { Rate of heat transfer, }[\mathrm{kW}] \\ R & \text { Calculated variable } \\ S & \text { Specific entropy }\left[\mathrm{kJ} \mathrm{kg}{ }^{-1} \mathrm{~K}^{-1}\right] \\ S & \text { Sample standard deviation } \\ S c & \text { Subcooling, }[\mathrm{K}] \\ S h & \text { Superheat, }[\mathrm{K}] \\ S . F l u i d & \text { Secondary Fluid } \\ t & \text { Student multiplier } \\ T & \text { Temperature }\left[{ }^{\circ} \mathrm{C}\right] \\ U & \text { Uncertainty } \\ \dot{V} & \text { Volumetric flow rate }\left[\mathrm{m}^{3} \mathrm{~s}^{-1}\right] \\ \dot{W} & \text { Rate of work, power }\left[\mathrm{kW}^{-1}\right. \\ X & \text { Measured variable }\end{array}$

\section{Greek symbols}

$\delta$

differential

$\Delta \quad$ Variation

$\eta \quad$ Efficiency

$\partial \quad$ Partial derivative 


\section{Subscripts}

0

Reference environment

$1,2,3, \ldots \quad$ State points of the cycle (Figure $3 b$ )

II Second law

a Pinch point at heat exchanger outlet

aux Auxiliary (Such as the water pumps)

$b \quad$ Pinch point at the refrigerant dew point (inside of condenser)

c Condenser

C Heat source

Carnot Ideal cycle with constant temperatures

comp Compressor

disch Discharge

D_Pinch Double pinch point situation

evap evaporator

Finite The size of the heat exchanger is considered

gc Gas Cooler

h Heating

$H \quad$ Heat sink

hydraulic Due to water as secondary fluid

in inlet

infinite Infinite heat transfer area assumption

Lorenz Ideal cycle for variable temperatures

LR Liquid Receiver

norm Normalized

opt Optimal

out Outlet

pinch pinch point

refer Reference conditions

rev Reversible Cycle

sf secondary fluid, heat sink

sub Subcooler 


$\begin{array}{ll}w & \text { Water } \\ w, c i & \text { Water condenser/subcooler inlet } \\ w, \mathrm{co} & \text { Water condenser outlet } \\ w, e i & \text { Water evaporator inlet }\end{array}$

\section{Acronyms and abbreviations}

BPHE Brazed Plate Heat Exchanger

CFC Chlorofluorocarbon

EU European Union

EV Expansion Valve

GHG Green House Gas

GWP Global warming potential

HCFC Hydrochlorofluorocarbon

HFC Hidrofluorocarburos

HFO Hydrofluoroolefins

HP Heat Pump

HX Heat Exchanger

Impr. Improvement

LCCP Life-Cycle Climate Performance

LR Liquid Receiver

Max. Maximum

ODP Ozone depletion potential

PID Proportional Integral Derivative control

SHW Sanitary Hot Water

SMC Subcooling made in condenser

SMCL Subcooling Made in Condenser (Larger)

SMS Subcooling made in subcooler

SPF Seasonal Performance Factor

TV Throttling Valve 



\section{Chapter 1}

\section{Introduction}

\subsection{Motivation}

In the last decades, the total primary energy consumption in the world has increased significantly (IEA, 2016), which has led to scarcity of natural resources, such as petroleum, and to a more polluted world with evidence consequences on the climate change. Therefore, one of the biggest challenges of humanity nowadays is to cut down the energy consumption, as well as the use of energy systems more respectful with the environment without decreasing levels of comfort. According to World Business Council for Sustainable Development (WBCS, 2009), one of the biggest energy consumption is produced in buildings. It accounts for around $40 \%$ worldwide, where the space heating, appliances and the sanitary hot water (SHW) have the most important contribution, varying the significance of each one depending on the geographical situation, time of the year or type of building usage. In Europe, the space heating accounts for $70 \%$ of the total energy consumption in the residential buildings, while the second major consumption is for SHW, which accounts for around $14 \%$ of the total energy consumption. Nevertheless, due to the implementation of more severe building codes in the last decades, the heat loss through the building envelope has been reduced notably in new houses. Hence the annual heating demand for SHW has a higher share of the total heating demand in new houses. The SHW ratio ${ }^{1}$ usually ranges from 20 to $45 \%$ in new and low-energy houses (Stene, 2005). Therefore, SHW production is an interesting case study in

\footnotetext{
${ }^{1}$ The ratio of the annual SHW heating demand and the total annual heating demand of the House when heating due to ventilation air is excluded
} 
order to make the process more efficient and have a great impact on the total energy consumption.

Most residential water heaters are equipped with conventional heaters generating heat by consuming fossil fuels or electricity. Those water heaters are usually simple, but not desirable in view of energy utilization efficiency. For instance, electric water heaters are convenient for installation and operation. However, the overall efficiency in converting a potential energy of fossil fuels into electric energy, and then into thermal energy is quite low. Compared to those water heaters, heat pump water heating systems can supply much more heat just with the same amount of electric input used for conventional heaters (Kim et al., 2004)

In this sense, an interesting alternative to the conventional SHW systems is the use of heat pump (HP) technologies, which is an application of growing interest nowadays, due to its potential for high efficiency. This is recognized by (Directive, 2009/28/EC) "European Parliament and Council of 23 April 2009 on the promotion of the use of energy from renewable sources", where a portion of the energy captured by a heat pump having an estimated average seasonal performance factor higher than a reference value $(\mathrm{SPF}>2.5)$ is considered as if it were obtained from renewable energy sources. Since part of the energy extracted from the heat source, like air or water, is pumped to the heat sink.

A heat pump needs a working fluid, i.e. a refrigerant, in order to absorb heat from one area and reject it into another. The selected refrigerant must satisfy many requirements, such as chemical stability under conditions of use, safety codes of flammability and toxicity, environmental consequences of refrigerant leaks, cost, availability, efficiency and compatibility with compressor lubricants and components materials. Regarding the environmental performance, (ASHRAE, 2013) pointed out that the environmentally preferred refrigerants should:

- Have low or zero Ozone Depletion Potential (ODP)

- Have relatively short atmospheric lifetimes

- Have very low Global Warming Potential for 100 years' horizon (GWP ${ }_{100}$ )

- Provide good system efficiency

- Have appropriate safety properties

In general, the preferred refrigerant should yield a low Life-Cycle Climate Performance (LCCP), which includes the direct refrigerant emissions expressed in terms of $\mathrm{CO}_{2}$ equivalents, the indirect emissions of $\mathrm{CO}_{2}$ due to energy consumption at operation and direct and indirect emissions effects associated with manufacturing the refrigerant. 
Refrigerants that have been used widely in the last century are now being replaced due to these environmental reasons. For instance, the Montreal Protocol (Buxton 1988), because of their ODP, has phased out some fluorinated gasses. This is the case of the chlorofluorocarbons (CFCs), which were pointed out as a safe and harmless solution (Midgley Jr. and Henne, 1930), but it turned out to have a high impact on the ozone depletion and has been already phased out. The hydrochlorofluorocarbons (HCFCs) will be phased out definitely in 2020 and 2030 in developed and developing countries respectively. Since then, the group of suitable refrigerants was reduced to hydrofluorocarbons (HFCs) and natural refrigerants. HFCs do not contain chlorine or bromine. Hence it is considered a negligible ODP, but due to their high GWP, they are considered as a greenhouse gasses (GHG), what have motivated countries to reduce HFC emissions. It is the case of the "F-Gas" regulation on fluorinated greenhouse gasses (Regulation (EU) No 517/2014), which concerns all 28 European Union (EU) member states and aim to reduce the emission of GHG, hence limiting the use of HFCs. Therefore, the two possibilities left are the natural refrigerants and the new hydrofluoroolefins (HFOs).

HFOs is a new family of synthetic fluids with low ODP and GWP, born due to the unflagging search of the chemical industry for the ideal refrigerant. In the last years, the HF01234yf has been proposed for mobile air-conditioners due to its low global warming potential (GWP) and performance comparable to that of R134a. However, as well as the R134a, if HF01234yf were to be substituted directly into a stationary heat pump system, the coefficient of performance (COP) would decrease because HF01234yf has smaller latent heat than R410A (Li et al., 2012). Furthermore, they are mildly flammable, and there is no guaranty that these artificial chemical substances may be found in a longer perspective to have unexpected negative consequences on the environment as it happened with the CFCs.

On the other hand, natural refrigerants have been used since a long time ago (before the CFCs were presented in the 1930s), they are found in nature in abundance (what prevents from market monopolies), and they are saved on recycling.

Although there are different implementation problems depending on the natural refrigerant (toxicity, flammability, low critical temperature, high boiling temperature, etc.), they have advantages that make them interesting to become the next generation of refrigerants (Lorentzen, 1995; Cavallini, 1996): 
- Null Ozone depletion potential (OPD)

- Almost negligible Global Warming Potential (GWP)

- They are not synthetic so that we are $100 \%$ sure they are not harmful to the environment.

- Some natural fluids possess very good thermodynamic properties to be employed as refrigerants. Development of equipment specifically designed for them will lead to higher efficiencies than the ones obtained with synthetic refrigerants, contributing to the reduction of the global environmental impact of the future heat pumps and refrigeration equipment.

Therefore, it seems that natural refrigerants will play a major role in the heat pump technology as the technical problems are being overcome (Granryd, E., 2001).

For all the reasons expressed above it seems an interesting research to study the capacities of a heat pump working with natural refrigerants for the SHW production. In addition, the source heat must be selected to narrow down the problem. Although in principle, it could work with any kind of source ${ }^{2}$; air, water, brine, geothermal, waste energy..., for this research the recovering waste heat has been selected as a source due to its high potential. For instance, Schmid (2008) pointed out that $15 \%$ of the thermal energy provided to the building is lost, unused, via the sewage system.

\subsection{Conditions for the waste heat recovery and the SHW application}

\subsubsection{Waste heat recovery}

As commented in the previous section, recovering heat from the sewage in the residential sector is an opportunity to save energy. For instance, in Tokyo, the district heat supply uses a sewage source heat pump station (CADDET, 1997). Alnhhal and Spremberg (2016) studied the possibility to recover energy from the sewage for an in-house system. Liu et al. (2014) studied the application of a heat pump system using untreated urban sewage as a heat source. Hepbasli et al. (2014) made a review of the heat pumps using wastewater as a heat source. The temperature of the sewage depends on the period of the year and the geographical location, but typical temperatures are between $10^{\circ} \mathrm{C}$ to $35^{\circ} \mathrm{C}$.

\footnotetext{
2 This study is inside of FP7 European Project, Next Generation of Heat Pumps working with Natural fluids, NxtHPG, where other group researchers have tested HPs with different sources
} 
Besides the sewage system, other sources of waste heat could be used as a heat source for the heat pump. Law et al. (2013) made an analysis of the heat recovery opportunities in the food and drink industries. Furthermore, in the industrial and commercial sector (chemical plants, supermarkets, hotels, hospital, etc.) there is a huge cooling demand. In these cooling systems, many times, the heat is dissipated to the ambient (loosed). In cold climates, one option is to utilize heat recovery from condensers directly for heating, but the required temperature of the condenser coolant is around $39^{\circ} \mathrm{C}$, decreasing the performance of the refrigeration system (Arias and Lundqvist, 2006). Baxter (2003), Minea (2006) and Minea (2007) studied the implementation of a heat pump system using the waste heat from supermarket refrigerators. They said that the advantage of using heat pumps to recover waste heat is that the condensing temperature of the refrigeration system does not need to be maintained at a high level in order to profit this heat directly in the heating system. The water temperature at the condensing loop outlet (inlet of the heat pump evaporator) is usually above $20^{\circ} \mathrm{C}$.

\subsubsection{SHW application}

Sanitary hot water is usually consumed at temperatures lower than $40^{\circ} \mathrm{C}$. Water heaters working in small installations, such as a gas boiler in a family house, usually provide the hot water directly to the consumer, without a storage tank. Nevertheless, in most of the cases with higher capacity, a storage tank needs to be installed. The storage tank separates consumption from production, if there is a need for hot water during few minutes, there is no need to switch on the heat pump. In the case of installing a storage tank, the hot water is required to be stored at $60^{\circ} \mathrm{C}$ to prevent the growth of the legionella bacteria, which can cause the fatal legionnaire's diseases, and other microorganisms (OSHA, 2016). Furthermore, the water delivered at the faucet has to be at a minimum of $50^{\circ} \mathrm{C}$.

There are two main designs for the storage tank:

- Mixed storage tank: The water mass flow rate through the heat pump is high, so water temperature lifts are usually between $5^{\circ} \mathrm{C}$ to $10^{\circ} \mathrm{C}$. The required $60^{\circ} \mathrm{C}$ cannot be reached directly from the city water temperature. Instead, the water recirculates until the required temperature is reached. Several heat pumps in the market work with this system (this will be seen in section 1.3.2).

- Stratified storage tank: The water mass flow rate is lower than in the mixed storage tank, so it has higher water temperature lifts. The water is produced directly to the required storage temperature (usually $60^{\circ} \mathrm{C}$ or higher). The cold and hot water are kept separated in the tank. 
Cecchinato et al. (2005) pointed out the stratified tank as the best energy efficiency solution. Furthermore, the heat pump connected to the stratified storage tank is able to produce hot water directly at $60^{\circ} \mathrm{C}$. Hence, the heat pump can supply hot water during the peak demand period. This allows minimizing the sizing of the storage tank. Figure 1.1 shows the scheme of a heat pump connected to the stratified storage tank system. One way to keep stratification is to separate the water in separate storage tanks connected between them.

The temperature at the heat pump inlet will depend mainly on the city water temperature. The city water temperature depends on the region and the period of the year. For instance, in Helsinki, the city water temperature ranges from $4^{\circ} \mathrm{C}$ to $11^{\circ} \mathrm{C}$, while in Athens ranges from $16^{\circ} \mathrm{C}$ to $26^{\circ} \mathrm{C}$ (Tammaro et al., 2017). Nevertheless, the inlet water temperature could also be higher than the city water temperature. For instance, in storage tanks where perfect stratification is not achieved, or during water tank recirculation due to heat losses in long periods of inactivity.

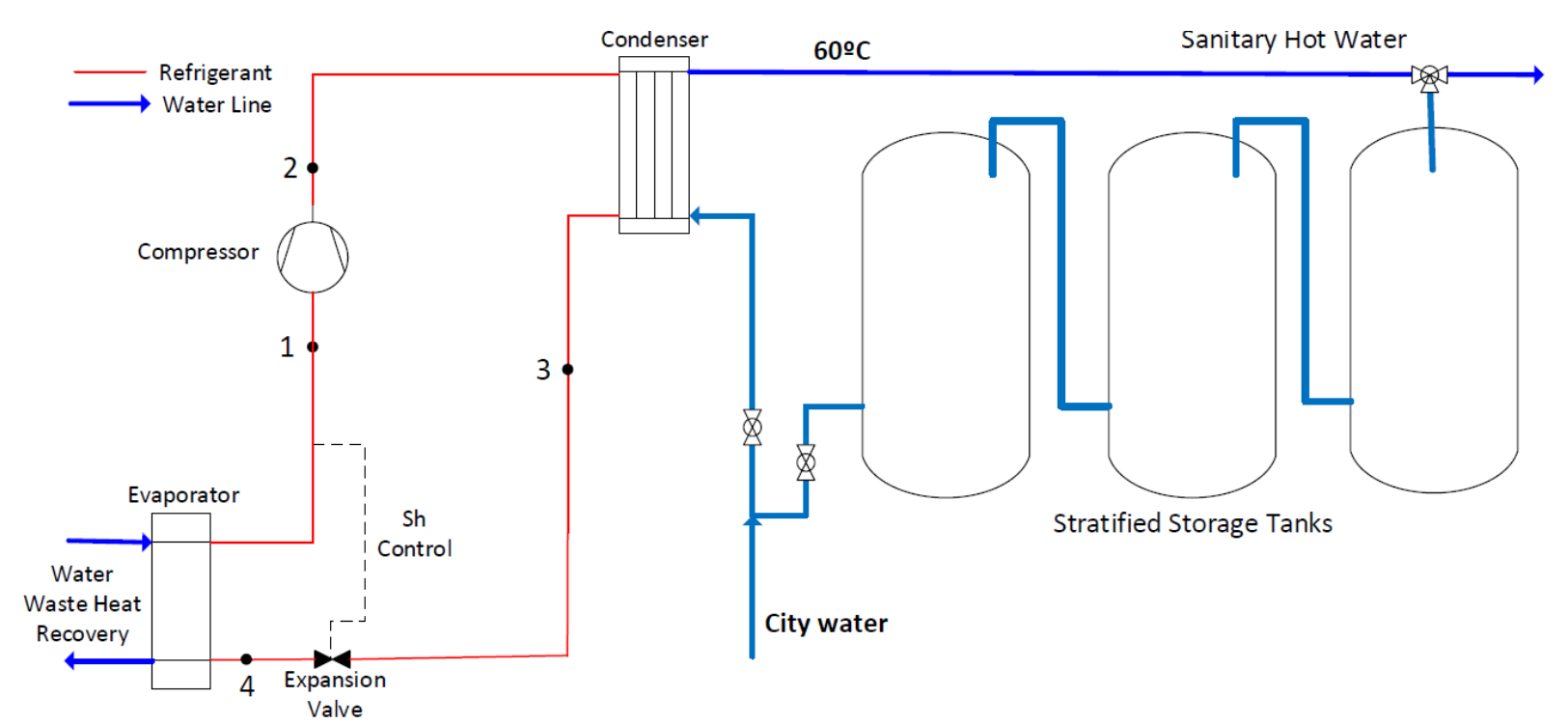

Figure 1.1: Sketch of a heat pump connected to the stratified storage system 


\subsection{Natural refrigerants for the SHW application}

As it was exposed before, natural refrigerants seem a good alternative to synthetic ones. However, each one has different drawbacks, and the selection will depend on the application, in this case, for the SHW production:

Ammonia (R717): Riffat et al. (1997) showed that ammonia could have a better coefficient of performance (COP) than CFCs, HFCs, and other refrigerants. The main problem of Ammonia is the toxicity; it is considered highly toxic. This makes inappropriate to use Ammonia for the SHW application. Furthermore, Ammonia has other drawbacks as the bad smell, flammability, and combined with water can be corrosive to copper and copper alloys, which makes this refrigerant an expensive alternative to existing systems.

Water (R718): One of the main problems of water is the freezing point at $0^{\circ} \mathrm{C}$. Other is the boiling point at atmospheric pressure $\left(100^{\circ} \mathrm{C}\right)$. Riffat et al. (1997) say that there are few studies of water working with evaporating temperatures lower than $100^{\circ} \mathrm{C}$. Furthermore, since it has to work at low pressure (low volumetric cooling capacity of vapor), the volumetric flow rate is higher than other common refrigerants, leading to bigger equipment. Therefore, water does not fit in the SHW application.

$\mathbf{C O}_{2}$ (R744): The critical temperature of $\mathrm{CO}_{2}\left(30.96^{\circ} \mathrm{C}\right)$ is lower than the heat rejection temperature at the $\mathrm{SHW}$ application. Therefore, the $\mathrm{CO}_{2}$ cycle operates in transcritical conditions and no condensation takes place. This cycle has been widely used for the SHW application.

Propane (R290): It has a good efficiency, and it has already been used in heat pump applications. The main problem of Propane is the flammability.

Therefore, among the natural refrigerants, Propane and $\mathrm{CO}_{2}$ seem to be the more appropriate refrigerants for the SHW application. In the following sections, the suitability of propane and $\mathrm{CO}_{2}$ for the SHW application will be analyzed. 


\subsubsection{The transcritical $\mathrm{CO}_{2}$ cycle}

One of the peculiarities of the $\mathrm{CO}_{2}$ cycle working in transcritical conditions is the control of the high-pressure (rejection pressure). In these systems, the rejection pressure is an independent variable and can be controlled at any external condition. Figure 1.2 shows an example of a heat pump design to control the rejection pressure. In this case, the expansion valve does not use the superheat at the compressor inlet as a control variable. Instead, the opening of the expansion valve will determine the rejection pressure, which has an important influence in COP and its control is crucial in order to obtain a good performance of this type of systems. The rejection pressure is adjusted by changing the active refrigerant charge of the system (this charge does not include the charge contained in reservoirs like a liquid receiver). In order to change the active charge of the system, a liquid receiver (LR) is needed to hold the charge variation at different conditions.

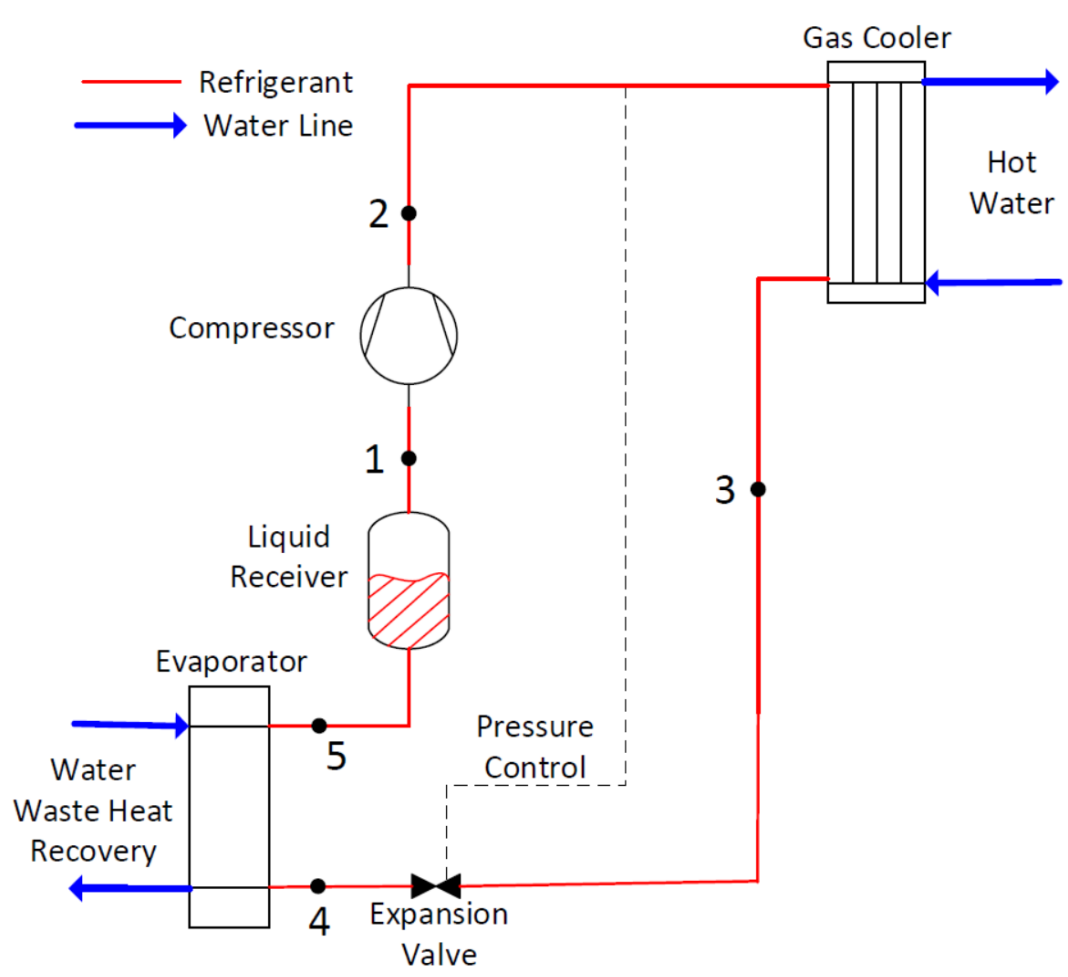

Figure 1.2: Sketch of a transcritical $\mathrm{CO}_{2}$ cycle with high-pressure control in the expansion valve. 
Already in 1928, Inokuty (1928) presented a graphical method to find the rejection pressure to maximize COP. Liao et al. (2000) developed different equations to obtain the optimal rejection pressure as a function of system parameters. From another point of view (Chen and Gu, 2005, Sarkar et al., 2004, Yang et al., 2005) made an exergy analysis of the $\mathrm{CO}_{2}$ transcritical cycle in order to look for improvement strategies for these cycles. They found larger irreversibilities in the expansion valve. All the above authors pointed out the refrigerant outlet temperature of the gas cooler, as the most important parameter to determine the optimal rejection pressure. This temperature is determined by the secondary fluid inlet temperature at the gas cooler.

Nevertheless, in many applications with high-temperature lift in the secondary fluid, such as in the SHW application (usually $50 \mathrm{~K}$ ), it is not possible to set the theoretical optimal rejection pressure due to an internal pinch point, i.e. the refrigerant temperature profile is limited by the water temperature along the gas cooler. Taking these facts into account, Cecchinato (2010) developed a numerical approach to calculate the optimal pressure depending on the inlet and outlet temperatures of the secondary fluid. Therefore, based on the previous study, the rejection pressure can be adjusted in order to optimize the refrigerant cycle at any external condition.

Many researchers have pointed out the natural refrigerant $\mathrm{CO}_{2}$ working in transcritical conditions, as an efficient solution for the SHW application due to the high-temperature glide in the refrigerant side. This effort has been materialized in projects such as ECO-CUTE in Japan (ECO-CUTE project). Works like (Cecchinato et al., 2005; Nekså et al., 1998; Nekså, 2002; Rieberer et al., 1997) has shown high efficiency of these cycles at water temperature lifts even higher than $50 \mathrm{~K}$.

Stene (2004) discussed the existence of the gas cooler pinch point and the effect of the rejection pressure control for $\mathrm{CO}_{2}$ heat pump water heaters. Figure 1.3 illustrates the result of increasing the rejection pressure from 85 bar to 110 bar for a $\mathrm{CO}_{2}$ heat pump water heater, where water is heated up from $5^{\circ} \mathrm{C}$ to $70^{\circ} \mathrm{C}$. The situation at each rejection pressure is: 

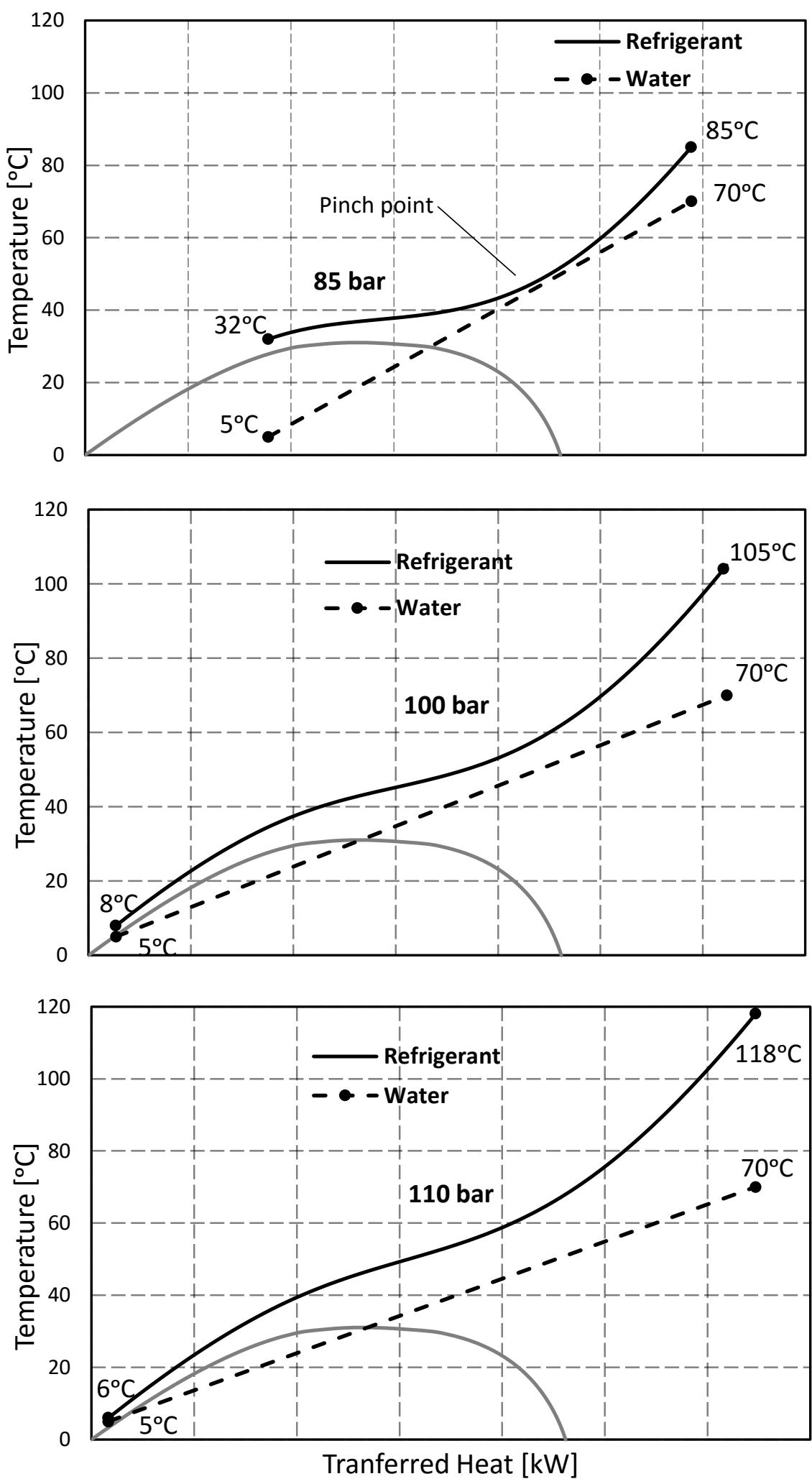

Figure 1.3: Illustration of the tight dependency between the rejection pressure, the pinch point and the $\mathrm{CO}_{2}$ outlet temperature from the gas cooler for a $\mathrm{CO}_{2}$ heat pump water heater. 
- Rejection pressure 85 bar: There is a pinch point inside of the gas cooler. The refrigerant outlet temperature is $32^{\circ} \mathrm{C}$, while the inlet water temperature is $5^{\circ} \mathrm{C}$.

- Rejection pressure 100 bar: The refrigerant outlet temperature has decreased to $8^{\circ} \mathrm{C}$, but the temperature difference at the internal pinch point has increased.

- Rejection pressure 110 bar: The refrigerant outlet temperature has decreased to $6^{\circ} \mathrm{C}$, but the temperature difference at the internal pinch point has increased even more.

In this case, the optimal rejection pressure is 100 bar. The optimum point is a compromise between the gain in the heating capacity due to the increase in the enthalpy difference and the increase of power input to the compressor.

Furthermore, the performance of the transcritical cycle strongly depends on the inlet water temperature to the gas cooler. Pitarch et al. (2014) compared in a theoretical study the COP penalty of different heat pump systems $\left(\mathrm{CO}_{2}\right.$ transcritical cycle working at the optimal rejection pressure with different subcritical refrigerants working without subcooling, Figure 1.4) when the water inlet temperature at the gas cooler is increased (different water temperature lift). This study shows a higher $\mathrm{COP}$ for the $\mathrm{CO}_{2}$ cycle at low water inlet temperatures (hightemperature lift). After a certain value of the inlet water temperature, COP is higher for the subcritical systems.

Another point to take into account is its low critical temperature $\left(30.98^{\circ} \mathrm{C}\right)$. Chaichana et al. (2003) studied the option of using natural working fluids as a substitute of R22 for solar-boosted heat pumps. They say that $\mathrm{CO}_{2}$ is not an appropriate choice for solar-boosted heat pumps due to its low critical pressure leading to lower heat pump COP at evaporating temperatures approaching the critical temperature. This issue needs to be investigated if $\mathrm{CO}_{2}$ is used for the waste heat recovery application, where the water temperature at the evaporator inlet could be up to $35^{\circ} \mathrm{C}$. 


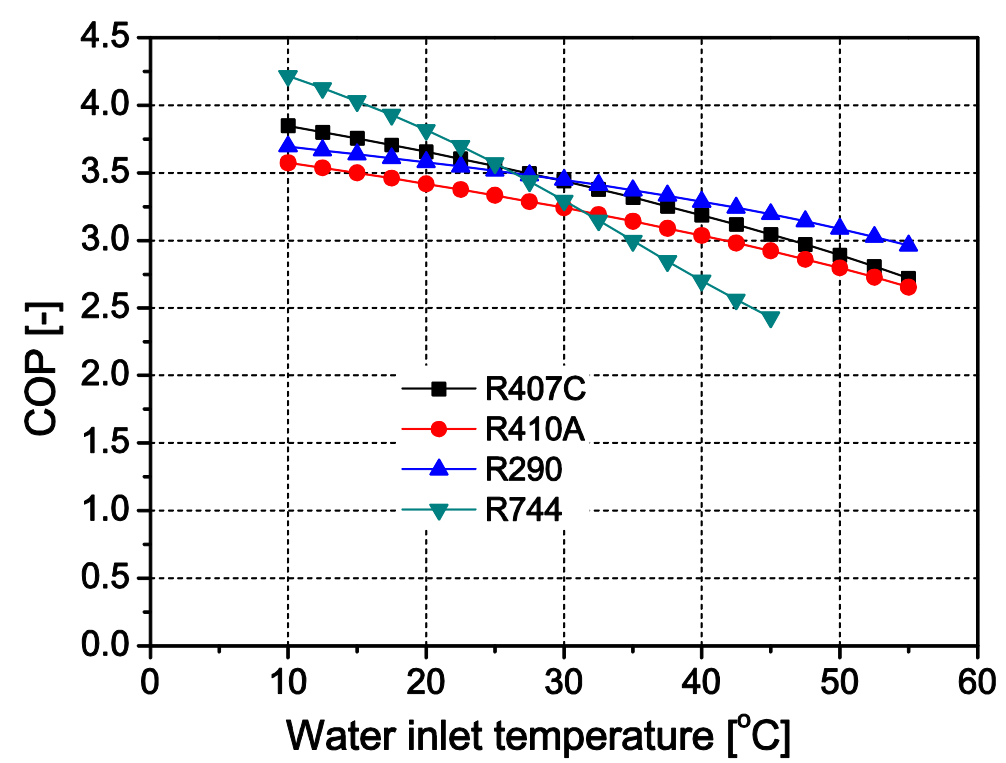

Figure 1.4: COP dependency with water inlet temperature for different subcritical refrigerants without subcooling and the transcritical $\mathrm{CO}_{2}$ cycle working at the optimal rejection pressure. Water outlet temperature $60^{\circ} \mathrm{C}$. (Pitarch et al., 2014)

\subsubsection{Propane (R290) for the SHW application}

Propane has a higher critical temperature than $\mathrm{CO}_{2}\left(96.7^{\circ} \mathrm{C}\right)$. Hence, Propane is usually used in subcritical conditions. In these systems, it is a common practice to use the expansion valve to control the superheat at the compressor inlet by modifying the evaporating pressure, while the condensing side is not controlled. The condensing pressure will depend on the external conditions (water temperatures) and the heat rejection at the condenser. In these systems, the refrigerant temperature at the condenser outlet depends on the condenser conditions and the active refrigerant charge of the system. In the subcritical systems, the temperature difference between the condenser refrigerant outlet and the condensing temperature is known as subcooling.

It is a common belief that subcritical systems working with high subcooling have a lower performance due to the area reduction for condensation. For example, in the book of Stoecker (1998) says:

The refrigerant leaving industrial refrigeration condensers may be slightly sub-cooled, but sub-cooling is not normally desired since it indicates that some of the heat transfer surface that should be used for condensation is used for sub-cooling. 
This sentence is true for a low-temperature lift of the secondary fluid used as a heat sink (high flow rate), but it has not been proved for high temperature lift like in the SHW application (usually 50K).

In many applications (refrigeration, air conditioning, heat pump...), subcritical systems are designed with a liquid receiver to ensure saturated liquid at the condenser outlet (Figure 1.5). In fact, most of the subcritical heat pumps to produce SHW use recirculation to heat up the water from the city temperature to the required $60^{\circ} \mathrm{C}$. This is the case of the commercial heat pump working with propane Quantum (Quantum), which heats up the water in sequences using low water temperature lifts (around $5 \mathrm{~K}$ ), trying to increase the overall heating COP at the end of the process (heating water at typical temperatures of $60^{\circ} \mathrm{C}$ ). With this technique, the heat pump has a higher performance when the water inlet/outlet temperature is low, and it decreases as the water inlet/outlet temperature increases. The main disadvantage of this process is that the heat pump is not able to supply the SHW directly from the typical city water temperatures (around $10^{\circ} \mathrm{C}$ ). Other examples of heat pumps that work in a similar way are the commercial Dimplex (Dimplex), with different models working with R290 and R404a, and the Nibe heat pump (Nibe), which uses R134a as refrigerant.

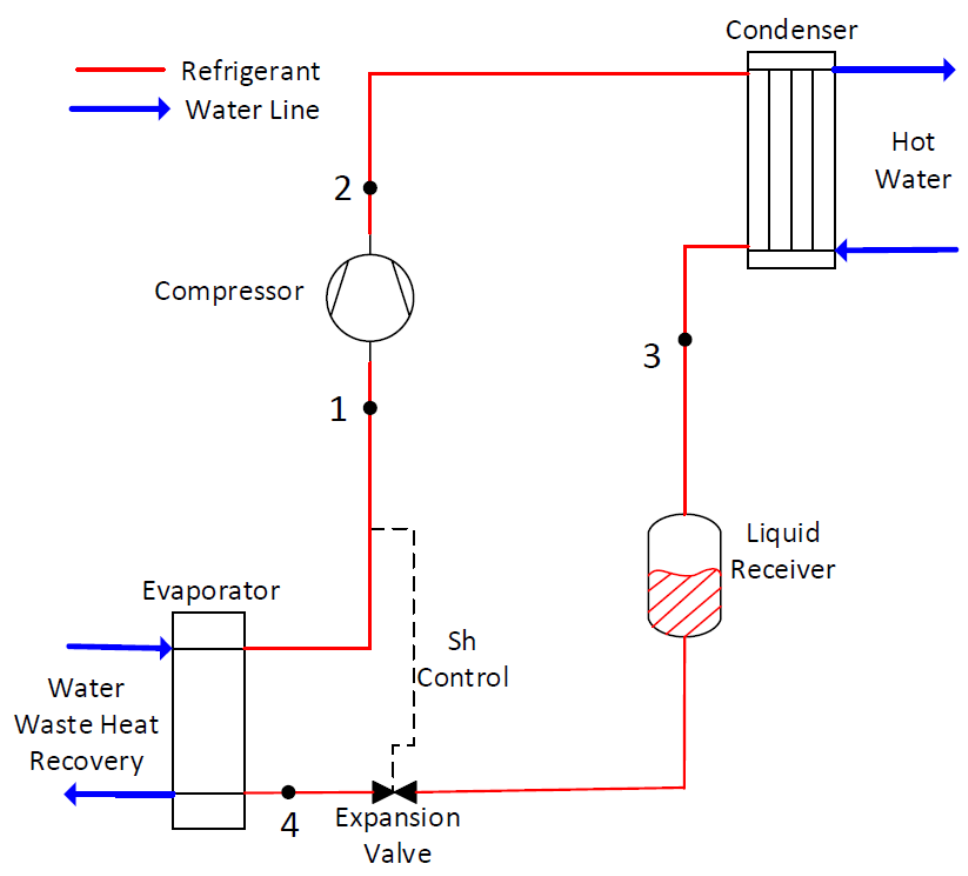

Figure 1.5: Sketch of a subcritical R290 cycle with superheat control in the expansion valve and working without subcooling 
Researchers are continuously struggling to improve the efficiency of the heat pumps. There are several works in the literature dedicated to the optimization of charge in heat pumps based on finding the corresponding optimal refrigerant charge from the experimental point of view (Choi and Kim, 2004; Corberán et al., 2008; Fernando et al., 2004). Corberán et al. (2011) studied from the theoretical and experimental point of view the role of the charge in the R290 cycle and pointed out that an optimum charge exists for a given external condition. As commented before, the effect of varying the active charge of the system is to change the subcooling. In that sense, these authors have indirectly studied the effect of subcooling in the heat pump. These studies are made for different refrigerants and applications.

More directly, others researchers have reported COP improvement with a certain subcooling, although in some cases, the degree of subcooling is not indicated (Cecchinato et al., 2005, Hjerkinn, 2007, Redon et al., 2014). In addition, in a more recent study, Pottker and Hrnjak (2015) theoretically studied the effect of subcooling in an air conditioning system for different refrigerants, they pointed out the existence of an optimal subcooling that maximizes COP for their equipment.

As in the transcritical case, the cycle with R290 has an internal pinch point (dew point). Figure 1.6 shows a hypothetical case in order to illustrate the result of increasing subcooling from $5 \mathrm{~K}$ to $50 \mathrm{~K}$ for an R290 heat pump water heater. Water is heated up from $10^{\circ} \mathrm{C}$ to $60^{\circ} \mathrm{C}$. The situation at each subcooling is:

- Subcooling $5 \mathrm{~K}$ : This is the situation with the lowest active refrigerant charge. The condensing temperature is $55^{\circ} \mathrm{C}$. There is an internal pinch point at the refrigerant dew point.

- Subcooling $40 \mathrm{~K}$ : The active refrigerant charge on the system has increased, so the refrigerant outlet temperature is now $20^{\circ} \mathrm{C}$. The condensing temperature is $60^{\circ} \mathrm{C}$, and the temperature difference at the internal pinch point has increased.

- Subcooling $50 \mathrm{~K}$ : The refrigerant outlet temperature is $15^{\circ} \mathrm{C}$, but the condensing temperature has increased to $65^{\circ} \mathrm{C}$.

There is not any published work that optimizes subcooling at this conditions. Nevertheless, as in the transcritical cycle, the optimum point (optimal subcooling or active refrigerant charge) would be a compromise between the gain in the heating capacity due to the increase in the enthalpy difference with subcooling and the increase of power input in the compressor due to the pressure increase. 

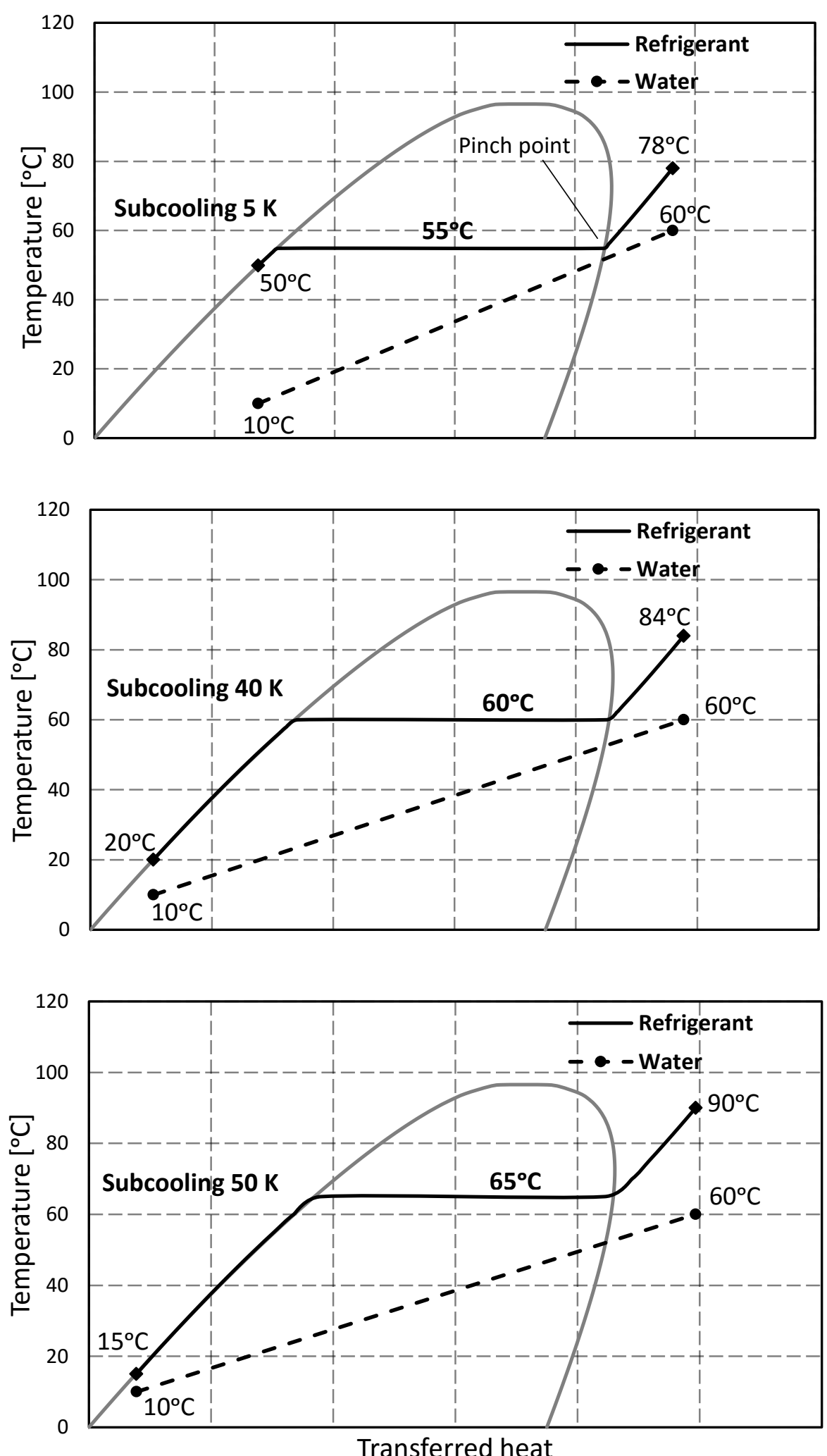

Figure 1.6: Illustration of the tight dependency between the subcooling, the pinch point and the R290 outlet temperature from the condenser for an R290 subcritical heat pump water heater. 
If subcooling wants to be controlled to search for the optimum point as it is done with the rejection pressure in the transcritical $\mathrm{CO}_{2}$ cycle, the heat pump design must allow this degree of freedom. Jensen and Skogestad (2007) discuss different heat pump designs in order to produce subcooling and theoretically evaluates an ammonia case for the refrigeration application. They find an optimal subcooling, but the improvement is only about $2 \%$ respect to zero subcooling for the given application. Based on one of those heat pump designs, Xu (2014) studied in his Master thesis the subcooling effect on an air conditioner system working with R410A. In that work, the subcooling was controlled with the expansion valve, and a liquid receiver was placed at the evaporator outlet in a similar way as it is done in the transcritical systems. An optimal subcooling to maximize COP was found. They studied the influence of the air inlet temperature to the condenser on the optimal subcooling, but no information about the outlet temperature was reported. One should notice that the outlet temperature of the secondary fluid is essential to know whether if an internal pinch point is limiting the heat pump operation (as in the transcritical case), in fact, the results would be different depending on the considered outlet temperature. Koeln and Alleyne (2014) used one of the designs to control the subcooling and developed a sophisticated methodology in order to optimize the control of a system in such a way that it can work in optimum conditions at any point (extremum seeking control). Nevertheless, the developed algorithm is complicated, spends three hours to reach the optimum and accuracy is compromised if there is a change in an external variable (simulation case study).

Nevertheless, most of these works reporting a higher system efficiency working with certain subcooling are focus on low temperature lift in the secondary fluid, where usually the optimum subcooling is found between $5 \mathrm{~K}$ and $10 \mathrm{~K}$. There are not any publication studying the advantage of making subcooling in order to take profit of the high water temperature lift in the SHW application (around $50 \mathrm{~K}$ ). Furthermore, there is no study in which subcooling has been considered as a design parameter, in such a way that, it is analyzed and optimized before the construction of the equipment based on its influence for a given system/application. Hence, the subcritical cycle should require a systematic study on the subcooling that optimizes COP depending on the external conditions, in the same way as it has been done for the rejection pressure in the transcritical cycle.

Propane is a good candidate for subcooling, not only due to its good environmental properties but also due to thermodynamic ones. Propane has a high specific heat in liquid state compared to other refrigerants, like with R134a, so it takes profit from doing subcooling (Lemmon et al., 2007). Another characteristic of propane are: 
- Propane can work at high evaporating temperatures, being a good solution for the waste heat recovery (Chaichana et al., 2003).

- Propane has a low-pressure ratio between the evaporator and the condenser. This is relevant for compressor efficiencies, volumetric and isentropic, which are strongly related to pressure ratio (Granryd, E., 2001).

The main drawback of Propane to be used as a refrigerant is the flammability. Propane is classified as A3 (non-toxic, highly flammable) by ASHRAE (2009). Therefore, due to strict regulations (EN 378-1:2008), propane has been used in small installations or in open vented locations. For instance, a propane heat pump can be installed in places with general occupancy like hospitals, courts, schools, supermarkets, hotels, restaurants, etc., if the system is installed in a separated vented enclosure and the refrigerant charge is lower than $5 \mathrm{~kg}$.

\subsection{Objectives}

In the previous sections, it has become apparent the important role of the heat pumps for the application of SHW production. Furthermore, the waste heat recovery seems also an important factor to reduce the energy consumption. The safe use of refrigerants with high performance and good environmental properties, such as the natural refrigerants, is also a key parameter.

This work is framed in the European project: "Next Generation of Heat Pumps working with Natural fluids" (NxtHPG), aims at the development of a set of safe, reliable, high efficiency and high capacity heat pumps working with Propane and $\mathrm{CO}_{2}$. In this thesis, the aim is to investigate the role of subcooling in the performance of a propane water-to-water heat pump for SHW production, in the application of heat recovery from any water source.

The main objectives of this thesis are:

1. Theoretically investigate the role of subcooling in a heat pump.

2. Design and built two different heat pump concepts working with propane and able to work efficiently with the theoretical optimal subcooling in the SHW application.

3. Experimentally evaluate the two heat pump prototypes at different conditions for the SHW application.

4. Compare the experimental results of both heat pumps and with a possible competitor working with $\mathrm{CO}_{2}$. 
This thesis is organized as follows: first, the aspects that motivate the study of the heat pump for the SHW application and the state of the art of the heat pumps working with natural refrigerants are presented in the introduction. Then, a theoretical study about the role of subcooling in the optimal performance of a heat pump is presented in chapter 2. Chapter 3 presents the heat pump concept and design of the constructed prototypes. Chapter 4 contains the description of the test rig designed to test the prototypes and the performed test. The results obtained with the two heat pump prototypes are presented in chapter 5 . Chapter 6 presents a comparison between both heat pump designs.

The main results shown in chapter 2, 5 and 6 have been published or accepted (one is under revision) in four international journals (Pitarch et al., 2017A; Pitarch et al., 2017B; Pitarch et al., 2017C; Pitarch et al., 2017D). Two more papers were published during the first two years of the Ph.D., they are not totally related to the results presented in this thesis, but they helped to better understand the problem (Redon et al., 2014; Pitarch et al., 2015). Furthermore, another paper in which I have participated (not as the main author) has been accepted (Hervas et al., 2017). This paper studies the Propane heat pump working with subcooling from the installation point of view, and it is the beginning of a new doctoral thesis that will continue the work done in this thesis to study the implementation of this heat pump in a real system.

Other articles have been published in conferences, but the main results are already included in the articles commented above. Nevertheless, if the information of one of these papers is needed, it will be cited in the text. 


\section{Chapter 2}

\section{Theoretical analysis}

This chapter presents a theoretical analysis of the role of subcooling in the heat pump performance. The analysis of the optimal working condition is generalized to different applications by considering different external conditions at the inlet/outlet of the condenser. Furthermore, other subcritical refrigerants, as well as the transcritical $\mathrm{CO}_{2}$ cycle, are included in the study.

Part of the results of this section has been published in the journal "International Journal of Refrigeration" (Pitarch et al., 2017A).

\subsection{Introduction}

The Coefficient of Performance (COP) is used to calculate the performance of a working cycle, for a heat pump application, the heating COP is:

$$
C O P_{h}=\frac{\dot{Q}_{h}}{\dot{W}_{\text {comp }}}
$$

Where $\dot{Q}_{h}$ and $\dot{W}_{\text {comp }}$ are the heating capacity and the compressor power input of the heat pump.

In the applications where the heat source and sink temperatures (secondary fluid) are considered constant during the heat transfer process, it is known that the subcritical cycle working without subcooling and condensing temperature close to the heat sink temperature has the higher COP for the given application (external 
temperatures). Nevertheless, a constant temperature of the secondary fluid means infinite capacitance rate $\left(\dot{m} c_{p}\right)$ on the secondary fluid, which is not a normal situation. Usually, the secondary fluid undergoes to a change in temperature during the heat transfer process, which can vary depending on the application. In these conditions, it is not obvious which subcooling and condensing temperature will give the highest COP. Figure 2.1 shows a P-h diagram with two propane cycle at different condensing temperatures and subcooling. The heat transferred between the refrigerant and the secondary fluid from point 2 to 3 is the useful heat in a heat pump application $\left(\dot{Q}_{h}\right)$. The input work to rise the refrigerant pressure (point 1 to 2 ) is done by the compressor ( $\dot{W}_{\text {comp }}$ ).

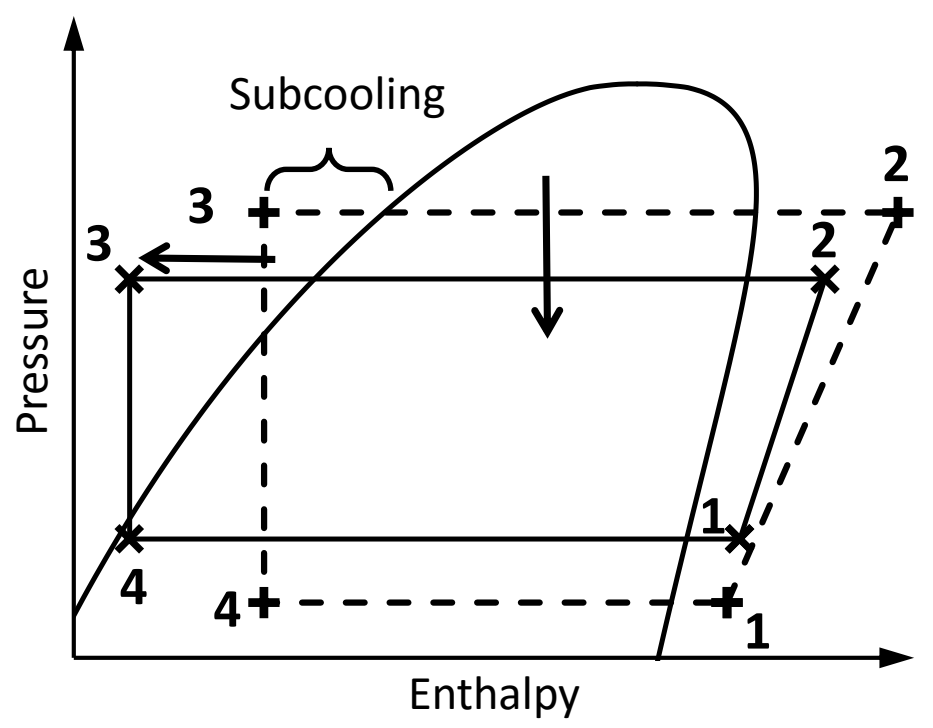

Figure 2.1: P-h diagram for propane cycles

In the SHW application, the change in temperature at the heat sink is imposed. For instance, in a heat pump with direct supply to the water tank, a typical water temperature lift is $10^{\circ} \mathrm{C}$ to $60^{\circ} \mathrm{C}$. Besides the conditions of the secondary fluid in the heat sink, other considerations must be taken into account when analyzing the performance of a heat pump system. For this theoretical study, the following assumptions have been taken:

- Compressor efficiency is constant and equal to one (isentropic compression). 
- Expansion valve: Isenthalpic expansion. Expansion valves are the most common device performing that operation in this kind of application.

- Evaporator: The secondary fluid in the evaporator is not considered. Instead, the evaporating temperature is fixed, and the superheat is $10 \mathrm{~K}$ at the evaporator outlet.

- Condenser: Condensing temperature and subcooling can be varied with one limitation: refrigerant temperature cannot be below the secondary fluid at any point (a consequence of the second law of thermodynamics).

Furthermore, the refrigerant pressure drop due to friction is neglected.

Figure 2.2a) shows the theoretical heating COP for the R290 cycle as a function of subcooling and condensing temperature, for an inlet/outlet water temperature at the condenser of $10^{\circ} \mathrm{C}$ and $60^{\circ} \mathrm{C}$ (evaporating temperature fixed to $0^{\circ} \mathrm{C}$ ). Figure $2.2 \mathrm{~b}$ ) shows the temperature profile of water and refrigerant (R290) as a function of the normalized ${ }^{3}$ capacity with two impossible situations. For the subcritical propane cycle in the SHW application, two critical points limit the subcooling and the condensing pressure. One is at the condenser outlet, and the other one is at the refrigerant dew point, inside of the condenser. One should notice that the condensing temperature can be below the water outlet temperature $\left(60^{\circ} \mathrm{C}\right)$ since the superheated gas (discharge temperature) has higher temperatures than $60^{\circ} \mathrm{C}$, and the limitation for the condensing temperature is inside the condenser at lower water temperatures.

\footnotetext{
3 The normalized capacity is the capacity at a given point in the condenser, divided by the total condenser capacity
} 


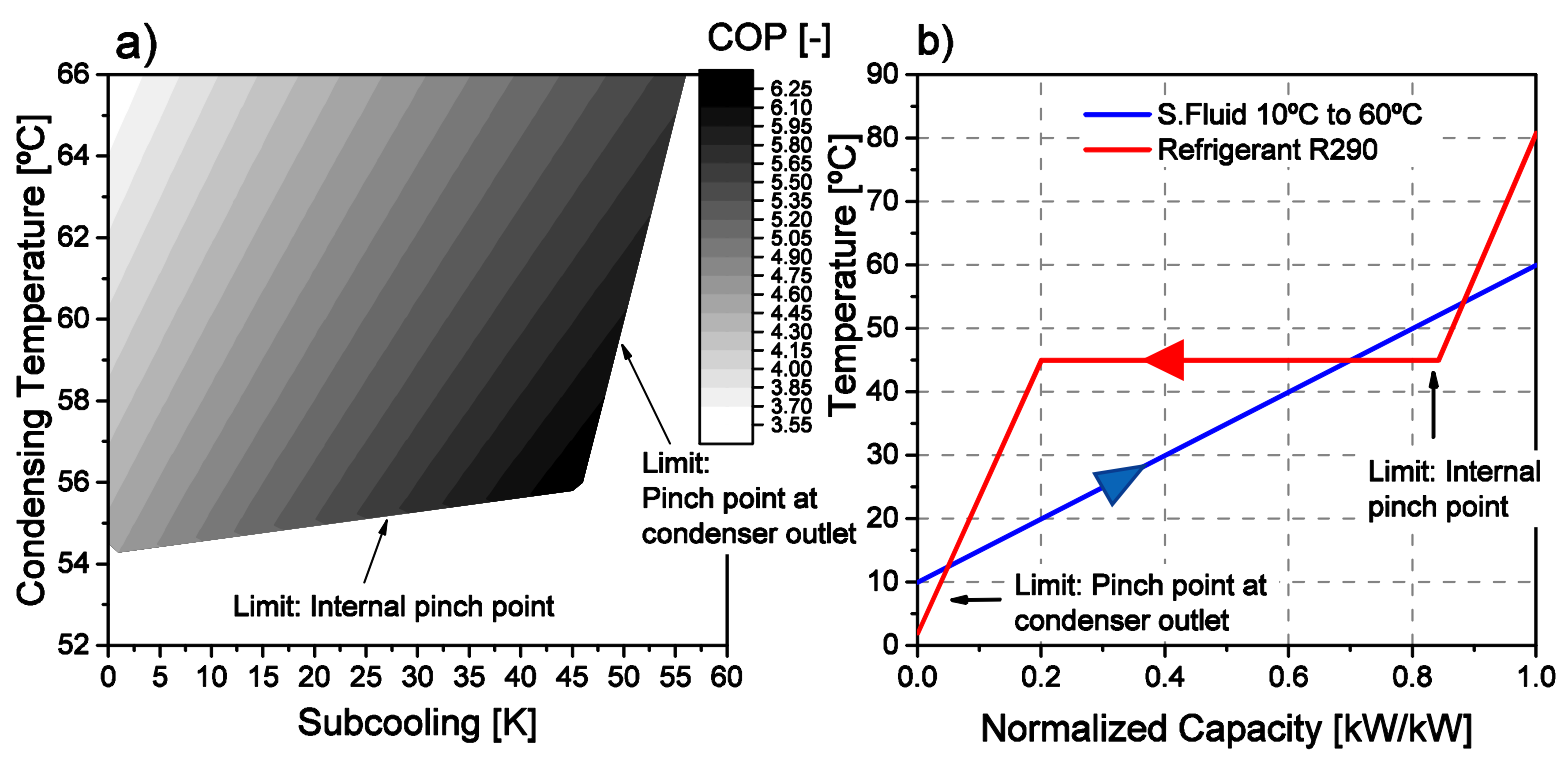

Figure 2.2: a) Heating COP as a function of subcooling and condensing temperature (Evaporating temperature $0^{\circ} \mathrm{C}$ ) b) Temperature limitation at the condenser

The maximum COP (Optimum point) is given where the two limitations occur at the same time. Higher subcoolings can be produced, but the condensing temperature increases considerably. Lower condensing temperatures than the optimum point can be obtained, but the subcooling decreases considerably. At the optimum point, the temperature difference between refrigerant and water is zero at the condenser outlet and at the refrigerant dew point. This situation is only possible if the condenser area is assumed infinite.

The infinite heat transfer area assumption implies that there is zero temperature difference between refrigerant and water in at least one point in the condenser. Therefore, the limits marked in figure 2.2a) show the heating COP for the infinite condenser assumption as a function of subcooling. The rest of the points in figure 2.2a) are possible for a real condenser with a finite heat transfer area. For instance, if subcooling is fixed to $25 \mathrm{~K}$, the corresponding condensing temperature for the infinite condenser assumption is around $55^{\circ} \mathrm{C}$, higher condensing temperatures with this subcooling means smaller condenser area.

For the rest of the theoretical study (in Chapter 2), it is assumed an infinite heat transfer area for the condenser. 
Figure 2.3 shows the temperature profile of the secondary fluid (water from $10^{\circ} \mathrm{C}$ to $60^{\circ} \mathrm{C}$ ) and the refrigerant R290 as a function of the normalized ${ }^{4}$ capacity for three possible situations (subcoolings). For subcooling of $5 \mathrm{~K}$, the condensing pressure is limited at the refrigerant dew point (internal pinch point). The temperature difference between the refrigerant and the water at the pinch point depends on the heat transfer in the condenser, for an ideal case with an infinite heat transfer area, the temperature difference is $0 \mathrm{~K}$. In a real condenser, this temperature difference would be higher, leading to a higher condensing temperature. In the ideal case, subcooling can be increased until the refrigerant outlet reaches the inlet water temperature, and have $0 \mathrm{~K}$ of temperature difference at both critical points (pinch points). At this point, the subcooling is about $46 \mathrm{~K}$, the condensing pressure has slightly increased, and the system is working at the optimal subcooling. More subcooling can be obtained, but the pinch point will exist only at the condenser outlet, and the condensing temperature considerably increases (subcooling $55 \mathrm{~K}$ ). Therefore, when the temperature of the heat sink is not constant, the refrigerant cycle with zero subcooling is not optimum anymore.

For this case, the improvement in COP when working at the optimal subcooling respect to the system working without subcooling is about $35 \%$.

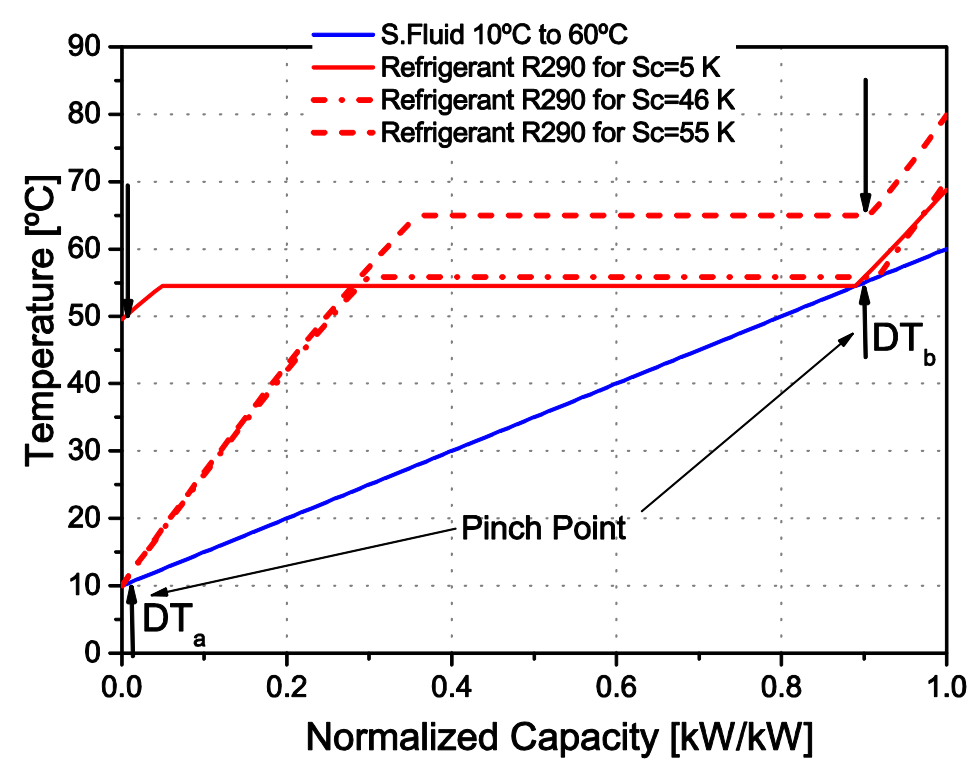

Figure 2.3: Temperature profile vs. normalized capacity, three subcoolings (infinite condenser assumption)

\footnotetext{
${ }^{4}$ The normalized capacity is the capacity at a given point in the condenser, divided by the total condenser capacity
} 
For clarity, from this point, the outlet and inner temperature difference between refrigerant and water will be named as $D T_{a}$ and $D T_{b}$ respectively.

As it was commented in the introduction, many researchers pointed out the natural refrigerant $\mathrm{CO}_{2}$ working in transcritical conditions, as an efficient solution for the SHW application due to the high-temperature glide in the refrigerant side. In the case of the subcritical system, the refrigerant "glide" grows with subcooling. Figure 2.4a) shows the $\mathrm{CO}_{2}$ and the propane temperature profiles for the water condition $10^{\circ} \mathrm{C}$ to $60^{\circ} \mathrm{C}$. The optimum point is reached when the inner and outlet pinch points occur at the same time for both refrigerants (double pinch point). A lower rejection pressure or subcooling than the optimal (for $\mathrm{CO}_{2}$ and propane respectively) leads to a non-optimal situation.

Nevertheless, for a low-temperature lift in the secondary fluid, the optimum point for the transcritical $\mathrm{CO}_{2}$ cycle is not the double pinch point situation. This situation has been widely studied in the literature, for instance, Liao et al. (2000) give an equation for the optimal gas cooler pressure as a function of the evaporating temperature $\left(T_{e}\right)$ and the refrigerant gas cooler outlet temperature $\left(T_{g c, o u t}\right)$. Figure $2.4 \mathrm{~b}$ ) shows the $\mathrm{CO}_{2}$ and the propane temperature profiles for the water condition $50^{\circ} \mathrm{C}$ to $60^{\circ} \mathrm{C}$. Both cycles are working at the optimum point. On the one hand, the optimal $\mathrm{CO}_{2}$ cycle has one pinch point at the gas cooler outlet. On the other hand, the propane cycle has the optimum at the double pinch point situation.
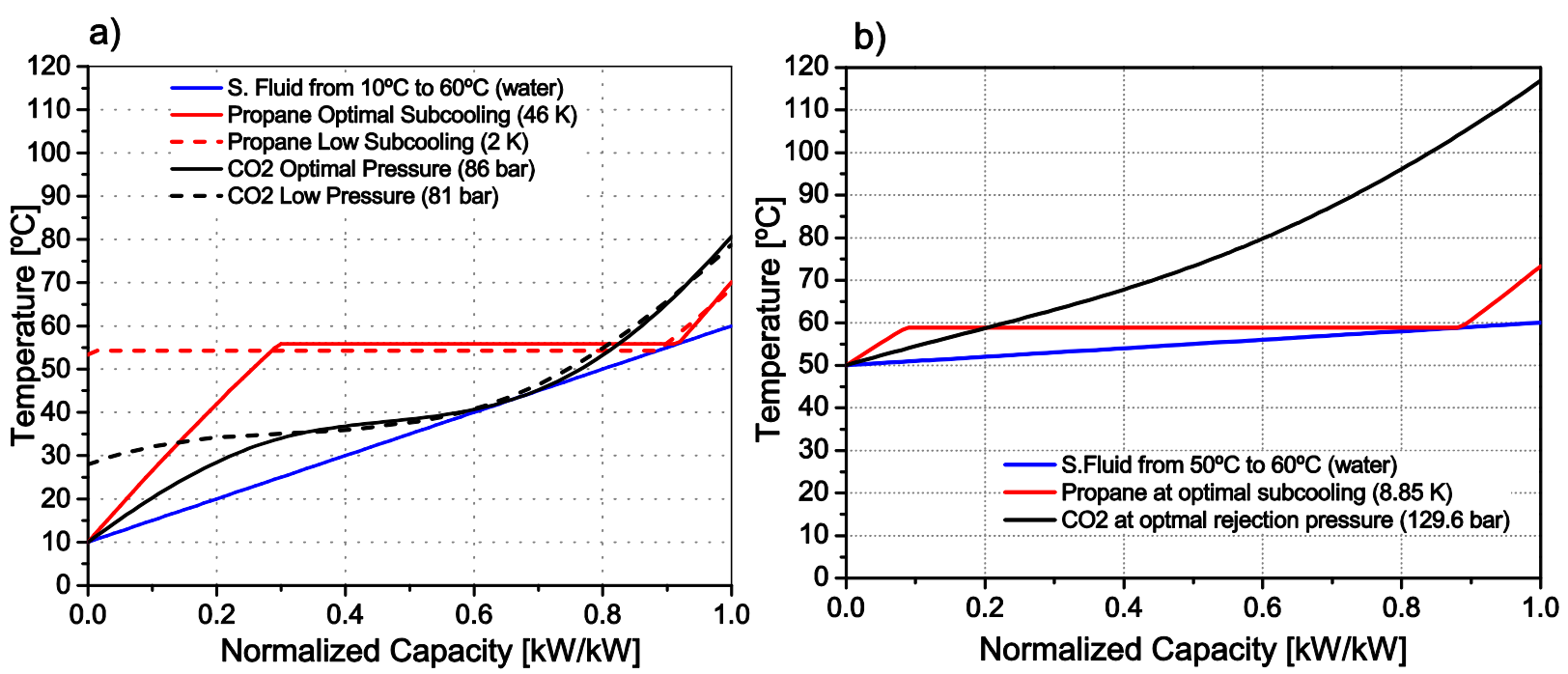

Figure 2.4: Temperature profile vs. normalized capacity (infinite condenser assumption) a) Water $10^{\circ} \mathrm{C}$ to $60^{\circ} \mathrm{C}$ b) Water $50^{\circ} \mathrm{C}$ to $60^{\circ} \mathrm{C}$ 


\subsection{Optimal subcooling}

In the section above, a theoretical optimal subcooling was observed for a heat pump in the SHW application working with the natural refrigerant propane. For the considered conditions, the optimum is at the double pinch point situation (in the condenser). At this point, subcooling is produced without a high increase in the condensing temperature. In this section, the heat pump performance is analyzed near the double pinch point in order to study the optimal subcooling in different refrigerants and conditions in the condenser.

Figure 2.5a) shows the heating COP as a function of subcooling for three different temperature lifts in the SHW application $\left(10^{\circ} \mathrm{C}\right.$ to $\left.60^{\circ} \mathrm{C}\right),\left(30^{\circ} \mathrm{C}\right.$ to $\left.60^{\circ} \mathrm{C}\right)$ and $\left(50^{\circ} \mathrm{C}\right.$ to $\left.60^{\circ} \mathrm{C}\right)$. The evaporating temperature is fixed to $0^{\circ} \mathrm{C}$. The optimal subcooling for the condition $\left(10^{\circ} \mathrm{C}\right.$ to $\left.60^{\circ} \mathrm{C}\right)$ is about $46 \mathrm{~K}$, while for the condition $\left(50^{\circ} \mathrm{C}\right.$ to $\left.60^{\circ} \mathrm{C}\right)$ it is about $8.8 \mathrm{~K}$. The degree of improvement respect to the cycle without subcooling is also higher for the higher temperature lift, the improvement is about $35 \%$ and $8.5 \%$ for $\left(10^{\circ} \mathrm{C}\right.$ to $\left.60^{\circ} \mathrm{C}\right)$ and $\left(50^{\circ} \mathrm{C}\right.$ to $\left.60^{\circ} \mathrm{C}\right)$ respectively.

Figure 2.5b) shows the condensing temperature as a function of subcooling. The condensing temperature slightly increases at low subcooling, but there is a point of inflection where the condensing temperature starts to increase considerably. This point of inflection determines the optimum working point, and it occurs at the double pinch point situation for the three considered cases.
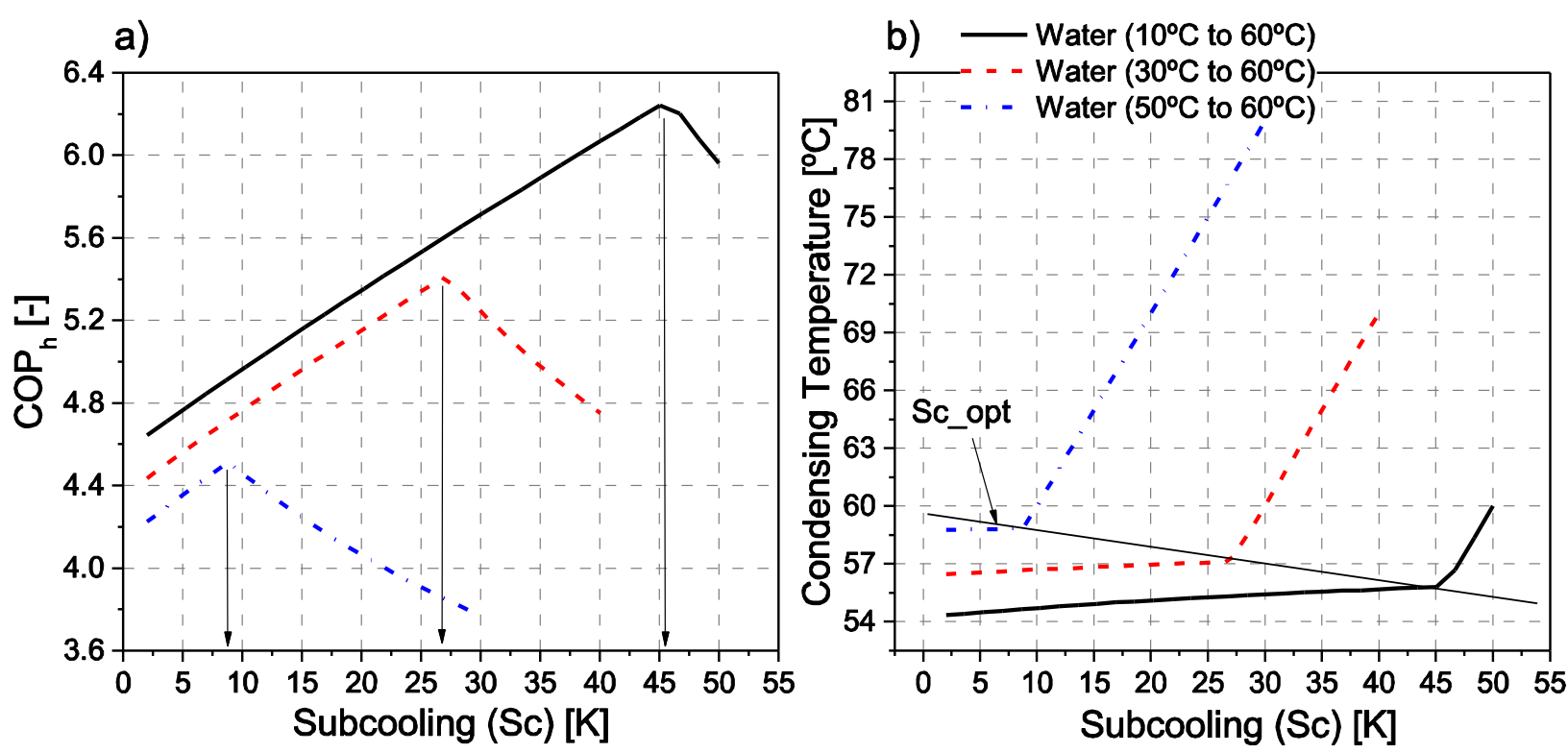

Figure 2.5: a) Heating COP as a function of subcooling b) Condensing temperature as function of subcooling (infinite condenser assumption) 
Until now, the optimum working condition for the subcritical propane cycle has been observed at the double pinch point situation. In order to study these results in other refrigerants and temperature lifts (secondary fluid), Figure 2.6 shows the normalized COP as a function of the subcooling deviation between the actual subcooling $(S C)$ and the subcooling at which two pinch points are found, $D T_{a}=D T_{b}=0 \mathrm{~K}\left(S c_{D_{-} P i n c h}\right)$. The normalized COP is:

$$
\mathrm{COP}_{\text {norm }}=\frac{\mathrm{COP}_{h}}{\mathrm{COP}_{D_{-} \text {Pinch }}}
$$

Where $\mathrm{COP}_{\mathrm{h}}$ is the performance at a given subcooling and $\mathrm{COP}_{\mathrm{D}_{-} \text {Pinch }}$ is the performance at the subcooling with two pinch points.
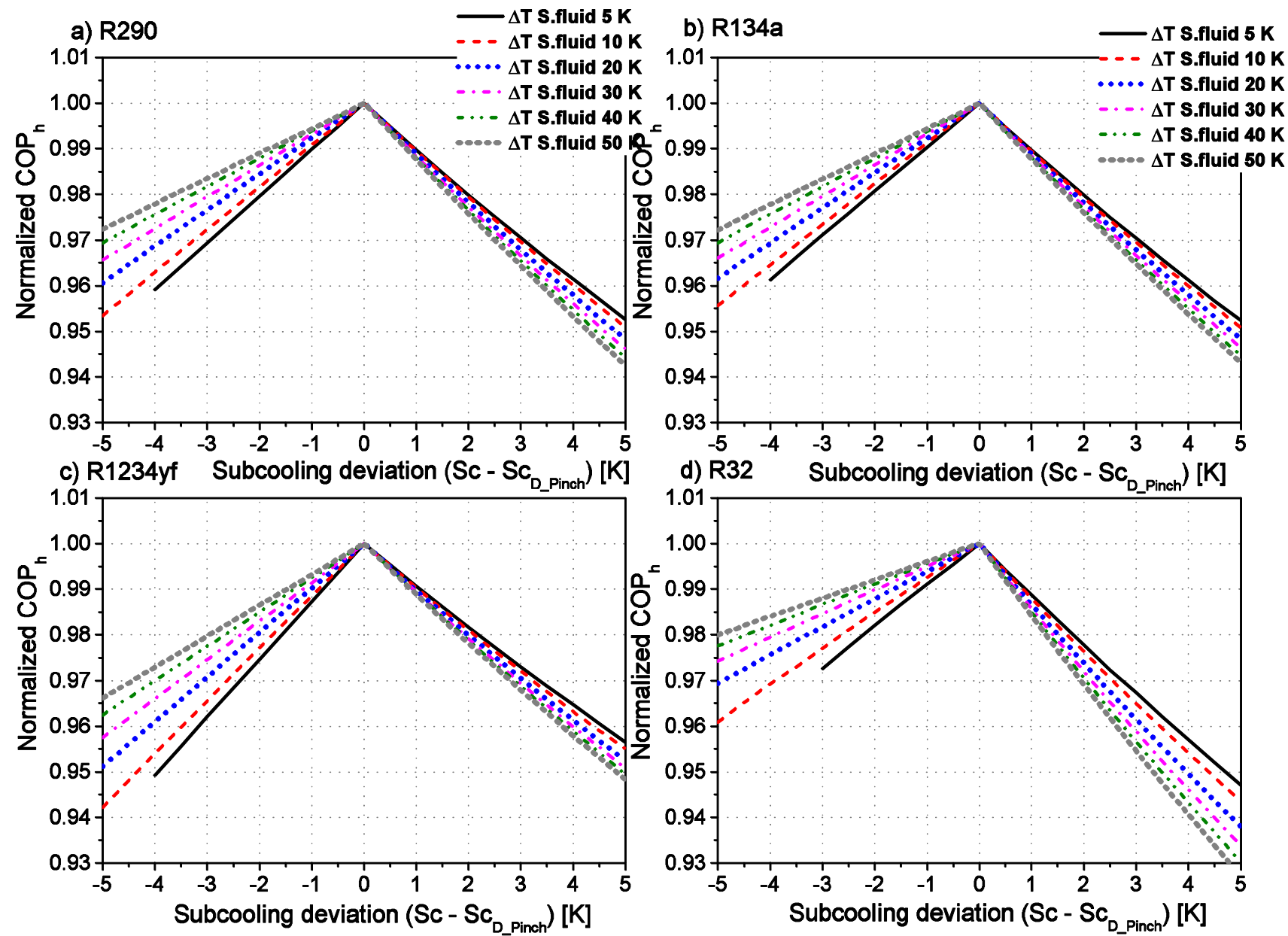

Figure 2.6: Normalized heating COP as a function of the subcooling deviation from the subcooling with two pinch point a) $R 290$ b) R134a c) R1234yf d) $R 32\left(T_{s f \text { out }}=60^{\circ} \mathrm{C}\right)$ 
The secondary fluid outlet temperature is fixed to $60^{\circ} \mathrm{C}$, and the considered temperature lifts go from $5 \mathrm{~K}\left(55^{\circ} \mathrm{C}\right.$ to $\left.60^{\circ} \mathrm{C}\right)$ to $50 \mathrm{~K}\left(10^{\circ} \mathrm{C}\right.$ to $\left.60^{\circ} \mathrm{C}\right)$. The study is extended to four refrigerants working under subcritical conditions. All four refrigerants have the maximum $\mathrm{COP}_{\mathrm{h}}$ when two pinch points occur at the same time, $D T_{a}=D T_{b}=0 \mathrm{~K}\left(S c=S c_{D_{-} P i n c h}\right)$, at any temperature lift. The $C O \mathrm{P}_{\mathrm{h}}$ degradation as a function of subcooling depends on the refrigerant used.

Table 2.1 shows the optimal subcooling, the COP at the optimum point, and the degree of improvement with respect to the case without subcooling for the four refrigerants at several secondary fluid temperature lifts $\left(T_{s f, o u t}=60^{\circ} \mathrm{C}\right)$. All refrigerants have a similar heating COP when working at the optimal subcooling (maximum COP), but subcooling is more crucial for some refrigerants than others. For instance, R1234yf has an improvement on COP of about 53\% (hightemperature lift) when working at the optimal subcooling compared to the case without subcooling, while the R32 has an improvement of about $21 \%$. The higher the secondary fluid temperature lift, the higher the optimal subcooling and the degree of improvement.

The same procedure commented above is applied to more than 700 conditions in order to generalize the results observed in figure 2.6. The inlet temperature of the secondary fluid $\left(T_{s f, i n}\right)$ ranges from $5^{\circ} \mathrm{C}$ to $55^{\circ} \mathrm{C}$, while the considered outlet temperature $\left(T_{s, \text { out }}\right)$ ranges from $30^{\circ} \mathrm{C}$ to $90^{\circ} \mathrm{C}$. The minimum considered temperature lift is $3 \mathrm{~K}$, e.g. $T_{s, \text { in }}=35^{\circ} \mathrm{C}$ and $T_{s f, o u t}=38^{\circ} \mathrm{C}$, while the maximum temperature lift is $85^{\circ} \mathrm{C}\left(5^{\circ} \mathrm{C}\right.$ to $\left.90^{\circ} \mathrm{C}\right)$. These conditions represent a wide range of applications. The optimum working point at the double pinch point was confirmed for all conditions. Therefore, it seems reasonable to consider that for subcritical systems the double pinch point situation is optimum in a wide range of conditions (applications). One should remember that the infinite condenser area is assumed in this study. 


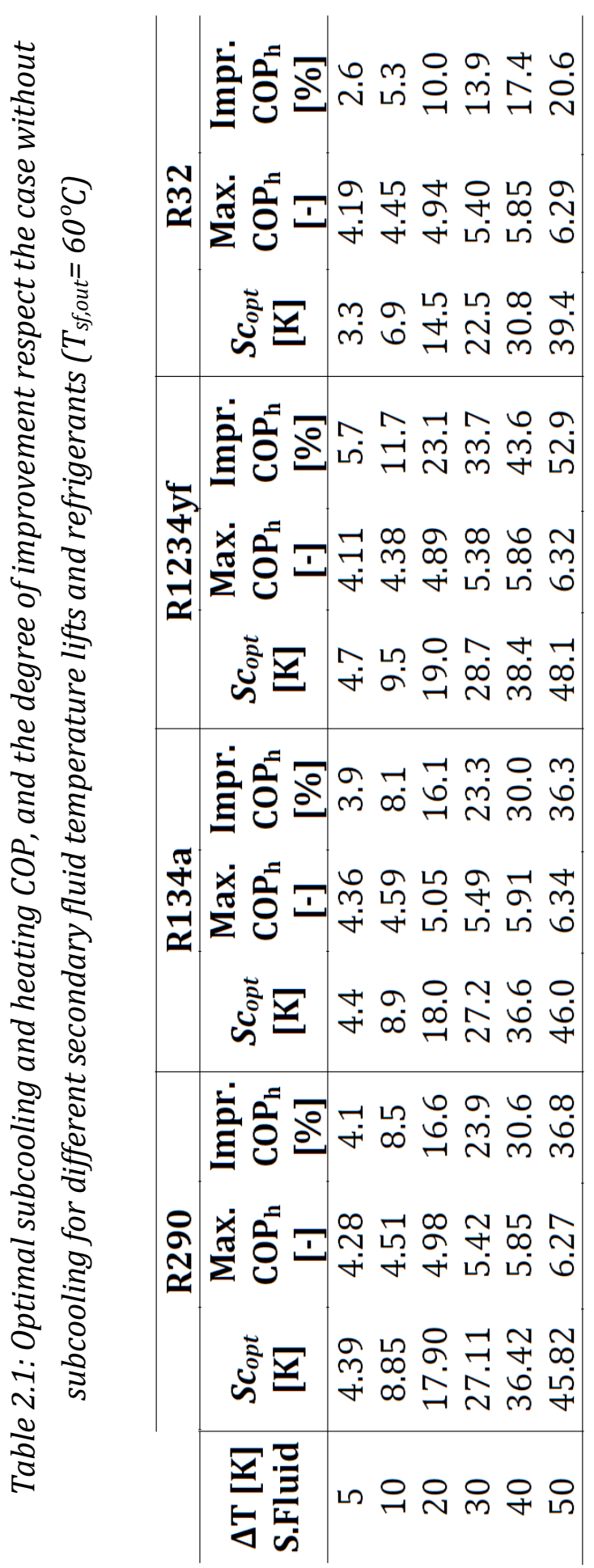


Figure 2.7 shows the optimal subcooling as a function of the temperature difference in the secondary fluid (temperature lift) for the range of conditions commented above (more than 700). For the same temperature lift, there are several conditions, for instance, for a temperature lift of $10 \mathrm{~K} \rightarrow 20^{\circ} \mathrm{C}$ to $30^{\circ} \mathrm{C}, 25^{\circ} \mathrm{C}$ to $35^{\circ} \mathrm{C}, 40^{\circ} \mathrm{C}$ to $50^{\circ} \mathrm{C}, 80^{\circ} \mathrm{C}$ to $90^{\circ} \mathrm{C}$, etc. The evaporating temperature is fixed to $0^{\circ} \mathrm{C}$. For the refrigerant $\mathrm{R} 290$ and R1234yf, the optimal subcooling mainly depends on the temperature lift, independently of the absolute values of the inlet and outlet secondary fluid temperatures. The optimal subcooling is slightly lower than the temperature lift, so it can vary from almost zero to more than $75 \mathrm{~K}$. For these two refrigerants, a linear function would be a good approach to control the operation of the system close to the optimum subcooling. Using the linear fit equation, the maximum error from the optimal subcooling is about $2 \mathrm{~K}$ for the complete range of considered conditions. On the other hand, the R32, which has a lower critical temperature $\left(78.1^{\circ} \mathrm{C}\right)$, has a higher dispersion from the linear fit, leading to higher errors if this control methodology is followed. The critical temperatures for propane and $\mathrm{R} 1234 \mathrm{yf}$ are $96.7^{\circ} \mathrm{C}$ and $94.7^{\circ} \mathrm{C}$ respectively.

Although these results show the high dependency of the optimal subcooling with the secondary fluid temperature lift, other system parameters could affect the optimal subcooling.

a)

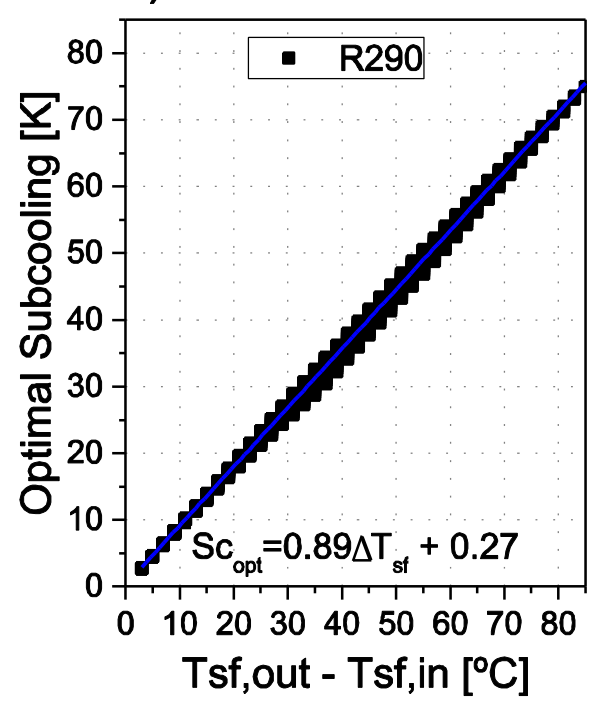

b)

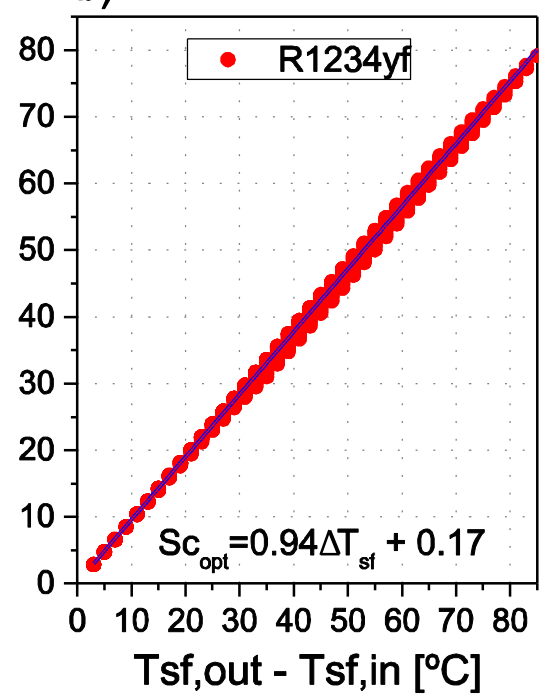

c)

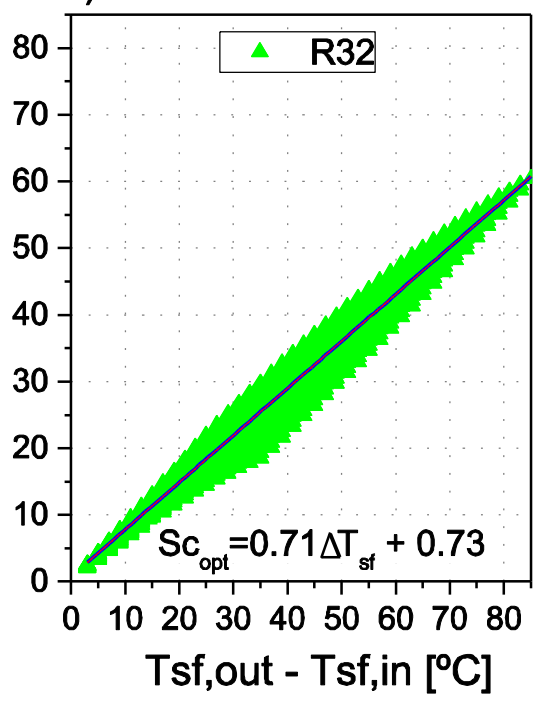

Figure 2.7: Optimal subcooling as a function of temperature difference in the heat sink 
Figure 2.8 shows a sensitivity analysis in order to evaluate the influence of evaporating temperature, superheat and compressor efficiency on the optimal subcooling. The reference point is a heat pump working at $0^{\circ} \mathrm{C}$ of evaporating temperature, a superheat of $10 \mathrm{~K}$, and an efficiency of the compressor of 1 . Then, these parameters are modified, and the corresponding optimal subcooling is compared to the reference at different temperature lifts (more than 700 conditions). The evaporating temperature does not significantly influence the optimal subcooling, $2 \%$ change per $10^{\circ} \mathrm{C}$ of evaporating temperature. Superheat can vary the optimal subcooling in about $6 \%$ per $10 \mathrm{~K}$ of superheat. Optimal subcooling increases if superheat decreases (and vice versa). A compressor efficiency of 0.5 could have a large influence on the optimal subcooling, up to $20 \%$ decrease on the optimal subcooling depending on the condition. These variations in the optimal subcooling do not only depend on the temperature lift of the secondary fluid but on its inlet and outlet temperatures (wide range of optimal subcooling change, for the same temperature lift). Furthermore, compressor efficiency is not constant with the external conditions, introducing some additional deviations on the control strategy if the equations showed in figure 2.7 are used.

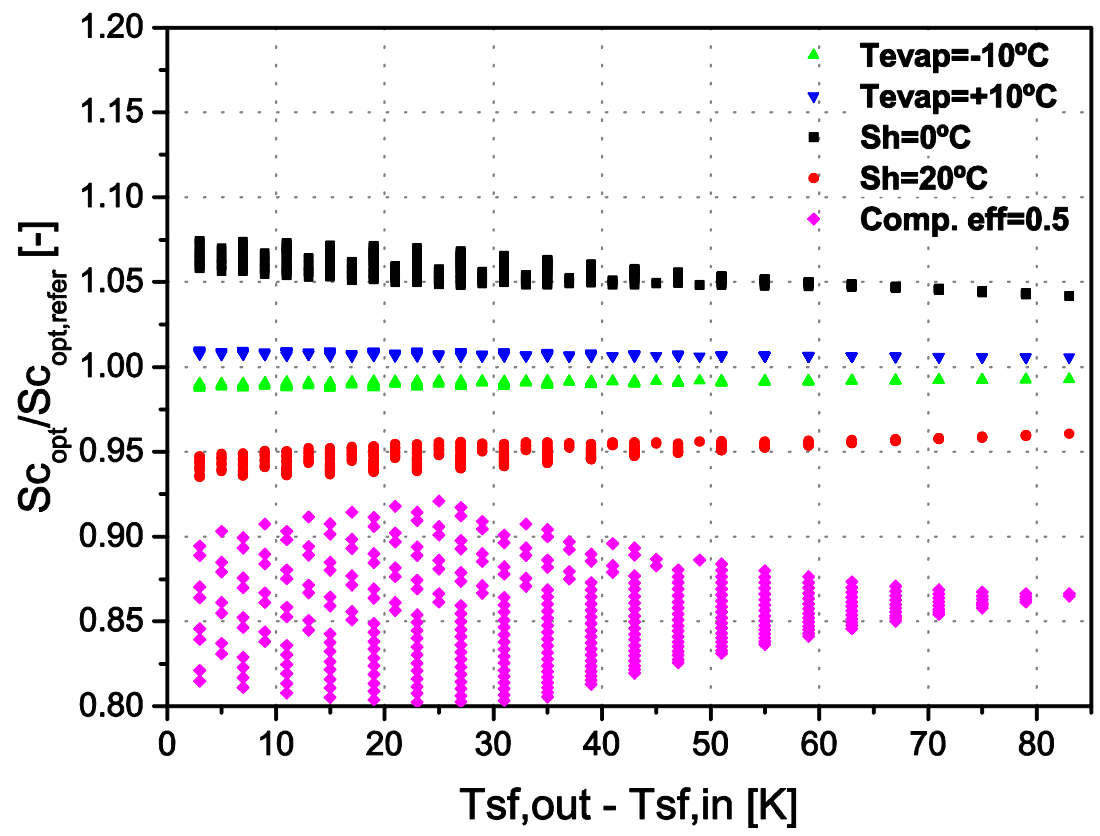

Figure 2.8: Optimal subcooling as a function of the temperature difference in the heat sink. Different scenarios are considered. The reference is: isentropic compression, $T_{e}=0^{\circ} \mathrm{C}$, $S h=10 \mathrm{~K}$ 


\subsection{Second law analysis}

In the above sections, the heat pump cycle was studied from the Coefficient of Performance point of view. This coefficient is useful to compare different refrigerant cycles working on a given application (external conditions). Nevertheless, it does not give information about the maximum performance that a refrigerant cycle could have in a given application. The maximum performance for a given application is determined by a reversible cycle working between the same considered heat source and sink temperatures. In this section, the reversible refrigerant cycle is taken into account to study the heat pump from the second law analysis point of view.

\subsubsection{Introduction}

The reversed Carnot cycle is used as a reference when the heat pump operates between constant external temperatures (heat source and sink). It is based on two isentropic and two isothermal transformations (Figure 2.9). The exchange of work is done through an adiabatic compression and expansion (the isentropic lines). The exchange of heat takes place isothermally (infinite capacitance rate) and with $0 \mathrm{~K}$ temperature difference between the heat source and sink temperatures.

Eq.2.2 is the heating COP of Carnot for a reverse cycle operating between the heat sink temperature $\left(\mathrm{T}_{\mathrm{H}}\right)$ and the heat source temperature $\left(\mathrm{T}_{\mathrm{C}}\right.$ ) (Moran and Shapiro, 2004).

$$
\mathrm{COP}_{\text {Carnot }}=\frac{\dot{Q}_{h}}{\dot{W}_{\text {comp }}}=\frac{\dot{Q}_{2-3}}{\dot{W}_{1-2}}=\frac{T_{H} \cdot\left(s_{2}-s_{1}\right)}{\left(T_{H}-T_{C}\right) \cdot\left(s_{2}-s_{3}\right)}=\frac{1}{1-T_{C} / T_{H}}
$$

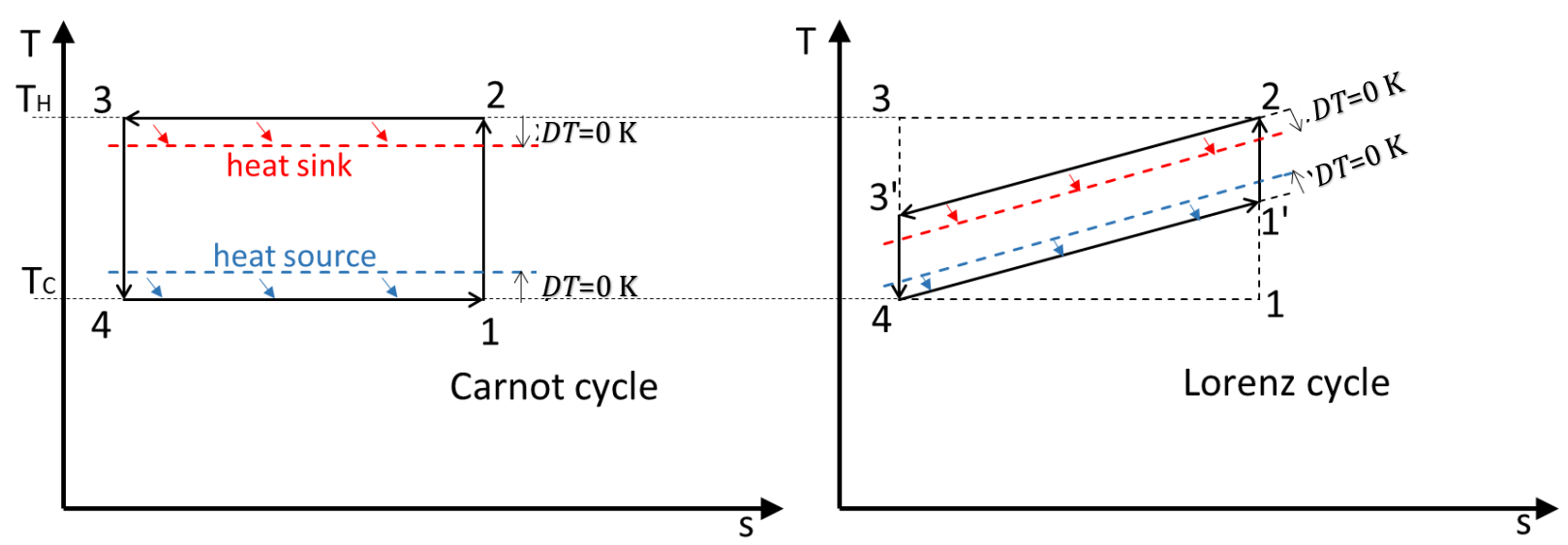

Figure 2.9: T-s diagram for Carnot and Lorenz cycles. Zero temperature difference between refrigerant and secundary fluid ( $D T=0 \mathrm{~K})$. 
In real applications, the source and sink temperatures are not constant along the process, either because this will require a large fluid mass flow, or because of the process itself. For instance, in the SHW application, the water temperature lift is typically over $40 \mathrm{~K}$. In these cases, the reversed Carnot cycle is not a good reference anymore (Yilmaz, 2003). Instead, the reversed Lorenz cycle considers the temperature lifts at the secondary fluid. Figure 2.9b) shows the theoretical reversed Lorenz cycle, it consists of an isentropic compression and expansion, and the exchange of heat takes place with $0 \mathrm{~K}$ temperature difference between the heat source and sink temperatures (Itard and Machielsen, 1994). The ideal Carnot and Lorenz cycles always refer to the external conditions.

The heating COP of the Lorenz cycle operating between $\mathrm{T}_{3^{\prime}}-\mathrm{T}_{\mathrm{H}}$ and $\mathrm{T}_{\mathrm{C}}-\mathrm{T}_{1^{\prime}}$ can be calculated as (Hasan et al., 2002):

$$
C_{\text {Lorenz }}=\frac{\dot{Q}_{h}}{\dot{W}_{\text {comp }}}=\frac{\dot{Q}_{2-3}}{\dot{W}_{\mathrm{I}-2}}=\frac{\bar{T}_{H} \cdot\left(s_{2}-s_{3}\right)}{\left(\overline{\bar{T}}_{H}-\bar{T}_{c}\right) \cdot\left(s_{2}-s_{3}\right)}=\frac{1}{1-\bar{T}_{c} / \bar{T}_{H}}
$$

Where the temperatures $\bar{T}_{H}$ and $\bar{T}_{c}$ are the entropy-averaged temperatures (average temperature in the temperature-entropy diagram). For constant capacitance rate $\left(\dot{m} c_{p}\right)$ and constant pressure process, the entropy-averaged temperature can also be written as (Hasan et al., 2002):

$$
\begin{gathered}
\bar{T}_{H}=\frac{h_{2}-h_{3^{\prime}}}{s_{2}-s_{3^{\prime}}}=\frac{T_{2}-T_{3^{\prime}}}{\ln \left(T_{2} / T_{3^{\prime}}\right)} \\
\bar{T}_{C}=\frac{h_{1^{\prime}}-h_{4}}{S_{1^{\prime}}-s_{4}}=\frac{T_{1^{\prime}}-T_{4}}{\ln \left(T_{1^{\prime}} / T_{4}\right)}
\end{gathered}
$$

In this study, the source temperature is taken constant, hence $\bar{T}_{C}=T_{C}$

Figure 2.10 represents the COP of the reversed Lorenz cycle for a set of different temperature conditions in the heat sink (secondary fluid) and a constant evaporating temperature of $0^{\circ} \mathrm{C}$. The inlet temperatures to the condenser $\left(T_{s f, i n}\right)$ range from $5^{\circ} \mathrm{C}$ to $55^{\circ} \mathrm{C}$, and the outlet temperatures $\left(T_{s f, o u t}\right)$ range from $30^{\circ} \mathrm{C}$ to $90^{\circ} \mathrm{C}$ (More than 700 conditions considered). For a given $T_{s f, i n}$, the lower the $T_{s, \text { out }}$ (smaller temperature lift) the higher the COP is. On the other hand, for a given $T_{s f, o u t,}$ the lower the $T_{s f, i n}$ (high-temperature lift) the higher the COP is. 


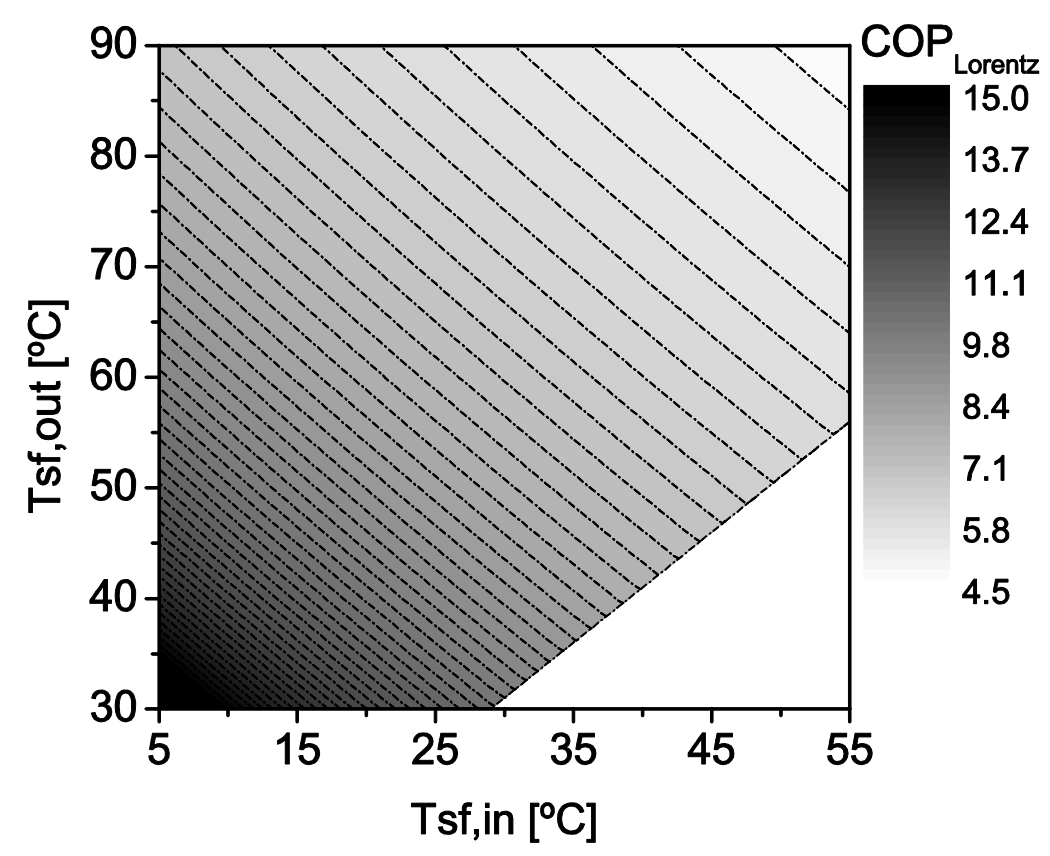

Figure 2.10: COP of Lorenz variation with the temperature lift in the $\operatorname{sink}\left(T_{s f, o u t}-T_{s f, i n}\right)$

For the case of the SHW application, where the typical inlet/outlet temperatures are $10^{\circ} \mathrm{C}$ and $60^{\circ} \mathrm{C}$ respectively, the COP of Lorenz cycle is 8.96 .

With these assumptions, the heating COP for a given refrigerant and condition can be compared to the corresponding reversed Lorenz cycle. The second law efficiency is defined as the ratio of the actual heating COP, to the obtained from a reversible cycle operating within the same thermal boundary conditions (Lorenz cycle) (Çengel and Boles, 1998).

$$
\eta_{I I}=\frac{C O P_{h}}{C O P_{\text {rev }}}=\frac{C O P_{h}}{C O P_{\text {Lorenz }}}
$$

\subsubsection{Results}

Figure 2.11 shows the second law efficiency (Eq. 2.6) for a wide range of inlet and outlet temperatures of the secondary fluid (heat sink). Three subcritical cycles (R290, R1234yf and R32) and the transcritical $\mathrm{CO}_{2}$ are considered. For each condition, all four cycles are working at the optimum point (optimal subcooling and rejection pressure). These graphs are useful to compare between the different cycles at a given point and to know how far from the reversible process it is. The three subcritical systems working at the optimal subcooling have a similar behavior. If these refrigerants are compared to the transcritical $\mathrm{CO}_{2}$, they have higher or lower efficiency depending on the external conditions ( $T_{s f, i n}$ and $\left.T_{s f, o u t}\right)$. 
For instance, for the condition $10^{\circ} \mathrm{C}$ to $60^{\circ} \mathrm{C}$, the second law efficiency for the R290 cycle is 0.70 , while it is 0.75 for the $\mathrm{CO}_{2}$. For the condition $30^{\circ} \mathrm{C}$ to $60^{\circ} \mathrm{C}$ the efficiencies are 0.76 and 0.70 for the $\mathrm{R} 290$ and $\mathrm{CO}_{2}$ respectively, and for the condition $50^{\circ} \mathrm{C}$ to $60^{\circ} \mathrm{C}$, the efficiencies are 0.76 and 0.50 for $\mathrm{R} 290$ and $\mathrm{CO}_{2}$ respectively. Therefore, for the SHW application, the $\mathrm{CO}_{2}$ is theoretically closer to the reversed cycle (Lorenz) for high water temperature lift, but for lower water temperature lift, propane is closer to the reversed cycle.
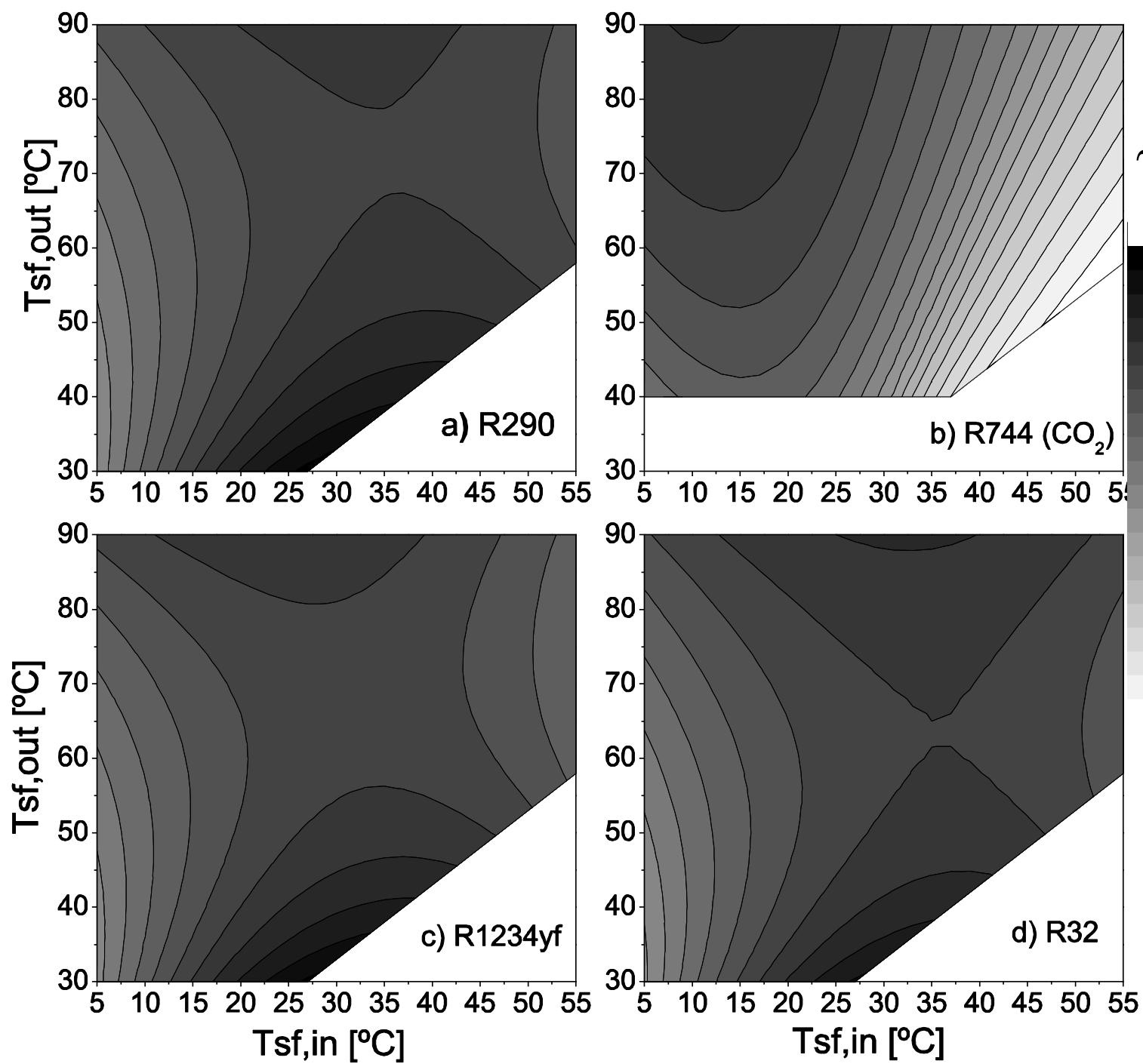

0.84

0.82

0.80

0.76

0.74

0.72

0.70

0.68

0.66

0.64

0.62

0.60

0.56

0.54

0.52

0.50

0.48

Figure 2.11: Second law efficiency at different inlet and outlet secondary fluid temperatures a) $\mathrm{R} 290 \mathrm{~b}$ ) $\mathrm{R} 744\left(\mathrm{CO}_{2}\right)$ c) R1234yf d) $R 32$ (infinite heat transfer area assumption). All cycles are working at the optimal subcooling or rejection pressure. 


\subsection{Conclusions}

The role of subcooling has been analyzed for different heat sink temperatures (water for the SHW application). The analysis includes four refrigerants working in subcritical conditions, paying special attention to R290. There are two main conclusions that can be drawn from this study:

- Theoretically, for the infinite heat transfer area assumption, the maximum COP is reached when two pinch points of $0 \mathrm{~K}$ between the refrigerant and the secondary fluid take place at the same time (optimal subcooling). One pinch point is at the condenser outlet, and the other at the refrigerant dew point. This has been proved in a wide range of applications and for four different refrigerants. The transcritical cycle has an analogous behavior, except for low secondary fluid temperature lifts.

- The optimal subcooling mainly depends on the temperature difference between the outlet and the inlet of the secondary fluid. Therefore, a single control equation depending only on this temperature difference can be set for a wide range of applications. Optimal subcooling significantly varies depending on the secondary fluid temperature lift $\left(T_{w, c 0^{-}} T_{w, c i}\right)$. For the SHW application: $46 \mathrm{~K}$ at condition $\left(10^{\circ} \mathrm{C}\right.$ to $\left.60^{\circ} \mathrm{C}\right)$ and $8.8 \mathrm{~K}$ for $\left(50^{\circ} \mathrm{C}\right.$ to $\left.60^{\circ} \mathrm{C}\right)$ (Propane).

Other relevant results are:

- The transcritical $\mathrm{CO} 2$ cycle has two pinch points at the optimal rejection pressure, but only at high-temperature lift in the secondary fluid.

- The degree of improvement respect to the case without subcooling is about $35 \%$ and $8.5 \%$ for $\left(10^{\circ} \mathrm{C}\right.$ to $\left.60^{\circ} \mathrm{C}\right)$ and $\left(50^{\circ} \mathrm{C}\right.$ to $\left.60^{\circ} \mathrm{C}\right)$ respectively (Propane).

- Other parameters, such as compressor efficiency must be taken into account to calculate the optimal subcooling accurately. Variations up to $20 \%$ in optimal subcooling for a compressor efficiency reduction from 1 to 0.5 , are observed.

- The transcritical $\mathrm{CO}_{2}$ cycle has a higher efficiency than the subcritical cycles at high-temperature lift, while it is lower at low-temperature lift.

Theoretically, for low inlet water temperatures $\left(T_{w, c i}=10^{\circ} \mathrm{C}\right)$ in the SHW application, the transcritical $\mathrm{CO}_{2}$ cycle has a slightly higher performance than the subcritical propane cycle. This situation is reversed for higher $T_{w, c i}\left(>25^{\circ} \mathrm{C}\right)$. Therefore Propane working with subcooling can be considered as a competitive alternative to $\mathrm{CO}_{2}$. In the following chapters, the experimental results of the 
implementation of this approach under several system configurations are presented and compared with catalog data of commercial $\mathrm{CO}_{2}$ heat pump system.

Furthermore, as it has been seen in this chapter, the subcooling approach has demonstrated to improve the COP respect the case without subcooling for all studied refrigerants and any application. This improvement depends on the temperature lift of the secondary fluid. 


\section{Chapter 3}

\section{Heat pump: concept and designs}

In the previous chapter, a theoretical study showed the role of subcooling depending on the application. For the typical SHW temperatures $\left(10^{\circ} \mathrm{C}\right.$ to $\left.60^{\circ} \mathrm{C}\right)$ the theoretical optimal subcooling was about $46 \mathrm{~K}$, with more than $35 \%$ of performance improvement respect to the case without subcooling (propane). Therefore, it is an important task to design a heat pump system able to produce high degrees of subcooling in order to take profit of the high-temperature lift in the SHW application.

This chapter describes the prototypes designed and built in order to experimentally study in the laboratory the effect of subcooling in the SHW production. They are water-to-water heat pumps for SHW production, in the application of waste heat recovery working with the natural refrigerant propane. The waste heat could come from any available source of energy, such as sewage water or a condensation loop, which temperatures usually range between $10^{\circ} \mathrm{C}$ and $35^{\circ} \mathrm{C}$. The set point for the hot water production is $60^{\circ} \mathrm{C}$, while different water inlet temperatures to the condenser are considered $\left(10^{\circ} \mathrm{C}\right.$ to $\left.55^{\circ} \mathrm{C}\right)$. The system has been designed to obtain around $50 \mathrm{~kW}$ in the nominal point, i.e. $20^{\circ} \mathrm{C} / 15^{\circ} \mathrm{C}$ at the water inlet/outlet evaporator and producing sanitary hot water at $60^{\circ} \mathrm{C}$ from an inlet temperature of $10^{\circ} \mathrm{C}$.

The degree of subcooling depends on the active refrigerant charge of the system. Hence, in order to control the subcooling, the heat pump configuration must be able to control the active refrigerant charge. In this thesis, two different configurations are proposed. First, it is presented a heat pump design that produces the subcooling in the condenser. This heat pump adds a new degree of 
freedom; subcooling can be controlled independently at any external condition (active refrigerant charge can be controlled). The second heat pump design produces the subcooling in a separate heat exchanger (HX), the subcooler. With this configuration, subcooling is not controlled, it will depend on the external conditions and the heat rejection at the subcooler. In order to refer to each HP prototype, the following nomenclature will be used:

1) SMC heat pump: The subcooling is made at the condenser (Active charge control).

2) SMS heat pump: The Subcooling is made in a separate heat exchanger, the subcooler.

Finally, the discussion of the different heat pump components design is presented.

\subsection{Subcooling made in the condenser (SMC heat pump)}

Figure 3.1 shows the scheme of the water-to-water heat pump to make subcooling in the condenser. Besides to the essential heat pump components (evaporator, compressor, condenser and expansion valve), this heat pump prototype includes a liquid receiver and a throttling valve. Both components are placed between the condenser and the expansion valve, being the throttling valve right after the condenser and then the liquid receiver. Liquid receivers are normally refrigerant charge reservoirs used to accommodate the changes in the active refrigerant charge due to changes in the operating mode or changes at external conditions. In this case, moreover, the liquid receiver has the functions of accommodating the changes in the active charge due to variations in the degree of subcooling at the condenser and guarantee saturated liquid refrigerant at the outlet of the throttling valve. The throttling valve is the active control component that introduces a new degree of freedom and allows setting the subcooling at the condenser independently from the external conditions. One should notice that in practice, the throttling valve is an electronic expansion valve, but since the refrigerant is in liquid saturated state at its outlet, it will be referred as a throttling valve in order to distinguish it from the main expansion valve that controls superheat. 
a)

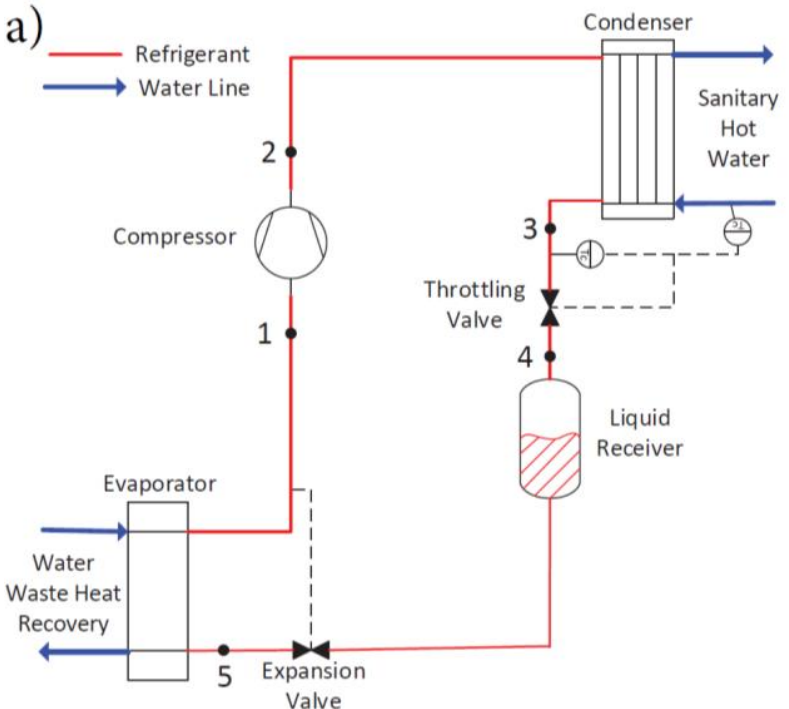

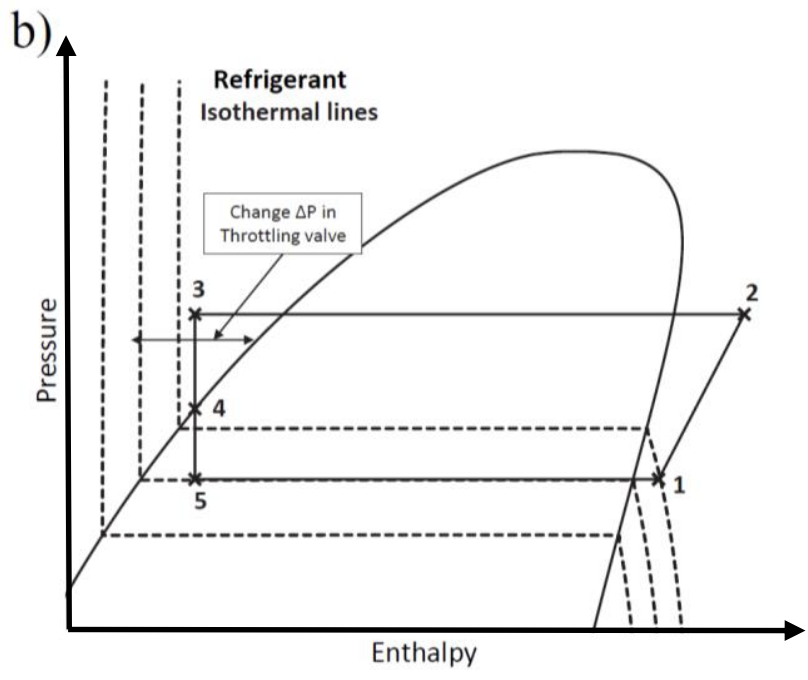

Figure 3.1: Heat Pump with subcooling at the condenser controlled by a throttling valve a) Scheme, b) P-h diagram.

The pressure at the throttling valve inlet (point 3) will depend on the heat transfer process at the condenser, while the pressure at the liquid receiver (point 4) will depend on the opening of the throttling valve. The liquid receiver ensures that the refrigerant leaves the throttling valve in liquid saturated state (point 4), which corresponds to the saturation temperature at the liquid receiver pressure. Therefore, since the throttling valve outlet is constrained to be on the saturation liquid line, the refrigerant stream at the condenser outlet (point 3) must be subcooled. The pressure drop at the throttling valve will determine the subcooling produced at the condenser:

- Throttling valve totally open: The liquid receiver and the condenser will be at similar pressure. This produces a low degree of subcooling.

- As the throttling valve closes, the pressure drop increases and the temperature of point 3 decreases, hence increasing subcooling.

Therefore, by increasing the pressure drop at the throttling valve, the refrigerant charge migrates from the liquid receiver to the condenser, which is flooded with refrigerant liquid and producing more subcooling. The temperature of point 3 can decrease up to a limit, which is determined by the water inlet temperature to the condenser and the heat transfer that takes place on it. Beyond this point, subcooling can only increase if the condensing saturation temperature is increased. 
The expansion valve controls the superheat at the compressor inlet. One should notice that the pressure drop at the expansion valve would not only depend on the condensing and evaporating conditions, but also on the degree of subcooling. The expansion and the throttling valve share the pressure drop between condenser and evaporator. The higher the subcooling, the higher the pressure drop at the throttling valve, and consequently the lower the pressure drop at the expansion valve. When producing high degrees of subcooling (up to $50 \mathrm{~K}$ ), most of the pressure drop between the condenser and evaporator is done at the throttling valve, and the pressure drop required at the expansion valve is minimum. Because of this behavior, the expansion valve needs to be carefully selected, as it will be seen in section 3.3.6.

With this configuration, the area dedicated to subcooling changes from point to point. This feature allows the condenser to dedicate the exact needed area for subcooling at each condition (the SMS system has a fixed heat transfer area for subcooling).

\subsection{Subcooler in series with condenser (SMS heat pump)}

Figure 3.2 shows the scheme of the water-to-water heat pump prototype with subcooler. A liquid receiver located right after the condenser ensures that (at steady state conditions) the refrigerant leaves the condenser in liquid saturated state (point 3) and serves as a charge reservoir. For continuity, the refrigerant leaves the liquid receiver at the saturation condition, the condenser saturation temperature. Thereafter, the refrigerant is subcooled in a heat exchanger specially designed for this reason (subcooler). The water is preheated at the subcooler, reaching its target temperature at the condenser outlet. The degree of subcooling will depend on the external conditions and the heat rejection at the subcooler. The refrigerant temperature at the subcooler outlet is limited by the water inlet temperature. In this case, the total area dedicated for subcooling is fixed in any condition. The expansion valve controls the superheat at the compressor inlet, and holds the total pressure drop between condenser and evaporator. The three-way valve located on the water side is used to limit the pressure drop at the subcooler. This will be discussed in section 3.3.3. 

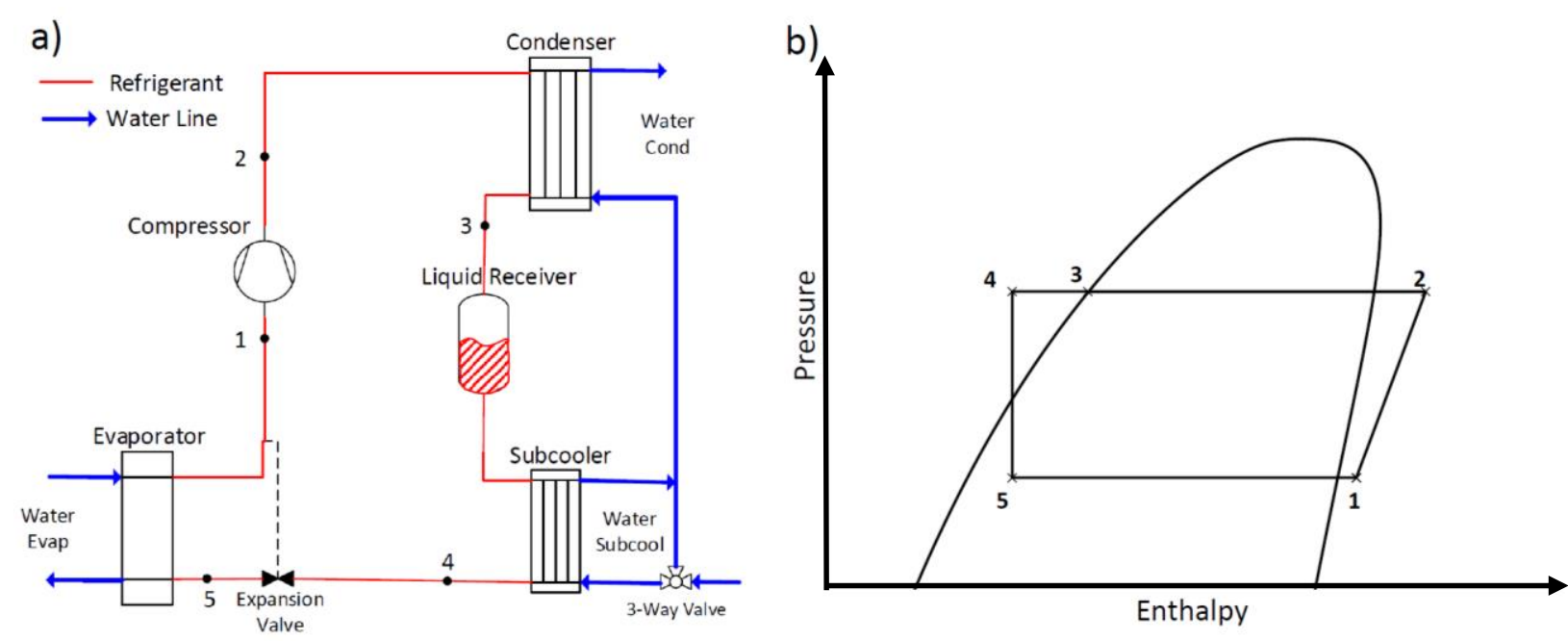

Figure 3.2: Heat Pump subcooler in series with condenser a) Scheme, b) P-h diagram.

\subsection{Heat Pump prototype: the real implementation of the systems}

Both heat pump designs (SMC and SMS) have been built in the same prototype, so they use the same evaporator, compressor, and condenser, with the only difference that in the SMS case, a subcooler is connected in series with the condenser, while in the SMC there is a throttling valve between the condenser and the liquid receiver. This configuration has the advantage of flexibility, allowing to obtain more experimental points in the same prototype. On the other hand, it is not a fair comparison, as the heat transfer area dedicated to condensation and subcooling is higher in the SMS design (condenser+subcooler) than in the SMC design (only condenser). The implications of this decision in the experimental results will be commented and analyzed in chapter 6 .

Figure 3.3 shows the scheme of the heat pump prototype. The selection between the SMS and the SMC design is done by means of manual valves. Due to the lowpressure drop needed in the SMC design, two expansion valves were connected in parallel (this will be discussed in section 3.3.6). Figure 3.4 shows a picture of the heat pump prototype taken from the top. 


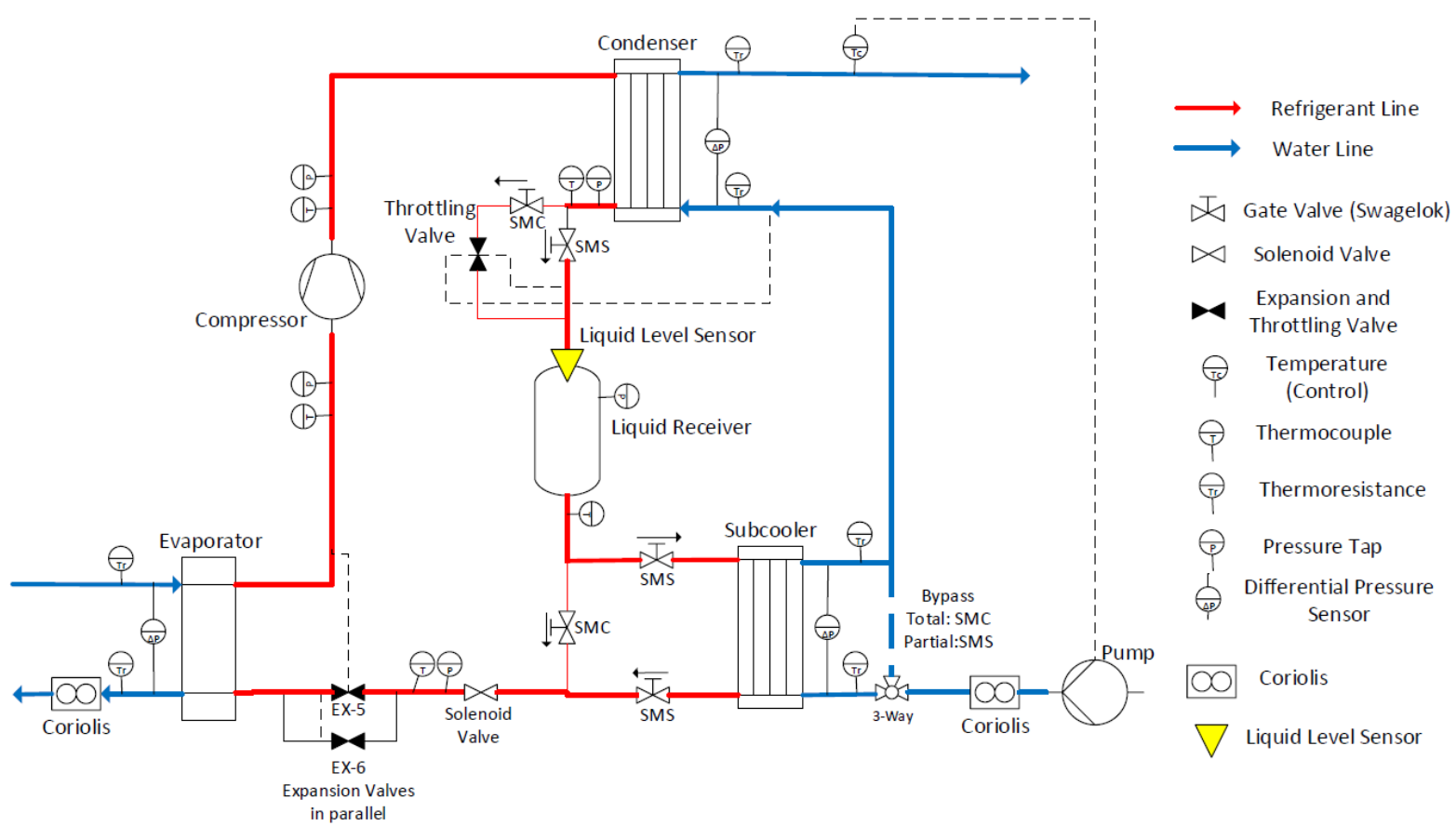

Figure 3.3: Scheme of the heat pump prototype to measure the SMS and SMC designs

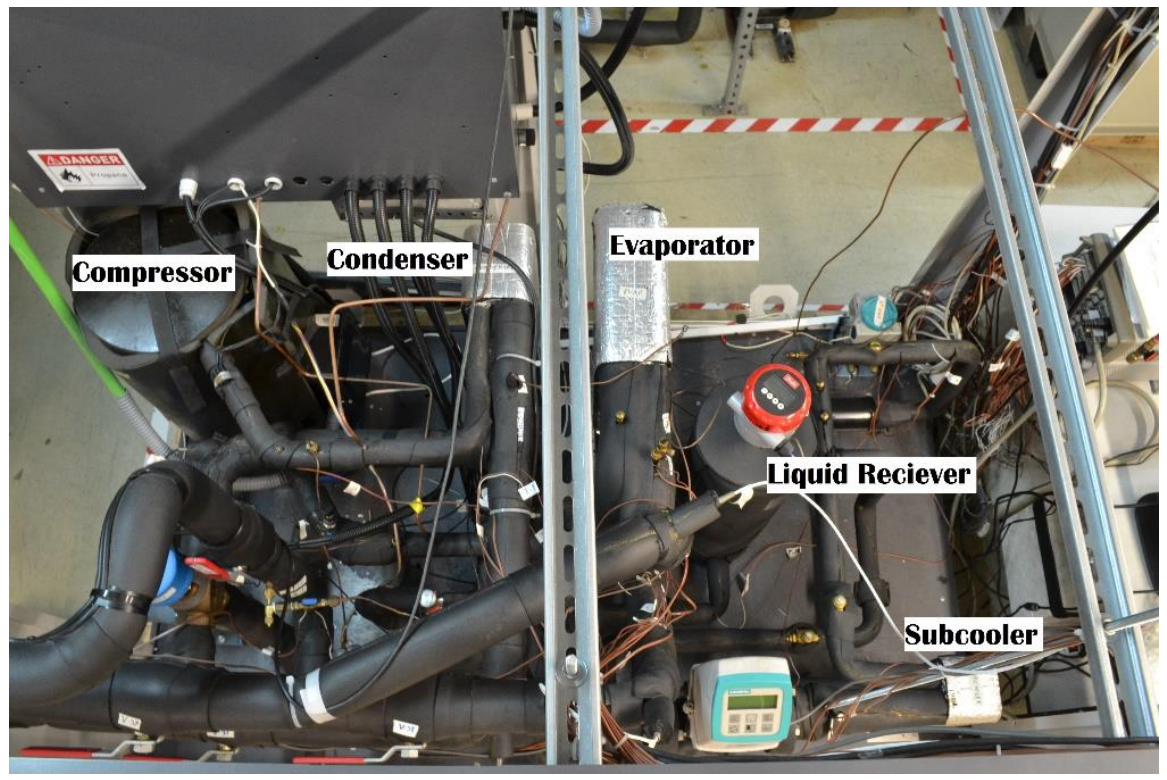

Figure 3.4: Photo of the heat pump prototype to measure the SMS and SMC designs

Applications with a high degree of subcooling have some peculiarities that must be taken into account when designing the system. Next sections concentrate on the components design (Table 3.1). With this configuration and the right components design, it is possible to produce high degrees of subcooling in order to take profit of the high water temperature lift in the SHW application and improve performance. 
Table 3.1: Components of the HP system

\begin{tabular}{|c|c|c|c|}
\hline Component & Type & Size & Used for \\
\hline Compressor & Scroll (2900 rpm) & $29.6 \mathrm{~m}^{3} \mathrm{~h}^{-1}$ & SMS and SMC \\
\hline Condenser & BPHE Counterflow & $3.5 \mathrm{~m}^{2}$ & SMS and SMC \\
\hline Subcooler & BPHE Counterflow & $0.87 \mathrm{~m}^{2}$ & SMS \\
\hline Evaporator & BPHE Counterflow & $6 \mathrm{~m}^{2}$ & SMS and SMC \\
\hline Liquid Receiver & - & 71 & SMS and SMC \\
\hline Expansion Valve $^{5}$ & Electronic EX-5 & $39 \mathrm{~kW}$ & SMS and SMC \\
\hline Expansion Valve ${ }^{5}$ & Electronic EX-6 & $93 \mathrm{~kW}$ & SMC \\
\hline Throttling Valve 5 & Electronic EX-5 & $39 \mathrm{~kW}$ & SMC \\
\hline
\end{tabular}

\subsubsection{Compressor}

The compressor is selected to obtain around $50 \mathrm{~kW}$ of heating capacity in the nominal point (water $20^{\circ} \mathrm{C} / 15^{\circ} \mathrm{C}$ at the evaporator and $10^{\circ} \mathrm{C}$ to $60^{\circ} \mathrm{C}$ for the hot water production). Figure 3.5 shows the compressor and volumetric efficiencies of the scroll compressor as a function of the pressure ratio. The efficiencies are obtained experimentally from the test campaign for this thesis. These results helped the manufacturer to improve the compressor efficiency at high evaporating pressures. One should notice that the swept volume of the scroll compressor is difficult to define. For this reason, there is one volumetric efficiency that is slightly over 1.
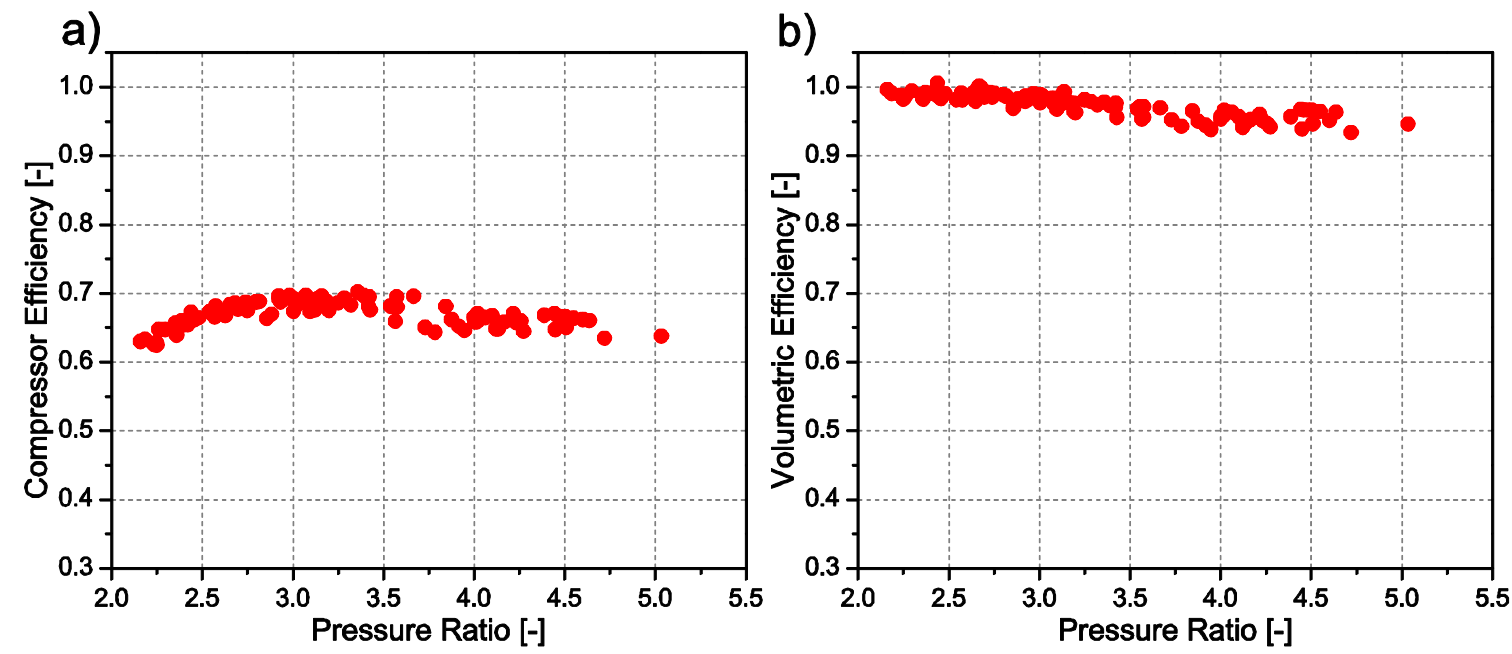

Figure 3.5: a) Compressor efficiency b) Volumetric efficiency as a function of the pressure ratio

\footnotetext{
${ }^{5}$ Capacity for R134a with the valve totally open and Tevap $=+4^{\circ} \mathrm{C}$; Tcond $=38^{\circ} \mathrm{C}$; Subcooling $=1 \mathrm{~K}$
} 


\subsubsection{Condenser}

The condenser will work mainly with two-phase refrigerant in the SMS design (subcooler), but it must be able to produce high degrees of subcooling in the SMC design in order to take profit from the high-temperature lift in the sanitary hot water application. The commercial software IMST-ART (IMST-ART v3.70) has been used in order to analyze the heat pump components and the overall performance.

The selected condenser has a horizontal port distance and vertical port distance of $60 \mathrm{~mm}$ and $470 \mathrm{~mm}$ respectively. Figure 3.6 shows the heating COP for the finite heat exchanger (calculated with IMST-ART) respect the theoretical maximum (infinite heat transfer area) as a function of the number of plates in the condenser. The heating COP for the infinite transfer area was calculated as in chapter 2, but with a compressor efficiency of 0.65 . For the nominal point (water $20^{\circ} \mathrm{C} / 15^{\circ} \mathrm{C}$ at the evaporator and $10^{\circ} \mathrm{C}$ to $60^{\circ} \mathrm{C}$ for the hot water production), the reference COP was 5.7, with an optimal subcooling of $43.4 \mathrm{~K}$. This subcooling was used in the IMST-ART calculations for all number of plates.

Finally, it has been decided to install a condenser with 62 plates, which has a heating COP of 5.53 (97\% respect to the infinite heat transfer area).

One should notice that the condenser would work without subcooling during the operation of the SMS design. In this case, the subcooling is made in a separate heat exchanger, the subcooler.

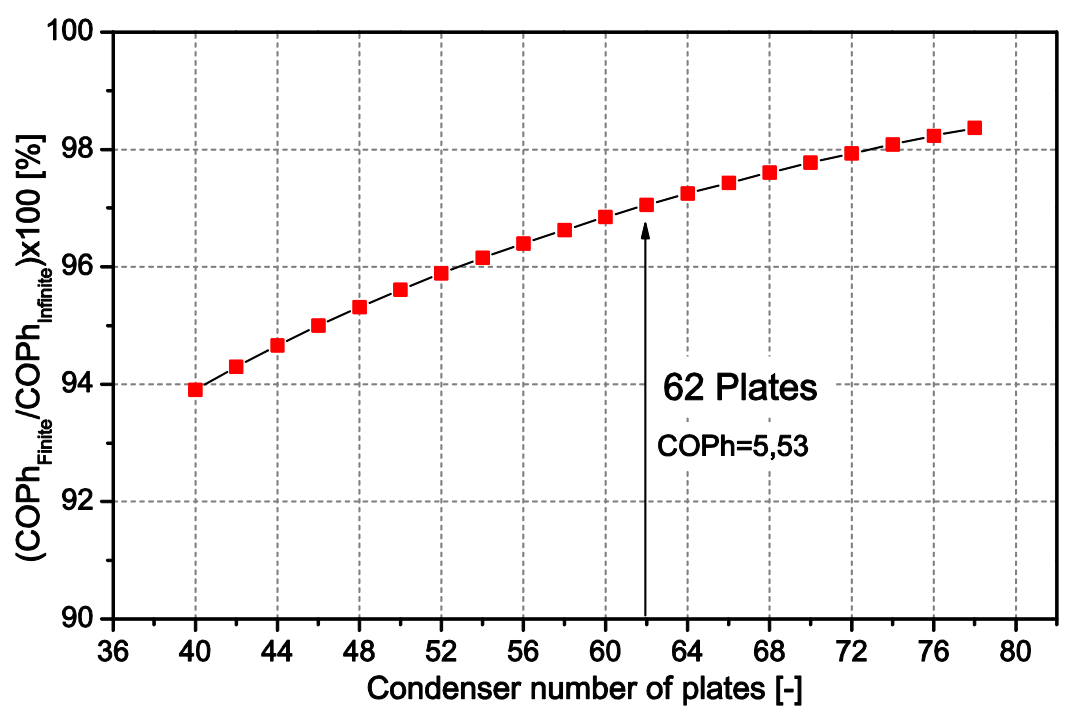

Figure 3.6: Heating Cop for a finite heat exchanger (IMST-ART) respect to the infinite heat transfer assumption (5.7, the theoretical maximum) as a function of the number of plates in the condenser. Nominal point, subcooling fixed to $43.4 \mathrm{~K}$ (propane) 


\subsubsection{Subcooler}

In the SMS prototype, the subcooling is made in the subcooler. The refrigerant density of the subcooled refrigerant is higher than in the two-phase state. Thereby, if a separate heat exchanger is used to produce subcooling, subcooler size can be optimized for refrigerant liquid, so it has an appropriate refrigerant velocity for heat transfer. In this way, subcooler requires smaller plate pitch than at the condenser. During the design period, it was discussed about the possibility of using the subcooler in series with a condenser (treating both heat exchangers as only one) for the SMC design. In this way, both heat pump designs would have the same heat transfer area, but the area for subcooling would be fixed for the SMS design (liquid receiver between both heat exchangers) and variable for the SMC design. The final decision was to use only one heat exchanger in the SMC design (the condenser) and an extra heat exchanger (subcooler) for the SMS design. In this way, the subcooler can be better optimized for subcooling, but in the analysis results, the HX area reduction in the SMC design must be taken into account.

The subcooler has as a smaller crossflow area than the condenser, so the velocity of the subcooled liquid is optimized for heat transfer. The selected subcooler has a horizontal port distance and vertical port distance of $46 \mathrm{~mm}$ and $270 \mathrm{~mm}$ respectively, with 40 plates and smaller plate pitch than in the condenser. This reduction in the crossflow area increases the heat transfer, but it also increases the pressure drop on the water side. Higher pressure drops lead to higher consumption of the auxiliary pump and lower global performance. Therefore, a control strategy must be followed in order to avoid undesirable situations.

The heat pump prototypes are tested at very different inlet water temperature at the heat sink (from $10^{\circ} \mathrm{C}$ to $55^{\circ} \mathrm{C}$ ). This variation in the inlet water temperature implies a large variation in the water mass flow rate (outlet temperature is fixed to $60^{\circ} \mathrm{C}$ ), about $0.9 \mathrm{~m}^{3} / \mathrm{h}$ and $6.3 \mathrm{~m}^{3} / \mathrm{h}$ for the water inlet temperature of $10^{\circ} \mathrm{C}$ and $55^{\circ} \mathrm{C}$ respectively. Figure $3.7 \mathrm{a}$ ) shows the pressure drop at the subcooler as a function of the water flow rate. Figure $7 \mathrm{~b}$ ) shows an estimated calculus for the high inlet water temperature $\left(55^{\circ} \mathrm{C}\right)$. 
a)

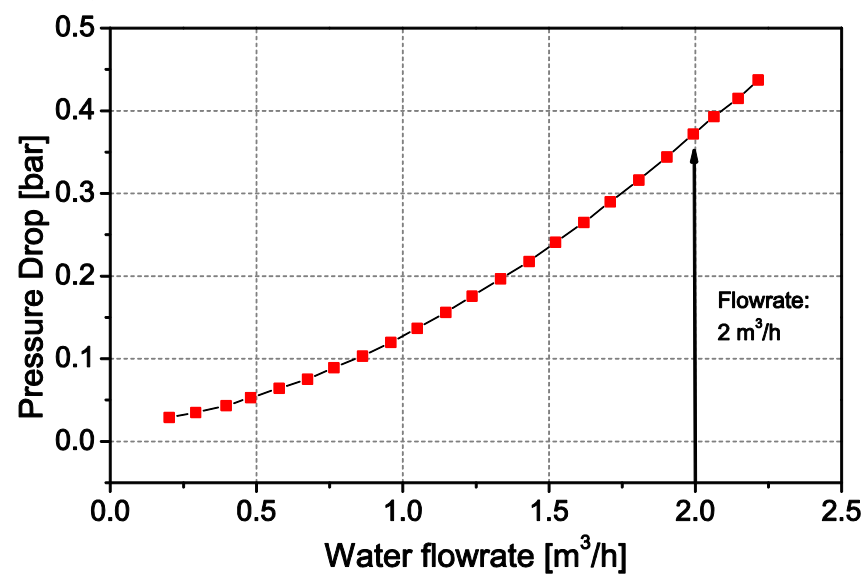

b)

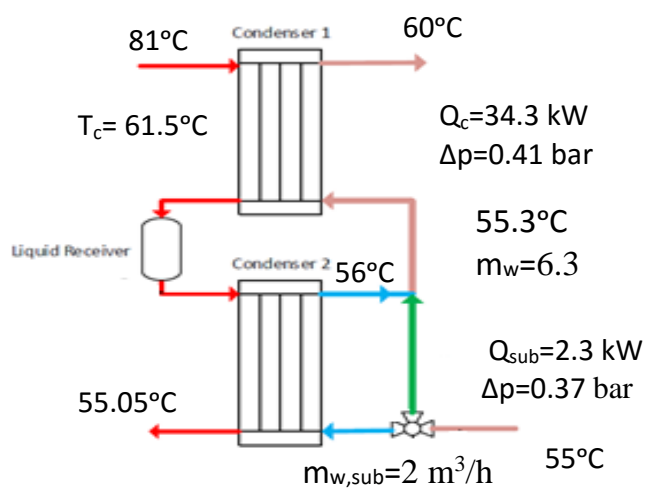

Figure 3.7: a) Pressure drop on the water side at the subcooler as a function of the water flow rate. b) Scheme of Condenser+Subcooler of the SMS design with a case study estimation (with IMST-ART)

The total water flow rate is $6.3 \mathrm{~m}^{3} / \mathrm{h}$, but the subcooler is partially bypassed in order to limit the flow rate through the subcooler at $2 \mathrm{~m}^{3} / \mathrm{h}$. This flow rate is enough to obtain the maximum possible subcooling at the subcooler, since the refrigerant temperature at its outlet is $55.04^{\circ} \mathrm{C}$, very close to the water inlet temperature $\left(55^{\circ} \mathrm{C}\right)$. For this flow rate, the pressure drop at the subcooler is around $0.37 \mathrm{bar}$, which is acceptable for the heat pump application. Therefore, all the measured points with the SMS prototype will limit the flow rate through the subcooler at $2 \mathrm{~m}^{3} / \mathrm{h}$ in order to limit the pressure drop at the subcooler. The partial bypass was only necessary for high inlet water temperature (more than $50^{\circ} \mathrm{C}$ ) and was controlled by a three-way valve.

\subsubsection{Evaporator}

The evaporator has to be large enough to have high efficiency at high evaporating temperatures. Furthermore, due to the high degree of subcooling, it is expected to have low refrigerant quality or even in subcooled liquid refrigerant at the evaporator inlet. Following the suggestions of the manufacturer, the selected evaporator has 120 plates and a horizontal port distance and vertical port distance of $50 \mathrm{~mm}$ and $466 \mathrm{~mm}$ respectively. 


\subsubsection{Liquid receiver}

The liquid receiver (LR) has to be able to hold the refrigerant variations in both heat pump designs:

- For the SMS prototype, the refrigerant in the subcooler does not change significantly, since it is always filled with liquid refrigerant. The refrigerant charge variation at the condenser is mainly due to pressure variations. The major refrigerant charge variations take place in the evaporator since the refrigerant quality at its inlet highly depends on the degree of subcooling, which mainly depends on the water temperature at the subcooler inlet.

- For the SMC prototype, there are also large variations in the refrigerant charge at the evaporator. Nevertheless, in this case, the refrigerant charge variation in the condenser is higher, since subcooling is done directly in the condenser.

Taking into account this charge variation, a volume of $7 \mathrm{l}$ for the LR has been estimated. The LR was specially built in order to install a refrigerant level sensor (Figure 3.8). In order to avoid measurement perturbations from the refrigerant coming into the LR, the inlet and the outlet ports were located at the bottom of the LR. For this reason, in order to avoid the direct connection between the inlet and outlet refrigerant mass flow, the inlet and outlet ports end in an elbow.
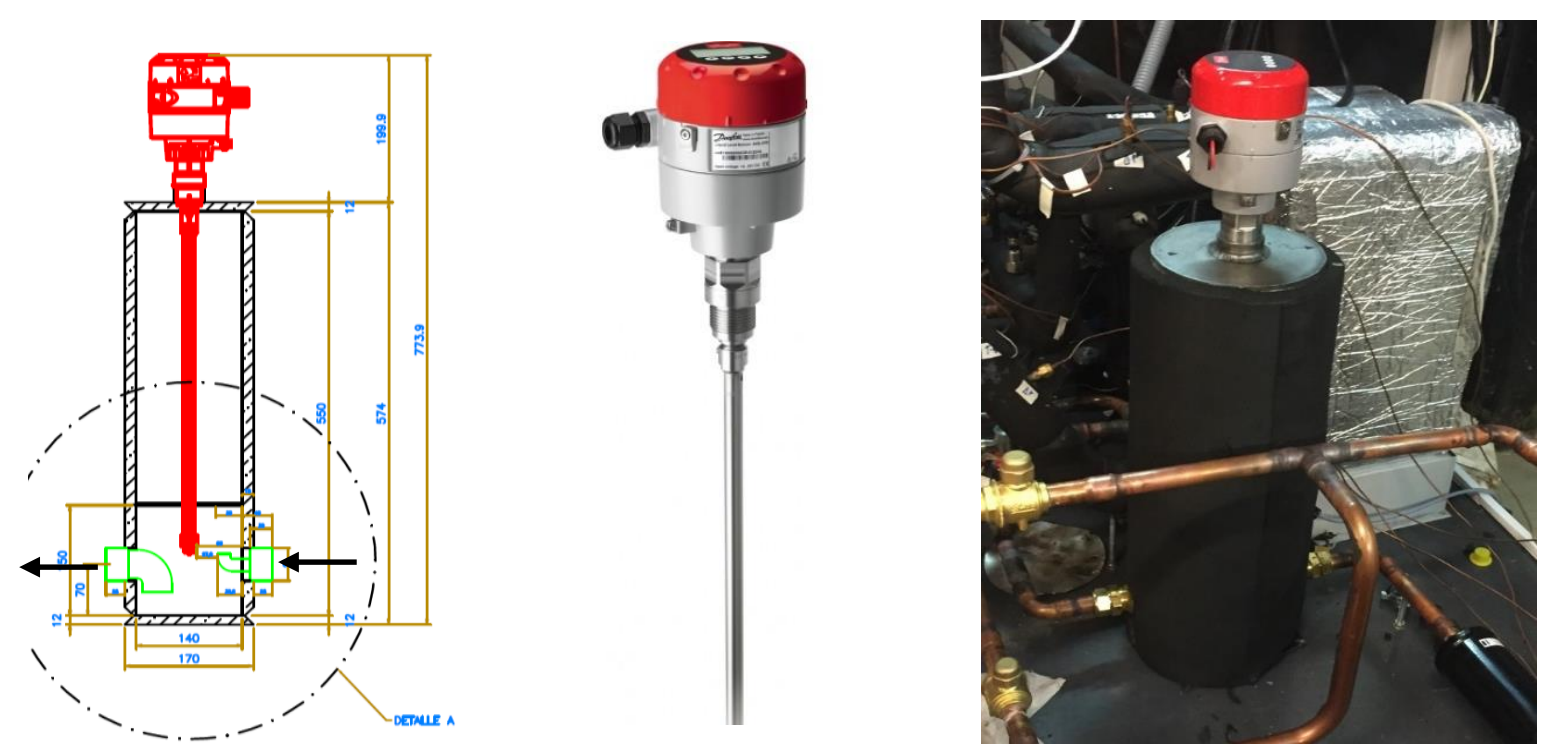

Figure 3.8: From the left to the right: Scheme of the liquid receiver with the level sensor, The AKS 100 level sensor, a picture of the liquid receiver with the level sensor installed 
The direction of the refrigerant inlet and outlet was found an important parameter to determine the duration of the transitory when an external condition was changed. This issue was published in the CYTEF conference (Pitarch et al., 2016). For instance, when the inlet water temperature to the subcooler was changed from $30^{\circ} \mathrm{C}$ to $10^{\circ} \mathrm{C}$ (SMS operation, without subcooling at the condenser) two different behaviors were found depending on the refrigerant direction at the LR inlet:

1) Refrigerant inlet coming downwards: High degree of subcooling appears at the condenser outlet. The subcooling at the condenser is reestablished to zero after 35 minutes.

2) Refrigerant inlet coming upwards: A small degree of subcooling is produced in the condenser. The subcooling at the condenser is reestablished to zero in less than 5 minutes.

Therefore, the LR has been installed with the refrigerant inlet port looking upwards. For a more detailed information, the paper Pitarch et al. (2016) on this issue has been attached as Appendix A.

\subsubsection{Expansion valve}

The first version of the prototype had only one expansion valve. This prototype was working correctly for the SMS design but did not work correctly for the SMC design. The problems faced during the operation of the SMC design forced us to redesign and improve the heat pump prototype in order to work correctly in a wide range of conditions for the SMC design. This section and the one dedicated to the throttling valve explain these modifications.

Figure 3.9 shows the P-h diagram of the SMC design working with low and high subcooling. In this case, depending on the subcooling, the required pressure drop at the throttling and the expansion valve can vary significantly. 

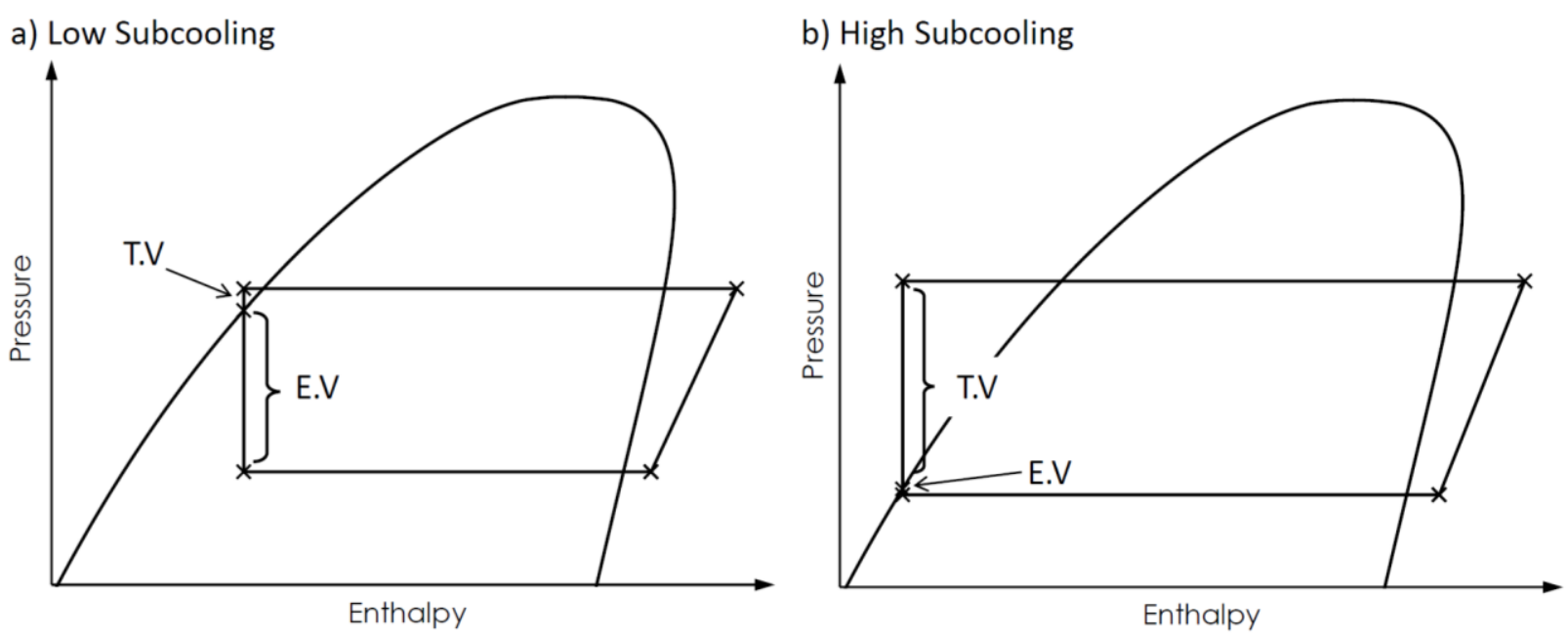

Figure 3.9: Pressure-enthalpy diagram for the propane cycle: a) Low subcooling, b) High subcooling

The selected expansion valve in the first version of the prototype, the EX5, has the right capacity for the SMS design. Nevertheless, the valve, even when totally open, produces a higher pressure drop than the desired one when the prototype operates in the SMC design with high subcooling. This is due to the share of the pressure drop with the throttling valve during the operation of the SMC design.

For this reason, a second expansion valve (EX6) was installed in parallel with the EX5. The EX5 always operates automatically with a PID control (XEV22D with the propane curve installed) to the superheat (usually $10 \mathrm{~K}$ ). The EX6 is only used for high degrees of subcooling (SMC design). In the case of having both expansion valves working at the same time, one will by kept partially open with the manual control (EX6) and the other will be controlled automatically (EX5).

If this heat pump would be commercialized, an alternative solution using only one expansion valve should be implemented, for instance, a higher capacity expansion valve. The solution of the two expansion valves was used in the prototype due to flexibility since there are two heat pump designs in the same prototype. 


\subsubsection{Throttling valve}

There is not a general procedure to select a throttling valve. The throttling valve installed in the first version of the heat pump prototype was the EXL 125/B1G. It is an electronic expansion valve with a capacity ${ }^{6}$ of $15.2 \mathrm{~kW}$, which is smaller to the obtained by the EX5 (39 kW). These capacities are given for expansion valves, but in this system (SMC design), the refrigerant is not expanded in the throttling valve and instead there is saturated liquid at its outlet. Therefore, the throttling valve was selected smaller, expecting lower pressure drops than in the expansion valve (for the same refrigerant mass flow and valve opening). Nevertheless, it was impossible to obtain low degrees of subcooling because the pressure drop produced by this valve (fully open) was too high. Hence, a second throttling valve was installed in parallel, the EX5.

Finally, the EX5 resulted in working correctly in all the measured conditions, and the EXL 125/B1G was not used. Figure 3.10 shows a picture of both throttling valves connected in parallel and the control scheme of the EX5 throttling valve.
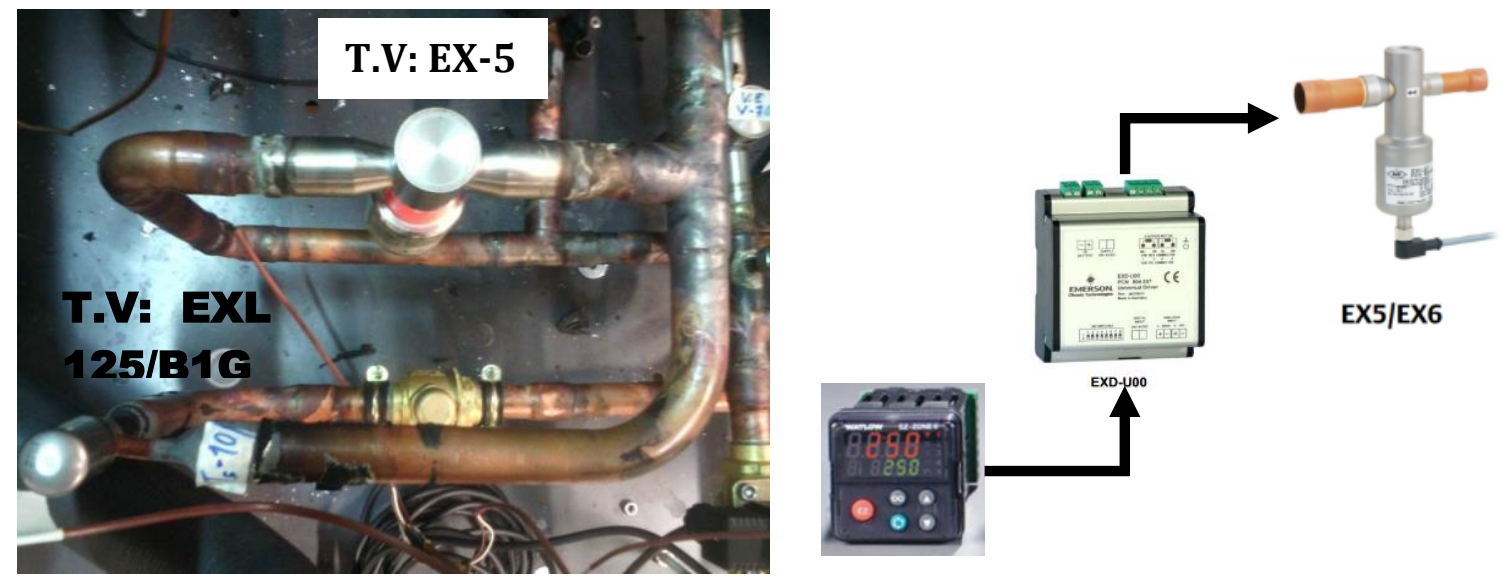

Figure 3.10: Picture of the throttling valves: EX5 and EXL 125/B1G and schematic of the control for the throttling valve: $\mathrm{PID} \rightarrow \mathrm{EXD}-\mathrm{U} 00 \rightarrow$ EX5

\footnotetext{
${ }^{6}$ Capacity for R134a with the valve totally open and Tevap $=+4^{\circ} \mathrm{C}$; Tcond $=+38^{\circ} \mathrm{C}$; Subcooling $=1 \mathrm{~K}$
} 


\section{Chapter 4}

\section{Experimental setup and test conditions}

The heat pump prototype was designed to have a heating capacity of $50 \mathrm{~kW}$ in the nominal point (water $20^{\circ} \mathrm{C} / 15^{\circ} \mathrm{C}$ at the evaporator and $10^{\circ} \mathrm{C}$ to $60^{\circ} \mathrm{C}$ for the hot water production), but higher capacities are expected at different conditions. The capacity of the laboratory in the Institut Universitari d'Investigació d'Enginyeria Energètica (Universitat Politècnica de València) was not enough to dissipate the heat pump capacity. Therefore, in order to test the heat pump prototype, a new test rig was designed and built in the laboratory. This test rig is able to recover energy from the heat sink to the heat source. Hence, less heat needs to be dissipated to the ambient.

This chapter presents the experimental setup (test rig) used to test the prototype with the two heat pump designs (chapter 3). Furthermore, it is presented: the sensors and the error analysis, and the test conditions for both heat pump designs.

There is no applicable standard to characterize the COP for this application (SHW production in the application of heat recovery from any water source). Nevertheless, the European Standard EN 14825 (EN 14825, 2011) has been used to select the conditions at the evaporator. 


\subsection{Experimental setup}

Figure 4.1 shows the test rig. The test rig is able to test water-to-water heat pumps with a heating capacity up to $70 \mathrm{~kW}$. Between the dashed lines it is the unit to be tested, where points $1 \& 2$ are the inlet/outlet for the heat sink (demand side), and $3 \& 4$ are the inlet/outlet for the heat source (waste heat side). The test rig is able to keep to a constant value the water temperature at these points.

Besides the main propane refrigerant cycle (between dashed line), the test rig consists of four more loops:

A. The water loop for the heat source (Evaporator). It simulates the heat recovery from a water source.

B. The water loop for the heat sink (Condenser). It simulates the SHW production.

C. The water/glycol loop.

D. The chiller. Works with R410A

Regarding the security issues related to the use of Propane: the laboratory is equipped with gas sensors and an alarm system able to detect a propane leakage and start with a security routine. The heat pump has a total refrigerant charge of $6.2 \mathrm{~kg}$. This charge includes the refrigerant to work with the SMS and the SMC designs at all considered conditions. The refrigerant charge can be significantly reduced if one of the systems is commercialized separately, below $5 \mathrm{~kg}$ (extra piping for the prototype, wide range of the operating conditions, optimization of the components size for the selected design, etc...). If commercialized, as commented in the introduction, this heat pump will be installed in a vented place outdoor. 


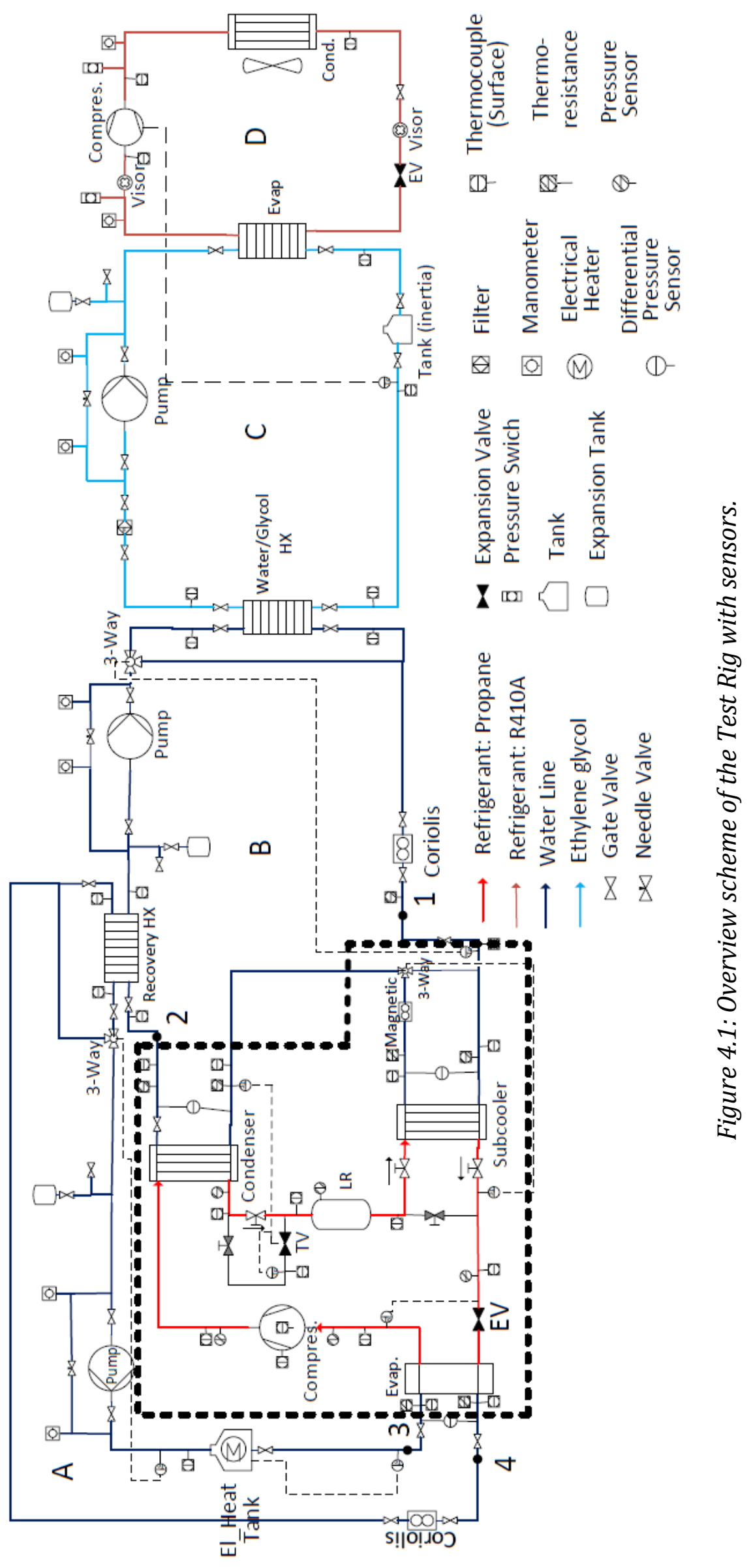




\subsubsection{Water loop for the heat source (Evaporator)}

Figure 4.2 shows the scheme of the evaporator water loop with typical temperatures at different points. The evaporating water loop ensures the desired water temperature at the inlet and outlet of the evaporator. A frequency variable water pump adjusts the water mass flow rate, which will determine the temperature at the outlet of the evaporator. Furthermore, a bypass with a needle valve connecting the outlet and inlet of the water pump can be used for a more precise water mass flow rate control. In order to achieve the target temperature at the inlet of the evaporator, this water loop consists of:

- A recovery heat exchanger that interacts with the condensing water loop to recover part of the energy in the condenser

- A three-way valve controlled by a PID in order to adjust the desired temperature at the outlet of the recovery HX.

- An electrical heater controlled by a PID adds the rest of the needed energy.

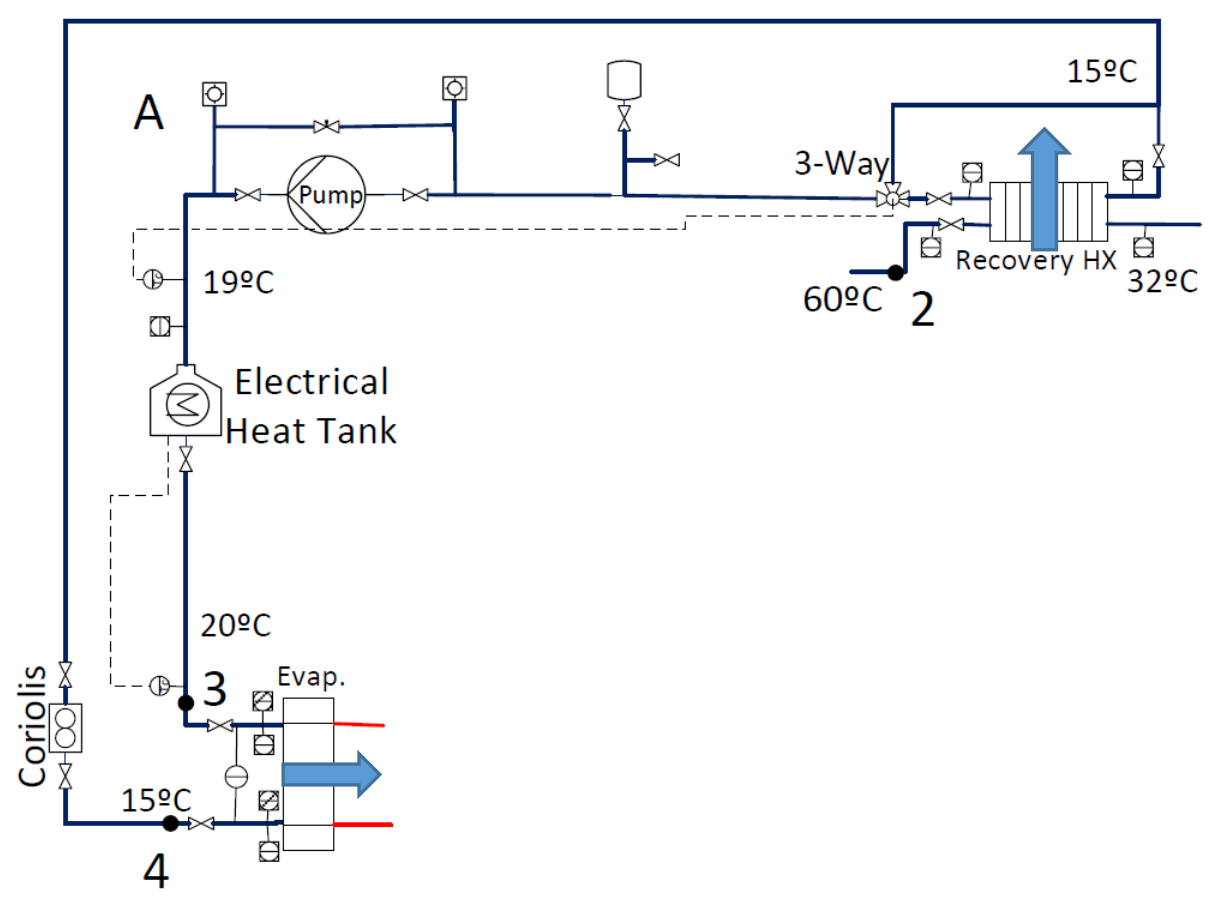

Figure 4.2: Scheme of the evaporator water loop with typical temperatures 


\subsubsection{Water loop for the heat sink (Condenser)}

Figure 4.3 shows the scheme of the condenser water loop with typical temperatures at different points. The condensing water loop must keep the supplied water after the condenser (2) at the constant temperature of $60^{\circ} \mathrm{C}$, and the inlet water temperature of the system fixed to a value ranging from $10^{\circ} \mathrm{C}$ to $55^{\circ} \mathrm{C}$. A frequency variable water pump adjusts the water mass flow rate, which will determine the temperature at the outlet of the condenser. Furthermore, a bypass with a needle valve connecting the outlet and inlet of the water pump can be used for a more precise water mass flow rate control. In order to achieve the target temperature at the inlet of the heat pump prototype, this water loop consists of:

- A recovery heat exchanger that interacts with the evaporator water loop to recover. The heat transfer will depend on the evaporator water loop control.

- A heat exchanger is interacting with the water/glycol loop, which is used to cool down the water at the condenser loop.

- A three-way valve controlled by a PID in order to adjust the desired temperature at inlet of the heat pump prototype $\left(10^{\circ} \mathrm{C}\right.$ to $\left.55^{\circ} \mathrm{C}\right)$

The three-way valve controlling the water mass flow rate through the subcooler is part of the heat pump prototype. Figure 4.4 shows a picture of the evaporator and condenser water loops.

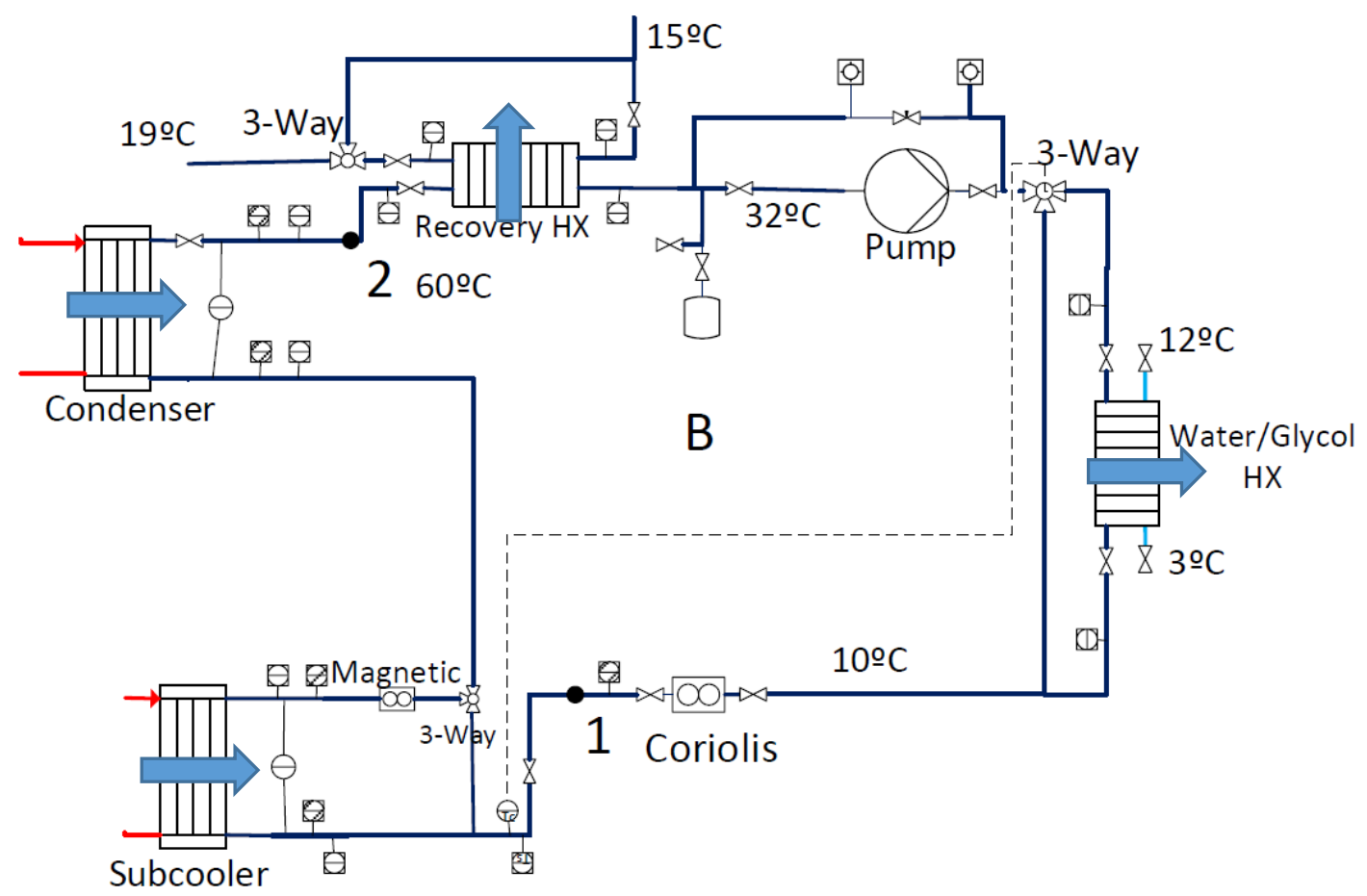

Figure 4.3: Scheme of the evaporator water loop with representative temperatures 


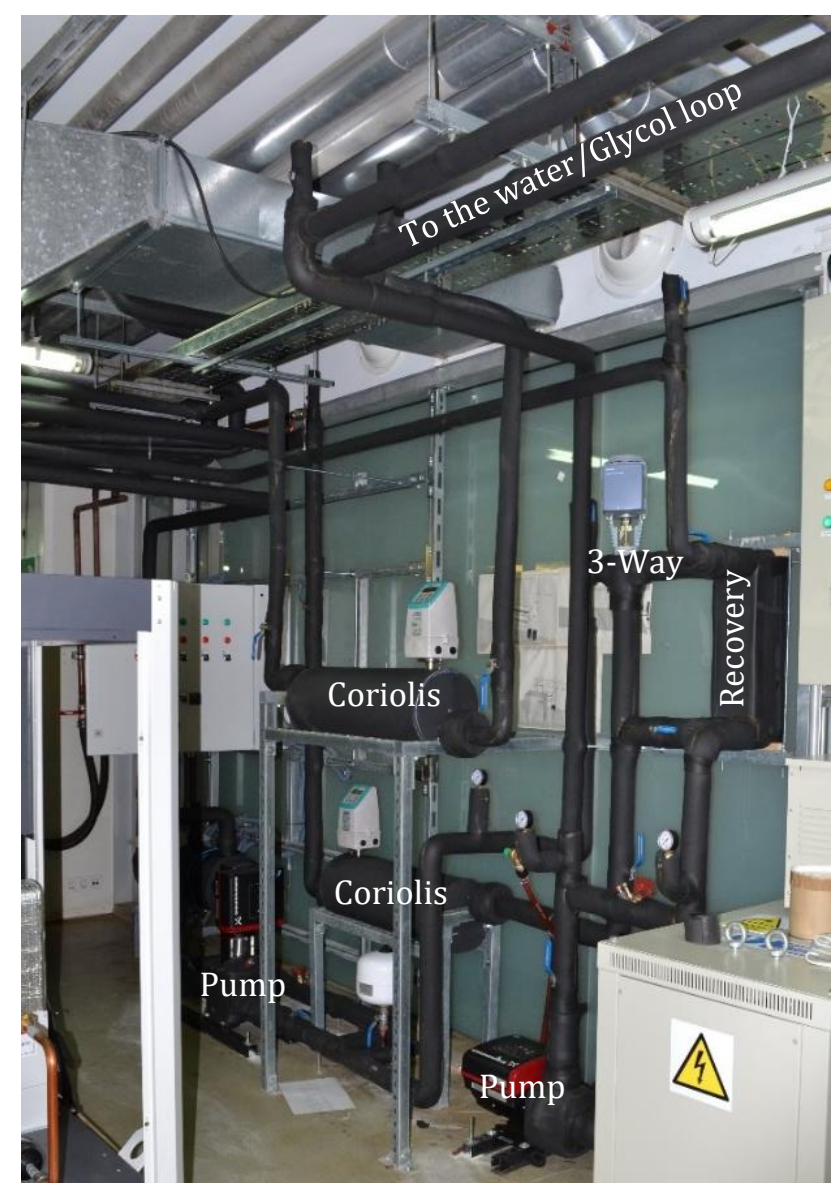

Figure 4.4: Picture of the evaporator and condenser water loop in the test rig

\subsubsection{Water/glycol loop and chiller working with R410A}

Figure 4.5 shows the scheme and the picture of the water/glycol loop and the chiller working with R410A. The chiller is in charge to pump out to the ambient the heat remaining in the water of the condenser loop after passing through the recovery heat exchanger. The capacity of the chiller is not controlled, so it does not match exactly with the required heat to be removed. To solve this issue, the water/glycol loop with an inertia tank connects the condenser water loop and the chiller. With this configuration, the overall needed capacity is achieved by an $\mathrm{ON}$ OFF control of the compressor (chiller). It starts or stops depending on the demand of cold of the system.

The ON/OFF control of the compressor is connected to the temperature at the outlet of the inertia tank (500 liters). The chiller is started when the controlled water/glycol temperature is above $4.5^{\circ} \mathrm{C}$ and stopped when this temperature is below $2^{\circ} \mathrm{C}$. 

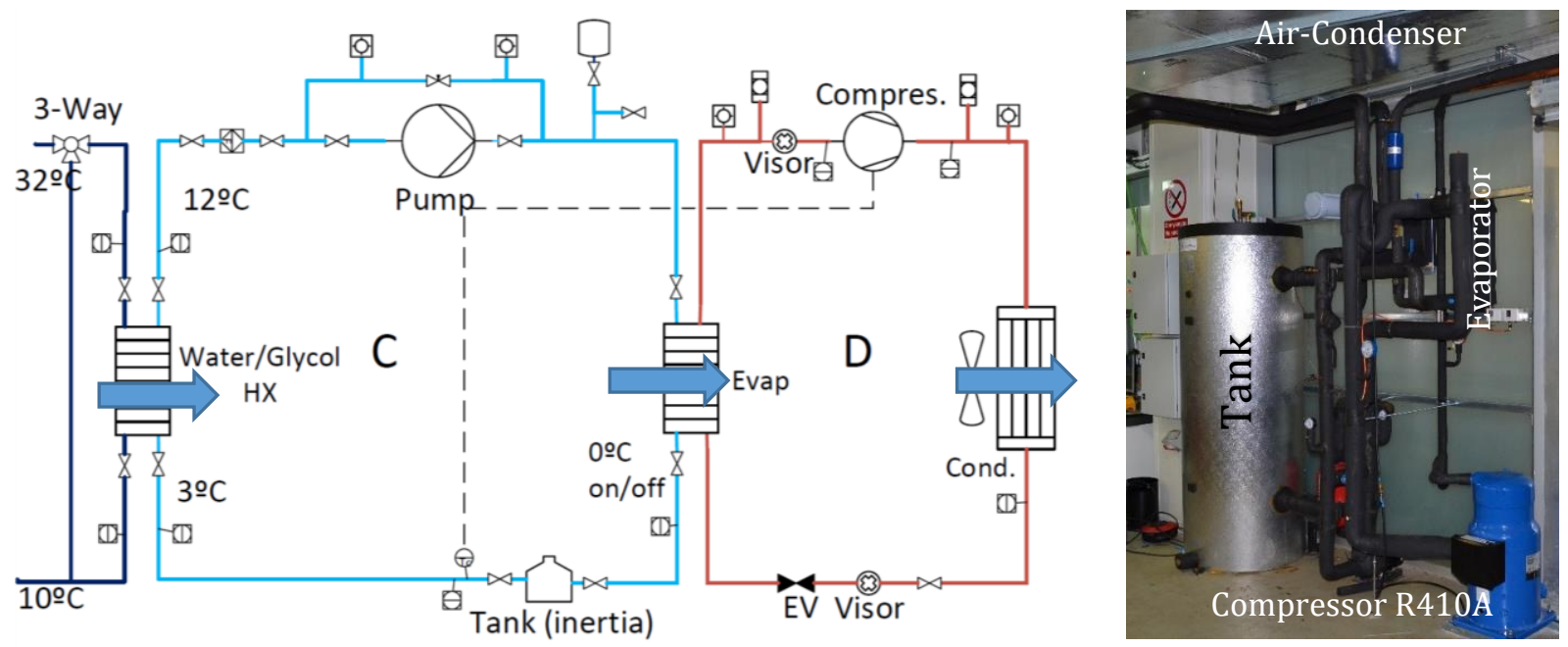

Figure 4.5: Scheme and picture of the water/glycol loop and chiller working with R410A

\subsection{Sensors and error analysis}

The evaporator and condenser capacities of the heat pump were measured on the water side. In order to measure them as accurate as possible, six thermoresistances were located at inlet/outlet of each heat exchanger directly in contact with the water. In order to monitor and measure temperature in other points, a total number of $27 \mathrm{~T}$-type thermocouples were used. The water mass flow through evaporator and condenser were measured with Coriolis mass flow meters. For control reasons, a magnetic mass flow meter was measuring the water mass flow through subcooler, which in most of the cases was the same as in the condenser. For the pressure, on the refrigerant side, there were three high accuracy Rosemount sensors. In the water side, there were 3 differential pressure sensors to measure the pressure drop in the heat exchangers. With these measurements and according to the norm EN 14511-3 "Test methods" (DIN EN 14511-3, 2013), the auxiliary consumption of the water pumps was calculated (Appendix B).

In order to monitor and measure those key parameters to evaluate the performance of the heat pump, all the sensors were connected to a data acquisition system "Agilent 34970A", where all parameters were monitored.

Table 4.1 shows the main sensors with the relative and absolute accuracy for the sensor. The reader can refer to Appendix B to find details about uncertainties and other information of the experimental results. 
Table 4.1: Sensors and their uncertainty

\begin{tabular}{|c|c|c|c|c|}
\hline Magnitude & Model & $\begin{array}{l}\text { Relative } \\
\text { Accuracy }\end{array}$ & $\begin{array}{l}\text { Absolute } \\
\text { Accuracy }\end{array}$ & Units \\
\hline \multirow{6}{*}{ Pressure } & $\begin{array}{c}\text { Differential } 1151 \text { Smart } \\
\text { Rosemount }\end{array}$ & $0.13 \%$ of Span & 5 E-04 & bar \\
\hline & Differential p Siemens Sitrans & $0.14 \%$ of Span & $4 \mathrm{E}-04$ & bar \\
\hline & Differential p Setra & $0.3 \%$ of Span & 1.7 E-03 & bar \\
\hline & P 1151 Smart GP7 Rosemount & $0.12 \%$ of Span & 0.03 & bar \\
\hline & P 1151 Smart GP8 Rosemount & $0.15 \%$ of Span & 0.08 & bar \\
\hline & P 3051 TG3 Rosemount & $0.14 \%$ of Span & 0.04 & bar \\
\hline \multirow{2}{*}{ Temperature } & Thermocouple T-Type & & 1 & ${ }^{\circ} \mathrm{C}$ \\
\hline & RTD Class 1/10 DIN & & 0.06 & ${ }^{\circ} \mathrm{C}$ \\
\hline \multirow{2}{*}{ Flow } & $\begin{array}{l}\text { Coriolis SITRANS F C MASS } \\
2100\end{array}$ & $0.3 \%$ of Reading & & \\
\hline & $\begin{array}{c}\text { Magnetic SITRANS FM } \\
\text { MAG5100 W }\end{array}$ & $0.4 \%$ of Reading & & \\
\hline Power & DME 442 & $0.3 \%$ of Reading & & \\
\hline
\end{tabular}

\subsection{Performed test}

The kind of application defines the boundary conditions. In the SHW application, $60^{\circ} \mathrm{C}$ was selected due to legionella legislation in EU countries. The inlet water temperature at the condenser depends on the city water temperature, which usually ranges between $10^{\circ} \mathrm{C}$ to $30^{\circ} \mathrm{C}$ depending on location and period of the year. However, it also depends on the water tank connection and sizing, making possible to have higher inlet water temperatures, for instance, when recovering heat losses at the tank in periods of inactivity. In this sense, the heat pump was tested at inlet water temperature to the condenser ranging from $10^{\circ} \mathrm{C}$ to $55^{\circ} \mathrm{C}$.

In the evaporator, the inlet water temperatures ranged from $10^{\circ} \mathrm{C}$ to $35^{\circ} \mathrm{C}$, which corresponds to the waste heat recovery application. The waste heat could come from any available source of energy, such as sewage or a condensation loop. The water mass flow through the evaporator was adjusted in order to obtain a $5 \mathrm{~K}$ water temperature decrease at the nominal point (water $20^{\circ} \mathrm{C} / 15^{\circ} \mathrm{C}$ at the evaporator and $10^{\circ} \mathrm{C}$ to $60^{\circ} \mathrm{C}$ for the hot water production). The water mass flow rate adjusted in the nominal point was kept constant for the rest of test points (around $7000 \mathrm{kgh}^{-1}$ ). This procedure is described in the European Standard EN 14825 (EN 14825, 2011). In the refrigerant side, superheat was kept constant to $10 \mathrm{~K}$ (unless the contrary is indicated). 
Once all the target parameters were reached, and the heat pump is working in steady state condition, the acquisition data record data every 10 seconds during 30 minutes. In order to ensure a steady state behavior, all the measured points were checked to lie under the limits marked by the norm EN 14511-3 "Test methods" (DIN EN 14511-3, 2013).

\subsubsection{Test for SMC design}

Table 4.2 contains the measurement points of the test matrix. In order to study the effect of subcooling at each external condition (water temperatures), each measured point has been tested at different subcooling values. The total number of measured points is 68. The selected conditions are: the water inlet temperature at the evaporator $\left(T_{w, e i}\right)$, the water inlet temperature at the condenser $\left(T_{w, c i}\right)$, the water outlet temperature at the condenser $\left(T_{w, c o}\right)$ and the subcooling $(S c)$.

Table 4.2: Test matrix with a total number of 68 measured points.

\begin{tabular}{|c|c|c|c|}
\hline$T_{w, e i}\left[{ }^{\circ} \mathrm{C}\right]$ & $T_{w, c i}\left[{ }^{\circ} \mathrm{C}\right]$ & $T_{w, c o}\left[{ }^{\circ} \mathrm{C}\right]$ & $\begin{array}{c}\text { Refrigerant } S c \\
\text { range }[\mathrm{K}]\end{array}$ \\
\hline \multirow{3}{*}{10} & 10 & & From 1 to 48 \\
\hline & 30 & & From 1 to 32 \\
\hline & 50 & & From 1 to 17 \\
\hline \multirow{3}{*}{20} & 10 & & From 1 to 52 \\
\hline & 30 & 60 & From 1 to 35 \\
\hline & 50 & & From 1 to 17 \\
\hline \multirow{3}{*}{30} & 10 & & From 4 to 45 \\
\hline & 30 & & From 4 to 35 \\
\hline & 50 & & From 3 to 14 \\
\hline
\end{tabular}

\subsubsection{Test for SMS design}

For the SMS design is not possible to control the degree of subcooling at each measured condition. Instead, the degree of subcooling is given by the subcooler. In order to limit the pressure drop at the subcooler (water side), the water flow rate was partially bypassed for water mass flow rates higher than $2 \mathrm{~m}^{3} / \mathrm{h}$ (usually for inlet water temperatures to the subcooler higher than $50^{\circ} \mathrm{C}$ ). Table 4.3 shows the conditions of the measured points. The number of points measured in the SMS design were 42 . 
Table 4.3: Test matrix with a total number of 42 measured points. *Water mass flow

\begin{tabular}{|c|c|c|c|}
\hline$T_{w, e i}\left[{ }^{\circ} \mathrm{C}\right]$ & $T_{w, c i}\left[{ }^{\circ} \mathrm{C}\right]$ & $T_{w, c o}\left[{ }^{\circ} \mathrm{C}\right]$ & $\begin{array}{c}\text { Mass flow ratio*: } \\
\dot{m}_{w, s u b} / m_{w, \text { cond }}\end{array}$ \\
\hline \multirow{6}{*}{10} & 10 & \multirow{29}{*}{60} & 1.00 \\
\hline & 20 & & 1.00 \\
\hline & 30 & & 1.00 \\
\hline & 40 & & 1.00 \\
\hline & 50 & & 0.83 \\
\hline & 55 & & 0.45 \\
\hline \multirow{6}{*}{20} & 10 & & 1.00 \\
\hline & 20 & & 1.00 \\
\hline & 30 & & 1.00 \\
\hline & 40 & & 1.00 \\
\hline & 50 & & 0.67 \\
\hline & 55 & & 0.30 \\
\hline \multirow{6}{*}{25} & 10 & & 1.00 \\
\hline & 20 & & 1.00 \\
\hline & 30 & & 1.00 \\
\hline & 40 & & 1.00 \\
\hline & 50 & & 0.63 \\
\hline & 55 & & 0.29 \\
\hline \multirow{6}{*}{30} & 10 & & 1.00 \\
\hline & 20 & & 1.00 \\
\hline & 30 & & 1.00 \\
\hline & 40 & & 1.00 \\
\hline & 50 & & 0.53 \\
\hline & 55 & & 0.29 \\
\hline \multirow{5}{*}{35} & 20 & & 1.00 \\
\hline & 30 & & 1.00 \\
\hline & 40 & & 1.00 \\
\hline & 50 & & 0.45 \\
\hline & 55 & & 0.26 \\
\hline \multirow{3}{*}{20} & 30 & 70 & 1.00 \\
\hline & 30 & 80 & 1.00 \\
\hline & 30 & 90 & 1.00 \\
\hline
\end{tabular}




\begin{tabular}{c|c|c|c}
\hline \multirow{2}{*}{$\boldsymbol{T}_{\boldsymbol{w}, \boldsymbol{e i}}\left[{ }^{\mathbf{0}} \mathbf{C}\right]$} & $\boldsymbol{T}_{\boldsymbol{w}, \boldsymbol{c i}}\left[{ }^{\mathbf{0}} \mathbf{C}\right]$ & $\boldsymbol{T}_{\boldsymbol{w}, \boldsymbol{c o}}\left[{ }^{\mathbf{o}} \mathbf{C}\right]$ & $\begin{array}{c}\text { Mass flow ratio*: } \\
\dot{\boldsymbol{m}}_{\boldsymbol{w}, \boldsymbol{s u b} \boldsymbol{b}} / \boldsymbol{m}_{\boldsymbol{w}, \boldsymbol{c o n d}}\end{array}$ \\
\hline \multirow{2}{*}{ 10 } & 10 & & 1.00 \\
(Target Sh: 5 K) & 30 & 60 & 1.00 \\
& 50 & & 0.81 \\
\hline \multirow{2}{*}{20} & 10 & & 1.00 \\
(Target Sh: 5 K) & 30 & 60 & 1.00 \\
& 50 & & 0.64 \\
\hline \multirow{2}{*}{20} & 10 & & Without \\
& 30 & 60 & Subcooling \\
\hline
\end{tabular}





\section{Chapter 5}

\section{Experimental results and discussion}

This chapter presents the experimental results and discussion for both heat pump designs:

1) SMC design: Subcooling Made in the Condenser. Subcooling can be modified with the throttling valve.

2) SMS design: Subcooling Made in the Subcooler. Subcooling is fixed for a given external condition.

The heat pump prototype with the two designs concepts was tested with the test rig presented in chapter 4 .

The heating COP and heating capacity were calculated at each condition according to the norm EN 14511-3 “Test methods" (DIN EN 14511-3, 2013), these calculations include the auxiliary consumption of the water pumps as it is indicated in the previous standard. The reader can refer to Appendix B to find details about uncertainties and other information of the experimental results.

\subsection{Subcooling in the condenser: SMC design}

Figure 5.1 shows the scheme of the water-to-water heat pump to make subcooling in the condenser (SMC design). 
a)

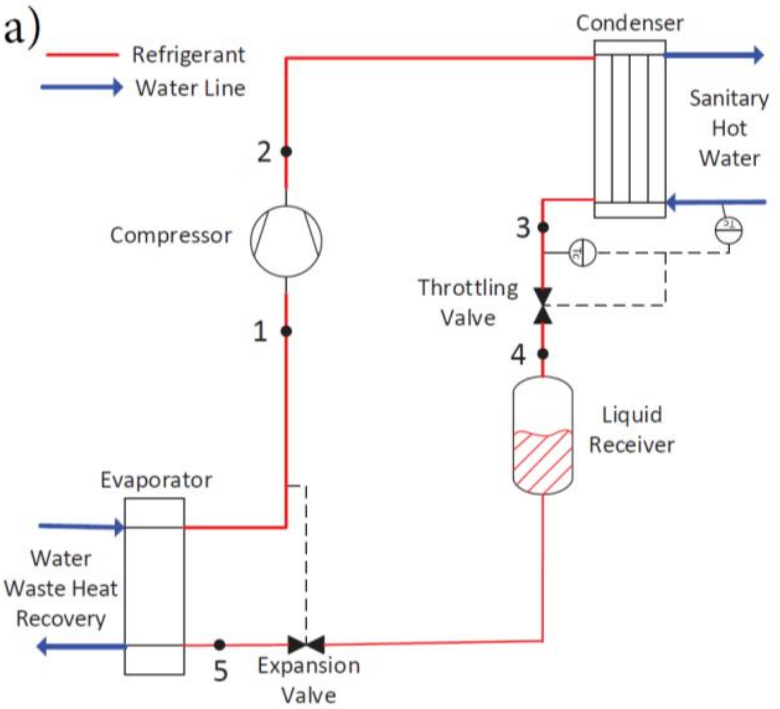

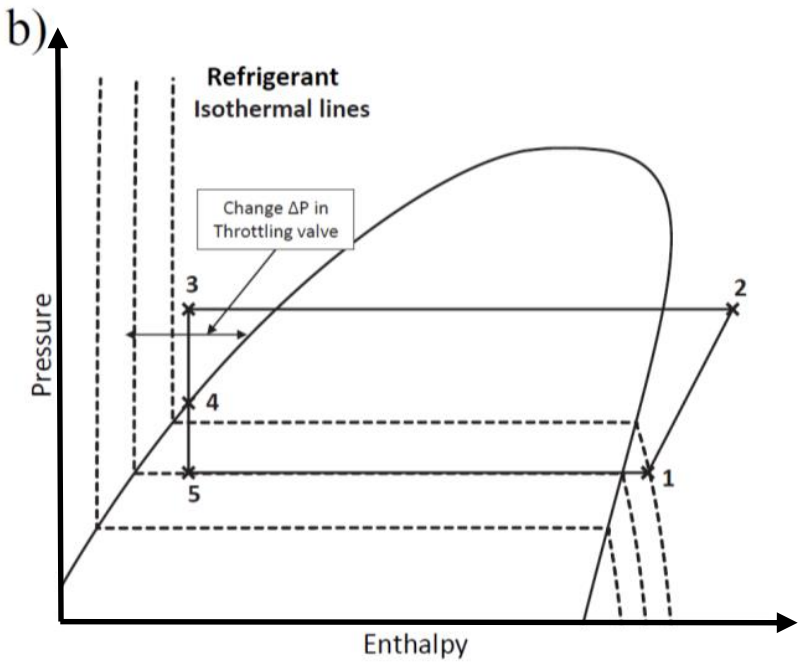

Figure 5.1: Heat Pump with subcooling controlled by a throttling valve a) Scheme, b) Ph diagram.

The SMC design incorporates a throttling valve, which produces a pressure drop between the condenser and the liquid receiver. This valve incorporates a new degree of freedom into the heat pump system, so the subcooling can be controlled at any time independently of the expansion valve control at the superheat. This heat pump design is used to investigate the role of subcooling at different water inlet temperature to the condenser in the application of SHW production (fixed outlet water temperature to $60^{\circ} \mathrm{C}$ ) experimentally. Therefore, the heat pump is tested at different water temperature lifts.

Part of the results of this section has been presented for publication in the journal "Science Technology for the Built Environment" (Pitarch et al., 2017B).

\subsubsection{Results}

Figures 5.2a), c) and e) show the heating COP as a function of subcooling. The water outlet temperature at the condenser is fixed to $60^{\circ} \mathrm{C}$. Different temperatures for the water inlet at the condenser $\left(T_{w, c i}\right)$ and water inlet at the evaporator $\left(T_{w, e i}\right)$ are considered. For a given external condition (fixed $T_{w, e i}$ and $T_{w, c i}$ ), there is an optimal subcooling where COP is maximized. The optimum subcooling can vary significantly depending on $T_{w, c i}$. The lower $T_{w, c i}$ (or higher temperature lift), the higher the optimal subcooling. As an example, the optimum COP for the nominal point $\left(T_{w, e i}=20^{\circ} \mathrm{C} ; T_{w, c i}=10^{\circ} \mathrm{C}\right)$ is 5.38 and corresponds to a subcooling of about 42 K. 
a) $\mathrm{Tw}$,ei $10^{\circ} \mathrm{C}$

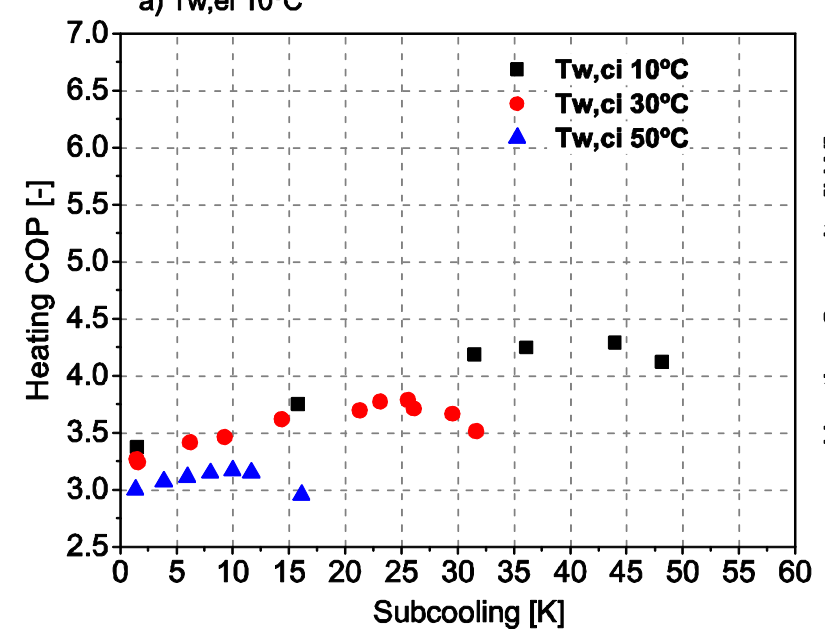

c) Tw,ei $20^{\circ} \mathrm{C}$

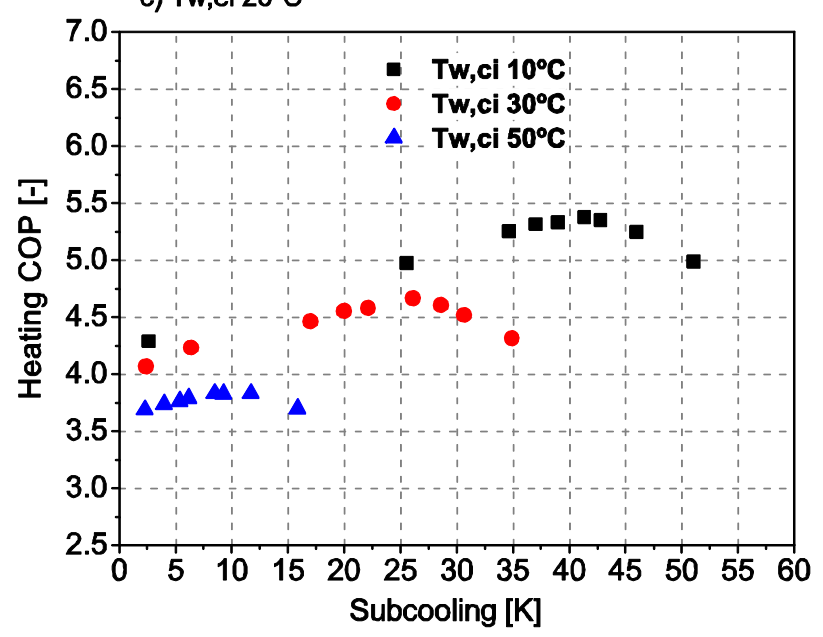

e) $\mathrm{Tw}$,ei $30^{\circ} \mathrm{C}$

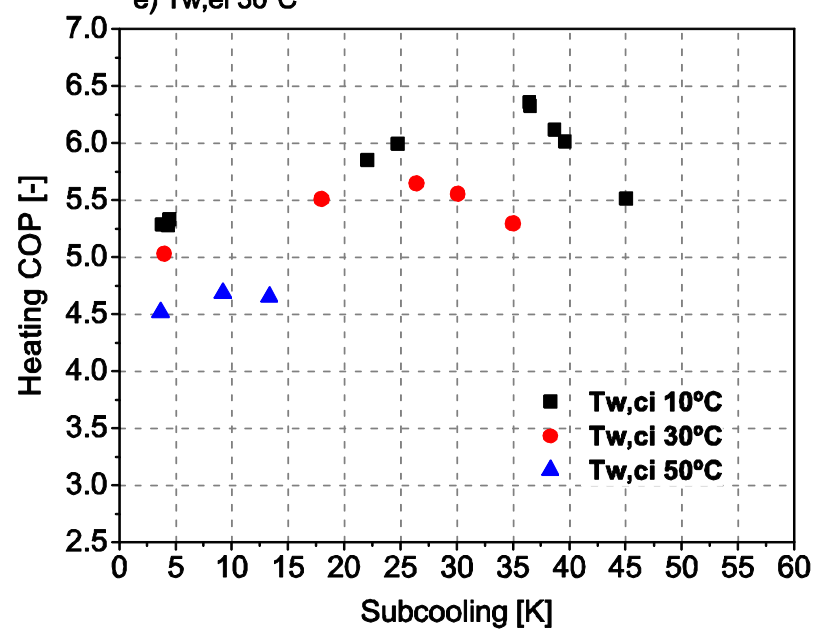

b) $\mathrm{Tw}$,ei $10^{\circ} \mathrm{C}$

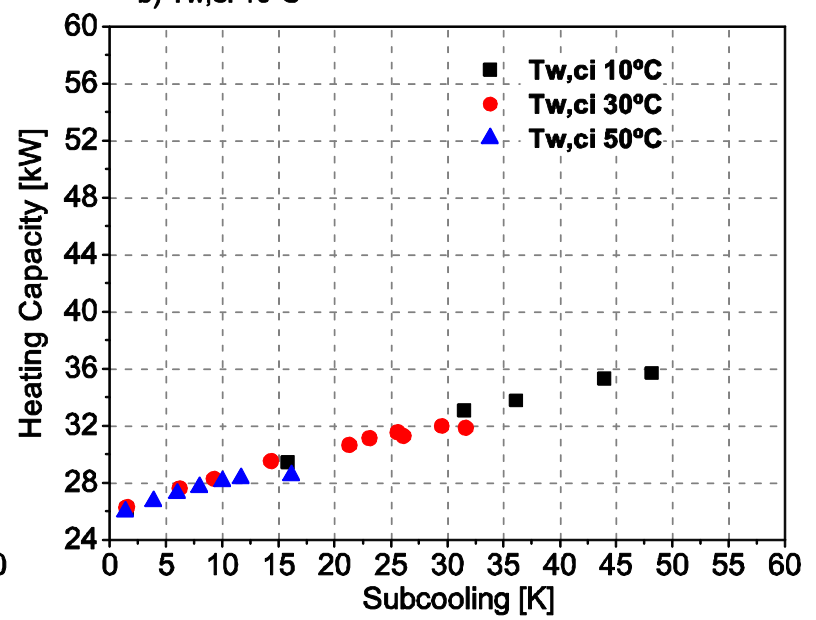

d) $\mathrm{Tw}$,ei $20^{\circ} \mathrm{C}$
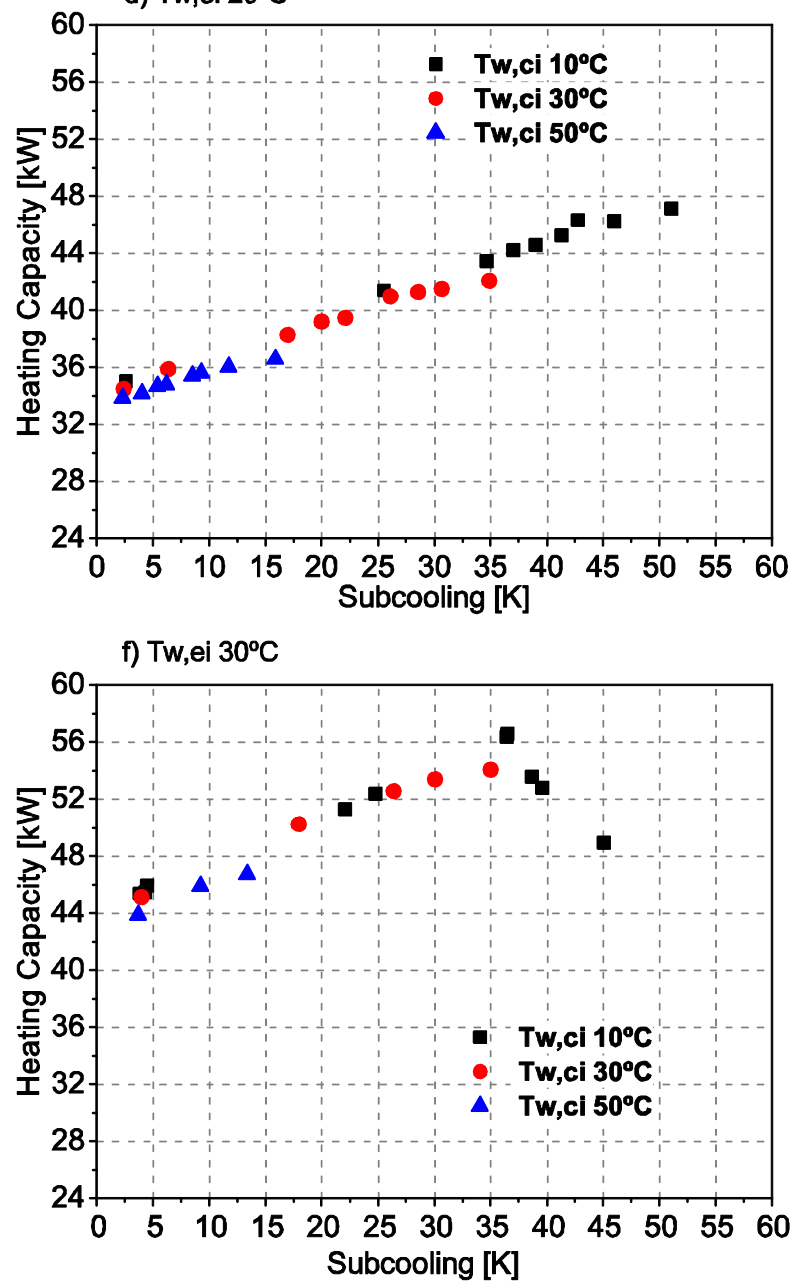

Figure 5.2: COP heating vs. subcooling (Maximum uncertainty \pm 0.08 ) : a) $T_{w, e i}=10^{\circ} \mathrm{C}$ c)

$T_{w, e i}=20^{\circ} \mathrm{C}$ e) $T_{w, e i}=30^{\circ} \mathrm{C}$. Heating capacity vs. subcooling (Maximum uncertainty \pm 0.05 $k W$ ): b) $T_{w, e i}=10^{\circ} \mathrm{C}$ d) $T_{w, e i}=20^{\circ} \mathrm{C}$ f) $T_{w, e i}=30^{\circ} \mathrm{C} .\left(T_{w, c o}=60^{\circ} \mathrm{C}\right)$. 
This maximum COP is around $25 \%$ higher than the COP corresponding to the same external water temperatures, but with the lowest subcooling (around $2 \mathrm{~K}$ ). In this case, it is clear the advantage taken from the low inlet water temperature $\left(T_{w, c i}\right)$ to produce subcooling and improve COP. For points with higher $T_{w, c i}$ (lower temperature lift), the improvement is less significant, for instance for $T_{w, c i}=50^{\circ} \mathrm{C}$, the degree of improvement is less than $7 \%$ when going from the minimum to the optimal subcooling (about $10 \mathrm{~K}$ ). The heat pump operated stable at all external conditions and subcoolings.

For a given $T_{w, e i}$, the heating COP is higher for lower $T_{w, c i}\left(T_{w, c o}\right.$ fixed to $\left.60^{\circ} \mathrm{C}\right)$. Table 5.1 shows the heating COP increase ${ }^{7}$ for $T_{w, c i}=10^{\circ} \mathrm{C}$ compared to $T_{w, c i}=50^{\circ} \mathrm{C}$ at different water inlet temperatures at the evaporator $\left(T_{w, e i}\right)$. Two situations are presented: 1) the heat pump working without subcooling, 2) the heat pump working at the optimal subcooling. There is a higher COP difference between both situations $\left(T_{w, c i}=10^{\circ} \mathrm{C}\right.$ compared to $\left.T_{w, c i}=50^{\circ} \mathrm{C}\right)$ when the heat pump works at the optimal subcooling. For instance, for $T_{w, e}=10^{\circ} \mathrm{C}$, when the heat pump works without subcooling, COP is $12 \%$ higher for $T_{w, c i}=10^{\circ} \mathrm{C}$. At this point, for the heat pump at the optimal subcooling, heating COP is about $36 \%$ higher when $T_{w, c i}=10^{\circ} \mathrm{C}$.

At the optimal subcooling, the COP increase for $T_{w, c i}=10^{\circ} \mathrm{C}$ compared to $T_{w, c i}=50^{\circ} \mathrm{C}$ is mainly due to two effects. One is related to the decrease of the condensing pressure and another with the increase of the optimal subcooling. The optimal subcooling for $T_{w, c i}=10^{\circ} \mathrm{C}$ is higher than for $T_{w, c i}=50^{\circ} \mathrm{C}, 43 \mathrm{~K}$ and $10 \mathrm{~K}$ respectively.

As expected, if the inlet condition at the condenser is fixed $\left(T_{w, c i}\right)$, it can be seen an increase of COP as the $T_{w, e i}$ increases. For instance, for the condition $T_{w, c i}=10^{\circ} \mathrm{C}$ and the optimal subcooling, COP increases about $24 \%$ when $T_{w, e i}$ passes from $10^{\circ} \mathrm{C}$ to $20^{\circ} \mathrm{C}$. This difference is directly related to the increase of the evaporating pressure.

Table 5.1: Heating COP increase for $T_{w, c i}=10^{\circ} \mathrm{C}$ compared to $T_{w, c i}=50^{\circ} \mathrm{C}$.

\begin{tabular}{ccc}
\hline $\boldsymbol{T}_{\boldsymbol{w}, \boldsymbol{e i},}{ }^{\mathbf{o}} \mathbf{C}$ & $\begin{array}{c}\text { COP increase Without } \\
\text { Subcooling }\end{array}$ & $\begin{array}{c}\text { COP increase at } \\
\text { Optimal Subcooling }\end{array}$ \\
\hline 10 & $12 \%$ & $36 \%$ \\
20 & $16 \%$ & $39 \%$ \\
30 & $18 \%$ & $35 \%$ \\
\hline
\end{tabular}

${ }^{7} \mathrm{COP}_{h}$ increase $=\frac{\operatorname{COP}_{h}\left(T w, c i=10^{\circ} \mathrm{C}\right)-\mathrm{COP}_{h}\left(T w, c i=50^{\circ} \mathrm{C}\right)}{\operatorname{COP}_{h}\left(T w, c i=50^{\circ} \mathrm{C}\right)} * 100[\%]$ 
Figures 5.2b), d) and f) show the heating capacity as a function of the degree of subcooling. The heating capacity does not have a maximum value for the optimal subcooling (maximum COP). Instead, in most of the measured points, there is a linear relationship between heating capacity and subcooling: as subcooling increases, the heating capacity increases. The linear relationship is evident below the optimal subcooling. From this point, heating capacity increases, but in a lower degree. In the linear part, the heating capacity depends weakly on the inlet water conditions at the condenser $\left(T_{w, c i}\right)$, it only depends on the degree of subcooling and the evaporator conditions $\left(T_{w, e i}\right)$. Nevertheless, since lower $T_{w, c i}$ has higher optimal subcoolings, lower $T_{w, c i}$ has higher capacities when working at the optimum point. There is an external condition, which does not have the same trend than the others, this condition is: $T_{w, e i}=30^{\circ} \mathrm{C}$ and $T_{w, c i}=10^{\circ} \mathrm{C}$. At this point, the heating capacity decreases for subcoolings higher than the optimal. This behavior will be explained in section 5.1.2.

Figure 5.3a) shows the optimal subcooling and the corresponding refrigerant temperature at the condenser outlet as a function of $T_{w, c i}$. For each $T_{w, c i}$, there are three points, which corresponds to the three measured $T_{w, e i}$. The optimal subcooling and the refrigerant outlet temperature have a linear relationship with $T_{w, c i .} T_{w, e i}$ does not affect significantly to these values. With a linear relationship between the optimal subcooling and $T_{w, c i}$, it is possible to set a control strategy to maximize COP as a function of $T_{w, c i}$. The refrigerant temperature at the condenser outlet is close to the corresponding $T_{w, c i}$ (about $2^{\circ} \mathrm{C}$ higher). This means that at the optimal subcooling (maximum COP), the condenser is able to produce a high degree of subcooling with a low-temperature approach at the condenser outlet. As observed before, the point corresponding to the condition: $T_{w, e i}=30^{\circ} \mathrm{C}$ and $T_{w, c i}=10^{\circ} \mathrm{C}$, does not have the same trend as the rest of the points. This behavior will be explained in section 5.1.2.

Figure 5.3b) shows the condensing temperature as a function of subcooling. For each external condition, the condensing temperature increases with subcooling. Two different zones can be seen in each condition:

1) At low subcooling: the condensing temperature slightly increases.

2) After a certain value of subcooling, the condensing temperature starts to increase at a higher rate.

The lower $T_{w, c i}$ (high water temperature lift), the higher the subcooling at which occurs the point of inflection. This point of inflection has a low dependency on $T_{w, e i}$. The optimum subcooling for each condition lies in the point of inflection, where the condensing temperature starts to increase at a higher rate. 


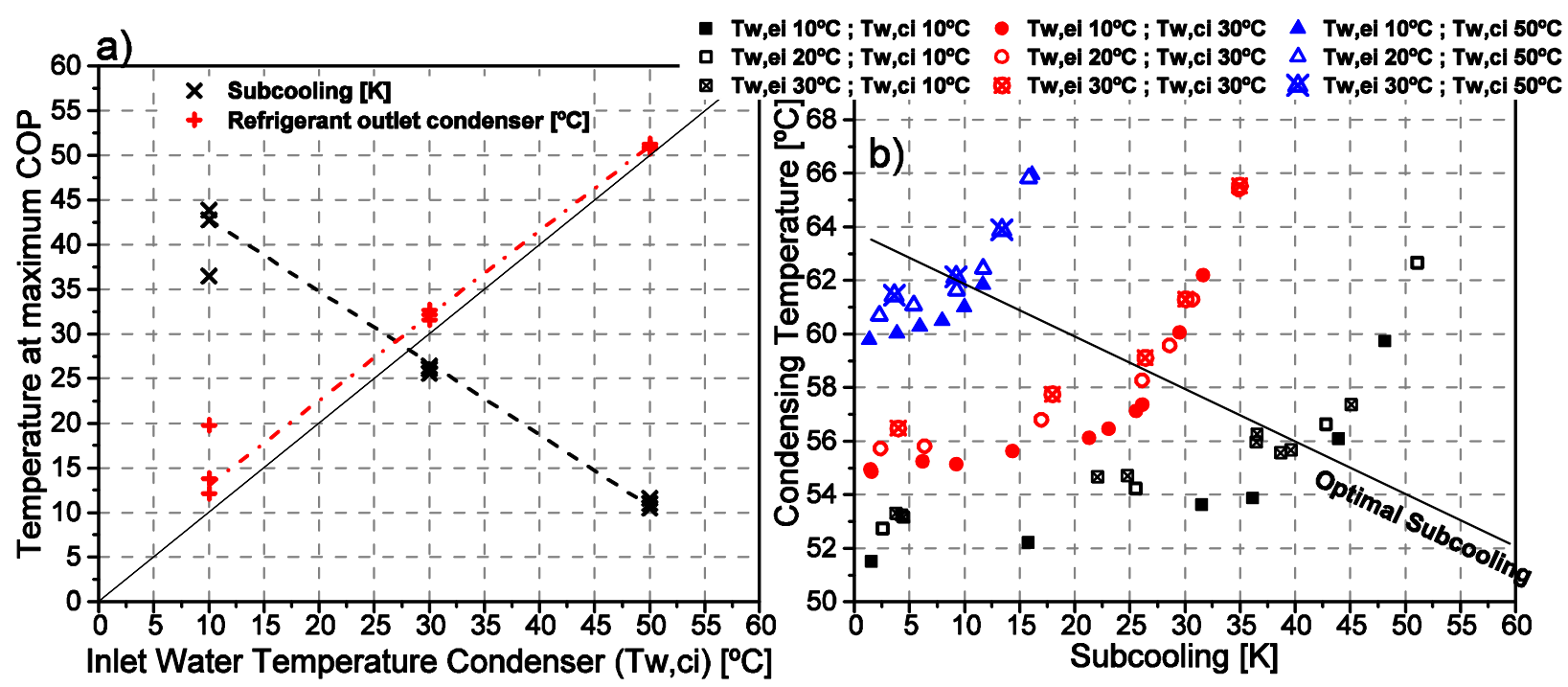

Figure 5.3: a) Subcooling and refrigerant outlet temperature at the condenser vs. $T_{w, c i}$ at the maximum COP point (optimal subcooling) b) Condensing temperature vs. subcooling

$$
\left(T_{w, c o}=60^{\circ} \mathrm{C}\right) \text {. }
$$

The minimum refrigerant temperature at the condenser outlet is limited by $T_{w, c i}$. At low ${ }^{8}$ subcooling, the refrigerant temperature is still far from $T_{w, c i}$, so subcooling can be increased by cooling down the refrigerant at the condenser outlet without increasing the condensing temperature significantly. When the refrigerant outlet of the condenser is closer to $T_{w, c i}$, the increase of subcooling is mainly due to an increase in the condensing temperature (point of inflection). This behavior is closely related to heating COP and heating capacity trends.

With near zero subcooling, the heat pump uses the major part of the condenser area to condensate. As the subcooling increases, the area for condensing decreases and more area of the condenser is used for subcooling. This produces an increase in the condensing temperature. The optimum point (maximum COP) is a compromise between the improvement due to an increase in the enthalpy change at the condenser with subcooling and the increase of power input in the compressor due to the pressure increase.

Regarding the heating capacity, below the optimal subcooling (where the changes of condensing temperature with subcooling are small), the heating capacity mainly depends on subcooling (Sc) (linear relationship between heating capacity and subcooling for constant refrigerant mass flow rate). Above the

\footnotetext{
${ }^{8}$ Low or high subcooling depends on the temperature lift (or $T_{w, c i}$ for a fixed $T_{w, c o}$ ). For instance, a subcooling of $10 \mathrm{~K}$ is low for the condition $\left(10^{\circ} \mathrm{C}\right.$ to $\left.60^{\circ} \mathrm{C}\right)$, but high for the condition $\left(50^{\circ} \mathrm{C}\right.$ to $\left.60^{\circ} \mathrm{C}\right)$
} 
optimum point, the heating capacity does not depend only on the subcooling, but also on the condensing temperature.

Figure 5.4 shows the evaporating temperature as a function of subcooling. For a given $T_{w, e i}$, the evaporating temperature is quite constant independently of the subcooling and $T_{w, c i}$. Hence, the system is able to control the subcooling and take profit of the water temperature lift with no side effect on the evaporating temperature. The refrigerant inlet quality to the evaporator decreases with subcooling, therefore, in order to keep a constant evaporating temperature at high subcooling, the evaporator needs to be designed accordingly. Smaller evaporators could lead to a decrease of the evaporating temperature with subcooling. One should notice that the point $\left(T_{w, e i}=30^{\circ} \mathrm{C} ; T_{w, c i}=10^{\circ} \mathrm{C}\right)$ has a decrease in the evaporating temperature for subcooling higher than $37 \mathrm{~K}$. This behavior is not due to the evaporator size, but due to the heat pump configuration (the behavior at this condition will be explained in section 5.1.2).

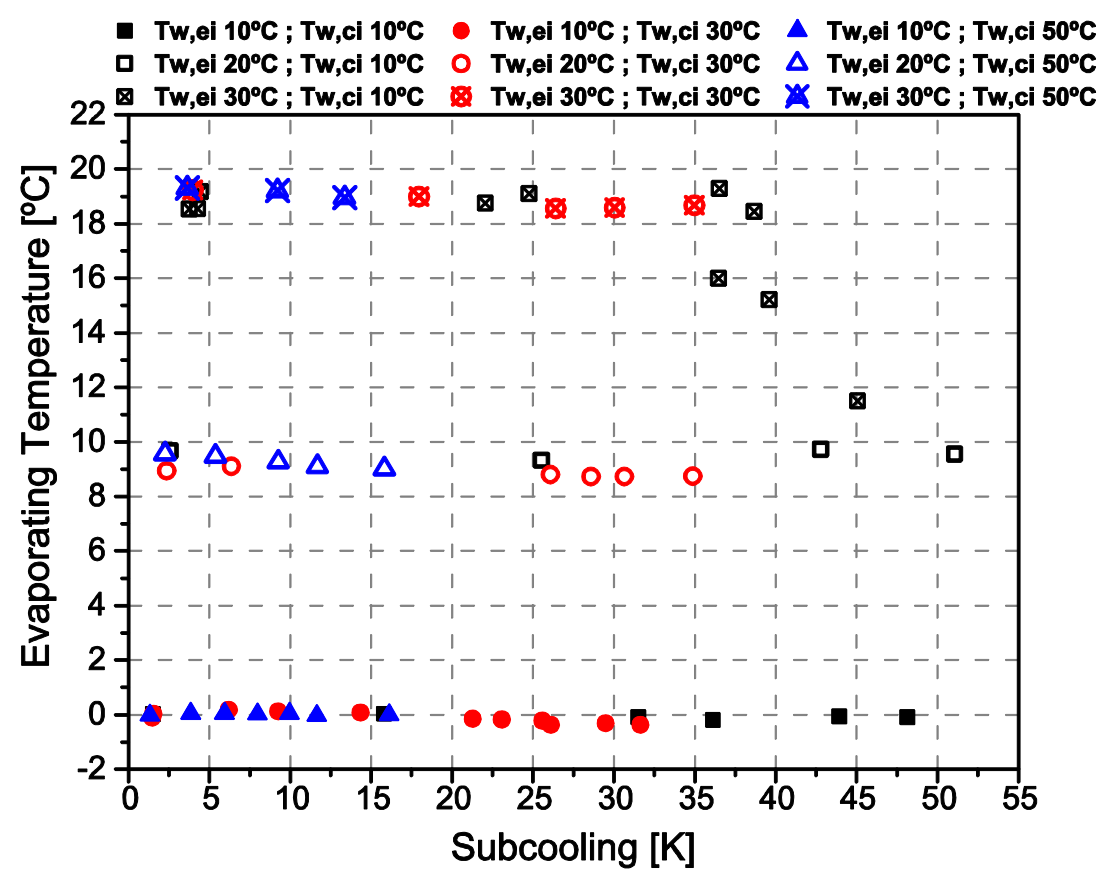

Figure 5.4: Evaporating temperature vs. subcooling $\left(T_{w, c o}=60^{\circ} \mathrm{C}\right)$. 
Figure 5.5 shows the refrigerant quality at the evaporator inlet as a function of subcooling. The degree of subcooling highly influences the refrigerant quality at the evaporator inlet. The higher the subcooling, the lower the refrigerant quality. For instance, for the condition with $T_{w, e i}=20^{\circ} \mathrm{C}$, the refrigerant quality at the evaporator inlet can vary from almost zero to 0.4 . The water inlet temperature to the evaporator also influences the refrigerant quality, since it will determine the evaporating pressure. Higher evaporating conditions means lower refrigerant quality. The minimum possible refrigerant quality is limited at zero since a liquid receiver is located before the expansion valve. Qualities near zero means that the expansion valve has a very low-pressure drop. These high variations in the inlet quality could lead to a high variation in the refrigerant charge contained in the evaporator, which needs to be taken into account in the design process of such a system.

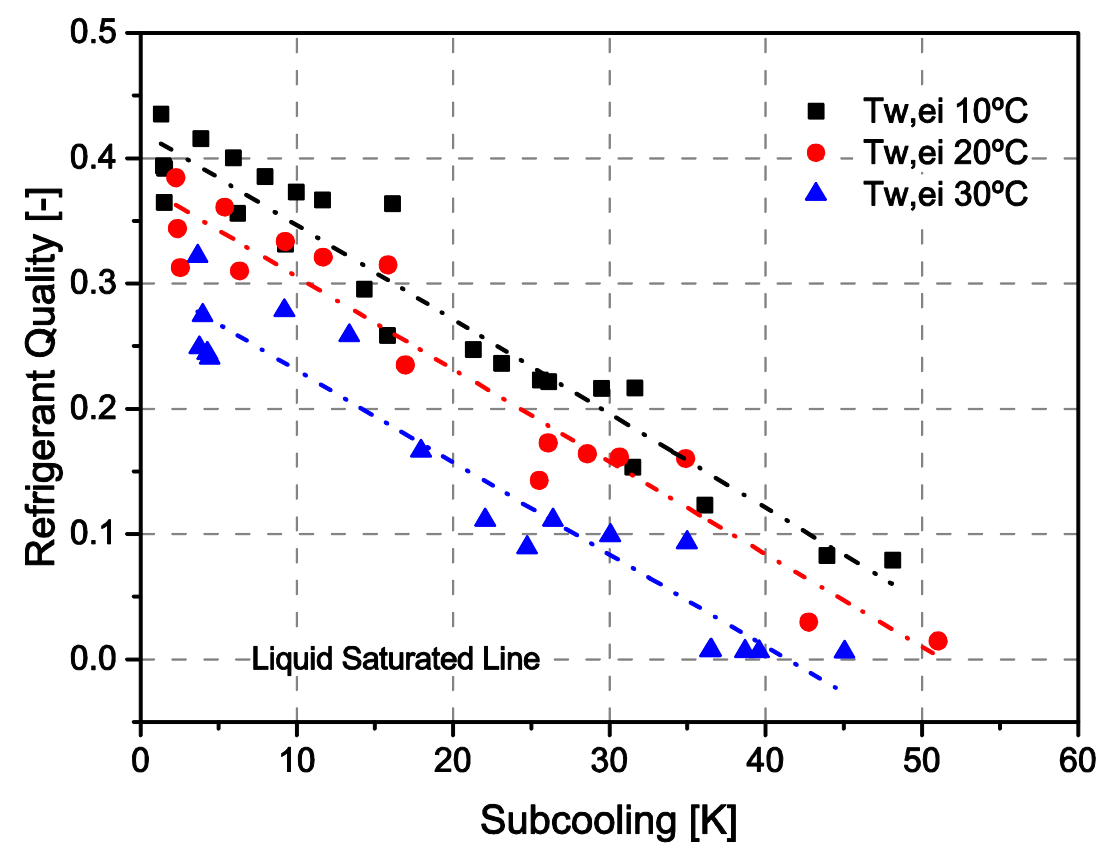

Figure 5.5: Refrigerant quality at evaporator inlet

Figure 5.6 shows the discharge temperature as a function of the condensing pressure for all the measured points. The discharge temperature has a linear relationship with the condensing pressure, and it depends on the evaporating conditions. All the measured points have a discharge temperature lower than $100^{\circ} \mathrm{C}$, which is much lower than the maximum working discharge temperature recommended by the compressor manufacturer $\left(130^{\circ} \mathrm{C}\right)$. 


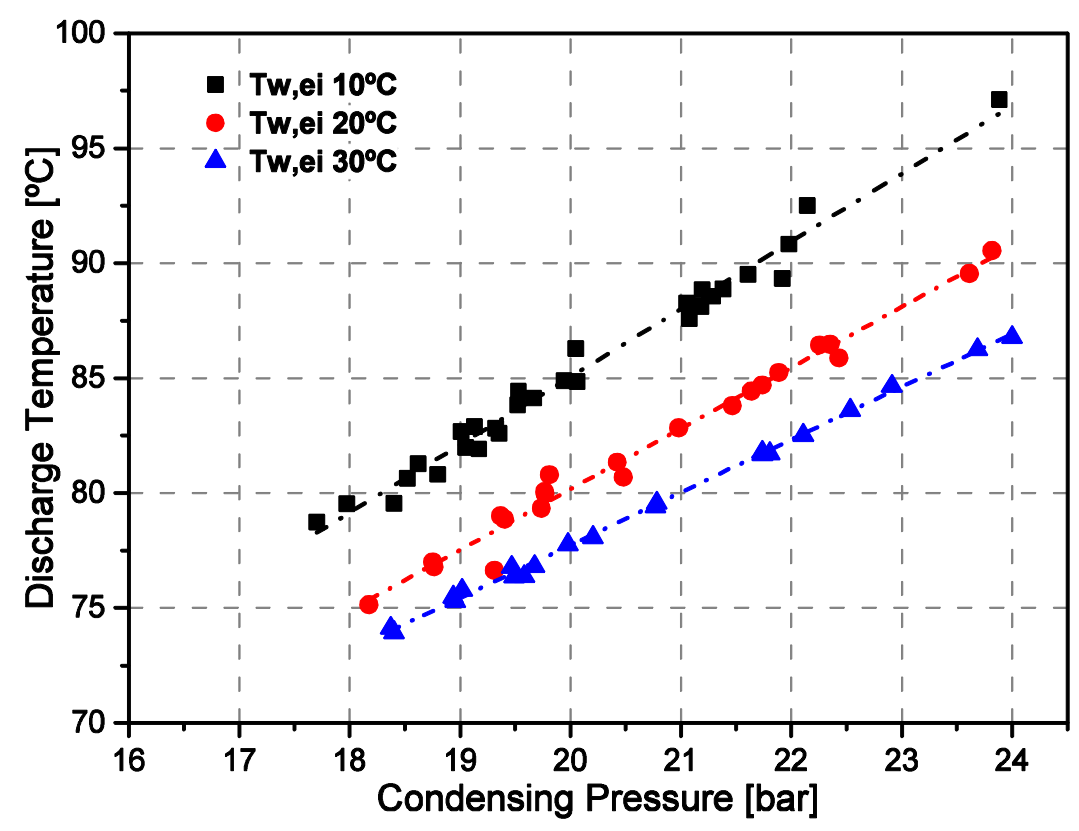

Figure 5.6: Discharge temperature as a function of the condensing pressure.

\subsubsection{Condition with high $T_{w, e i}$ and low $T_{w, c i}$}

As it has been seen in the previous section, the condition: $T_{w, e i}=30^{\circ} \mathrm{C}$ and $T_{w, c i}=10^{\circ} \mathrm{C}$, is out of the trend from the rest of the measured points. Lower optimal subcooling than expected, heating capacity decreases after the optimal subcooling, etc. This section analyzes this condition.

Table 5.2 contain the theoretical expected results for the optimal subcooling compared with the experimental ones. The theoretical optimal results are calculated as indicated in chapter 2: infinite heat transfer area at the condenser (two pinch points with $0 \mathrm{~K}$ between refrigerant and water). The compressor efficiency is fixed to 0.65 . Superheat is fixed to $10 \mathrm{~K}$, so the evaporating temperature in the model is considered: $\mathrm{T}_{\mathrm{evap}}=T_{w, e i}-10$.

The predicted values overestimate the experimental optimum COP since the infinite heat transfer area has been used. The model accurately predicts the optimal subcooling in most of the points. Furthermore, experiments are taken at discrete degrees of subcooling, so could be that the heat pump has not been measured in its exact optimum. There is one condition, at which the prediction differs more than the rest: $T_{w, e i}=30^{\circ} \mathrm{C}$ and $T_{w, c i}=10^{\circ} \mathrm{C}$. Hence, if the model does not capture this behavior, it must be a constraint due to the heat pump configuration. 
Table 5.2: Optimal subcooling and COP for the model (chapter 2) and experiments. The evaporating temperature in the model is considered $T_{\text {evap }}=T_{w, e i}-10$ (10 Kof subcooling).

\begin{tabular}{|c|c|c|c|c|c|}
\hline$T_{w, e i}\left[{ }^{\circ} \mathrm{C}\right]$ & $T_{w, c i}\left[{ }^{\circ} \mathrm{C}\right]$ & $\begin{array}{c}\text { Predicted } \\
S c_{o p t}[\mathrm{~K}]\end{array}$ & $\begin{array}{c}\text { Experimental } \\
S c_{\text {opt }}[\mathrm{K}]\end{array}$ & $\begin{array}{l}\text { Predicted } \\
\text { COP }\end{array}$ & $\begin{array}{c}\text { Experimental } \\
\text { COP }\end{array}$ \\
\hline \multirow{3}{*}{10} & 10 & 42.5 & 44.1 & 4.61 & 4.29 \\
\hline & 30 & 24.8 & 25.5 & 3.97 & 3.71 \\
\hline & 50 & 7.9 & 9.8 & 3.31 & 3.15 \\
\hline \multirow{3}{*}{20} & 10 & 43.4 & 41.5 & 5.70 & 5.38 \\
\hline & 30 & 25.4 & 26.1 & 4.88 & 4.67 \\
\hline & 50 & 8.2 & 11.5 & 4.03 & 3.83 \\
\hline \multirow{3}{*}{30} & 10 & 44.2 & 36.6 & 7.40 & 6.36 \\
\hline & 30 & 26.0 & 26.3 & 6.29 & 5.65 \\
\hline & 50 & 8.4 & 9.1 & 5.13 & 4.68 \\
\hline
\end{tabular}

Figure 5.7 shows the pressure-enthalpy diagram for the cycle working in the condition that was out of the trend showed by the rest of the points: b) $T_{w, e i}=30^{\circ} \mathrm{C}$; $T_{w, c i}=10^{\circ} \mathrm{C}$. In order to understand what is happening, another point is also represented: a) $T_{w, e i}=30^{\circ} \mathrm{C} ; T_{w, c i}=30^{\circ} \mathrm{C}$. Case a) is working at the optimal subcooling, which gave an outlet refrigerant temperature close to the water inlet temperature of the condenser and Case b) is working at the expected optimal subcooling (around $44 \mathrm{~K}$ ), which gave a lower experimental performance.

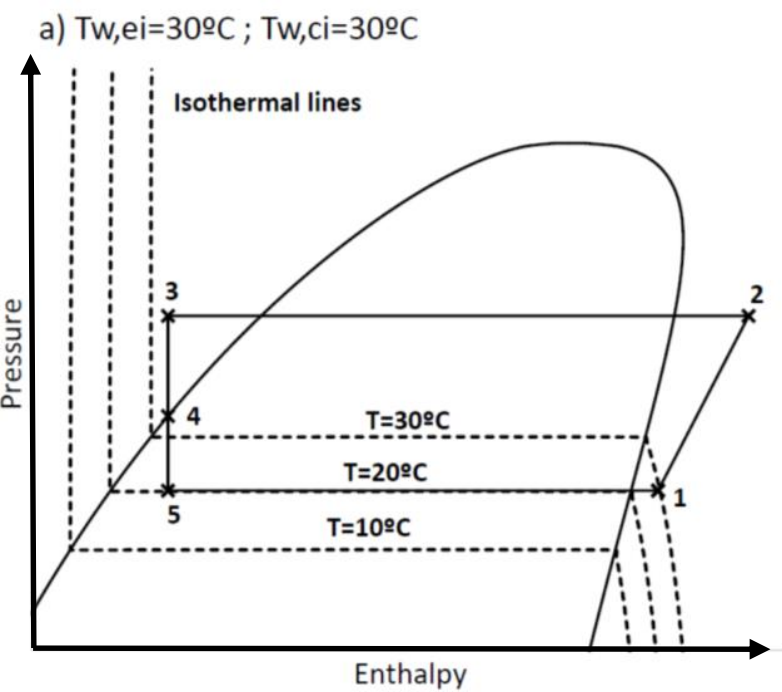

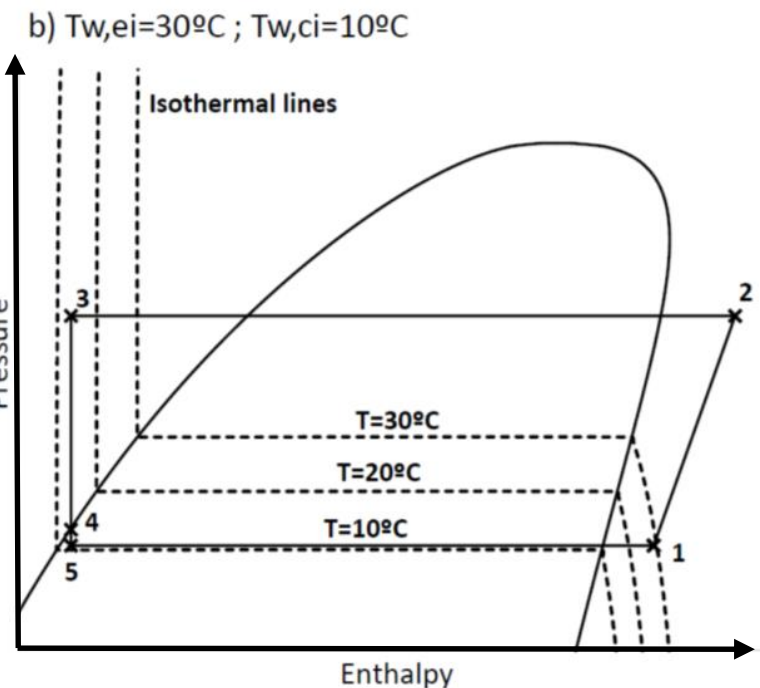

Figure 5.7: Pressure-Enthalpy diagram a) $T_{w, e i}=30^{\circ} \mathrm{C}$; $T_{w, c i}=30^{\circ} \mathrm{C}$ b) $T_{w, e i}=30^{\circ} \mathrm{C} ; T_{w, c i}=$ $10^{\circ} \mathrm{C}$ 
The throttling valve produces the pressure drop between point 3 and 4 to produce the target subcooling, while the expansion valve gives the needed pressure drop (point 4 to 5) to obtain $10 \mathrm{~K}$ of superheat at the compressor inlet. The observed behavior in each point is explained as follows:

a) $T_{w, e i}=30^{\circ} \mathrm{C}$ and $T_{w, c i}=30^{\circ} \mathrm{C}$ : The refrigerant outlet temperature (point 3) is limited by the water inlet temperature. At the optimum point, there is a temperature approach of $2 \mathrm{~K}$ between refrigerant and water. The refrigerant temperature at the evaporator outlet (point 1) is limited by the water temperature at the evaporator inlet $\left(T_{w, e i}=30^{\circ} \mathrm{C}\right)$. If the refrigerant temperature at point $1\left(\mathrm{~T}_{\mathrm{ref}, 1}\right)$ is close to $T_{w, e i}$, the evaporating temperature will be around $20^{\circ} \mathrm{C}\left(\mathrm{T}_{\text {sat,evap }}=\mathrm{T}_{\text {ref, } 1}-\mathrm{Sh}\right)$. At this condition, the expansion valve successfully controlled the superheat.

b) $T_{w, e i}=30^{\circ} \mathrm{C}$ and $T_{w, c i}=10^{\circ} \mathrm{C}$ : The refrigerant temperature at point 3 is limited by $T_{w, c i}=10^{\circ} \mathrm{C}$. This condition needs a higher pressure drop in the throttling valve if the outlet refrigerant temperature is close to the inlet water temperature. In order to obtain $10 \mathrm{~K}$ of superheat, the evaporating temperature should be around $20^{\circ} \mathrm{C}$ (same evaporating condition than before, $T_{w, e i}=30^{\circ} \mathrm{C}$ ). However, the pressure at the liquid receiver (point 4 ) is already lower than the one corresponding to the evaporating temperature of $20^{\circ} \mathrm{C}$. This situation will lead to a superheat higher than $10 \mathrm{~K}$. The expansion valve will open trying to increase the evaporating temperature (decrease superheat), but the pressure at the expansion valve inlet is already lower than the corresponding desired evaporating temperature. Therefore, the expansion valve will remain fully open with a low-pressure drop, and with no control on the superheat. This condition was stable, but without control on the superheat.

Hence, from a certain degree of subcooling, the expansion valve does not control the evaporating pressure anymore, having lower evaporating temperatures and higher superheat than expected. This leads to lower performance, even if the high subcooling is reached with an insignificant increase in the condensing pressure. In the theoretical study, there is no limitation on the evaporating temperatures, so the theoretical optimal subcooling is higher than the experimental one. Therefore, the limitation is a particular case for this heat pump design. The limitation can be avoided with a different heat pump configuration, as it will be seen in section 5.2. 
Nevertheless, this situation will be rare in practice, since a heat exchanger can be used to recover heat directly from the heat source $\left(T_{w, e i}\right)$ to the heat $\operatorname{sink}\left(T_{w, c i}\right)$ before the heat pump. The author of this thesis has participated (not as the main author) in an article about this issue Hervas et al. (2017).

\subsubsection{Pinch point analysis}

In chapter 2, the theoretical optimal subcooling was analyzed. The optimal subcooling was found when two pinch points take place at the same time, one at the condenser outlet $\left(D T_{a}\right)$ and one inside the condenser at the refrigerant dew point $\left(D T_{b}\right)$. At the pinch point, for the infinite HX area assumption, there is zero temperature difference between refrigerant and water $\left(D T_{a}=D T_{b}=0 \mathrm{~K}\right)$. Other assumptions, such as isentropic compression, were taken in this study.

The zero temperature approach at the condenser outlet is not the case of a real heat exchanger. The experiments showed that, for the tested heat pump, the pinch point at the condenser outlet ( $D T_{a}$ for the optimal subcooling) is about $2 \mathrm{~K}$ (depending on the measured point). This temperature difference is expected to change for different condenser sizes. For a smaller condenser, it is expected a higher temperature difference for $D T_{a}$.

Figure 5.8a) shows the experimental temperature profile of water and refrigerant working with three different subcoolings around the optimal point. With this information, it is possible to study the role of both pinch points $\left(D T_{a}\right.$ and $D T_{b}$ ) on the optimal subcooling for a real condenser. The temperatures are not measured directly inside the condenser. They are determined from the inlet and outlet temperature and pressure conditions. It can be seen that as the subcooling increases (reducing the temperature difference at the condenser outlet, $D T_{a}$ ), the temperature difference at the internal pinch point $\left(D T_{b}\right)$ increases. Figure $\left.5.8 \mathrm{~b}\right)$ shows the temperature difference at the pinch points as a function of subcooling. In the real case, $D T_{b}$ is not zero even at low subcooling. The optimum (maximum $\mathrm{COP})$ is found at the subcooling where $D T_{a}$ and $D T_{b}$ coincide $\left(D T_{a}=D T_{b}=2.5 \mathrm{~K}\right)$. Above this point, it is possible to reduce $D T_{a}$, but a small reduction leads to a high increase in $D T_{b}$. Below the optimal subcooling, a small reduction in $D T_{b}$ leads to a high increase in $D T_{a}$. 
a)

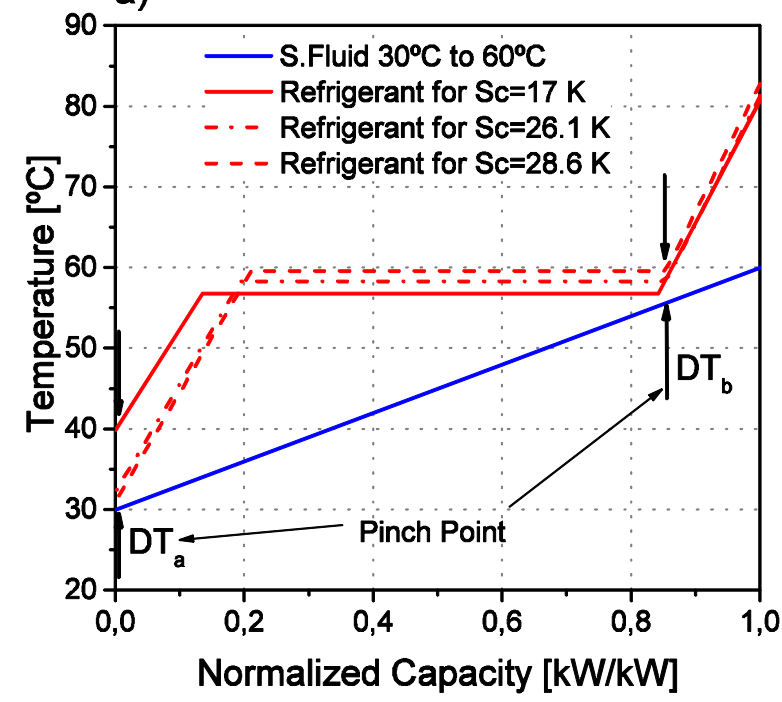

b)

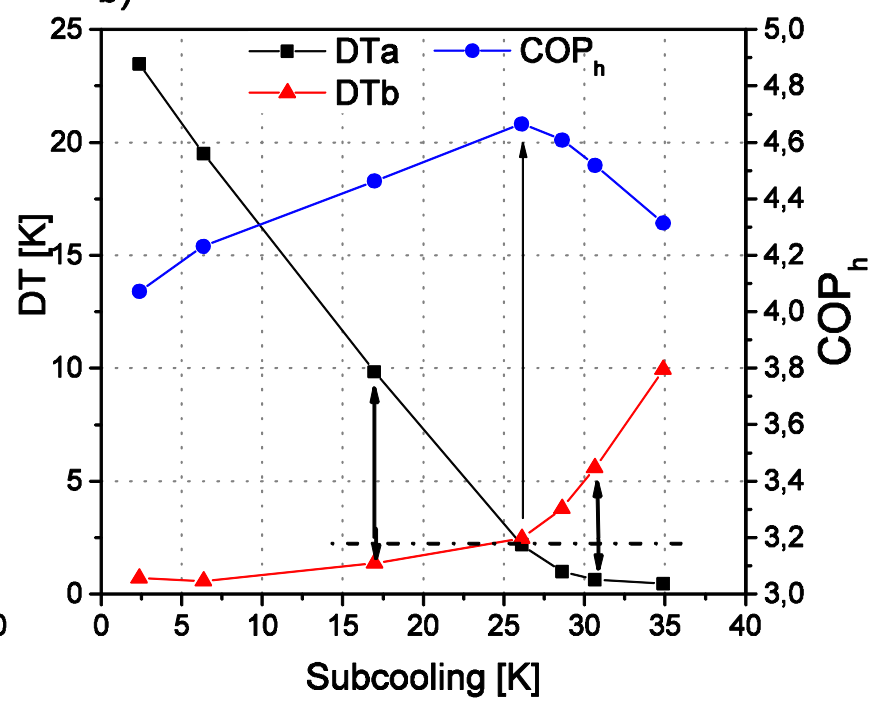

Figure 5.8: Experimental analysis a) Temperature profile vs. normalized capacity: Refrigerant R290 with different subcooling and the secondary fluid going from $30^{\circ} \mathrm{C}$ to $60^{\circ} \mathrm{C}$. b) Pinch point temperatures as a function of subcooling

Table 5.3 shows the pinch point temperature differences of the experimental points with $\left(T_{w, e i}=10^{\circ} \mathrm{C}\right.$ and $\left.T_{w, e i}=20^{\circ} \mathrm{C}\right)$ and for three subcoolings around the optimum. On the one hand, at the condenser water conditions $\left(10^{\circ} \mathrm{C}\right.$ to $60^{\circ} \mathrm{C}$ and $30^{\circ} \mathrm{C}$ to $60^{\circ} \mathrm{C}$ ) is seen that the optimum point is reached when $D T_{a}$ is similar to $D T_{b}$. On the other hand, for the condition $\left(50^{\circ} \mathrm{C}\right.$ to $\left.60^{\circ} \mathrm{C}\right)$ the optimum point is reached when $D T_{a}$ is slightly lower than $D T_{b}$. Therefore, it seems that the optimal subcooling for the real heat pump is not always when both pinch points have the same value. Nevertheless, the measured points near the optimum have a similar COP. Hence, it is difficult to extract such information from the experimental results, since more points need to be taken. 
Table 5.3: Normalized $\mathrm{COP}_{\mathrm{h}}$ at different $D T_{a}$ and $D T_{b}$ for different cases. Experimental results.

\begin{tabular}{|c|c|c|c|c|}
\hline Case & $\begin{array}{c}\text { Sc } \\
{[\mathrm{K}]}\end{array}$ & $\begin{array}{l}D T_{a} \\
{[\mathrm{~K}]}\end{array}$ & $\begin{array}{l}D T_{b} \\
{[\mathrm{~K}]}\end{array}$ & $\begin{array}{c}\text { Normalized } \\
\mathrm{COP}_{\mathrm{h}}\end{array}$ \\
\hline$T_{w, e i}=10^{\circ} \mathrm{C}$ & 36.1 & 7.8 & 1.2 & 0.991 \\
\hline SHW temperature: & 43.9 & 2.2 & 3.5 & 1 \\
\hline $10^{\circ} \mathrm{C}$ to $60^{\circ} \mathrm{C}$ & 48.1 & 1.6 & 7.4 & 0.960 \\
\hline$T_{w, e i}=10^{\circ} \mathrm{C}$ & 21.3 & 4.9 & 1.5 & 0.996 \\
\hline SHW temperature: & 26.1 & 1.3 & 2.8 & 1 \\
\hline $30^{\circ} \mathrm{C}$ to $60^{\circ} \mathrm{C}$ & 31.7 & 0.6 & 7.8 & 0.946 \\
\hline$T_{w, e i}=10^{\circ} \mathrm{C}$ & 8.0 & 2.6 & 2.5 & 0.994 \\
\hline SHW temperature: & 10.0 & 1.1 & 2.9 & 1 \\
\hline $50^{\circ} \mathrm{C}$ to $60^{\circ} \mathrm{C}$ & 11.6 & 0.2 & 3.9 & 0.995 \\
\hline$T_{w, e i}=20^{\circ} \mathrm{C}$ & 39.0 & 4.5 & 2.1 & 0.991 \\
\hline SHW temperature: & 41.5 & 2.7 & 2.7 & 1 \\
\hline $10^{\circ} \mathrm{C}$ to $60^{\circ} \mathrm{C}$ & 42.8 & 3.9 & 3.0 & 0.994 \\
\hline$T_{w, e i}=20^{\circ} \mathrm{C}$ & 22.1 & 4.2 & 1.9 & 0.981 \\
\hline SHW temperature: & 26.1 & 2.2 & 2.5 & 1 \\
\hline $30^{\circ} \mathrm{C}$ to $60^{\circ} \mathrm{C}$ & 28.6 & 1.0 & 3.8 & 0.987 \\
\hline$T_{w, e i}=20^{\circ} \mathrm{C}$ & 9.3 & 2.4 & 3.3 & 0.999 \\
\hline SHW temperature: & 11.7 & 0.8 & 4.2 & 1 \\
\hline $50^{\circ} \mathrm{C}$ to $60^{\circ} \mathrm{C}$ & 15.8 & 0.1 & 7.6 & 0.965 \\
\hline
\end{tabular}

In order to investigate the pinch point distribution at the optimal subcooling in a finite heat exchanger, Table 5.4 shows the theoretical results obtained with the software IMST-ART (IMST-ART v3.70). This software introduces the geometric information about condenser and evaporator, and the efficiencies of the compressor. In this way, it is easier to look at points close to the optimal subcooling. A similar behavior than in the experimental results is observed by the software. At low $T_{w, c i}$, it is worthier to approach the temperatures of refrigerant and water at the internal pinch point, while it is worthier to approach at the condenser outlet for high $T_{w, c i}$. For the condition $\left(30^{\circ} \mathrm{C}\right.$ to $\left.60^{\circ} \mathrm{C}\right)$, the optimum is when $D T_{a}$ similar to $D T_{b}$. 
Table 5.4: DT a and DTb for different cases. Results with the software IMST-ART.

$\left(T_{w, c o}=60^{\circ} \mathrm{C}\right)$

\begin{tabular}{|c|c|c|c|c|}
\hline$T_{w, e i}\left[{ }^{\circ} \mathrm{C}\right]$ & $T_{w, c i}\left[{ }^{0} \mathrm{C}\right]$ & $S \boldsymbol{S c}_{\text {opt }}[\mathrm{K}]$ & $D T_{a}[\mathrm{~K}]$ & $D T_{b}[\mathbf{K}]$ \\
\hline \multirow{3}{*}{10} & 10 & 41.0 & 4.1 & 2.6 \\
\hline & 30 & 25.0 & 2.2 & 2.4 \\
\hline & 50 & 9.0 & 1.2 & 2.3 \\
\hline \multirow{3}{*}{20} & 10 & 42.0 & 4.8 & 3.4 \\
\hline & 30 & 25.5 & 2.9 & 3.0 \\
\hline & 50 & 10.0 & 1.2 & 3.1 \\
\hline
\end{tabular}

The knowledge of the pinch point at the optimal subcooling is important from the control point of view. Since, it is an alternative control strategy to the one commented in Figure 5.2 (linear relationship between optimal subcooling and $T_{w, c i}$, controlling the temperature difference between refrigerant outlet and $T_{w, c i}$ to a constant value. Although the optimum $D T_{a}$ changes with the external conditions, if the same reference value is set for all conditions, the COP degradation is insignificant. In that way, a unique control value would be valid for all situations ( $T_{w, c i}, T_{w, c o}$, evaporating temperature and the like).

\subsubsection{Conclusions}

The main conclusions drawn from the present study are:

- With the proposed system configuration, subcooling can be varied independently from the external conditions (water temperatures).

- An optimal subcooling exists, being a compromise between the improvement due to an increase in the enthalpy change at the condenser with subcooling, and the increase in power input due to an increase in the condensing pressure (reduction of the condensation area).

- At the nominal condition $\left(10^{\circ} \mathrm{C}\right.$ to $60^{\circ} \mathrm{C}$ at the condenser), performance is increased by $25 \%$ when working at the optimal subcooling (about $42 \mathrm{~K}$ ) respect to the HP without subcooling.

- For the higher $T_{w, c i}\left(50^{\circ} \mathrm{C}\right)$, the rate of improvement due to subcooling is lower, approximately $7 \%$.

- The heating capacity increases with subcooling for all measured range. Only the point " $T_{w, e i}=30^{\circ} \mathrm{C}$ and $T_{w, c i}=10^{\circ} \mathrm{C}$ " has a decrease in heating capacity after the optimal subcooling. 
- The condensing temperature slightly increases with subcooling below the optimum point. From this point, the condensing pressure increases at a higher rate.

- At point " $T_{w, e i}=30^{\circ} \mathrm{C}$ and $T_{w, c i}=10^{\circ} \mathrm{C}$ " is not possible to work at high subcooling without decreasing the evaporating temperatures, which leads to higher superheats and lower performance.

- There is a linear relation between optimal subcooling and $T_{w, c i}$, which could be used as a control parameter.

- Another option to set the optimal subcooling is to control the temperature difference between the refrigerant and water at the condenser outlet $\left(D T_{a}\right)$. 


\subsection{Subcooling in a separate heat exchanger: SMS design}

Figure 5.9 shows the scheme of the water-to-water heat pump prototype with a separate heat exchanger to produce subcooling, the subcooler (SMS design).
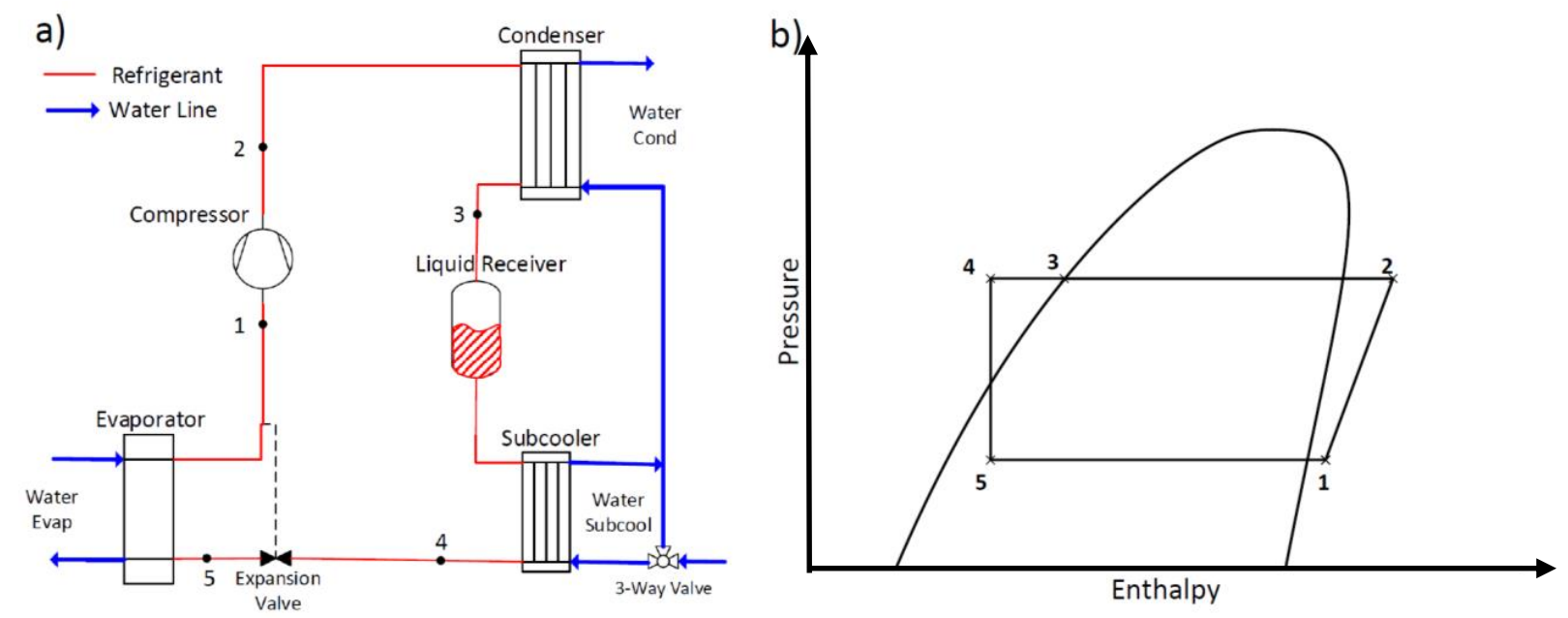

Figure 5.9: Heat Pump subcooler in series with condenser a) Scheme, b) P-h diagram.

In the section above (SMC design), subcooling was controlled as an independent variable (throttling valve). In this section, subcooling cannot be controlled as an independent variable. Instead, the subcooling is fixed by the external conditions and the heat transfer at the subcooler. One should notice, that now, the $T_{w, c i}$ refers to the inlet water temperature at the subcooler.

Part of the results of this section has been published in the journal "International Journal of Refrigeration" (Pitarch et al., 2017C). 


\subsubsection{Results}

Figure 5.10a) shows the heating $\mathrm{COP}$ as a function of the inlet water temperature to the subcooler $\left(T_{w, c i}\right)$. For a given inlet water temperature at the evaporator $\left(T_{w, e i}\right)$ it can be seen a linear relationship between the heating COP and the water inlet temperature at the subcooler $\left(T_{w, c i}\right)$. COP decreases as the $T_{w, c i}$ increases. The linear fitting adjusts to the experimental values, although the points corresponding to $10^{\circ} \mathrm{C}$ and $55^{\circ} \mathrm{C}$ are slightly over predicted. For the nominal water inlet temperature at the evaporator $\left(20^{\circ} \mathrm{C}\right)$, heating COP decreases about $35 \%$ when $T_{w, c i}$ passes from $10^{\circ} \mathrm{C}$ to $55^{\circ} \mathrm{C}$. Performance decreases due to two reasons: 1) Reduction of subcooling. 2) The increase of the condensing pressure. This linearity is also observed for a given $T_{w, c i}$ and changing $T_{w, e i}$. The slope of the linear fitting slightly increases as the $T_{w, e i}$ increases. The maximum measured heating COP is around 6.8, while at the nominal point $\left(T_{w, e i}=20^{\circ} \mathrm{C} ; T_{w, c i}=10^{\circ} \mathrm{C}\right) \mathrm{COP}$ is 5.61 .

The optimum results obtained with the SMC design are also plotted for comparison (points with $T_{w, e i}=35^{\circ} \mathrm{C}$ were not tested for SMC). The heating COP obtained with the SMC design are slightly lower than with SMS. Nevertheless, one should remember that the total heat transfer area for the SMS design is higher than for SMC since both are using the same condenser, but the SMS design has an extra heat exchanger, the subcooler. This leads to about $25 \%$ more heat transfer area for the SMS design. Chapter 6 presents a theoretical study with the IMSR-ART software in order to compare both heat pump designs fairly.
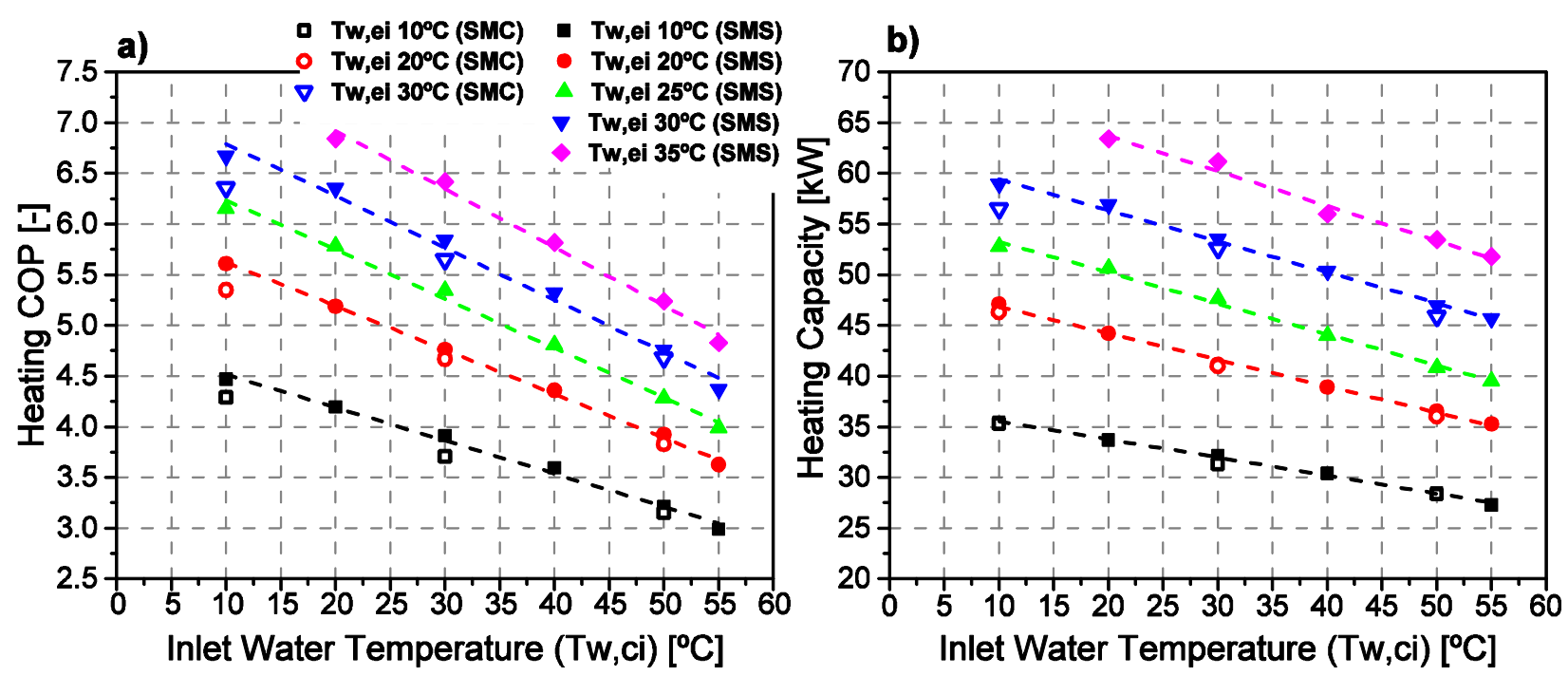

Figure 5.10: a) Heating COP, b) Heating capacity vs. inlet water temperature to subcooler for different water inlet temperature to the evaporator $\left(T_{w, c o}=60^{\circ} \mathrm{C}\right)$. 
Regarding heating capacity (Figure 5.10b), it had a similar behavior than the heating COP. The maximum measured capacity is about $63.4 \mathrm{~kW}$, and at nominal conditions is $47.1 \mathrm{~kW}$. For the nominal water inlet temperature at the evaporator, $20^{\circ} \mathrm{C}$, heating capacity decreases about $25 \%$ when $T_{w, c i}$ passes from $10^{\circ} \mathrm{C}$ to $55^{\circ} \mathrm{C}$.

COP and capacity increases as the temperature at the inlet evaporator $\left(T_{w, e i}\right)$ increases, which is directly related to the increase of the evaporating pressure. In this case, where all the measured points are plotted in the same graph, it is more clear the effect of the evaporating temperature in the heating COP and capacity. For instance, when $T_{w, e i}$ passes from $10^{\circ} \mathrm{C}$ to $30^{\circ} \mathrm{C}$, the heating COP and capacity increases by $49 \%$ and $66 \%$ respectively $\left(T_{w, c i}=10^{\circ} \mathrm{C}\right)$.

Figure 5.11a) compares the heating COP results for the cycle working with subcooling against the results obtained with a cycle working without subcooling (Subcooler is bypassed). $T_{w, e i}$ is fixed to $20^{\circ} \mathrm{C}$. The highest improvement is about $31 \%$, which corresponds to the lowest $T_{w, c i}\left(10^{\circ} \mathrm{C}\right)$, with a subcooling of $43.9 \mathrm{~K}$. As the $T_{w, c i}$ increases, the COP difference between subcooled and non-subcooled cycle decreases, having an improvement of about $6.8 \%$ for $T_{w, c i}=55^{\circ} \mathrm{C}$, which has a subcooling of $8.6 \mathrm{~K}$. Therefore, the highest improvement produced by adding subcooling is at low $T_{w, c i}$ (high water temperature lift), since this point has the greatest capacity for subcooling. Furthermore, the subcritical cycles working without subcooling have a bad water/refrigerant temperature match. One should remember that in this prototype, subcooling was made in a separate heat exchanger from the condenser, so condenser was exclusively used for condensing in all measured points (subcooler was bypassed for the measurements without subcooling).
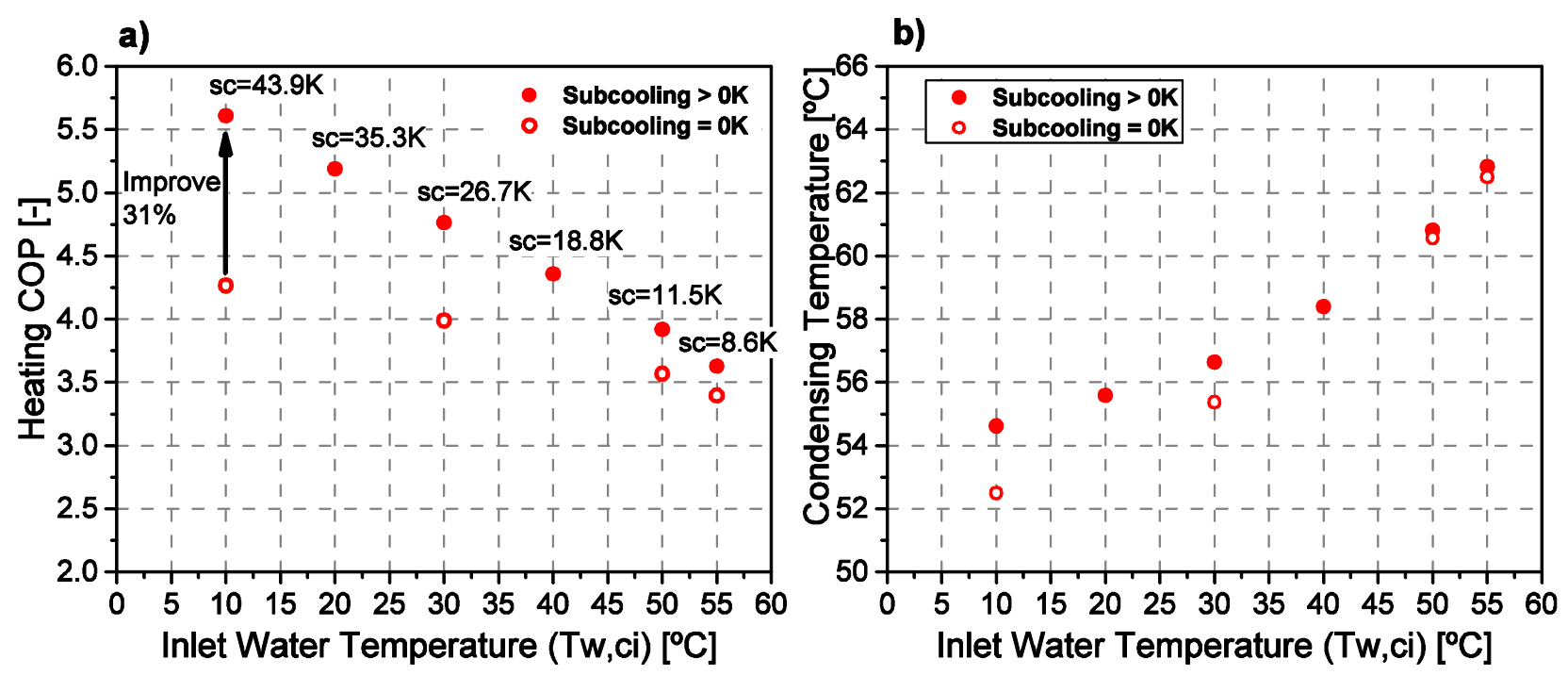

Figure 5.11: a) Heating COP, b) Condensing temperature vs. inlet water temperature to subcooler, with and without subcooling $\left(T_{w, c o}=60^{\circ} \mathrm{C}\right)$. 
Figure 5.11b) shows the comparison for the condensing saturation temperature for the cycle working with subcooling against the results obtained with a cycle working without subcooling $\left(T_{w, e i}=20^{\circ} \mathrm{C}\right)$. The condensing temperature is higher for the cycle working with subcooling, the difference is insignificant for high $T_{w, c i}$, but there is around $2 \mathrm{~K}$ temperature difference for low $T_{w, c i}$. This behavior is related to the degree of subcooling, because, even though condenser is not being used for subcooling, the water is pre-heated at the subcooler before entering to the condenser. For the same city water temperature $\left(T_{w, c i}\right)$, the inlet water temperature at condenser is higher at the cycle working with subcooler than for the cycle working without subcooling. Finally, it can be concluded that the benefits obtained from producing subcooling are higher than the COP degradation due to the increase of condensing temperature.

Figure 5.12a) shows the subcooling depending on the inlet water temperature at the subcooler. As in the SMC design, it can be seen a linear dependency, where the evaporating temperature had an insignificant influence. Nevertheless, this time, the condition $\left(T_{w, e i}=30^{\circ} \mathrm{C}\right.$ and $\left.T_{w, c i}=10^{\circ} \mathrm{C}\right)$ had the same trend as the other external condition (this will be analyzed in section 5.2.2). The refrigerant outlet temperature at the subcooler is quite close to the water inlet temperature. This means that the subcooler is able to produce the maximum possible subcooling at all conditions, even when subcooler is partially bypassed in the water side (conditions with high water mass flow rate, $T_{w, c i}>50^{\circ} \mathrm{C}$ ). Subcooling goes from $44 \mathrm{~K}$ to $9 \mathrm{~K}$ for $T_{w, c i}=10^{\circ} \mathrm{C}$ and $T_{w, c i}=55^{\circ} \mathrm{C}$ respectively.
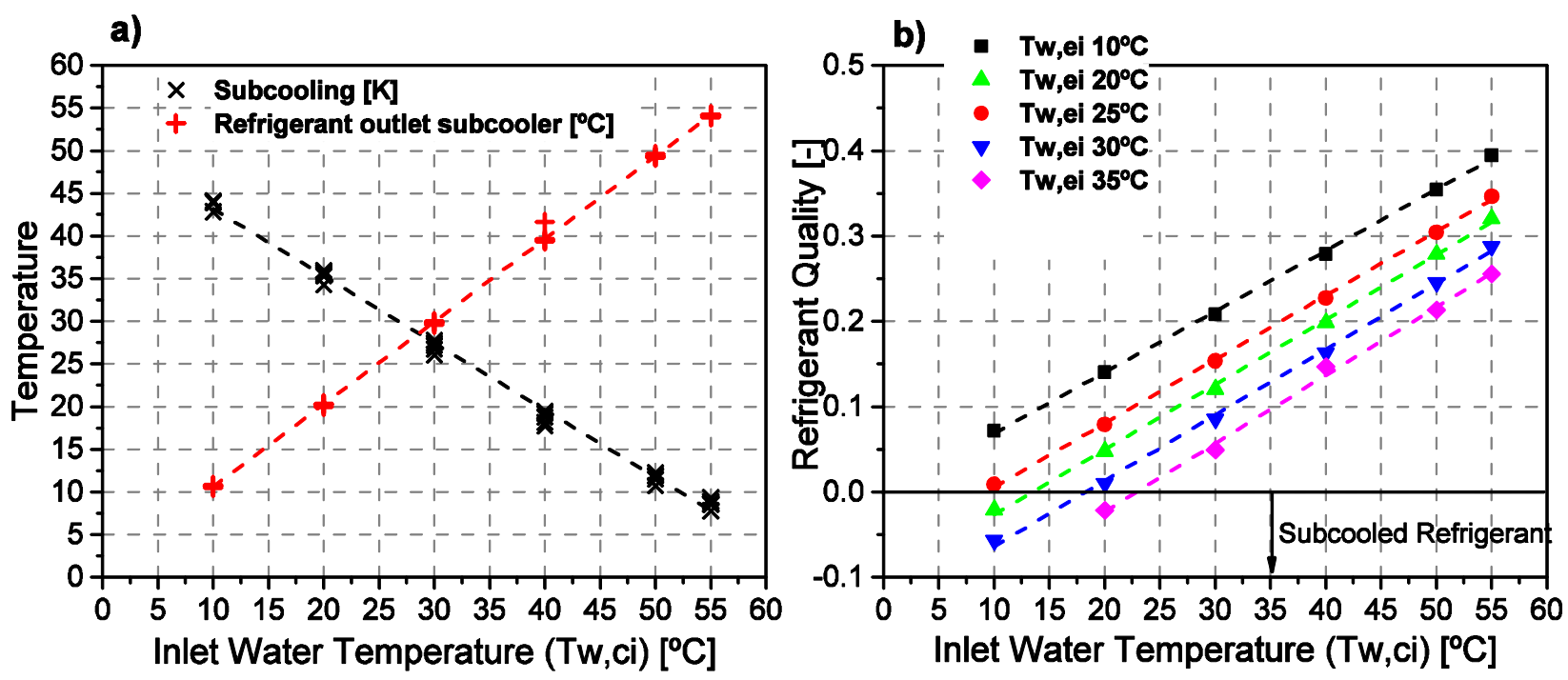

Figure 5.12: a) Subcooling and refrigerant temperature at subcooler outlet, b) Refrigerant quality at inlet evaporator vs. inlet water temperature to subcooler for different water inlet temperature to the evaporator $\left(T_{w, c o}=60^{\circ} \mathrm{C}\right)$. 
One particularity of this application with high subcooling and high evaporating temperatures is the low refrigerant quality at the evaporator inlet or even subcooled liquid. Figure 5.12b) shows the inlet refrigerant quality at the evaporator, where negative values mean subcooled refrigerant. It had a linear dependency with the inlet water temperature at the subcooler, which is related with subcooling, higher subcooling leads to lower refrigerant quality. The refrigerant quality also depends on the evaporator conditions, higher inlet water temperatures at the evaporator leads to lower refrigerant qualities. For the lowest quality values, the refrigerant is at subcooled state at the evaporator inlet, and, hence at the expansion valve outlet. On the other hand, the highest refrigerant quality is about 0.4 . These large variations in the inlet quality could lead to a high variation in the refrigerant charge contained in the evaporator, which needs to be taken into account in the design process of such a system.

This design was tested even at higher water inlet temperature at the evaporator than the SMC design. High evaporating temperatures lead to high power input in the compressor since refrigerant charge flow increases with evaporating pressure. Envelope for scroll compressors similar to the one used in this heat pump prototype is usually limited for evaporating temperatures up to $20^{\circ} \mathrm{C}$. During these test measurements, the maximum evaporating temperature is about $24^{\circ} \mathrm{C}$, corresponding for the $T_{w, e i}=35^{\circ} \mathrm{C}$, but no breakdown or performance decrease has been observed in the compressor. The good reliability of the compressor at these conditions can be explained by the use of propane since the envelope of the used compressor is given for refrigerant R410A. While the density of Propane at the compressor inlet for high evaporating temperatures is about $19.4 \mathrm{~kg} / \mathrm{m} 3$, the density for R410A at the same conditions will be $60.5 \mathrm{~kg} / \mathrm{m} 3$. This density difference leads to a higher current demand at the compressor for the refrigerant R410A. 


\subsubsection{Condition with high $T_{w, e i}$ and low $T_{w, c i}$}

In the SMC design, the external condition $\left(T_{w, e i}=30^{\circ} \mathrm{C}\right.$ and $\left.T_{w, c i}=10^{\circ} \mathrm{C}\right)$ gave a lower performance than expected. As it is seen in Figure 5.13a), the refrigerant temperature at point 3 is limited by $T_{w, c i}=10^{\circ} \mathrm{C}$. At this point, the pressure at the liquid receiver (point 4 ) is already lower than the target evaporating temperature of $20^{\circ} \mathrm{C}\left(T_{w, e i}=30^{\circ} \mathrm{C}\right.$ and $10 \mathrm{~K}$ of superheat). Furthermore, the expansion valve introduces an extra pressure drop, leading to lower evaporating temperatures and higher superheats.

This behavior was not observed for the SMS design (Figure 5.13b). In this case, the liquid receiver is located at the condenser outlet, and it is possible to have subcooled refrigerant at the expansion valve outlet (point 5). Therefore, the expansion valve outlet is not limited, and it is possible to control the superheat at this condition. One should notice that the situation with subcooled refrigerant at the expansion valve outlet (and evaporator inlet) is not possible with the SMC design.

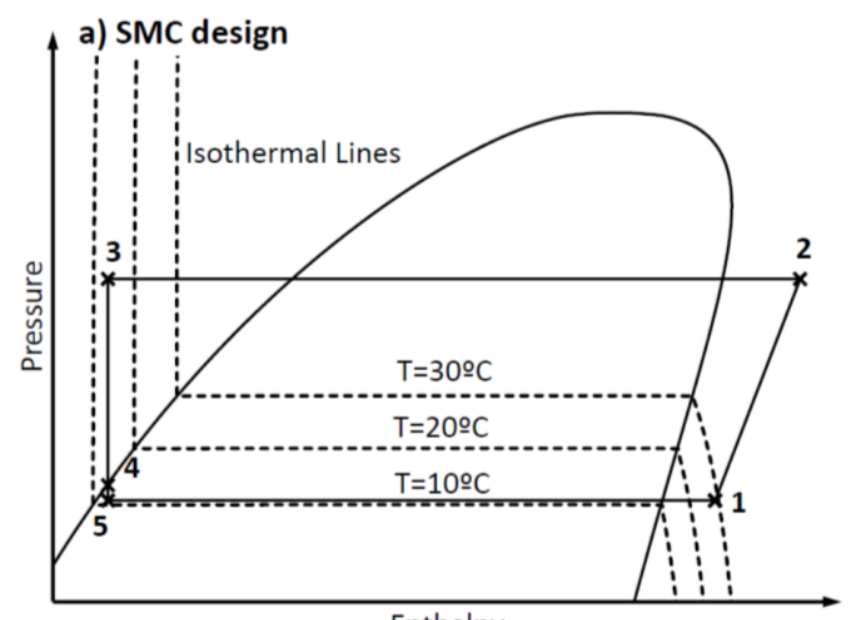

Enthalpy

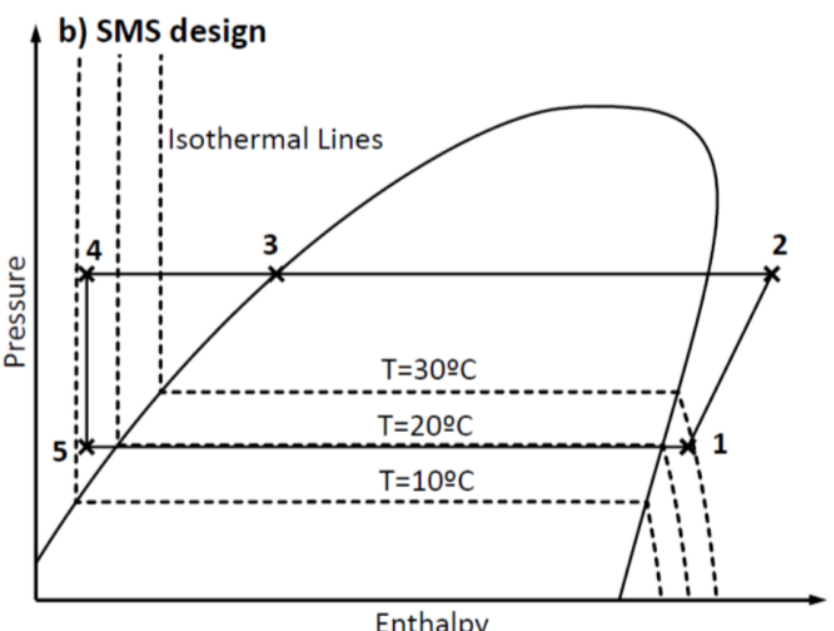

Enthalpy

Figure 5.13: Pressure-Enthalpy diagram for condition: $T_{w, e i}=30^{\circ} \mathrm{C} ; T_{w, c i}=10^{\circ} \mathrm{C}$, a) SMC design b) SMS design 


\subsubsection{Comparison between the SMS (R290) and the reference $\mathrm{CO}_{2}$ heat pump}

\section{for SHW}

AS commented in the introduction, the transcritical $\mathrm{CO}_{2}$ cycle has been pointed out as an efficient solution for the SHW application due to the high-temperature glide in the refrigerant side. Furthermore, the $\mathrm{CO}_{2}$ cycle is claimed to be able to heat water up to temperatures of $90^{\circ} \mathrm{C}$, while the propane cycle is usually tested heating water up to $60^{\circ} \mathrm{C}$. In this section, the experimental results obtained with the SMS design at different inlet and outlet water temperatures are compared to the commercial, high-efficiency HP for sanitary hot water production, Q-ton ${ }^{9}$. This is an air-to-water $\mathrm{CO}_{2}$ heat pump working in transcritical conditions. Since the secondary fluid at the evaporator is different for the propane and the $\mathrm{CO}_{2} \mathrm{HPs}$, in order to fairly compare both cycles, it was selected a higher air temperature $\left(25^{\circ} \mathrm{C}\right)$ than the inlet water temperature to the evaporator $\left(T_{w, e i}=20^{\circ} \mathrm{C}\right)$.

Figure 5.14a) shows the heating COP as a function of the water inlet temperature to the subcooler $\left(T_{w, c i}\right)$ and producing hot water at $60^{\circ} \mathrm{C}$. The figure compares the experimental results for the SMS design and the commercial Q-ton. The propane cycle working with subcooling has about a $5 \%$ to $14 \%$ higher COP than the commercial reference $\mathrm{CO}_{2} \mathrm{HP}$ based on the catalog data. There is no data for the reference $\mathrm{CO}_{2} \mathrm{HP}$ with water inlet temperatures $\left(T_{w, c i}\right)$ higher than $24^{\circ} \mathrm{C}$, but the trend of the available results indicates that the difference between the propane and the $\mathrm{CO}_{2}$ heat pumps would be greater than $14 \%$ at higher $T_{w, c i}$.
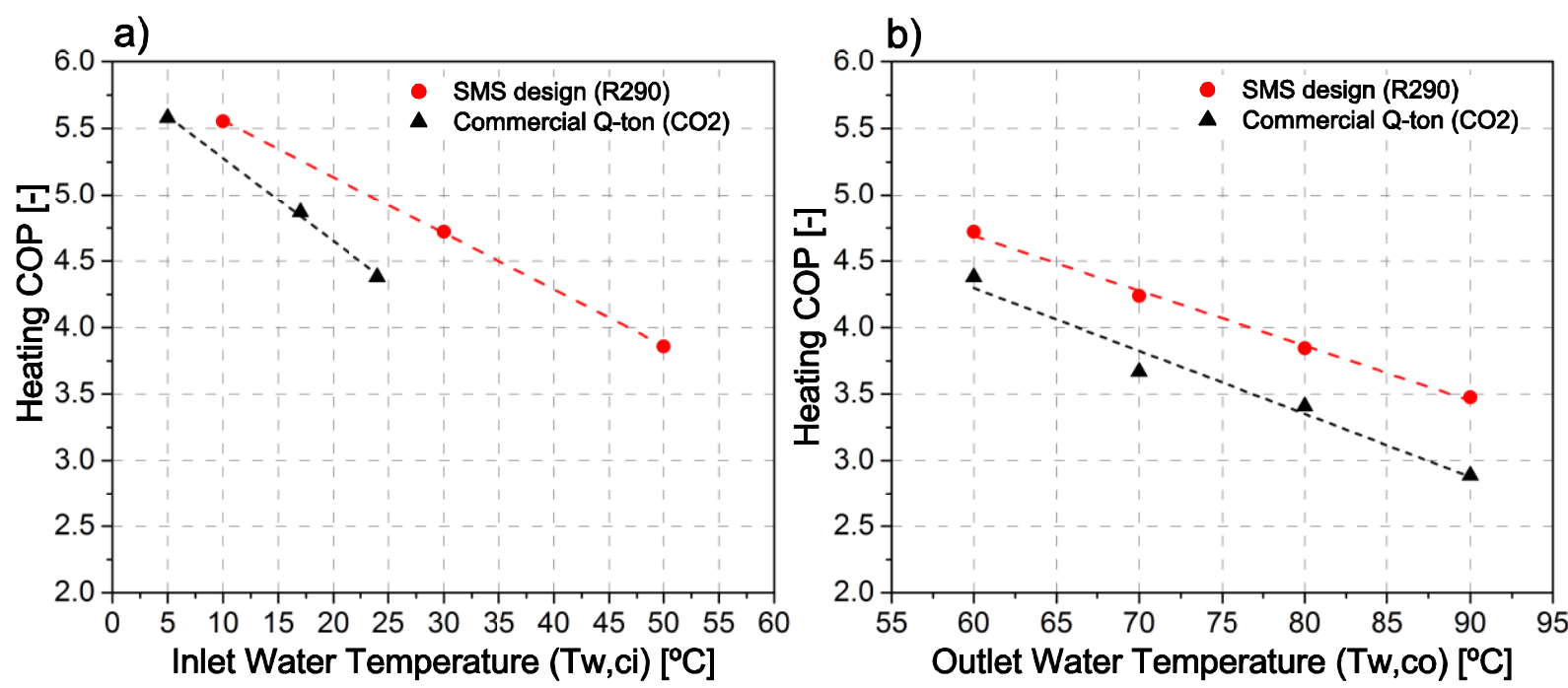

Figure 5.14: Heating COP as a function of a) $T_{w, c i}$ with $\left.T_{w, c o}=60^{\circ} \mathrm{C} \mathrm{b}\right) T_{w, c o}$ with $T_{w, c i}=30^{\circ} \mathrm{C}$.

9 The Q-ton information is taken from the catalogue data (Q-ton Catalogue data ESA30E-25) 
Figure 5.14b) shows the heating COP as a function of water production temperatures (from $60^{\circ} \mathrm{C}$ to $90^{\circ} \mathrm{C}$ ). $T_{w, c i}$ is fixed to $30^{\circ} \mathrm{C}$ for the propane heat pump, while it is $24^{\circ} \mathrm{C}$ for the $\mathrm{Q}$-ton (the closest in the catalog data). The figure compares the experimental results for the SMS design and the commercial Q-ton. The propane cycle has a $\mathrm{COP}$ about $20 \%$ higher than the commercial $\mathrm{CO}_{2}$ cycle when the hot water is produced at $90^{\circ} \mathrm{C}$. Hence, the propane cycle working with subcooling has proved, not only to be able to heat water up to $90^{\circ} \mathrm{C}$ but also to have a higher performance than the commercial transcritical heat pump Q-ton.

Table 5.5 shows the condensing and discharge temperature for the SMS design when producing water at high temperature. The refrigerant discharge temperature of the propane cycle producing hot water at $90^{\circ} \mathrm{C}$ is $111^{\circ} \mathrm{C}$, which is lower than the maximum working discharge temperature recommended by the compressor manufacturer $\left(130^{\circ} \mathrm{C}\right)$. The condensing temperature at this point is $78.9^{\circ} \mathrm{C}$ (the critical temperature for propane is $96.7^{\circ} \mathrm{C}$ ).

Table 5.5: SMS experimental results for different water temperature production $\left(T_{w, c o}\right)$.

$T_{w, c i}$ is fixed to $30^{\circ} \mathrm{C}$.

\begin{tabular}{ccccc}
\hline & $\boldsymbol{T}_{w, c o}=$ & $\boldsymbol{T}_{w, c o}=$ & $\boldsymbol{T}_{w, c o}=$ & $\boldsymbol{T}_{w, c o}=$ \\
& $\mathbf{6 0}^{\circ} \mathbf{C}$ & $\mathbf{7 0}^{\circ} \mathbf{C}$ & $\mathbf{8 0}^{\circ} \mathbf{C}$ & $\mathbf{9 0}^{\circ} \mathbf{C}$ \\
\hline $\mathbf{C O P}_{\mathbf{h}}$ & 4.72 & 4.24 & 3.84 & 3.48 \\
$\mathbf{T}_{\mathbf{c}}\left[{ }^{\circ} \mathbf{C}\right]$ & 56.7 & 64.5 & 71.9 & 78.9 \\
$\mathbf{T}_{\text {disch }}\left[{ }^{\circ} \mathbf{C}\right]$ & 81 & 90 & 100 & 111 \\
\hline
\end{tabular}

\subsubsection{Superheat study}

Superheat is measured as the temperature difference between the refrigerant temperature at the evaporator outlet (compressor inlet) and the evaporating temperature. Until now, the experimental results were given with $10 \mathrm{~K}$ of superheat. Usually, the lower the superheat, the higher the performance, since the evaporating temperature increases with low superheat. Nevertheless, a minimum superheat needs to be produced in order to avoid liquid refrigerant droplets at the compressor inlet and to obtain a stable control in the expansion valve. Therefore, many manufacturers' gives the heat pump performance at $10 \mathrm{~K}$ of superheat, although lower superheat can be achieved. In this section, the experimental results obtained with the SMS design for a target superheat of $5 \mathrm{~K}$ are presented.

First, the target superheat was reduced progressively. It was observed that for superheats below $8 \mathrm{~K}$, the automatic control of the expansion valve becomes more unstable. When superheat was set to $5 \mathrm{~K}$, superheat started to oscillate between 0 
and $10 \mathrm{~K}$ (unstable control). Due to this behavior, the controller was set manual, to avoid these oscillations. It was observed that setting the controller to manual, the large oscillations disappeared, although superheat control was not fine. A change of $1 \%$ on the expansion valve opening could lead to $2 \mathrm{~K}$ change in superheat or higher. Therefore, it is difficult to control low superheat accurately. The results presented here were done trying to control superheat to $5 \mathrm{~K}$, but some differences could be found due to the poor accuracy at low superheat.

Table 5.6 compares the results of heating COP obtained for a target superheat of $10 \mathrm{~K}$ and $5 \mathrm{~K}$. The total improvement is calculated with Eq.5.1.

$$
\% \text { Improvement }=\frac{\operatorname{COP}(5 K)-\operatorname{COP}(10 K)}{\operatorname{COP}(10 K)}
$$

The improvement per degree of superheat is the total improvement divided by the superheat difference between the two points. This can also be seen in figure 5.15 , where the improvement is plotted against $T_{w, c i}$. The greater improvement is at the condition $T_{w, c i}=50^{\circ} \mathrm{C}$, while the lowest improvement is at $T_{w, c i}=30^{\circ} \mathrm{C}$ (around $0.55 \%$ per $\mathrm{K}$ ). It seems that the degree of improvement depends on $T_{w, c i}$, but the trend is not clear. Superheat is not only reduced by the increase of the evaporating temperature since the refrigerant temperature at the evaporator outlet slightly decreases. For superheats around $10 \mathrm{~K}$, the evaporator is able to keep the refrigerant outlet temperature close to the water inlet temperature.

Table 5.6: Comparison of results at different Superheats

\begin{tabular}{cc|cc|cc|cc}
\cline { 3 - 6 } & & \multicolumn{2}{|c|}{ Target Sh: 5K } & \multicolumn{2}{c|}{ Target Sh: 10K } & \\
\cline { 1 - 5 }$T_{w, e i}$ & $T_{w, c i}$ & $\begin{array}{c}\text { Superheat } \\
{[\mathrm{K}]}\end{array}$ & $\begin{array}{c}\mathrm{COP}_{\mathrm{h}} \\
{[-]}\end{array}$ & $\begin{array}{c}\text { Superheat } \\
{[\mathrm{K}]}\end{array}$ & $\begin{array}{c}\mathrm{COP}_{\mathrm{h}} \\
{[-]}\end{array}$ & $\begin{array}{c}\text { Total } \\
\text { Improvement } \\
{[\%]}\end{array}$ & $\begin{array}{c}\text { Improvement } \\
\text { per 1 K Sh [\%] }\end{array}$ \\
\hline \multirow{3}{*}{10} & 10 & 5.4 & 4.65 & 10.2 & 4.48 & 3.9 & 0.8 \\
& 30 & 5.9 & 3.97 & 10.3 & 3.88 & 2.6 & 0.6 \\
& 50 & 5.5 & 3.45 & 10.3 & 3.19 & 8.3 & 1.8 \\
& 10 & 6.2 & 5.89 & 10.2 & 5.63 & 4.7 & 1.2 \\
20 & 30 & 5.9 & 4.92 & 9.9 & 4.83 & 1.9 & 0.5 \\
& 50 & 5.1 & 4.28 & 10.2 & 3.94 & 8.8 & 1.7 \\
\hline
\end{tabular}



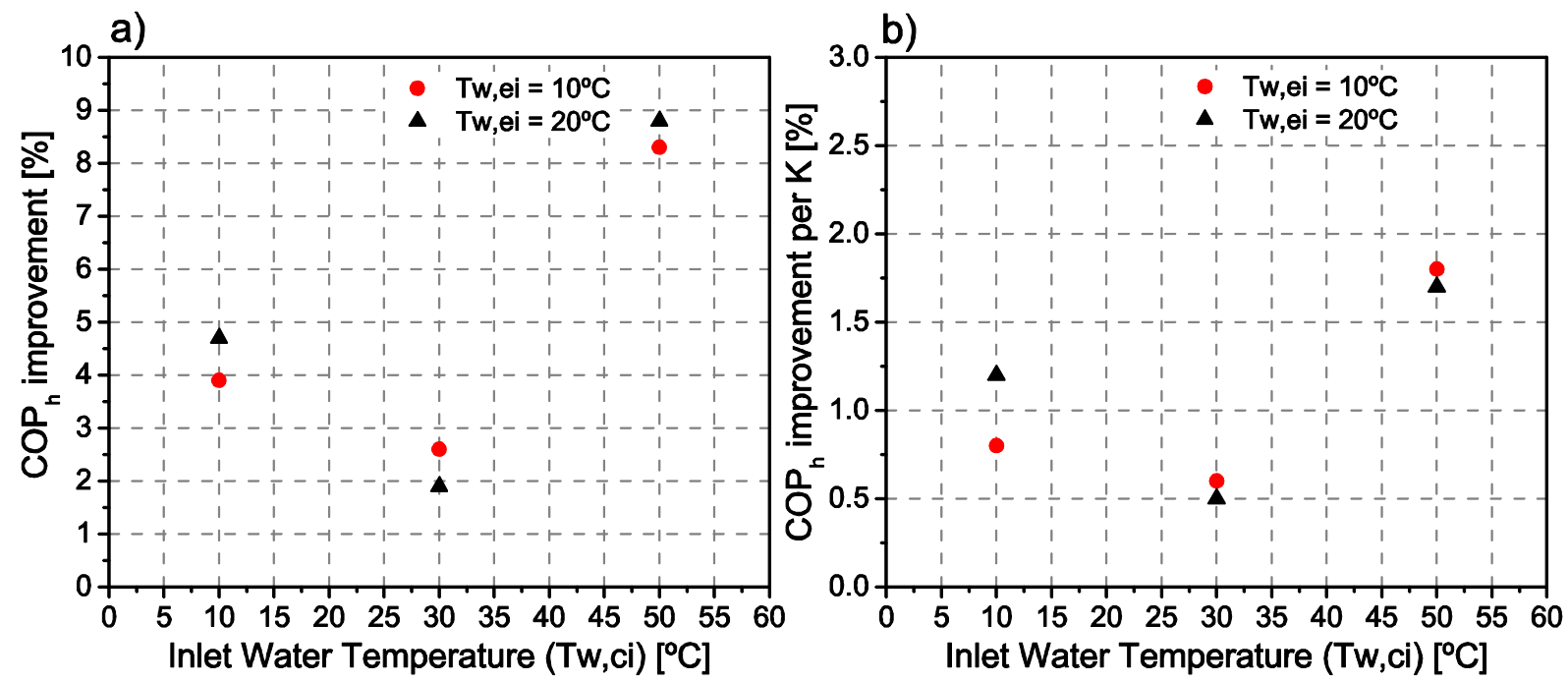

Figure 5.15: Improvement when reducing superheat from $10 \mathrm{~K}$ to $5 \mathrm{Ka}$ ) Total improvement b) Improvement per Kof superheat

\subsubsection{Thermography: Evaporator refrigerant distribution}

The subcritical R290 cycle working at high evaporating temperatures and subcooling had a low refrigerant quality, or even subcooled refrigerant, at the evaporator inlet. Good stability was observed during operation when the system worked with $10 \mathrm{~K}$ of superheat, but the system turned unstable when the superheat was set to $5 \mathrm{~K}$. In order to investigate the refrigerant distribution in the evaporator at different refrigerant qualities, and superheats, thermography images during operation have been taken. All thermographies were taken with an inlet water temperature of the evaporator of $25^{\circ} \mathrm{C}$. Figure 5.16 shows a picture of the evaporator taken from the same side than the thermography images. The refrigerant enters to the evaporator from the bottom to the top, with the water flowing in counterflow. The heat exchanger has 120 plates. 

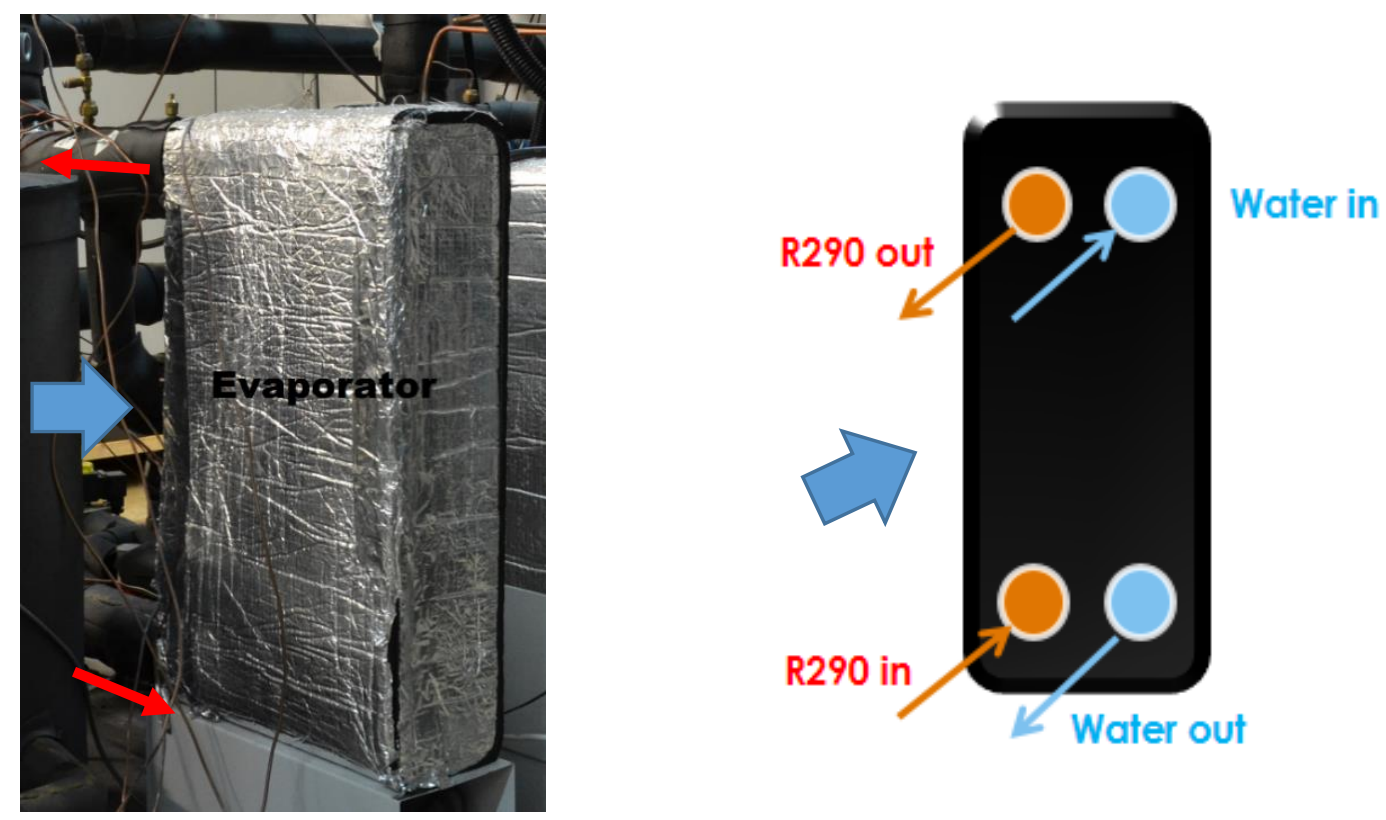

Figure 5.16: Picture of the evaporator and location of the input/output ports for refrigerant and water.

Figure 5.17 shows the thermography images for three different superheats. The condition at the heat sink is $10^{\circ} \mathrm{C}$ to $60^{\circ} \mathrm{C}$ (high subcooling). For superheat 6 and $10 \mathrm{~K}$, the liquid refrigerant accumulates at the HX channels closer to the refrigerant inlet (the refrigerant is subcooled at the evaporator inlet). For superheat $6 \mathrm{~K}$, it seems that the refrigerant going through the channels closer to the evaporator inlet does not reach the outlet at the required superheat. Furthermore, the difference in evaporating temperature is only $0.7 \mathrm{~K}$ between the superheat of $6 \mathrm{~K}$ and $10 \mathrm{~K}$. The refrigerant distribution could be the reason for the instability at low superheat since refrigerant liquid droplets could be leaving the evaporator. Superheat of 17 $\mathrm{K}$ has an even distribution along the evaporator. The target superheat is reached close to the bottom, so the evaporator is oversized for this condition.

Figure 5.18 shows the thermography images for three different $T_{w, c i}(\mathrm{Sh}=10 \mathrm{~K})$. The refrigerant quality at the evaporator inlet highly depends on subcooling, and hence it depends on $T_{w, c i}$. As seen in the figure 5.17, for $T_{w, c i}=10^{\circ} \mathrm{C}$, the liquid refrigerant accumulated at the HX channels closer to the refrigerant inlet (the refrigerant is subcooled at the evaporator inlet). For $T_{w, c i}=15^{\circ} \mathrm{C}$, the refrigerant at the evaporator inlet is not subcooled but had a low refrigerant quality. At this point, the refrigerant distribution is more even. For $T_{w, c i}=30^{\circ} \mathrm{C}$, the refrigerant quality is about 0.14 . At this point, the refrigerant distribution totally changes from the case $T_{w, c i}=10^{\circ} \mathrm{C}$. Now the refrigerant accumulates at the HX channels farther to the refrigerant inlet. Therefore, the refrigerant quality at the evaporator inlet highly influences the refrigerant distribution in the evaporator. 
a) $\mathrm{Sh}=6 \mathrm{~K}$

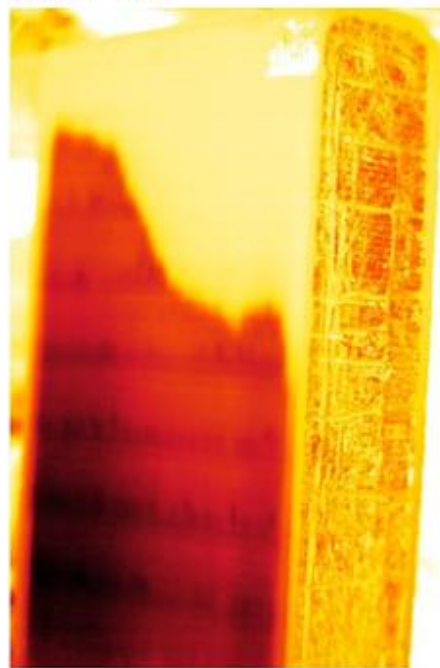

m_ref $=0.127 \mathrm{~kg} / \mathrm{s}$

Quality inlet $=-\mathbf{0 . 0 2 7}$

T_evap $=14.8^{\circ} \mathrm{C}$ b) $\mathrm{Sh}=10 \mathrm{~K}$

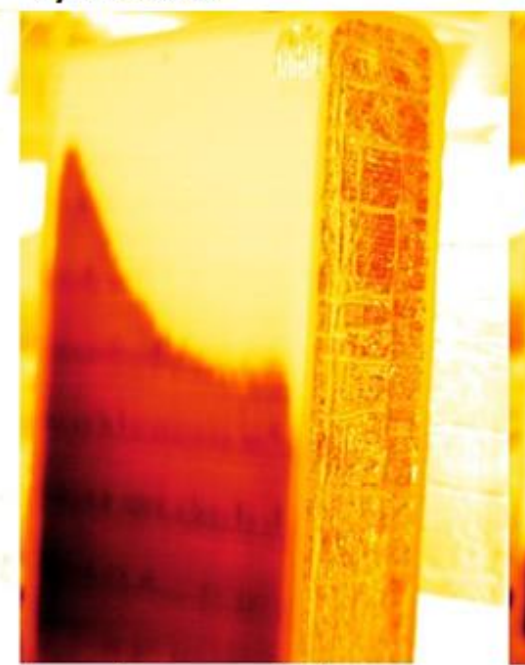

m_ref $=0.122 \mathrm{~kg} / \mathrm{s}$

Quality inlet $=-0.024$

T_evap $=14.1^{\circ} \mathrm{C}$ c) $\mathrm{Sh}=17 \mathrm{~K}$

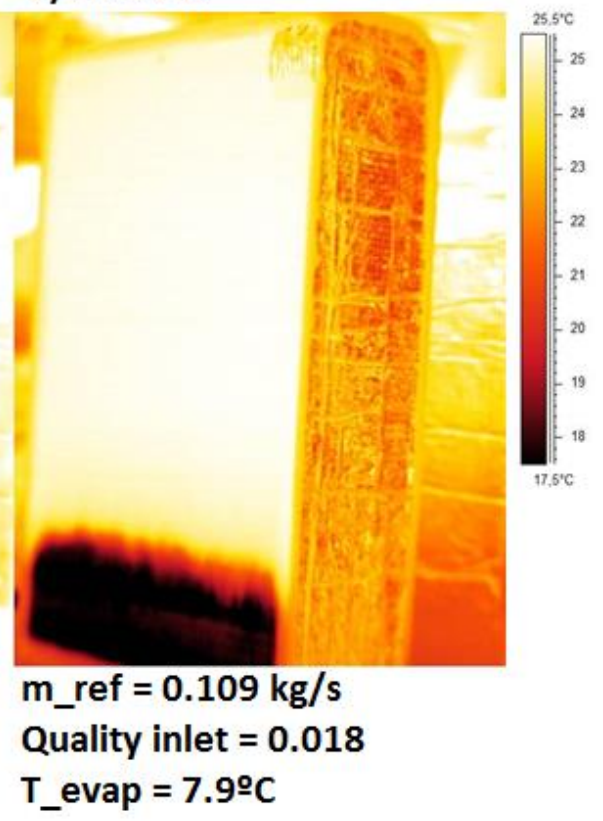

Figure 5.17: Thermography of evaporator $\left(T_{w, e i}=25^{\circ} \mathrm{C} ; T_{w, c i}=10^{\circ} \mathrm{C} ; T_{w, c o}=60^{\circ} \mathrm{C}\right)$ a) Superheat of $6 \mathrm{~K}$ b) Superheat of $10 \mathrm{~K}$ c) Superheat of $17 \mathrm{~K}$

a) $\mathrm{Tw}, \mathrm{ci}=10^{\circ} \mathrm{C}$

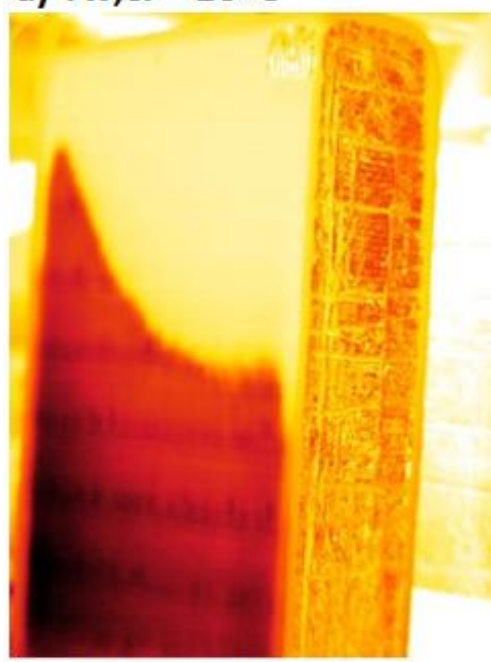

m_ref $=0.122 \mathrm{~kg} / \mathrm{s}$

Quality inlet $=-0.024$

T_evap $=14.1^{\circ} \mathrm{C}$ b) $\mathrm{Tw}, \mathrm{ci}=15^{\circ} \mathrm{C}$

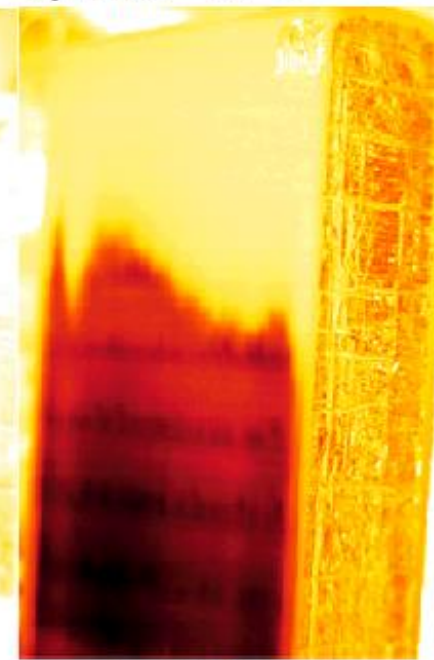

m_ref $=0.118 \mathrm{~kg} / \mathrm{s}$

Quality inlet $=0.039$

T_evap $=14.4^{\circ} \mathrm{C}$ c) $\mathrm{Tw}, \mathrm{ci}=30^{\circ} \mathrm{C}$

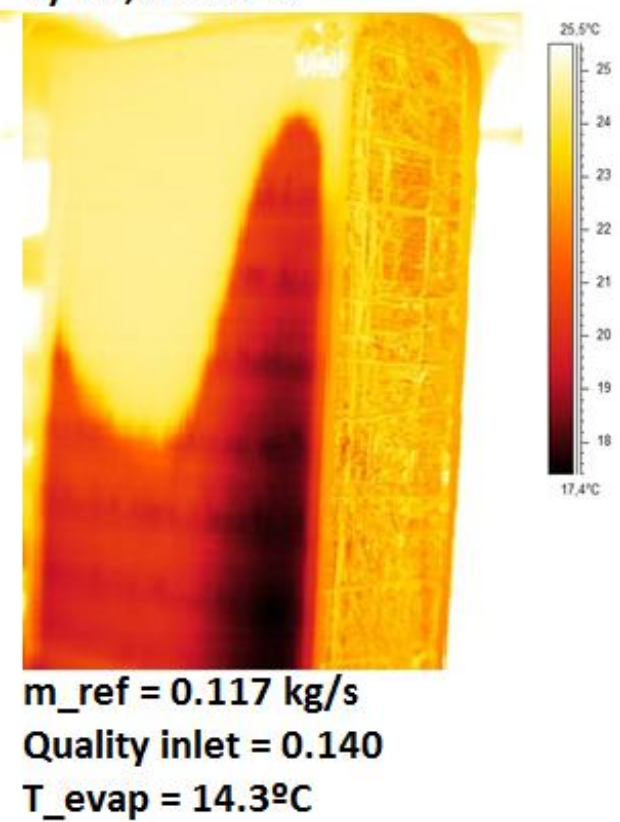

Figure 5.18: Thermography of evaporator $\left(T_{w, e i}=25^{\circ} \mathrm{C} ; T_{w, c o}=60^{\circ} \mathrm{C} ; \mathrm{Sh}=10 \mathrm{~K}\right)$ a) $T_{w, c i}=$ $10^{\circ} \mathrm{C}$ b) $T_{w, c i}=15^{\circ} \mathrm{C} c$ ) $T_{w, c i}=30^{\circ} \mathrm{C}$ 


\subsubsection{Conclusions}

The main points derived from the present study have been:

- The heating COP for the SMS design is slightly higher than the SMC design working at the optimal subcooling. One should remember that the SMS design has $25 \%$ more heat transfer area for the heat sink.

- COP heating and heating capacity decrease linearly with the inlet water temperature at the subcooler $\left(T_{w, c i}\right)$.

- Subcooling depends mostly on the water inlet temperature to the subcooler, and not on the inlet water temperature to the evaporator.

- For the selected subcooler, the maximum subcooling is reached at all conditions (refrigerant temperature at the subcooler outlet close to $T_{w, c i}$ ).

- There is no limitation in the evaporating temperature for the condition $\left(T_{w, e i}=30^{\circ} \mathrm{C}\right.$ and $\left.T_{w, c i}=10^{\circ} \mathrm{C}\right)$.

- The Propane cycle working with a high degree of subcooling has demonstrated to be competitive with the transcritical $\mathrm{CO}_{2}$ heat pump for the SHW application, even to heat water up to $90^{\circ} \mathrm{C}$.

- Low refrigerant quality or even subcooled liquid can be found at evaporator inlet with points working at elevated evaporating pressure and high subcooling.

- The heat pump control for low superheats was unstable. This issue could be related to the refrigerant distribution in the evaporator.

- The refrigerant distribution in the evaporator depended on the refrigerant quality at the evaporator inlet. For subcooled refrigerant (and qualities near 0 ), the refrigerant accumulates in the channels close to the inlet, while it accumulates at the further channels for higher refrigerant qualities.

In addition, it has been proved that the proposed designs could be used in an efficient way in a broader range of applications that require higher water temperatures, such as old boilers used in some parts of Europe, which require water at $80^{\circ} \mathrm{C}$, or industrial cleaning processes requiring water at a high temperature. 



\section{Chapter 6}

\section{Theoretical comparison between SMS and SMC}

Chapter 5 presented the experimental results for the SMC and SMS heat pump designs. The heating COP of the SMS design (subcooling made in the subcooler) was slightly higher than for the SMC design (subcooler made in the condenser). Nevertheless, the SMS design has 25\% more heat transfer area, so the SMS design cannot be claimed as the best solution to produce subcooling in the SHW application.

In this chapter, it is developed a model using the commercial software IMST-ART (IMST-ART v3.70) in order to compare both heat pump designs fairly. First, the model is validated with the experimental results (SMC design). Then, the condenser of the model is increased to have the same heat transfer area than the HP design with a separate subcooler (SMS).

Part of the results of this chapter has been published in the journal "Applied Energy" (Pitarch et al., 2017D). 


\subsection{Model}

IMST-ART is a dedicated software for modeling heat pump systems as a whole, according to the state-of-the-art. The model incorporates a number of sub-models representing the different parts of the heat pump: compressor, condenser, evaporator and expansion valve. The definition of the heat exchangers is based on their geometric characteristics. The heat exchangers are discretized in cells throughout the refrigerant and secondary fluid paths, assuming one-dimensional flow. The model is able to take into account both heat transfer and pressure drop, with local evaluation of the heat transfer coefficient and friction factor, by built in correlations, as well as that of the fluid properties. This model is able to consider most of the geometrical and operation parameters of current evaporators and condensers. Then, the global solution method employed is called SEWTLE (SemiExplicit method for Wall Temperature Linked Equations) (Corberán et al., 2002). For the compressor, it is used the available information supplied by manufacturers (compressor size and polynomial equations for the compressor efficiency and volumetric efficiency). The expansion valve is modeled as an isenthalpic pressure drop in order to fulfill the desired superheat - in this case $10 \mathrm{~K}$.

On the one hand, the throttling valve (SMC design) cannot be modeled, but the subcooling can be introduced as a parameter, so in practice, the SMC design can be modeled with the IMST-ART software. On the other hand, the subcooler cannot be modeled as a separate heat exchanger, so the SMS design cannot be modeled with the IMST-ART software.

In this chapter, the heating COP calculation does not take into account the consumption of the auxiliary components, neither in the model results nor in the experimental ones when used for validation.

\subsubsection{Model validation: Subcooling made in the condenser (SMC)}

Figure 6.1 compares the model results with the experiments, for COP and condensation pressure. The results are presented as a function of the subcooling and for different water inlet temperatures for the condenser $\left(T_{w, i}\right)$. The inlet water temperature for the evaporator $\left(T_{w, e i}\right)$ is fixed to $20^{\circ} \mathrm{C}$.

There is good agreement between the experimental and theoretical values for the heating COP; the model captures COP dependency with subcooling. COP increases with subcooling up to a maximum and then decreases. The maximum discrepancies are found at high water inlet temperatures to the condenser 
$\left(T_{w, c i}=50^{\circ} \mathrm{C}\right)$, being less than $4 \%$. The optimal subcooling is predicted by the model with a deviation lower than $2 \mathrm{~K}$.

Regarding the condensing pressure, the model results also match the experimental results. At low subcooling, the condensing pressure increases slowly with subcooling, and after a certain value of the subcooling, it starts to increase at a higher rate. This point of inflection is where the maximum COP takes place. As in the heating COP, the greatest discrepancies are found at high water inlet temperatures to the condenser $\left(T_{w, c i}=50^{\circ} \mathrm{C}\right)$, being less than $2 \%$.

Table 6.1 shows the heating COP, the heating capacity and the compressor power input for the model as well as the experimental values working at the optimal subcooling. Great agreement for the three variables can be seen. COP discrepancies are below $1 \%$ for $T_{w, c i}=10^{\circ} \mathrm{C}$ and $30^{\circ} \mathrm{C}$, while the heating capacity and the compressor power input are all below $2 \%$ of discrepancies.
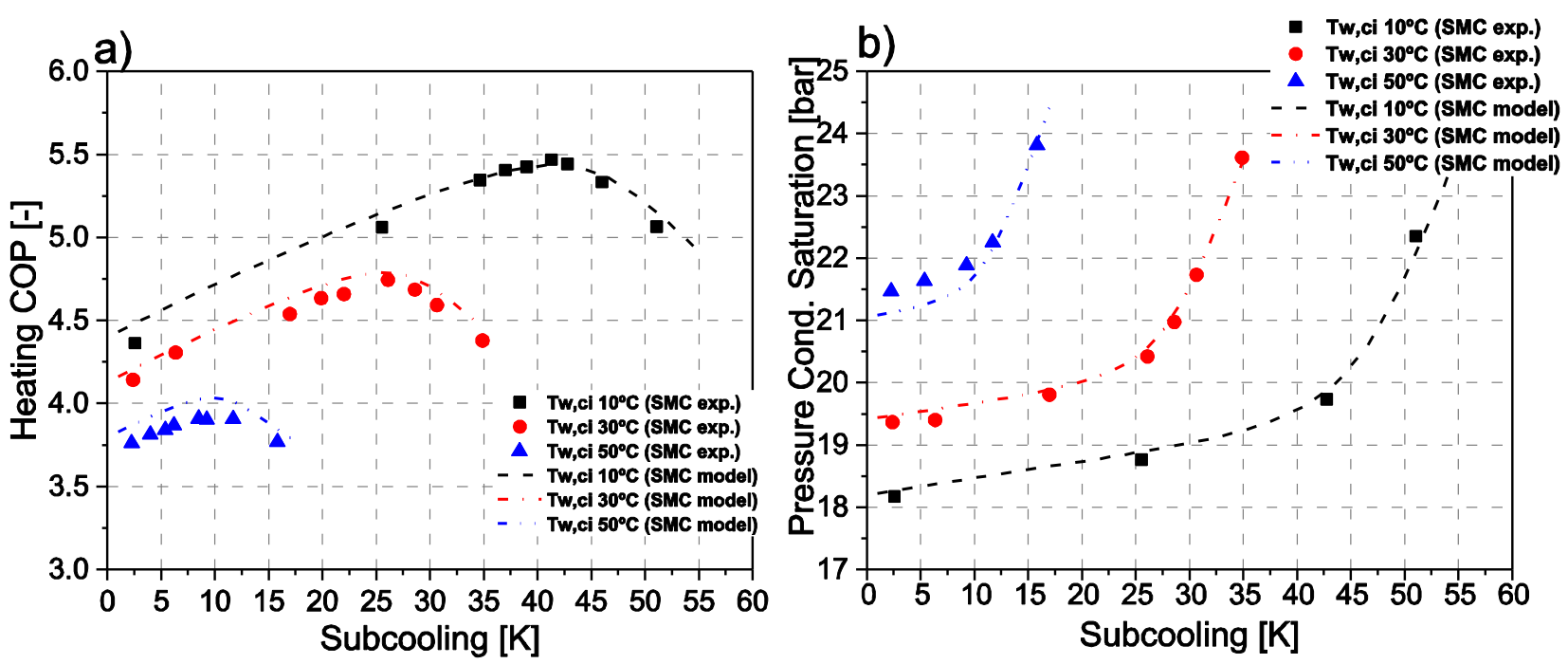

Figure 6.1: Model validation; a) heating COP, b) condensing pressure. $\left(T_{w, e i}=20^{\circ} \mathrm{C}\right)$

Table 6.1: SMC model validation at the optimum subcooling $\left(T_{w, e i}=20^{\circ} \mathrm{C}\right)$.

\begin{tabular}{cccc|ccc}
\cline { 2 - 7 } & \multicolumn{3}{c|}{ SMC Experimental } & \multicolumn{3}{c}{ SMC Model } \\
\cline { 2 - 7 } & $\mathbf{C O P}_{\mathbf{h}}[-]$ & $\begin{array}{c}\mathbf{Q}_{\mathbf{h}} \\
{[\mathbf{k W}]}\end{array}$ & $\begin{array}{c}\mathbf{W c} \\
{[\mathbf{k W}]}\end{array}$ & $\mathbf{C O P}_{\mathbf{h}}[-]$ & $\begin{array}{c}\mathbf{Q}_{\mathbf{h}} \\
{[\mathbf{k W}]}\end{array}$ & $\begin{array}{c}\mathbf{W c} \\
{[\mathbf{k W}]}\end{array}$ \\
\hline $\boldsymbol{T}_{\boldsymbol{w}, \boldsymbol{c i}}=\mathbf{1 0}^{\mathbf{0}} \mathbf{C}$ & 5.47 & 45.25 & 8.28 & 5.43 & 45.57 & 8.39 \\
$\boldsymbol{T}_{\boldsymbol{w}, \boldsymbol{c i}}=\mathbf{3 0}^{\mathbf{0}} \mathbf{C}$ & 4.75 & 40.98 & 8.64 & 4.79 & 41.55 & 8.68 \\
$\boldsymbol{T}_{\boldsymbol{w}, \boldsymbol{c} \boldsymbol{i}}=\mathbf{5 0}^{\mathbf{0}} \mathbf{C}$ & 3.91 & 35.96 & 9.21 & 4.03 & 36.54 & 9.06 \\
\hline
\end{tabular}




\subsubsection{Model adjustment to the heat pump with subcooler}

Comparing the experimental results for both heat pump designs, the SMS heat pump configuration (with subcooler) has a slightly higher performance than the SMC heat pump configuration (subcooling at condenser). For instance, at the nominal point $\left(T_{w, e i}=20^{\circ} \mathrm{C}\right.$ and heating water from $10^{\circ} \mathrm{C}$ to $\left.60^{\circ} \mathrm{C}\right)$, the heating COP for the SMS heat pump is 5.66, while the heating COP for SMC is 5.47.

Nevertheless, the experimental results obtained with the separate subcooler configuration cannot be fairly compared with the SMC heat pump configuration, since the first one has a $25 \%$ greater heat transfer area on the high-pressure side.

In order to make a fair comparison between both systems, the condenser of the SMC model has been enlarged in order to have the same heat transfer area as the condenser + subcooler of the SMS heat pump design. In this sense, the results of both systems can be compared directly.

In order to have an equal heat transfer area in the high-pressure side without significantly changing the heat transfer coefficient, the height of the condenser has been increased. The other alternative, increasing the number of plates, affects the refrigerant velocity, and hence, the heat transfer coefficient. Therefore, the condenser height will go from $0.476 \mathrm{~m}$ to $0.591 \mathrm{~m}$, which is $25 \%$ longer (25\% more area). The area of the modified condenser will be $4.37 \mathrm{~m}^{2}$, which is the same as the condenser and the subcooler together. For the sake of clarity, the SMC model with the enlarged condenser will be referenced as SMCL (the subcooling made with larger condenser). One should notice that, although the subcooler area has been added to the condenser, the plate pitch of the subcooler (SMS design) is different from the SMCL system. The plate pitch of the subcooler was optimized for liquid refrigerant, while the plate pitch in the condenser was designed mainly for twophase refrigerant.

\subsection{Results}

Figure 6.2a) shows the heating COP as a function of the subcooling for the SMC and SMCL models (different condenser height) and the experimental results for the SMS heat pump configuration. COP increases for the whole range of subcoolings for the SMCL model (condenser height $0.59 \mathrm{~m}$ ). At low and high subcooling, the COP improvement is moderate. For instance, in the case of $T_{w, c i}=50^{\circ} \mathrm{C}$ at subcooling higher than $12 \mathrm{~K}$, the COP is practically the same for both condenser heights. The maximum COP improvement is found at the optimum subcooling. 
When the SMS configuration is compared with the SMC model (with a smaller heat transfer area), the SMS design has a greater performance. This situation changes if the SMC design is equipped with a larger condenser, the SMCL model with the same heat transfer area than the SMS design. In this case, the performance of SMCL is still below the experimental results for the SMS design at $T_{w, c i}=10^{\circ} \mathrm{C}$, but at higher $T_{w, c i}\left(30^{\circ} \mathrm{C}\right.$ and $\left.50^{\circ} \mathrm{C}\right)$, SMCL has a higher performance than SMS. Nevertheless, as seen in figure 6.1 , the model results for $T_{w, c i}=50^{\circ} \mathrm{C}$ where slightly over predicted. Hence, it can be concluded that the SMC design would improve performance by adding heat transfer area (SMCL), but it is not clear that SMCL has a higher performance than SMS design for these conditions.

Figure $6.2 \mathrm{~b}$ ) shows the condensing pressure as a function of subcooling. The condensing pressure is reduced for the enlarged condenser model (SMCL). This decrease is more significant at the optimal and low subcooling. At $T_{w, c i}=50^{\circ} \mathrm{C}$, the condensing pressure at the optimal subcooling decreases below the corresponding experimental pressure for the SMS HP design. At lower $T_{w, c i}\left(10^{\circ} \mathrm{C}\right.$ and $\left.30^{\circ} \mathrm{C}\right)$, the condensing pressure at the optimal subcooling is still higher than the corresponding experimental pressure for the SMS heat pump design.

Table 6.2 shows the heating $\mathrm{COP}$, the heating capacity $\left(\mathrm{Q}_{\mathrm{h}}\right)$, the heat corresponding to the subcooling $\left(\mathrm{Q}_{\text {sub }}\right)$, the heat corresponding to condensing + desuperheat $\left(Q_{c}\right)$ and the compressor power input. These parameters are shown for the SMS heat pump prototype (experimental) and for the SMCL model (height of $0.59 \mathrm{~m}$ ) working at the optimal subcooling. The heating capacity is slightly higher for the SMCL model, while the compressor power input depends on the point.
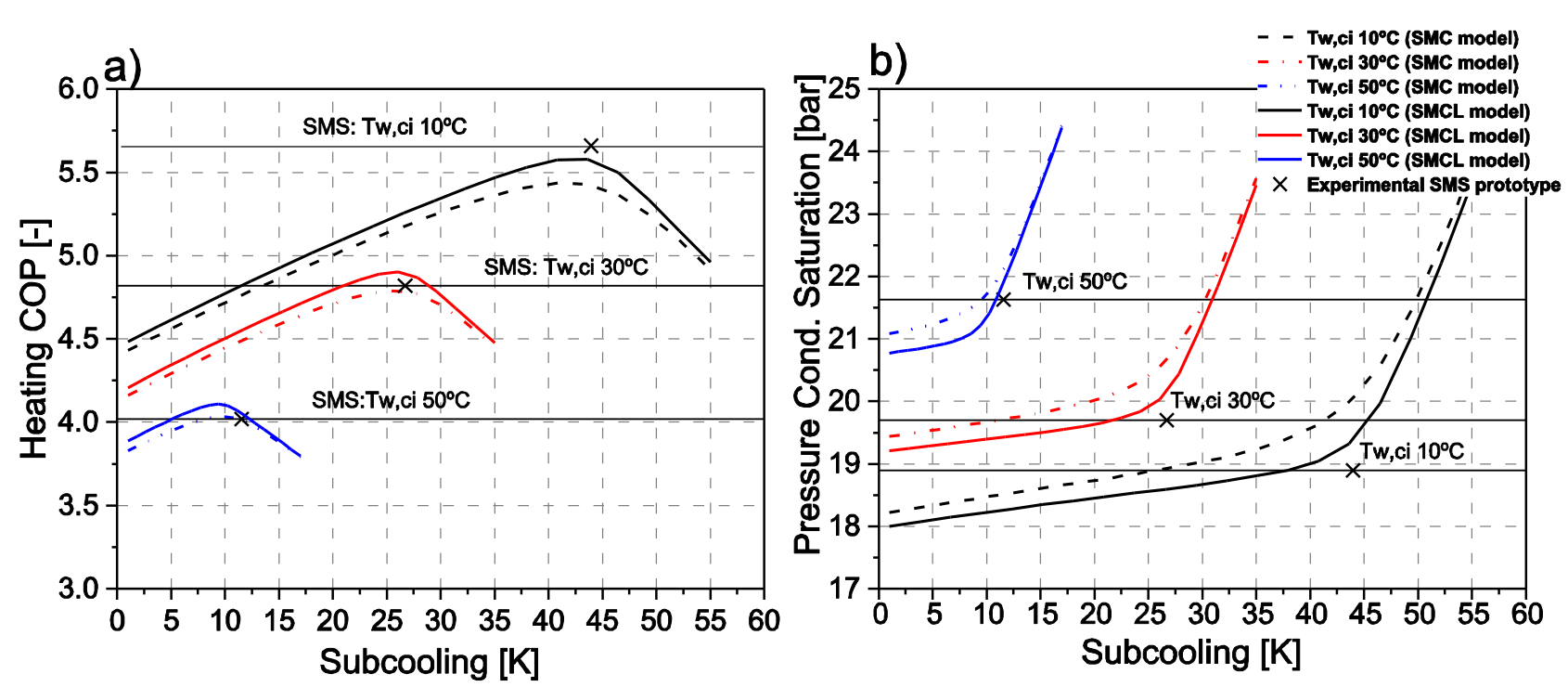

Figure 6.2: Results for two condenser height; a) heating COP, b) condensing pressure.

$$
\left(T_{w, e i}=20^{\circ} \mathrm{C}\right) \text {. }
$$


Table 6.2: Experimental SMS and SMCL model comparison at optimal subcooling.

$$
\left(T_{w, e i}=20^{\circ} \mathrm{C}\right)
$$

\begin{tabular}{|c|c|c|c|c|c|c|c|c|c|c|}
\hline & \multicolumn{5}{|c|}{ SMS Experimental } & \multicolumn{5}{|c|}{ SMCL Model } \\
\hline & $\mathrm{COP}_{\mathrm{h}}$ & $\begin{array}{c}\mathrm{Qh}_{\mathrm{h}} \\
{[\mathrm{kW}]}\end{array}$ & $\begin{array}{c}\mathrm{Q}_{\text {sub }} \\
{[\mathrm{kW}]}\end{array}$ & $\begin{array}{c}\mathrm{Q}_{\mathrm{c}} \\
{[\mathrm{kW}]}\end{array}$ & $\begin{array}{l}W_{\text {comp }} \\
{[\mathrm{kW}]}\end{array}$ & $\mathrm{COP}_{\mathrm{h}}$ & $\begin{array}{c}\mathrm{Qh}_{\mathrm{h}} \\
{[\mathrm{kW}]}\end{array}$ & $\begin{array}{c}Q_{\text {sub }} \\
{[\mathrm{kW}]}\end{array}$ & $\begin{array}{c}\mathrm{Q}_{\mathrm{c}} \\
{[\mathrm{kW}]}\end{array}$ & $\begin{array}{r}\mathrm{W}_{\text {comp }} \\
{[\mathrm{kW}]}\end{array}$ \\
\hline$T_{w, c i}=10^{\circ} \mathrm{C}$ & 5.66 & 45.72 & 12.07 & 33.65 & 8.08 & 5.58 & 46.15 & 12.47 & 33.68 & 8.26 \\
\hline$T_{w, c i}=30^{\circ} \mathrm{C}$ & 4.82 & 40.07 & 7.30 & 32.77 & 8.31 & 4.91 & 41.76 & 8.03 & 33.73 & 8.52 \\
\hline$T_{w, c i}=50^{\circ} \mathrm{C}$ & 4.00 & 35.95 & 3.26 & 32.68 & 8.98 & 4.11 & 36.53 & 3.15 & 33.38 & 8.89 \\
\hline
\end{tabular}

Figure 6.3 shows the condenser area dedicated for subcooling as a function of subcooling. Different water inlet temperatures to the condenser $\left(T_{w, c i}\right)$ are considered for the SMCL model. The subcooler area in the SMS design accounts for $20 \%$ of the total heat transfer area at the heat sink. The used area per subcooling degree depends strongly on the $T_{w, c i}$. For instance, the dedicated area to produce $15 \mathrm{~K}$ of subcooling goes from $5 \%$ to $65 \%$ for $T_{w, c i}=10^{\circ} \mathrm{C}$ and $T_{w, c i}=50^{\circ} \mathrm{C}$, respectively. Nevertheless, when the system works at optimal subcooling, the area dedicated to subcooling is lower as $T_{w, c i}$ increases. The dedicated area at optimum subcooling for $T_{w, c i}=10^{\circ} \mathrm{C}$ is $47 \%$, while it is $24 \%$ when $T_{w, c i}=50^{\circ} \mathrm{C}$. The SMCL model is using more heat transfer area for subcooling, even though the degree of subcooling (optimum point) is quite similar to the SMS design. This point could be related to the fact that the subcooler of the SMS system has been designed specifically for liquid refrigerant. Hence, the heat transfer during subcooling is expected to be higher in the subcooler, and less area would be required to produce the same subcooling.

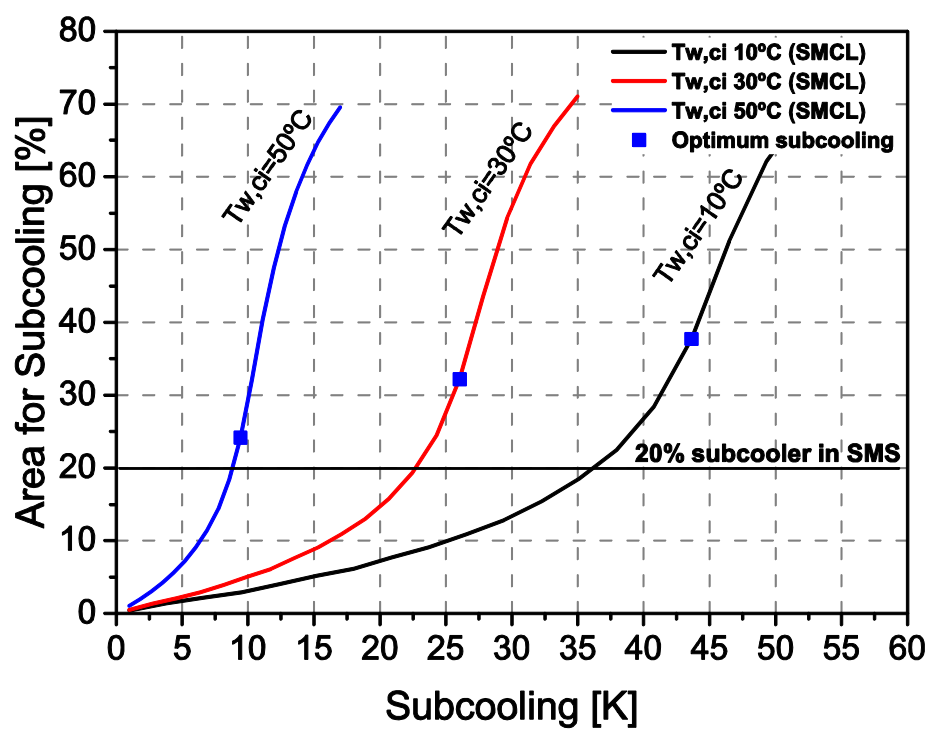

Figure 6.3: Percentage of the area dedicated for subcooling as a function of subcooling and $T_{w, c i}$ (SMCL and the fixed area for SMS). $\left(T_{w, e i}=20^{\circ} \mathrm{C}\right.$ ). 
Nevertheless, one should notice that the area used to produce subcooling is adjusted at each condition in the design making subcooling at the condenser, while the SMS design uses the same heat transfer area for all conditions. At some points, the subcooler could be oversized, and it would be better to use that heat transfer area in the condenser. On the other hand, at the SMCL system, the subcooling area is exactly the needed one at any point. Hence, at some conditions, the SMCL design could be using less area for subcooling than the SMS design.

Figure 6.4 shows the heating $\mathrm{COP}$ and the condensing pressure as a function of subcooling and the condenser size for the IMST-ART model (height of condenser). The inlet and outlet water temperature to the condenser are fixed at $30^{\circ} \mathrm{C}$ and $60^{\circ} \mathrm{C}$, respectively. For a constant condenser size, the COP increases with subcooling up to a maximum value. The optimal subcooling does not significantly depend on the condenser size. It is around $25 \mathrm{~K}$ for all condenser sizes and for the selected temperature lift. Condenser size has different trends depending on the degree of subcooling:

1) At low subcoolings, the COP increases slightly with the condenser size. Beyond a defined size, the increase in COP is insignificant.

2) At the optimum subcooling, the COP increases significantly with the condenser size. Although the degree of improvement is higher at smaller sizes, COP increased for the studied range of condenser sizes.

3) At high subcoolings, the COP increased at small condenser sizes, but after a certain point, condenser size had no effect on the COP.
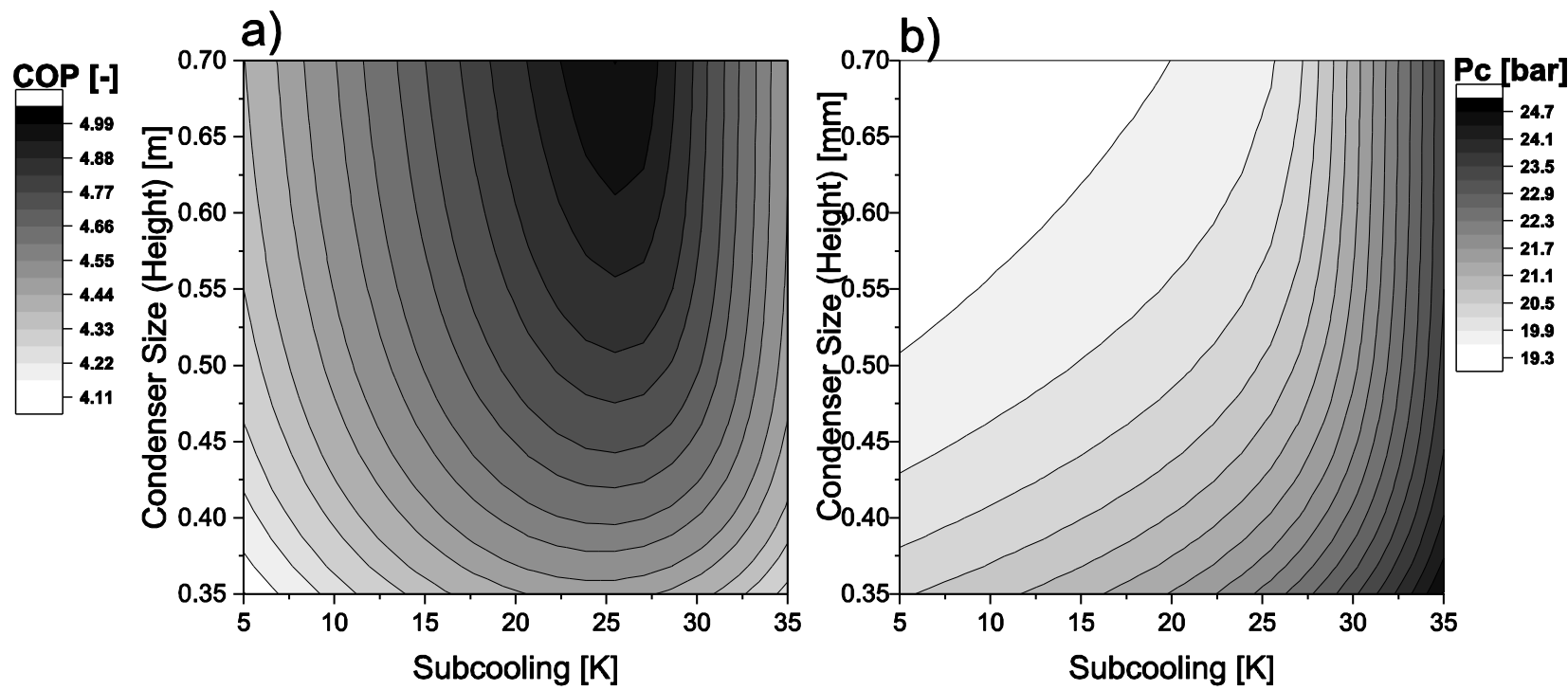

Figure 6.4: a) Heating COP and b) condensing pressure as a function of subcooling and condenser size $\left(T_{w, c i}=30^{\circ} \mathrm{C}, T_{w, c o}=60^{\circ} \mathrm{C}\right.$ and $\left.T_{w, e i}=20^{\circ} \mathrm{C}\right)$ 
Regarding the condensing pressure, it decreases with the condenser size for low and optimal subcooling, but at high subcooling, the condenser size had almost no effect on the condensing pressure.

Figure 6.5a) shows the condenser-dedicated area as a function of condenser size for three refrigerant phases: de-superheat, two-phase and subcooling. The dedicated area for de-superheat and subcooling decreases slightly with condenser size, by about $2 \%$ when going from a condenser height of $0.35 \mathrm{~m}$ to $0.7 \mathrm{~m}$. On the other hand, the dedicated area for the two-phase flow increases by $4 \%$. One should notice that, although the percentage of the dedicated area for subcooling decreases with size, the total area for subcooling increases. Figure 6.5b) shows the refrigerant and water temperature profile in the condenser for two different condenser sizes, $0.35 \mathrm{~m}$ and $0.70 \mathrm{~m}$. There is a better temperature match between the refrigerant and water at the bigger condenser.

From all these results, it can be concluded that, depending on the working conditions, the SMC design could obtain a better performance than the SMS due to the ability to adjust the area dedicated for subcooling at any point. Although, even if the heat pump producing subcooling at the condenser can adjust the heat transfer area for subcooling at any point, it needs more area for subcooling than the minimum required area for the SMS design due to the fact that the subcooler is optimized for liquid refrigerant.
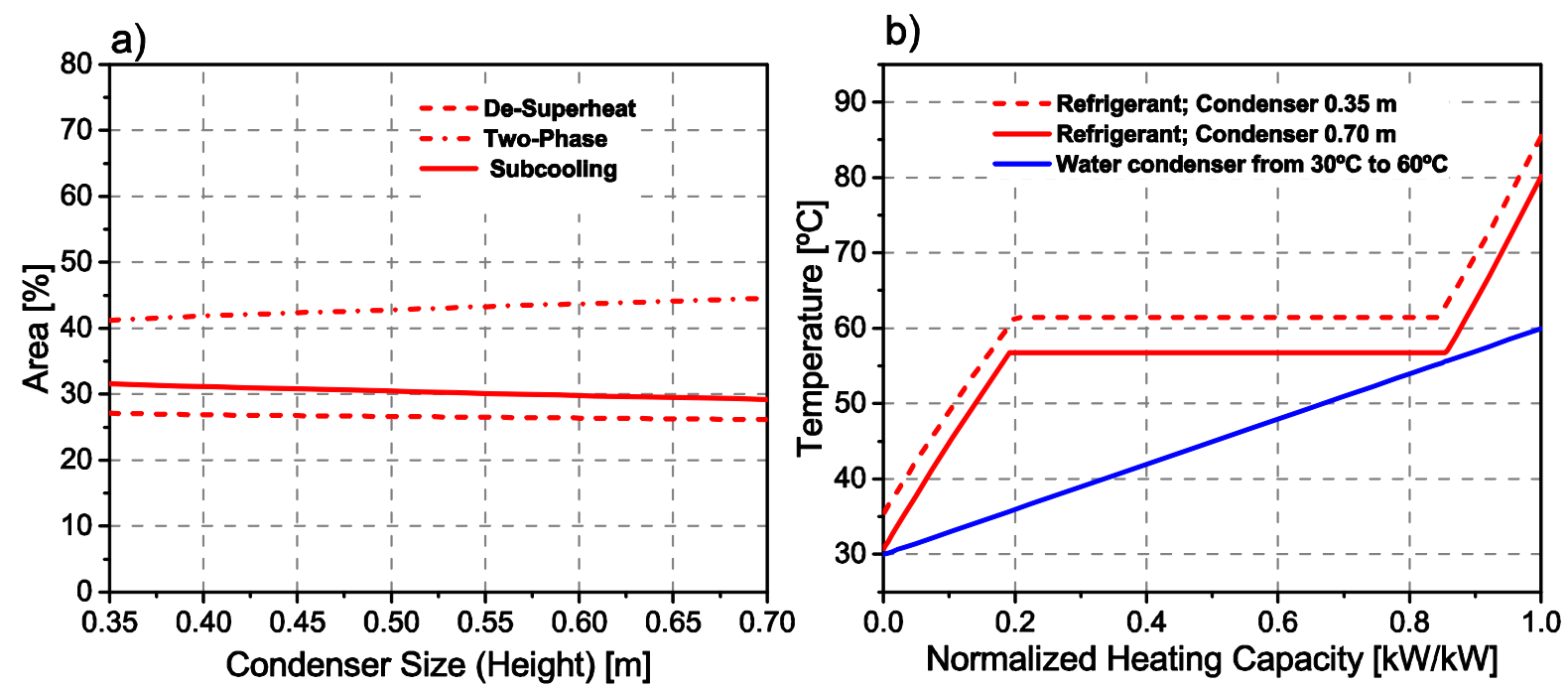

Figure 6.5: a) Condenser-dedicated area as a function of condenser size, b) refrigerant and water temperature profile in the condenser $\left(T_{w, c i}=30^{\circ} \mathrm{C}, T_{w, c o}=60^{\circ} \mathrm{C}\right.$ and $\left.T_{w, e i}=20^{\circ} \mathrm{C}\right)$. 
Furthermore, the SMC design has other disadvantages that need to be considered. As it was shown in section 5.1.2, the SMC design is not able to work at the optimum condition when the refrigerant outlet temperature at the condenser $\left(T_{w, c i}\right)$ is lower than the evaporating temperature, for instance, at the condition $T_{w, c i}=10^{\circ} \mathrm{C}$ and $T_{w, e i}=30^{\circ} \mathrm{C}$. At this point, the refrigerant temperature at the condenser outlet is limited by $T_{w, c i}$, which is the maximum possible evaporating temperature. The evaporating temperature at the expected optimal subcooling (43 $\mathrm{K})$ was around $12^{\circ} \mathrm{C}$. Therefore, at this point, the maximum evaporating pressure is lower than the corresponding one at $T_{w, e i}=30^{\circ} \mathrm{C}$ (expected evaporating temperature around $19^{\circ} \mathrm{C}$ ), leading to lower performance than expected by the boundary conditions.

Figure 6.6 shows this behavior in the experimental values, where the heating COP starts to decrease after $36 \mathrm{~K}$ of subcooling. For the case of the SMS design, the evaporating temperature is not limited, since the refrigerant can enter the evaporator in subcooled conditions (see section 5.2.2). Hence, in the case of working at high evaporating temperatures and high subcooling, the SMS design could be considered a better solution.

The limitation on the evaporating temperature is not captured by the SMC model, which has the optimum COP at $43 \mathrm{~K}$ of subcooling. The limitation on the evaporating temperature is a consequence of the liquid receiver arrangement, which is at the condenser outlet. Different heat pump concepts to control the subcooling in the condenser could be used in order to avoid the low evaporating pressure.

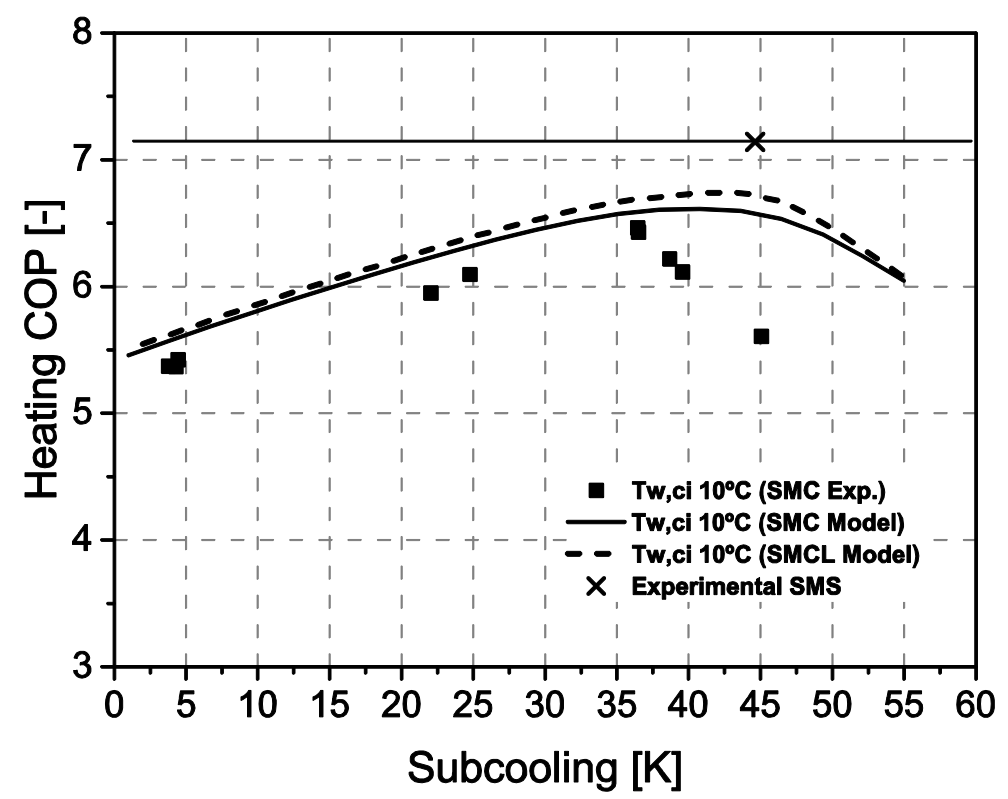

Figure 6.6: Heating COP as a function of subcooling for $T_{w, e i}=30^{\circ} \mathrm{C}$ and $T_{w, c i}=10^{\circ} \mathrm{C}$. 
One possibility, shown in Lihan (2014), is to place the liquid receiver at the evaporator outlet and to control the subcooling directly with the expansion valve. In this way, the evaporating pressure would not be limited by the refrigerant temperature at the condenser outlet. With this setup, superheat is not controlled, and subcooling depends on the pressure drop at the expansion valve.

Furthermore, this situation will be rare in practice, since a heat exchanger can be used to recover heat directly from the heat source $\left(T_{w, e i}\right)$ to the heat sink $\left(T_{w, c i}\right)$ before the heat pump. The author of this thesis has participated (not as the main author) in an article about this issue Hervas et al. (2017).

\subsection{Conclusions}

The main conclusions from the comparison in this chapter are:

- The heat pump producing subcooling at the condenser can obtain at least, a comparable heating COP than the heat pump with a separate subcooler, if the same heat transfer area is considered.

- The SMC design is able to optimize the heat transfer area for subcooling at any condition.

- The SMS design optimizes the heat transfer at the subcooler, but since the area is fixed, the subcooler could be oversized depending on the condition.

- The evaporating temperature is not limited for the SMS design when the refrigerant outlet temperature at the condenser $\left(T_{w, c i}\right)$ is lower than the evaporating temperature.

- SMCL has one less heat exchanger, but an additional electronic valve and a more sophisticated control algorithm than the SMS system.

- The obtained results have shown that in order to be able to reach the higher COPs obtained in this work, it is critical to dimensioning the condenser properly.

In order to choose between both systems, cost criteria should be the most important factor. From the point of view of energy efficiency, both systems have shown very competitive and close COP with only minor differences for some specific working conditions. 


\section{Chapter 7}

\section{General conclusions and future work}

\subsection{Conclusions}

In this thesis, the aim is to investigate the role of subcooling in the performance of a Propane water-to-water heat pump for SHW production, in the application of heat recovery from any water source.

The main objectives of this thesis (described in chapter 1 ) have been widely fulfilled:

1. A theoretical analysis investigating the role of subcooling in a subcritical heat pump was presented in chapter 2 .

2. Two different heat pump concepts (designs) working with propane and able to work efficiently with the theoretical optimal subcooling in the SHW application were designed and built (prototype chapter 3 ).

3. The two heat pumps concepts have been tested in a wide range of conditions for the SHW application (chapter 5).

4. The results obtained with the heat pump prototype have been analyzed. Both heat pump designs were fairly compared between them and with the commercial heat pump working with $\mathrm{CO}_{2}$, the Q-ton ${ }^{10}$. (chapter 5 and 6 )

Furthermore, in order to measure the heat pump prototype, a new test rig was designed and built in the laboratory (chapter 4).

10 The Q-ton information is taken from the catalogue data (Q-ton Catalogue data ESA30E-25) 
The following sections describe in more detail the main conclusions of the theoretical and experimental analysis carried out in this thesis.

\subsubsection{From the theoretical analysis}

- Theoretically, for the infinite heat transfer area assumption, the maximum COP is reached when two pinch points of $0 \mathrm{~K}$ between the refrigerant and the secondary fluid take place at the same time (optimal subcooling). One pinch point is at the condenser outlet, and the other at the refrigerant dew point. This has been proved in a wide range of applications and for four different refrigerants.

- The optimal subcooling mainly depends on the temperature difference between outlet and inlet of the secondary fluid. Therefore, a single control equation depending only on this temperature difference can be set for a wide range of applications. Optimal subcooling significantly varies depending on the secondary fluid temperature lift $\left(T_{w, c 0^{-}} T_{w, c i}\right)$. For the SHW application: $46 \mathrm{~K}$ at condition $\left(10^{\circ} \mathrm{C}\right.$ to $\left.60^{\circ} \mathrm{C}\right)$ and $8.8 \mathrm{~K}$ for $\left(50^{\circ} \mathrm{C}\right.$ to $\left.60^{\circ} \mathrm{C}\right)$ (Propane).

- Theoretically, for low inlet water temperatures $\left(T_{w, c i}=10^{\circ} \mathrm{C}\right)$ in the SHW application, the transcritical $\mathrm{CO}_{2}$ cycle has a slightly higher performance than the subcritical propane cycle. This situation is reversed for higher $T_{w, c i}$ $\left(>25^{\circ} \mathrm{C}\right)$.

\subsubsection{From the experimental results}

Two different heat pump designs were built and tested in order to take profit from the high-temperature lift of the heat sink in the SHW application: 1) Subcooling is made at the condenser (SMC design with active charge control). 2) Subcooling is made in a separate heat exchanger, the subcooler (SMS design). The main conclusions are:

- The results obtained with the SMC design proved that there is an optimal subcooling for each external condition. At the nominal condition $\left(T_{w, c i}=10^{\circ} \mathrm{C}\right.$, $T_{w, e i}=20^{\circ} \mathrm{C}$ ), performance is increased about $25 \%$ respect to the HP without subcooling.

- The optimal subcooling depends mainly on $T_{w, c i}\left(T_{w, c o}\right.$ is fixed to $\left.60^{\circ} \mathrm{C}\right)$. For instance, the optimal subcoolings are around $42 \mathrm{~K}$ and $11 \mathrm{~K}$ for a $T_{w, c i}$ of $10^{\circ} \mathrm{C}$ and $50^{\circ} \mathrm{C}$ respectively. 
- For subcoolings below the optimal, the condensing temperature slightly increases with subcooling. The condensing temperature considerably increases above the optimal subcooling.

- At the optimal subcooling, the refrigerant outlet temperature is close to the water inlet temperature. This temperature difference could be used as a control parameter.

- Due to the liquid receiver at the throttling valve outlet in the SMC design, COP is limited at high $T_{w, e i}$ and low $T_{w, c i}\left(T_{w, e i}=30^{\circ} \mathrm{C}\right.$ and $\left.T_{w, c i}=10^{\circ} \mathrm{C}\right)$. This limitation was not observed in the SMS design.

- The results with the SMS design were slightly higher than with SMC design. SMS design has 25\% more heat transfer area than SMC.

- The SMS design with the fixed area for subcooling is able to work at the optimal subcooling for all the external conditions.

- The Propane cycle working with a high degree of subcooling has demonstrated to be competitive with the transcritical $\mathrm{CO}_{2}$ heat pump for the SHW application (Q-ton ${ }^{11}$ ). Even to heat water up to $90^{\circ} \mathrm{C}$.

- The refrigerant quality at the evaporator inlet highly influences the refrigerant distribution in the evaporator. This could affect the control stability at low superheats.

The SMC design has been modeled in the commercial software IMST-ART in order to increase the condenser area and compare these results with the SMS design. Both systems have shown very competitive and close COP with only minor differences for some specific working conditions. The SMC design adjusts the heat transfer area dedicated to subcooling depending on the needs. The SMS design has a constant heat transfer area for all conditions, but the subcooler can be optimized for liquid refrigerant. Therefore, in order to choose between both systems, cost criteria should be the most important factor.

11 The Q-ton information is taken from the catalogue data (Q-ton Catalogue data ESA30E-25) 


\subsection{Future work}

The results obtained in this thesis encourage to continue working on the application of the subcritical propane cycle for the SHW production (or any application where subcooling would substantially increase performance).

\subsubsection{Integration in a real system}

The Ph.D. student Estefania Hervas recently started her doctoral thesis, which will continue the work done in this thesis to study the implementation of the propane heat pump working with subcooling in a real SHW system. I have participated (not as the main author) in the first article of this new thesis (Hervas et al., 2017). This article studies, from the economical point of view, the optimization of the heat pump size (for a given wastewater mass flow rate) and the relevance of a heat exchanger to recover the waste heat directly when $T_{w, e i}$ is higher than $T_{w, c i}$. The results confirm that the recovery heat exchanger installed before the heat pump is the best solution when $T_{w, e i}$ is higher than $T_{w, c i}$. Therefore, conditions like the ones showed in section 5.1.2, would be rare in real situations. Figure 7.1 shows the SMC heat pump system with the recovery heat exchanger. With this configuration, the temperatures at the condenser inlet and evaporator inlet will depend on the heat transfer at the recovery heat exchanger.

It would also be interesting to study the heat pump performance with the ambient air as a heat source.

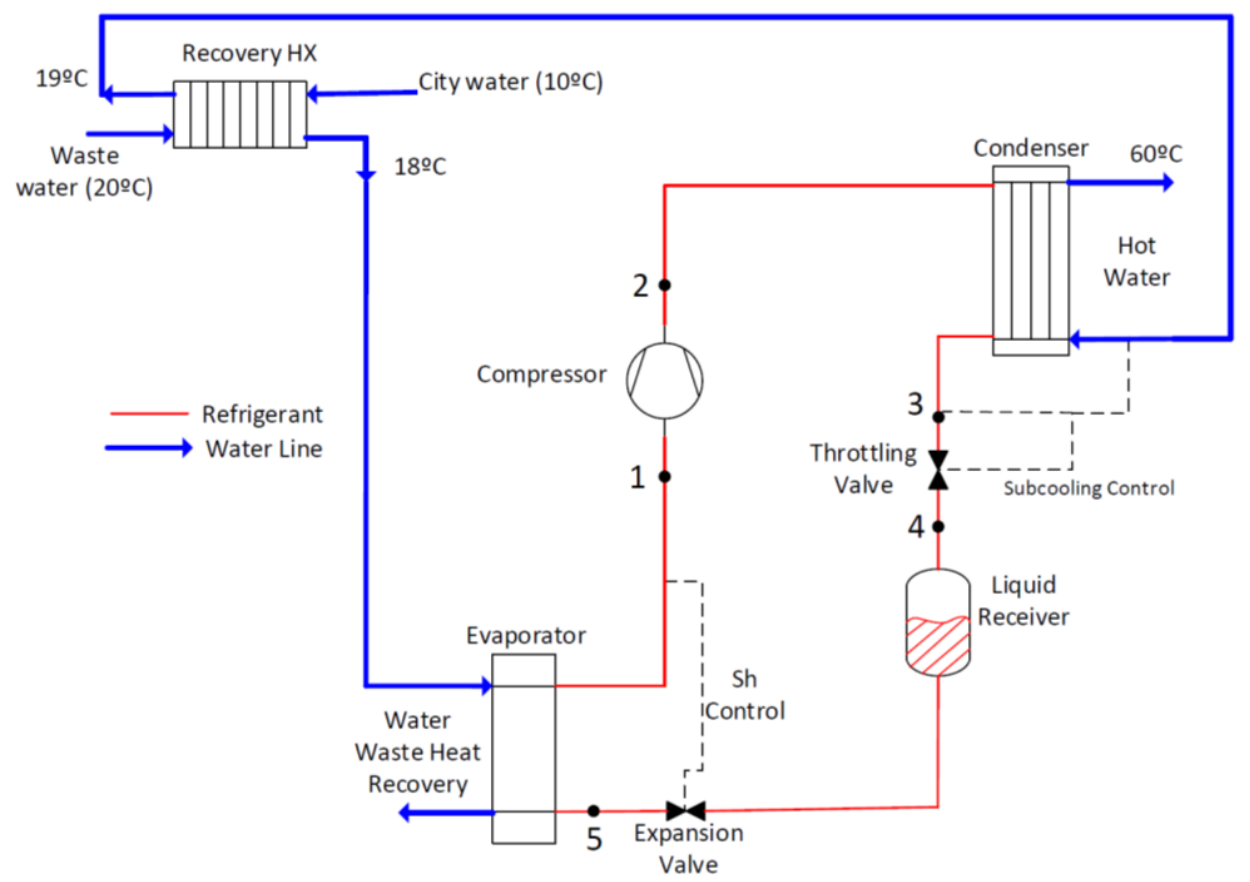

Figure 7.1: System layout of the heat pump with an additional recovery heat exchanger 


\subsubsection{Improvement of the heat pump design}

In this thesis, the control of the active charge in the system is done with the throttling valve. In this way, the subcooling is controlled independently of the superheat, which is controlled by the expansion valve. Due to the low-pressure drop required at high subcooling, in this prototype, two expansion valves were installed in parallel to increase crossflow area. If commercialized, this issue needs to be solved in a different way, for instance with a higher capacity expansion valve. It would also be interesting to test a different heat pump design, able to control the subcooling, but with only one expansion valve (without the throttling valve).

Figure 7.2 shows a heat pump system that controls subcooling with the expansion valve. This configuration is similar to the one used to control the rejection pressure in the transcritical $\mathrm{CO}_{2}$ systems. With this setup, superheat is not controlled, and subcooling depends on the pressure drop at the expansion valve. This system works well in the transcritical cycles, where there are large variations in the rejection pressure. In the subcritical system, a slight variation in the condensing pressure has a considerable effect on the subcooling. Therefore, the accuracy to work at the optimal subcooling needs to be tested.

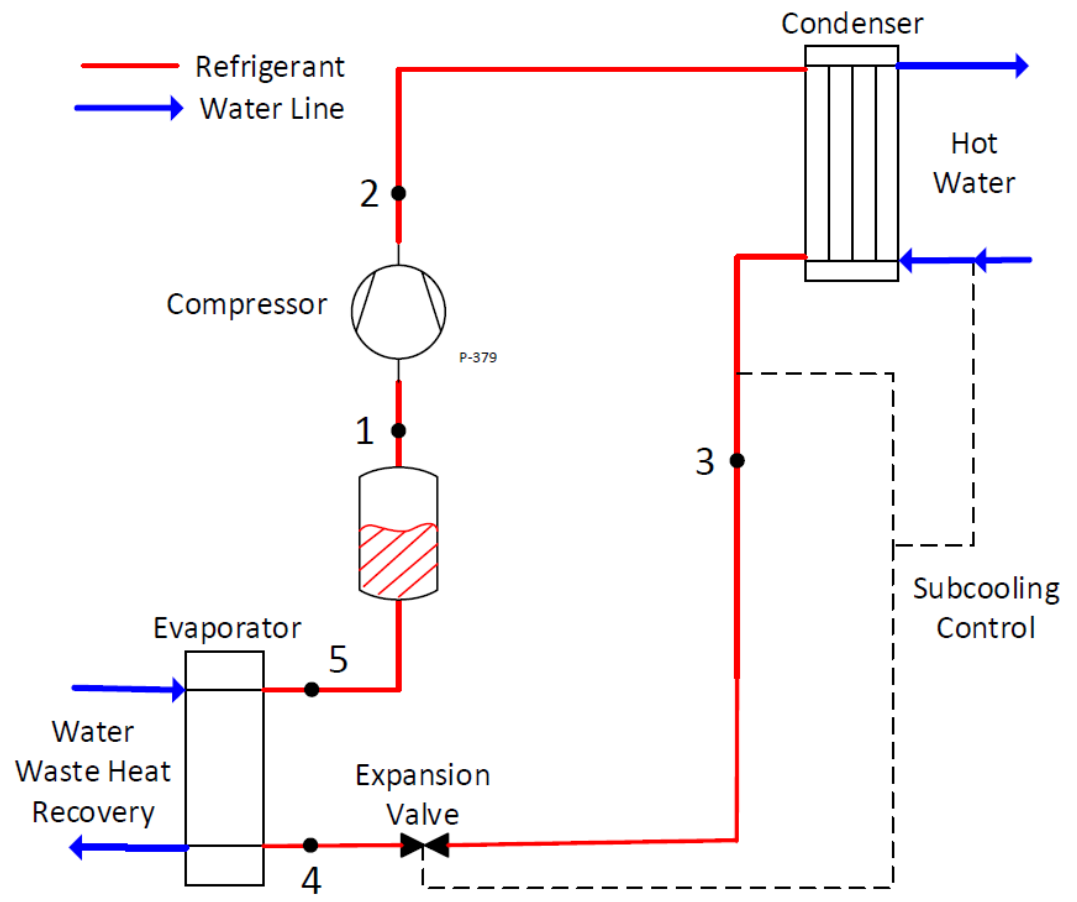

Figure 7.2: Heat Pump with subcooling controlled by the expansion valve. 
Subcooling has proved a high degree of improvement in the production of SHW. The degree of improvement is higher at low $T_{w, c i}$ Nevertheless, the chapter with the theoretical analysis showed that for low $T_{w, c i}\left(>25^{\circ} \mathrm{C}\right)$, the transcritical cycle working at the optimal rejection pressure had a higher performance than the subcritical propane cycle working at the optimal subcooling (under the assumptions considered). It would be interesting to make a systematic study of the heat pump components in order to see where the losses concentrate and see if there are room for improvement. 


\section{References}

Abraham, G.S., Ravikumar, A.S., Shah, R.K., 2006. Design considerations for an integral-receiver dryer condenser (No. 2006-01-0725). SAE Technical Paper.

Alnahhal, S., Spremberg, E., 2016. Contribution to Exemplary In-House Wastewater Heat Recovery in Berlin, Germany. Procedia CIRP, 40, 35-40.

Arias, J., Lundqvist, P., 2006. Heat recovery and floating condensing in supermarkets. Energy and Buildings 38(2), pp. 73-81.

ASHRAE, 2006. American Society of Heating, Refrigerating and Air-Conditioning Engineers. 2006 ASHRAE Handbook-Refrigeration. Atlanta.

ASHRAE, 2009. American Society of Heating, Refrigerating and Air-Conditioning Engineers. 2009 ASHRAE handbook: HVAC applications. Atlanta.

ASHRAE, 2013. American Society of Heating, Refrigerating and Air-Conditioning Engineers. 2013 ASHRAE Handbook-Fundamentals. Atlanta.

Baxter, V.D., 2003. IEA Annex 26: Advanced Supermarket Refrigeration/Heat Recovery Systems: Final Report Volume 1-Executive Summary. Boras, Sweden: IEA Heat Pump Centre

Buxton, G., 1988. The Montreal protocol on substances that deplete the ozone layer.

CADDET, 1997. (CADDET: the Centre for the Analysis and Dissemination of Demonstrated Energy Technologies), First DHC system in Japan using untreated sewage as a heat source, Result 290.

Cavallini, A., 1996. Working fluids for mechanical refrigeration. International Journal of Refrigeration, 19(8), 485-496.

Cecchinato, L., Corradi, M., Fornasieri, E., Zamboni, L., 2005. Carbon dioxide as refrigerant for tap water heat pumps: a comparison with the traditional solution. International Journal of Refrigeration 28(8), 1250-1258. 
Cecchinato, L., Corradi, M., Minetto, S., 2010. A critical approach to the determination of optimal heat rejection pressure in transcritical systems. Applied Thermal Engineering, 30(13), 1812-1823.

Çengel Y.A. and Boles M.A., 1998. Thermodynamics: An Engineering Approach. (3 $3^{\text {rd }}$ edition) McGraw-Hill, New York.

Chaichana, C., Ayea, L., Chartersb, W.W.S., 2003. Natural working fluids for solarboosted heat pumps. International Journal of Refrigeration 26, 637-643

Chen, Y., Gu, J., 2005. The optimum high pressure for $\mathrm{CO}_{2}$ transcritical refrigeration systems with internal heat exchangers. International Journal of Refrigeration 28(8), 1238-1249.

Choi, J.M., Kim, Y.C., 2004. Influence of the expansion device on the performance of a heat pump using $\mathrm{R} 407 \mathrm{C}$ under a range of charging conditions. International Journal of Refrigeration 27, 378-384

Corberán, J. M., Gonzálvez, J., Montes, P., Blasco, R., 2002. 'ART’a computer code to assist the design of refrigeration and $\mathrm{A} / \mathrm{C}$ equipment. In: International Refrigeration and Air Conditioning Conference (Purdue University). Paper 570.

Corberán, J.M., Martínez-Galván, I., Gonzálvez-Maciá, J., 2008. Charge optimization study of a reversible water-to-water propane heat pump. International Journal of Refrigeration 31, 716-726

Corberán, J.M., 2010. “Role, Sizing and Influence of the Liquid Receiver," in IIR 2nd workshop on Refrigerant Charge Reduction, no. 2006.

Corberán, J.M., Martínez-Galván, I., Martínez-Ballester, S., Gonzálvez-Maciá, J., Royo-Pastor, R., 2011. Influence of the source and sink temperatures on the optimal refrigerant charge of a water-to-water heat pump. International Journal of Refrigeration 34, 881-892

Dimplex, Commercial Heat Pump for SHW: http://www.dimplex.com/en/ (Last accessed: 27-12-2016)

DIN EN 14511-3, 2013. Air conditioners, liquid chilling packages and heat pumps with electrically driven compressors for space heating and cooling - Part 3: Test methods. 
Directive 2009/28/EC of the European Parliament and of the Council of 23 April 2009 on the promotion of the use of energy from renewable sources and amending and subsequently repealing Directives 2001/77/EC and 2003/30/EC.

ECO-CUTE project, Transcritical heat pump for SHW production http://www.r744.com/assets/link/enEX ecocute.pdf (Last acceded: 05-102016)

EN 378-1, 2008. European Standard: Refrigerating Systems and Heat Pumps Safety and Environmental Requirements. European Committee for Standardizations (CEN)

EN 14825, 2011. European standard: Air conditioners, liquid chilling packages and heat pumps, with electrically driven compressors, for space heating and cooling - Testing and rating at part load conditions and calculation of seasonal performance (2011). European Committee for Standardization (CEN)

Gosney, W.B., 1982. Principles of refrigeration. Cambridge University Press, 1982.

Granryd, E., 2001. Hydrocarbons as refrigerants-an overview. International journal of refrigeration, 24(1), 15-24.

Fernando P, Palm B, Lundqvist P, Granryd E. 2004. Propane heat pump with low refrigerant charge: design and laboratory tests. International Journal of Refrigeration 27 (7), 761-773.

Hasan, A.A., Goswami, D.Y., Vijayaraghavan, S., 2002. First and second law analysis of a new power and refrigeration thermodynamic cycle using a solar heat source. Solar Energy, 73(5), 385-393.

Hepbasli, A., Biyik, E., Ekren, O., Gunerhan, H., Araz, M., 2014. A key review of wastewater source heat pump (WWSHP) systems. Energy Conversion and Management, 88, 700-722

Hervas-Blasco, E., Pitarch, M., Navarro-Peris, E., Corberán, J.M., 2017. Optimal sizing of a heat pump booster for sanitary hot water production to maximize benefit for the substitution of gas boilers. Energy, 127, 558-570

Hjerkinn, T., 2007. Analysis of Heat Pump Water Heater Systems for Low-Energy Block of Flats (in Norwegian with English summary). Master thesis at the Norwegian University of Science and Technology (NTNU), Dept. of Energy and Process Engineering. EPT-M-2007-24 
IMST-ART v3.70: Simulation tool to assist the selection, design and optimization of refrigerator (v3.70), http://www.imstart.com. (Last accessed: 07-07-2016)

IEA, 2016. World Energy Balances - 2016 edition - excerpt - Key World Energy Trends. http://www.iea.org/ (Last accessed: 29-12-2016)

Inokuty, $\mathrm{H} ., 1928$. Graphical method of finding compression pressure of $\mathrm{CO}_{2}$ refrigerating machine for maximum coefficient of performance. In: Proceedings of the $5^{\text {th }}$ International Congress Refrigeration, Rome, pp. 185-192.

Itard, L.C.M., Machielsen, C.H.M., 1994. Considerations when modelling compression/resorption heat pumps. International journal of refrigeration, $17(7), 453-460$.

Jensen, J.B., Skogestad, S., 2007. Optimal operation of simple refrigeration cycles: Part I: Degrees of freedom and optimality of sub-cooling. Computers \& chemical engineering, 31(5), 712-721.

Kim, M., Kim, M.S. \& Chung, J.D., 2004. Transient thermal behavior of a water heater system driven by a heat pump. International Journal of Refrigeration, 27(4), 415-421.

Koeln, J.P., Alleyne, A.G., 2014. Optimal subcooling in vapor compression systems via extremum seeking control: Theory and experiments. International Journal of Refrigeration, 43, 14-25.

Law, R., Harvey, A., Reay, D., 2013. Opportunities for low-grade heat recovery in the UK food processing industry. Applied thermal engineering, 53(2), 188-196.

Lemmon, E. W., Huber, M. L., \& McLinden, M. O. 2007. REFPROP: Reference fluid thermodynamic and transport properties. NIST standard reference database, $23(8.0)$.

Li, M., Dang, C. \& Hihara, E., 2012. Flow boiling heat transfer of HF01234yf and R32 refrigerant mixtures in a smooth horizontal tube: Part I. Experimental investigation. International Journal of Heat and Mass Transfer, 55(13-14), 3437-3446.

Liao, S.M., Zhao, T.S., Jakobsen, A., 2000. A correlation of optimal heat rejection pressures in transcritical carbon dioxide cycles. Applied Thermal Engineering, 20(9), 831-841. 
Lihan X., 2014. Potential of controlling subcooling in residential Air conditioning system. Master's thesis, University of Illinois at Urbana-Champaign.

Liu, Z., Ma, L., Zhang, J., 2014. Application of a heat pump system using untreated urban sewage as a heat source. Applied Thermal Engineering, 62(2), 747-757.

Lorentzen, G., 1995. The use of natural refrigerants: a complete solution to the CFC/HCFC predicament. International Journal of Refrigeration, 18(3), pp.190197.

Marchese, J., 2014. The Role of the Liquid Receiver. Available at: http://www.achrnews.com/articles/128203-the-role-of-the-liquid-receiver (Last Accessed: 27-Nov-2015).

Midgley Jr, T., Henne, A.L., 1930. Organic Fluorides as Refrigerants. Industrial \& Engineering Chemistry, 22(5), 542-545.

Minea, V., 2006. Improved Supermarket Refrigeration and Heat Recovery System. ASHRAE transactions, 112(2), pp. 592-596

Minea, V., 2007. Supermarket Refrigeration System with Completely Secondary Loops. ASHRAE Journal 49(9), pp. 40-56.

Moffat, R.J., 1988. Describing the uncertainties in experimental results. Experimental thermal and fluid science, 1(1), 3-17.

Moran, M.J., Shapiro, H.N., 2004. Fundamentals of Engineering Thermodynamics (4th edition) John Wiley \& Sons, Inc., Hoboken (NJ), USA

Nekså, P., Rekstad, H., Zakeri, G.R., Schiefloe, P.A., 1998. CO2-heat pump water heater: characteristics, system design and experimental results. International Journal of Refrigeration 21(3), 172-179.

Nekså, P., 2002. $\mathrm{CO}_{2}$ heat pump systems. International Journal of Refrigeration 25 (4), 421-427

Nibe, Commercial Heat Pump for SHW: http://www.nibe.eu/ (Last accessed: 2712-2016)

NxtHPG, Next Generation of Heat Pumps working with Natural fluids. FP7-ENERGY project. Website of the project: http://www.nxthpg.eu/. (Last accessed: 20-112016). 
OSHA, 2016. Ocuppational Safety \& Health Administration (United Stats Department of Labor). Last acces 26-12-2016 https://www.osha.gov/dts/osta/otm/legionnaires/hotwater.html\#maintenan ce

Parrino, M., Dongiovanni, M., Milone, M., Chiara, M., 1999. Influence of Receiver Capacity on the Refrigerant Charge and on the Performance of an A/C System (No. 1999-01-0871). SAE Technical Paper.

Pitarch. M., Navarro-Peris. E., Gonzálvez-Maciá. J., Montagud. C., Corberan. JM., 2014. Influence of Water Lift Temperature in Transcritical and Subcritical Refrigerants. In: VII Congreso Ibérico de Ciencias y Técnicas del Frío, Tarragona, Spain.

Pitarch, M., Navarro-Peris, E., Gonzalvez, J., \& Corberan, J.M., 2016. Analysis and optimisation of different two-stage transcritical carbon dioxide cycles for heating applications. International Journal of Refrigeration, 70, 235-242.

Pitarch. M., Navarro-Peris. E., Gonzálvez-Maciá. J., López-Navarro, A., Corberan. JM., 2016. The importance of heat pump liquid receiver configuration on the impact during transient behavior. In: VII Congreso Ibérico de Ciencias y Técnicas del Frío, Coimbra, Portugal.

Pitarch, M., Hervas, E., Navarro-Peris, E., Gonzálvez-Maciá, J., 2017A. Evaluation of optimal subcooling in subcritical heat pump systems. International Journal of Refrigeration, 78, 18-31.

Pitarch, M., Navarro-Peris, E., Gonzálvez-Maciá, J., Corberan, J.M., $2017 \mathrm{~B}$. Experimental study of a heat pump with high subcooling in the condenser for sanitary hot water production. Science Technology for the Built Environment, 'Accepted'

Pitarch, M., Navarro-Peris, E., Gonzálvez-Maciá, J., Corberan, J.M., 2017C. Experimental study of a subcritical heat pump booster for sanitary hot water production using a subcooler in order to enhance the efficiency of the system with a natural refrigerant (R290). International Journal of Refrigeration, 73, 226-234. Doi: 10.1016/j.ijrefrig.2016.08.017.

Pitarch, M., Navarro-Peris, E., Gonzálvez-Maciá, J., Corberan, J.M., 2017D. Evaluation of different heat pump systems for sanitary hot water production using natural refrigerants. Applied Energy, 190, 911-919. 
Pottker, G., Hrnjak, P., 2015. Effect of the condenser subcooling on the performance of vapor compression systems. International Journal of Refrigeration, 50, 156164.

Q-ton Catalog data ESA30E-25, Commercial use Heat pump water heater Q-ton catalog data ESA30E-25, Mitsubishi Heavy Industries.

Quantum, Commercial Heat Pump for SHW: http://quantumenergy.com.au/ . (Last accessed: 15-11-2016)

Rajapaksha, L., Suen, K.O., 2004. Influence of liquid receiver on the performance of reversible heat pumps using refrigerant mixtures. International Journal of Refrigeration, 27(1), 53-62.

Redón, A., Navarro-Peris, E., Pitarch, M., Gonzálvez-Macia, J., \& Corberán, J.M., 2014. Analysis and optimization of subcritical two-stage vapor injection heat pump systems. Applied Energy, 124, 231-240.

Rieberer, R., Kasper, G., Halozan, J., 1997. $\mathrm{CO}_{2}$-a Chance for once through Heat Pump Heaters, $\mathrm{CO}_{2}$ Technology in Refrigeration, Heat Pumps and Air Conditioning Systems. IEA Heat Pump Centre, Trondheim, Norway.

Regulation (EU) No 517/2014 of the European Parliament and the Council of 16 April 2014 on fluorinated greenhouse gasses and repealing regulation (EC) No 842/2006. Off. J. Eur. Union 150, 2014, 195e230.

Riffat, S.B., Afonso, C.F., Oliveira, A.C., Reay, D.A., 1997. Natural refrigerants for refrigeration and air-conditioning systems. Applied Thermal Engineering, 17(1), $33-42$.

Sarkar, J., Bhattacharyya, S., Ram Gopal, M., 2004. Optimization of a transcritical $\mathrm{CO}_{2}$ heat pump cycle for simultaneous cooling and heating applications. International Journal of Refrigeration 27, 830-838.

Schmid, F., 2008. Sewage water: interesting heat source for heat pumps and chillers. In 9th International IEA Heat Pump Conference, Switzerland. Paper (No. 5.22, pp. 1-12).

Stene, J., 2004. Residential $\mathrm{CO}_{2}$ Heat Pump System for Combined Space Heating and Hot Water Heating. Doctoral thesis, NTNU - Norwegian University of Science and Technology 
Stene, J., 2005. Residential $\mathrm{CO}_{2}$ heat pump system for combined space heating and hot water heating. International Journal of Refrigeration, 28(8), 1259-1265.

Stoecker, W.F., 1998. Industrial refrigeration handbook. McGraw-Hill.

Tammaro, M., Montagud, C., Corberán, J.M., Mauro, A.W., Mastrullo, R., 2017. Seasonal performance assessment of sanitary hot water production systems using propane and CO 2 heat pumps. International Journal of Refrigeration, 74, 222-237.

$\mathrm{Xu}, \mathrm{L} ., 2$ 2014. Potential of controlling subcooling in residential Air conditioning system. Master thesis, University of Illinois at Urbana-Champaign

Yang, J.L., Ma, Y.T., Li, M.X., Guan, H.Q., 2005. Exergy analysis of transcritical carbon dioxide refrigeration cycle with an expander. Energy, 30(7), 1162-1175.

Yilmaz, M., 2003. Performance analysis of a vapor compression heat pump using zeotropic refrigerant mixtures. Energy conversion and Management, 44(2), 267282.

WBCS, 2009. World Business Council for Sustainable Development, 2009. Energy efficiency in Buildings. , F, p.261: http://www.wbcsd.org/ (Last accessed: 1502-2016) 


\section{Appendix A}

\section{The importance of heat pump liquid receiver configuration on the impact during transient behavior.}

Miquel Pitarch-Mocholí, Emilio Navarro-Peris, José Gonzalvez-Maciá, Alejandro López-Navarro, José Miguel Corberán

Paper presented at:

CYTEF 2016 - VIII Iberian Congress | VI Ibero-American Refrigeration Sciences and Technologies Coimbra-Portugal, 3-6 May 2016

\section{A.1 Abstract}

The liquid receiver (LR) is a common accessory in heat pumps and refrigeration systems. Not only to accommodate an excess of refrigerant to recover from losses along time, but also to control the active refrigerant charge in order to work with the optimal subcooling'. Nevertheless, in the scientific literature, not many authors have paid attention to the influence of liquid receiver characteristics on the system performance, and none of them has studied its influence during transient behavior due to changes in the operating conditions.

This work compares the effect of two different configurations designs of the inlet port for the liquid receiver experimentally. The differences are found in the shape of the inlet and outlet port inside the liquid receiver. The LR is installed in a heat pump for producing domestic hot water and working with propane, in such a systems the distribution of the charge is very important to obtain great performance. 
118 Appendix A The importance of heat pump liquid receiver configuration on the impact during transient behavior.

Results have shown that transient behavior differs highly depending on which LR configuration is used. For instance, the transient period last 35 minutes in one configuration, while in the other one takes less than 5 minutes.

\section{A.2 Introduction}

One of the main porpoises of the liquid receiver (LR) is to accommodate changes in the active charge (refrigerant charge) of the system due to variations in the operating conditions or in reversible systems. Hence, LR is essential in those systems where refrigerant charge changes considerably, and its performance depends strongly on the charge. Nevertheless, the role of this component has not been widely studied in the scientific literature. Most of the information about it can be found in refrigeration textbooks (Gosney, 1982), in a variety of sites on the internet (Marchese, 2014), manufacturers or distributors which give commercial information and installation guidelines, and technicians and installers forums, where the question about how to size and how to charge the LR appears time to time arising a good number of answers (Corberán, 2010). ASHRAE (2006) explains the two basic ways of installing a LR in a refrigeration unit, Through-Type, and Surge-Type (Figure A.1). The Through-Type LR is mounted in such a way that acts as a separator of the possible vapor coming from the condenser ensuring that the feeding of the expansion valve will be exempt of vapor bubbles. The Surge-Type installation, in contrast, allows the direct flow from the condenser to the expansion valve.

In the scientific literature, one of the sector that has put more attention into LRs is the automotive one. In this field, Parrino et al. (1999) described the need for the LR in the air conditioner equipment of cars and discussed in detail the procedure to find the optimum charge of a system, and Abraham et al. (2006) reviewed the evolution of the LR technology for the integration in the condenser. Other authors, such as Rajapksha and Suen (2004), studied by means of computer simulation the influence of the receiver on the circulating mixture composition and therefore on the performance of the unit for reversible systems. Finally, Corberán (2010) made an extensive study of the different LR designs (see Figure A.1), the connection to the system and its influence on refrigerant charge and system operation. 
a)

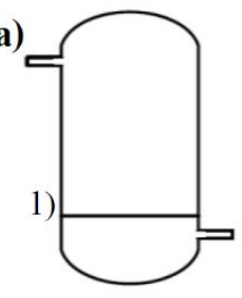

2)

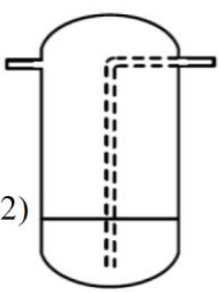

3)

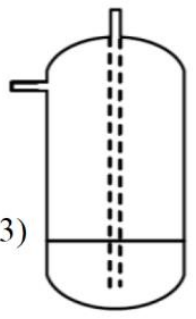

4)

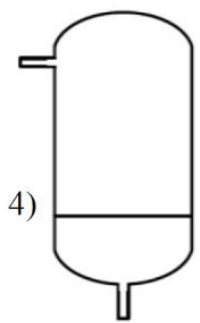

5)

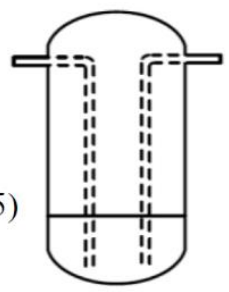

b)
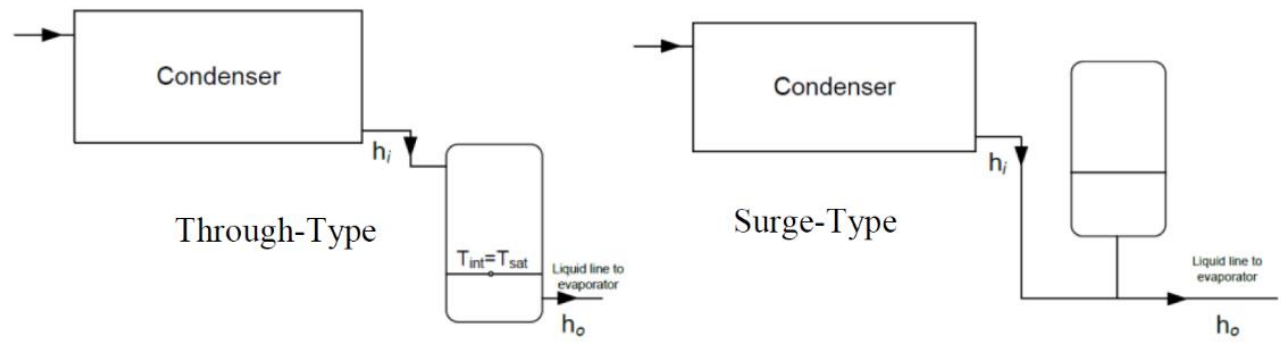

Figure A. 1: a) Typical combinations of inlet and outlet ports. b) Type of connection to the unit (Corberán, 2010).

Nevertheless, all the studies mentioned before concentrate on the steady state operation. As far of the knowledge of the authors, there is not any scientific study about the transient behavior of the LR when changing from one operating point to another.

This work has been done between the European Project Next Generation of Heat Pumps working with Natural fluids (NxtHPG), which dedicates one of the development tracks to the study of a propane heat pump booster for waste heat recovery trying to exploit the advantage of subcooling when there is a low inlet water temperature. In order to obtain the desired subcooling at each condition, the LR is essential in order to overcome the changes on refrigerant active charge.

This work presents an experimental study of two different inlet/outlet port configurations on the LR, focusing on the transient effect of different parameters, such as the subcooling, and its duration on time when the operation point of the heat pump changes.

\section{A.3 Experimental setup}

The LR is installed in a heat pump prototype working with Propane, which is able to produce domestic hot water at $60^{\circ} \mathrm{C}$. In order to study the influence of the water temperature lift with the performance of the heat pump, it is tested at different water inlet temperatures, inlet temperatures are in the range: $10^{\circ} \mathrm{C}$ to $55^{\circ} \mathrm{C}$. This variation in the water temperature influence significantly on the optimal 
120 Appendix A The importance of heat pump liquid receiver configuration on the impact during transient behavior.

subcooling, and hence on the needed active refrigerant charge, requiring a liquid receiver. The evaporator water temperature is kept constant to around $10^{\circ} \mathrm{C}$ with a superheat at the inlet of the compressor of $10 \mathrm{~K}$. A test rig built for this purpose can easily control all these parameters. The heating capacity is around $47 \mathrm{~kW}$ at the nominal point.

\section{A.3.1 Refrigerant cycle}

Figure A.2 shows the scheme of the water to water heat pump with subcooler. In this case, a liquid receiver located right after the condenser ensures that (at steady state conditions) the refrigerant leaves the condenser in liquid saturated state (point 3), so condenser is used mainly for condensation. The liquid receiver is large enough to fulfill this condition for all test conditions. Hence, for continuity the refrigerant leaves the liquid receiver near the saturation condition, the condenser saturation temperature, which value for this application is around $58^{\circ} \mathrm{C}$. Then a certain subcooling is reached after passing through the subcooler (point 4).

The large variations in subcooling influence the quality of refrigerant at the inlet of the evaporator, hence the evaporator accounts in large part to the changes of refrigerant charge needed on the system, and the liquid receiver has to be designed accordingly. One should notice that subcooling is filled with liquid refrigerant for all conditions, while the condenser it is expected to "never" be flooded with liquid refrigerant, leading to smaller variations in refrigerant charge compared to flooded condensers.
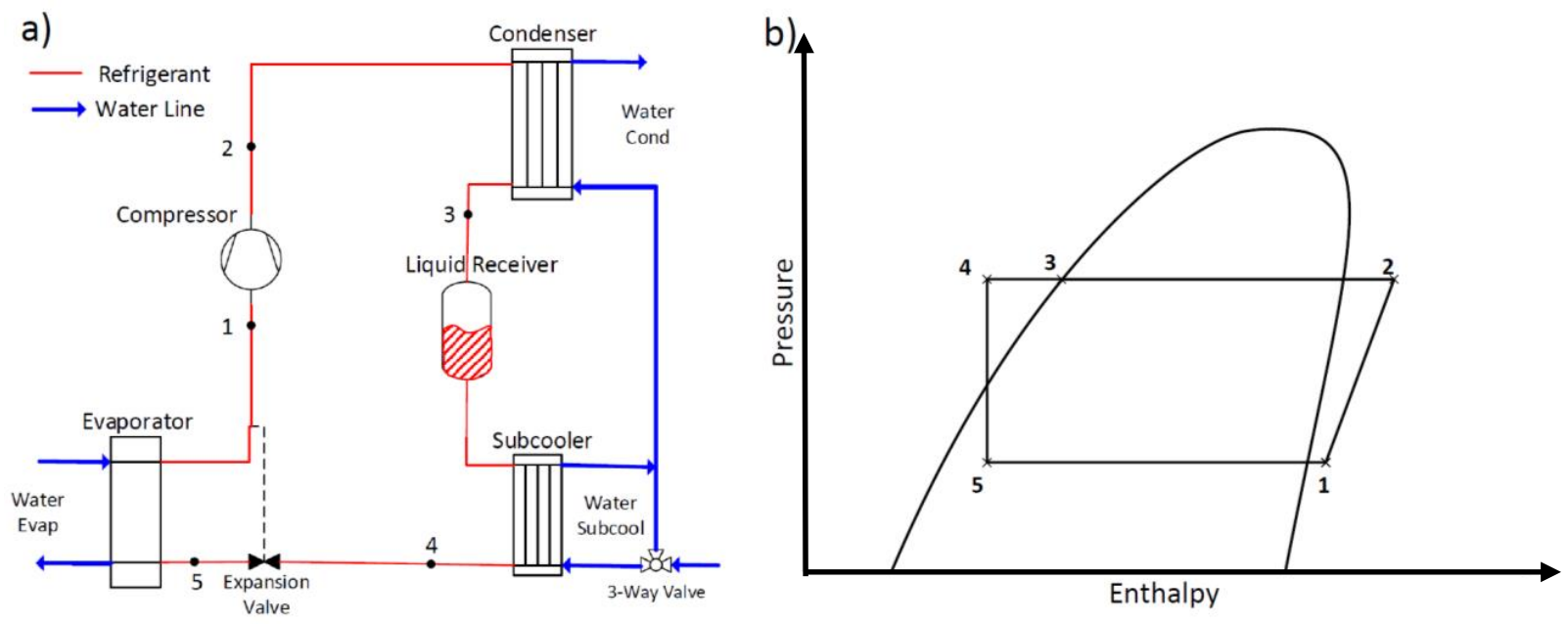

Figure A. 2: Subcooler in series with condenser a) Scheme, b) P-h diagram. 


\section{A.3.2 Liquid receiver design}

A liquid receiver was designed and built specially to allocate a liquid sensor capable of measuring the change of liquid level in the LR. This information is quite useful, not only for the refrigerant charge study but also to obtain a control algorithm depending on the charge of the system in order to work in the optimal subcooling (maximize COP).

Two different configurations of the inlet and the outlet ports were measured, although the main body of the LR was kept the same (Figure A.3). In order to avoid measurement perturbations from the refrigerant coming into the LR, the inlet and the outlet ports were located at the bottom of the LR. A similar port combination would be the number 5 from Figure A.1a). Regarding the type of connection to the unit, Corberán (2010) hypothesized that Surge-Type (Figure A.1b) could have some oscillation on condensation pressure since it will be more difficult for the LR to absorb small bubbles coming from the condenser. For this reason, in order to avoid the direct connection between the inlet and outlet refrigerant mass flow (similar to Surge-Type), at least one of the port ends in an elbow. The main differences between the two measured LR designs can be seen in Figure A.3

1) The inlet port ends in an elbow looking downwards and a straight port for the outlet.

2) The inlet port ends in an elbow looking upwards and an elbow looking downwards for the outlet port.
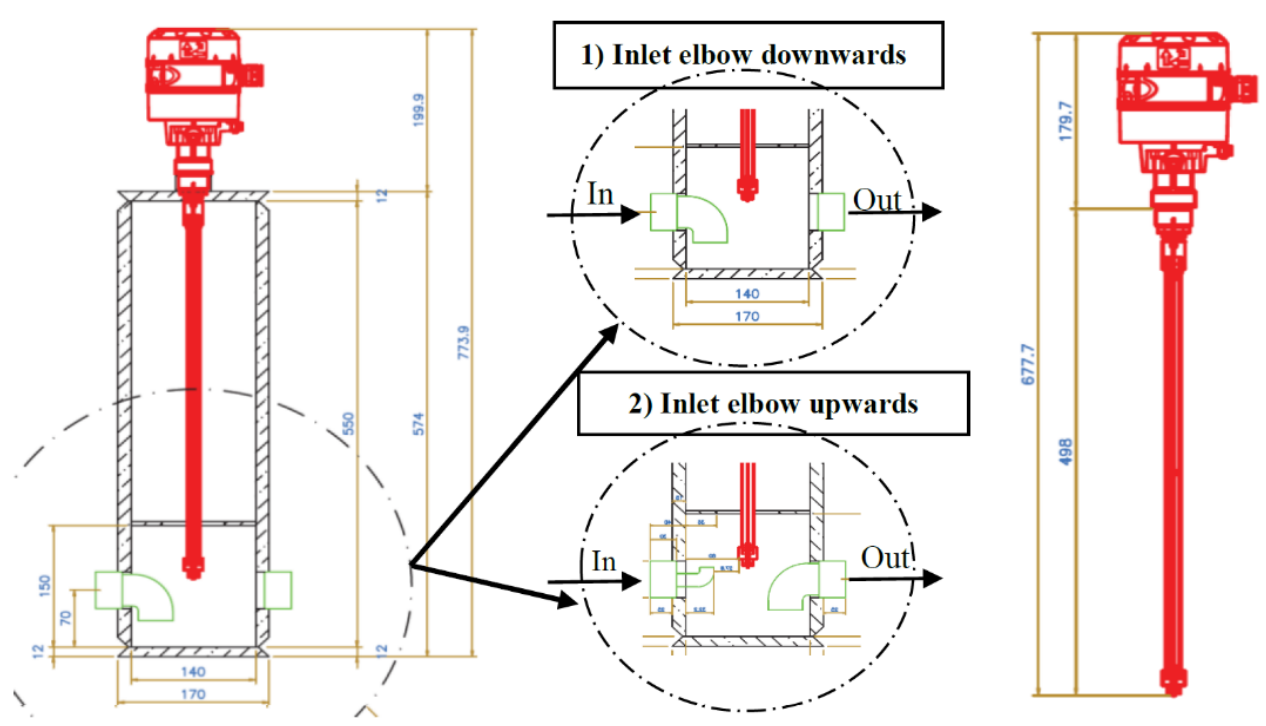

Figure A. 3: Scheme of the LR, the liquid sensor and a detail of the two port configurations. 
122 Appendix A The importance of heat pump liquid receiver configuration on the impact during transient behavior.

\section{A.3.3 Test procedure}

The main target of the experiments is to find the different transient behavior depending on the port design at the LR. For this porpoise, the following dynamic test has been elaborated: The heat pump is set to work steadily with inlet and outlet water temperature on the hot side of $30^{\circ} \mathrm{C}$ and $60^{\circ} \mathrm{C}$ respectively. Then, the inlet water temperature is set to $10^{\circ} \mathrm{C}$, and the main parameters are measured during the transient operation. The measurement finishes when the steady state condition is reached with the new water inlet temperature. The key parameters are:

- The liquid level of the LR, which indicates the refrigerants mass migration in the system.

- The subcooling at the outlet of the condenser, which indicates how much flooded it is.

- The total subcooling, this shows how is the subcooling share between condenser and subcooler. Moreover it is an indicator of how fast the target condition of $10^{\circ} \mathrm{C}$ for the inlet water temperature is reached.

These tests were performed with the two LR configurations.

\section{A.4 Results}

\section{A.4.1 Inlet elbow downwards}

This section contains the experimental results for the configuration where the inlet port is looking downwards and a straight port for the outlet. Figure A.4a) shows the liquid level as a function of time and Figure A.4b) shows the total degree of subcooling and the subcooling at the condenser as a function of time. It can be seen that at the beginning (inlet water temperature of $30^{\circ} \mathrm{C}$ ) the total subcooling is made at the subcooler since the subcooling at the condenser is close to zero as it is expected in steady state conditions. In the minute 15 , the change in the inlet water temperature occurs. From the total subcooling, it can be concluded that this temperature stabilized quite fast to the target temperature $\left(10^{\circ} \mathrm{C}\right)$ since it only takes few minutes to pass from $27 \mathrm{~K}$ to $42 \mathrm{~K}$. Nevertheless, during the first ten minutes, most of the subcooling is done in the condenser, and it takes around 35 minutes to go back to nearly zero subcooling at the condenser. This effect would be expected if the liquid receiver would be totally filled with liquid refrigerant. But, as it can be seen in Figure A.4a) this is not the situation. Instead, the liquid level at 
the receiver falls down quickly (below sensor limit) because the refrigerant charge is migrating to the condenser. As the subcooling at the condenser disappears, the liquid level at the LR increases until it stabilizes at a certain level lower than at the first operating condition.

One should notice that the main reason for the difference between the liquid levels at both operating conditions (in equilibrium) is due to refrigerant charge changes at the evaporator. The condenser has near zero subcooling in steady state and subcooler is always flooded with liquid, but the change on the total subcooling implies a variation in the refrigerant quality at the inlet of the evaporator, from 0.154 to 0.007 .

Therefore, in systems with a separate subcooler, where the condenser was designed to work without subcooling, this transient behavior could lead to a loss in performance. When subcooling is produced in the condenser, the condensing temperature tends to increase. Applications, where contour conditions (such as the inlet water temperature) can change frequently and have large variations in the subcooling, the use of this port configuration, would be inadequate.
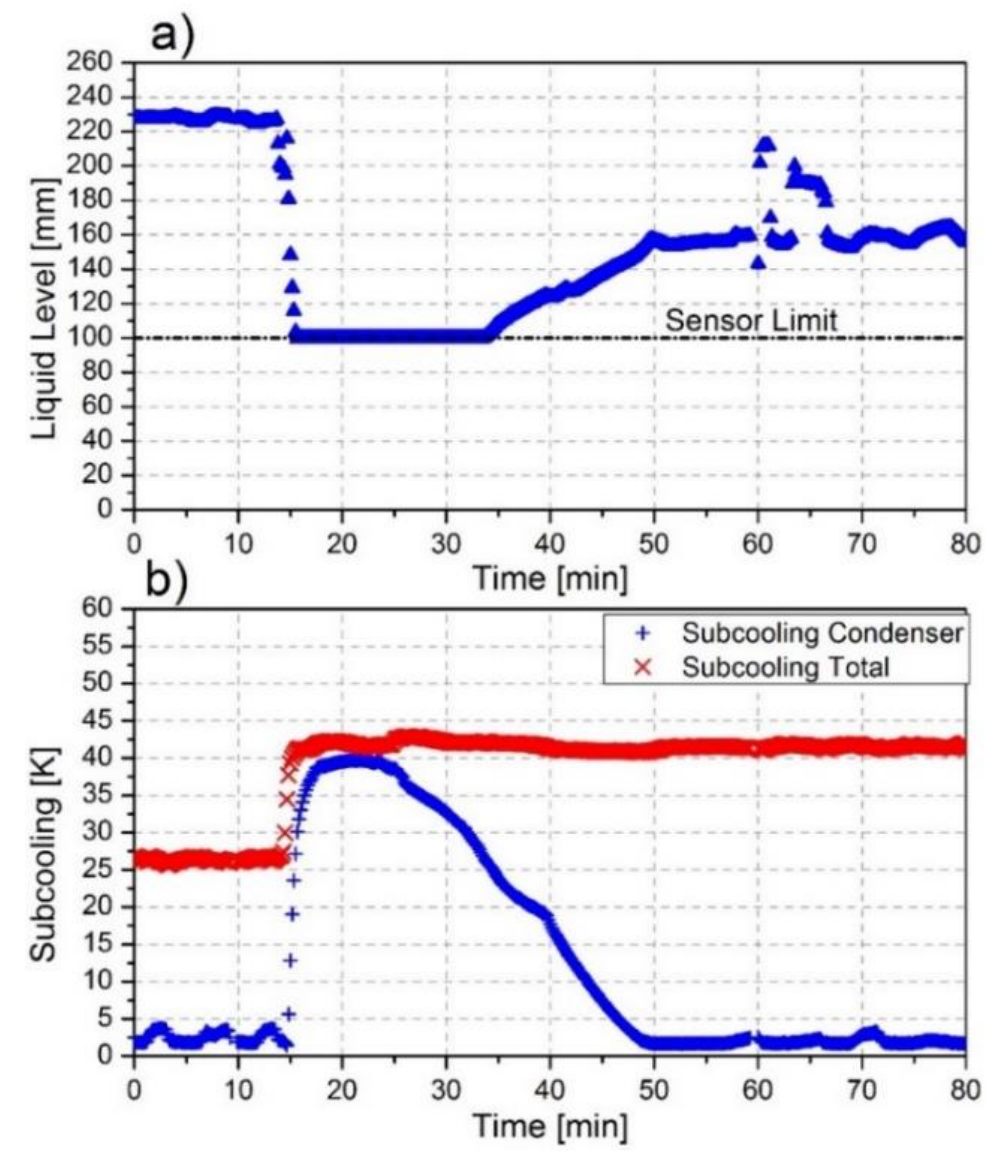

Figure A. 4: Transient behavior for inlet "elbow looking downwards" a) liquid level, b) Subcooling. 
124 Appendix A The importance of heat pump liquid receiver configuration on the impact during transient behavior.

A possible explanation would be that the inlet and outlet of the LR are "bypassed" and the LR is not able to absorb the bubbles coming from the condenser. In the beginning, when the refrigerant liquid starts to enter subcooled at the LR, the refrigerant temperature is stratified, and the temperature at the liquid-gas interface at the LR is still at the saturation temperature (Condenser pressure). Then, the gas in the LR starts to condensate, recovering the refrigerant charge from the condenser and decreasing the subcooling at the condenser. This situation continues until it gets to an equilibrium where the condenser has near zero subcooling. This behavior is similar to the one hypothesized by Corberán (2010) for the Surge-Type of connection.

\section{A.4.2 Inlet elbow upwards}

In this case, the inlet port ends in an elbow looking upwards and an elbow looking downwards for the outlet port. Figure A.5 shows that the transient behavior last less than 5 minutes and most of the subcooling is done is the subcooler at every moment. Now it seems that the refrigerant bubbles coming from the condenser are absorb easily in the LR. As in the previous experiment, the mean refrigerant level at the $L R$ has decreased, since the $10^{\circ} \mathrm{C}$ situation requires more active charge on the system than the water inlet temperature of $30^{\circ} \mathrm{C}$.
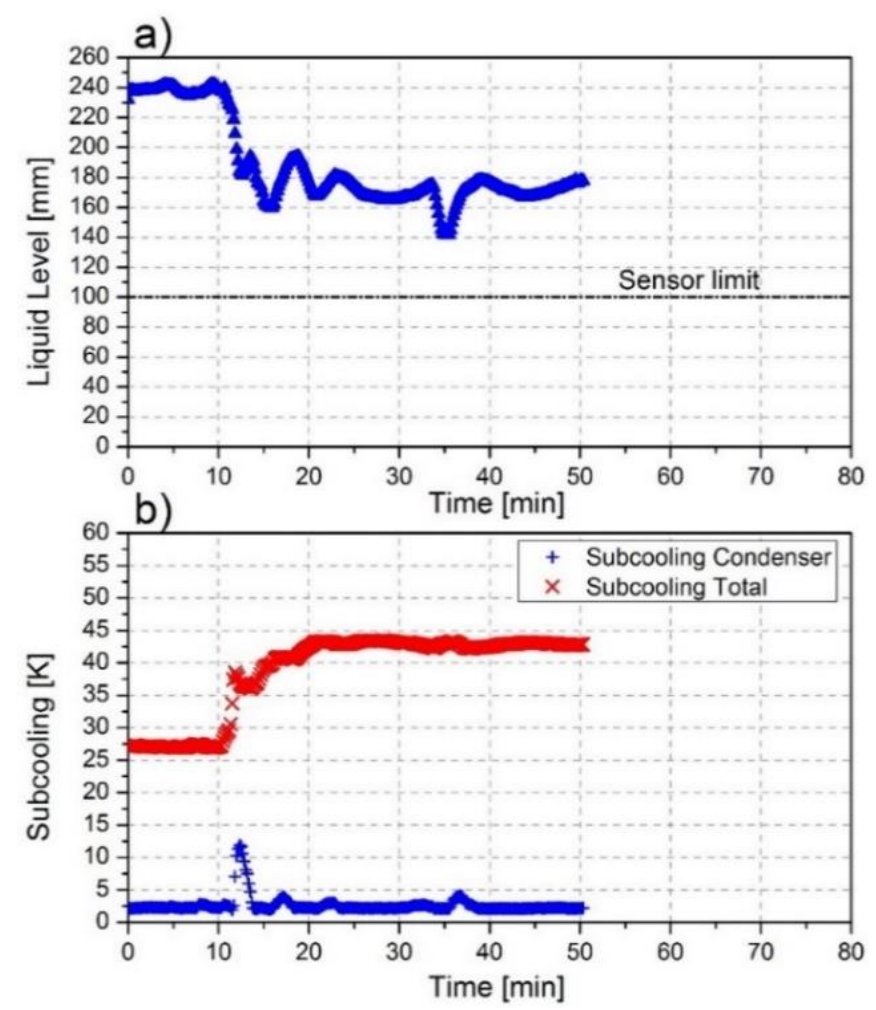

Figure A. 5: Transient behavior for "inlet elbow looking upwards" a) liquid level, b) Subcooling 
This could be explained due to the improvement of heat transfer inside of the LR. This time, the refrigerant coming from the condenser is flushed into the main volume of the LR. Even if the refrigerant is subcooled at the condenser due to any change in the operation, the subcooled refrigerant drops quickly interact with the hot refrigerant gas. This makes the gas to condensate much faster, recovering the refrigerant charge accumulated in the condenser.

This configuration is preferred, so the subcooling is controlled at any time.

\section{A.5 Conclusions}

It is important to size and to select the right liquid receiver in order to optimize charge on the system. Another important point is the design configuration, which greatly affects the transient behavior of the system when the operating condition is changed. The main conclusions for the two LR designs are:

1) The inlet port ends in an elbow looking downwards and a straight port for the outlet:

- After a change in the water inlet condition, the refrigerant migrates from the LR to the condenser. This produces subcooling in the condenser.

- During 10 minutes, most of the subcooling is done in the condenser instead of in the subcooler.

- It takes $\mathbf{3 5}$ minutes to the condenser to get back to equilibrium.

- Heat pump performance is loss due to an increase of the condensing pressure.

2) The inlet port ends in an elbow looking upwards and an elbow looking downwards for the outlet port:

- After a change in the water inlet condition, only a small part of subcooling is done in the condenser.

- It takes less than 5 minutes to the condenser to get back to equilibrium.

- This LR configuration is more appropriate for systems where contour conditions could change frequently and have large variations in the subcooling.

From all this experimental campaign, it has been demonstrated that the configuration of the ports of the LR is critical in order to have an appropriate response to this kind of heat pumps for sanitary hot water production. 



\section{Appendix B}

\section{Results and error analysis}

This appendix first presents the equations to calculate the heating COP and capacity accounting with the auxiliary consumption as it is indicated in EN 145113 "Test methods" (DIN EN 14511-3, 2013). Then the procedure to calculate the total uncertainty of the measured parameters and calculated variables is presented. Finally, two tables include the main parameters and its total uncertainty for all measured points.

All the physical properties of propane and water are calculated using the software REFPROP 9.0 (Lemmon et al., 2007)

\section{B.1 Auxiliary consumption}

The heating COP and the heating capacity for the heat pump can be calculated as the heating capacity divided by the compressor energy input:

$$
\begin{aligned}
& C O P_{h}=\frac{\dot{Q}_{h}}{\dot{W}_{c o m p}} \\
& \dot{Q}_{h}=\dot{m}_{w, c} \cdot{ }_{p, w} \cdot\left(T_{w, c o}-T_{w, c i}\right)
\end{aligned}
$$

Where $\dot{m}_{w, c}$ is the water mass flow rate through the condenser, and $c_{p, w}$ is the specific heat for the water. 
The auxiliary consumption of the water pumps to drive the water through the heat pump, can be added to the COP calculation as it is indicated in EN 14511-3 "Test methods" (DIN EN 14511-3, 2013) when the water pump is located outside the unit (as it is the case):

$$
C O P_{h, \text { aux }}=\frac{\dot{Q}_{h}+\dot{W}_{\text {aux }, c}}{\dot{W}_{\text {comp }}+\dot{W}_{\text {aux }, c}+\dot{W}_{\text {aux }, e}}
$$

$\dot{W}_{\text {aux }, c}$ accounts with the auxiliary consumption due to the condenser and subcooler ( $\mathrm{kW})$, and it is added to the heating capacity because part of this losses goes to the water that wants to be heated up. This term is also added to the compressor power input, together with the consumption due to the evaporator ( $\dot{W}_{\text {aux }, e}$ ).

The auxiliary consumption is calculated with the hydraulic power (due to pressure drop, in $\mathrm{kW}$ ) and a predefined pump efficiency defined by the norm:

$$
\dot{W}_{\text {aux }}=\frac{\dot{W}_{\text {hydraulic }}}{\eta_{\text {hydraulic }}}=\frac{\dot{W}_{\text {hydraulic }}}{0.0721 \cdot\left(\dot{W}_{\text {hydraulic }} \cdot 1000\right)^{0.3183}}
$$

The hydraulic power depends on the pressure drop (in $\mathrm{kPa}$ ) at the heat pump components and the volumetric mass flow rate (for water in this case, in $\mathrm{m}^{3} / \mathrm{s}$ ):

$$
\dot{W}_{\text {hydraulic }}=\Delta p \cdot \dot{V}_{w}
$$

One should notice that, if the heating COP is given with the auxiliary consumption, the heating capacity must also include the auxiliary of the condenser. Then the heating capacity accounting with auxiliary:

$$
Q_{h, a u x}=\dot{Q}_{h}+\dot{W}_{\text {aux }, c}
$$

In this thesis, all the experimental results account for the auxiliary consumption unless the contrary is indicated. Therefore, for simplicity, the heating COP and capacity are always named as $\mathrm{COP}_{\mathrm{h}}$ and $\mathrm{Q}_{\mathrm{h}}$. 


\section{B.2 Uncertainty}

Once the steady state is reached, the physical properties are measured during half an hour every ten seconds. The mean value of each variable is used for the calculations. The total uncertainties include the systematic uncertainty of the sensor, the acquisition data (data logger), and the standard deviation of the mean value, which was calculated from the measured sequence during 30 minutes. The method described by Moffat (1988) was used to calculate the uncertainties.

The uncertainty analysis for each of the measured variables is calculated as:

$$
U_{0.95}=\left\{\left(B_{X i}\right)^{2}+\left(t S_{\overline{X i}}\right)^{2}\right\}^{1 / 2}
$$

Where $B_{X i}$ is the systematic uncertainty of the sensor and the acquisition data (at $95 \%$ of confidence), $t$ is the Student's multiplier, which for $95 \%$ confidence and large sample data is equal to $1.96 . S_{\bar{X} i}$ is the sample standard deviation of the mean for the variable $\mathrm{X}$

$$
S_{\bar{X} i}=\frac{S_{X i}}{\sqrt{N}}
$$

Where $S_{X i}$ is the sample standard deviation and $N$ the number of observations at the test.

If the function $R$ is calculated from several independent variables $\left(\mathrm{X}_{\mathrm{i}}\right)$, the propagation error for the calculated parameters such as heating COP, the equation of propagating error is used.

$$
\delta R=\left\{\sum_{i=1}^{n}\left(\frac{\partial R}{\partial X_{i}} \delta X_{i}\right)^{2}\right\}^{1 / 2}
$$

For instance, in eq.B.2, the heating capacity would be the variable $\mathrm{R}$, while the water mass flow rate and temperatures would be the variables $\mathrm{X}_{\mathrm{i}}$, which have been measured directly with the Coriolis and the thermoresistances respectively. 


\section{B.3 Experimental results for the SMC design}

Table B. 1: Experimental results and uncertainties for the SMC design

\begin{tabular}{|c|c|c|c|c|c|c|c|c|c|c|c|}
\hline $\begin{array}{l}T_{w, e i} \\
{\left[{ }^{\circ} \mathrm{C}\right]}\end{array}$ & $\begin{array}{l}T_{w, c i} \\
{\left[{ }^{\circ} \mathrm{C}\right]}\end{array}$ & $\begin{array}{l}T_{w, c o} \\
{\left[{ }^{\circ} \mathrm{C}\right]}\end{array}$ & $\begin{array}{c}\mathbf{m}_{\mathrm{w}, \mathrm{e}} \\
{[\mathrm{kg} / \mathrm{h}]}\end{array}$ & $\begin{array}{c}\mathbf{m}_{\mathrm{w}, \mathrm{c}} \\
{[\mathrm{kg} / \mathrm{h}]}\end{array}$ & $\begin{array}{c}\mathbf{p}_{\mathbf{c}} \\
\text { [bar] }\end{array}$ & $\begin{array}{c}\mathbf{p}_{\text {LR }} \\
\text { [bar] }\end{array}$ & $\begin{array}{c}\text { Wc } \\
{[\mathrm{kW}]}\end{array}$ & $\begin{array}{c}\text { Tc } \\
{\left[{ }^{\circ} \mathrm{C}\right]}\end{array}$ & $\begin{array}{c}\text { Sc } \\
{[\mathrm{K}]}\end{array}$ & $\begin{array}{c}\mathrm{COP}_{\mathrm{h}} \\
{[-]}\end{array}$ & $\begin{array}{c}\mathbf{Q}_{\mathrm{h}} \\
{[\mathrm{kW}]}\end{array}$ \\
\hline 9.96 & 10.08 & 60.38 & 1.953 & 0.1244 & 17.70 & 17.13 & 7.61 & 51.51 & 1.5 & 3.38 & 26.155 \\
\hline \pm 0.08 & \pm 0.08 & \pm 0.09 & \pm 0.004 & \pm 0.0005 & \pm 0.05 & \pm 0.03 & \pm 0.05 & \pm 0.14 & \pm 0.2 & \pm 0.02 & \pm 0.007 \\
\hline 9.95 & 10.05 & 59.99 & 1.952 & 0.1412 & 17.97 & 12.60 & 7.70 & 52.22 & 15.7 & 3.76 & 29.477 \\
\hline \pm 0.08 & \pm 0.08 & \pm 0.08 & \pm 0.004 & \pm 0.0005 & \pm 0.05 & \pm 0.03 & \pm 0.05 & \pm 0.14 & \pm 0.2 & \pm 0.03 & \pm 0.007 \\
\hline 10.06 & 9.90 & 60.32 & 1.951 & 0.1571 & 18.52 & 8.84 & 7.76 & 53.63 & 31.5 & 4.19 & 33.113 \\
\hline \pm 0.08 & \pm 0.08 & \pm 0.09 & \pm 0.004 & \pm 0.0006 & \pm 0.05 & \pm 0.03 & \pm 0.05 & \pm 0.14 & \pm 0.2 & \pm 0.03 & \pm 0.009 \\
\hline 9.92 & 9.98 & 60.12 & 1.946 & 0.1613 & 18.62 & 7.88 & 7.81 & 53.88 & 36.2 & 4.25 & 33.802 \\
\hline \pm 0.08 & \pm 0.08 & \pm 0.1 & \pm 0.004 & \pm 0.0006 & \pm 0.06 & \pm 0.03 & \pm 0.05 & \pm 0.14 & \pm 0.2 & \pm 0.03 & \pm 0.009 \\
\hline 9.91 & 10.00 & 59.92 & 1.941 & 0.1691 & 19.52 & 6.77 & 8.08 & 56.10 & 44.1 & 4.29 & 35.287 \\
\hline \pm 0.08 & \pm 0.08 & \pm 0.09 & \pm 0.004 & \pm 0.0006 & \pm 0.05 & \pm 0.03 & \pm 0.05 & \pm 0.13 & \pm 0.2 & \pm 0.03 & \pm 0.009 \\
\hline 9.88 & 9.97 & 60.08 & 1.941 & 0.1706 & 21.05 & 6.66 & 8.52 & 59.73 & 48.3 & 4.12 & 35.722 \\
\hline \pm 0.08 & \pm 0.08 & \pm 0.09 & \pm 0.004 & \pm 0.0006 & \pm 0.06 & \pm 0.03 & \pm 0.05 & \pm 0.13 & \pm 0.2 & \pm 0.03 & \pm 0.009 \\
\hline 9.93 & 29.98 & 60.26 & 1.954 & 0.2075 & 19.05 & 18.46 & 7.89 & 54.94 & 1.44 & 3.27 & 26.267 \\
\hline \pm 0.08 & \pm 0.08 & \pm 0.08 & \pm 0.004 & \pm 0.0006 & \pm 0.05 & \pm 0.03 & \pm 0.05 & \pm 0.13 & \pm 0.15 & \pm 0.02 & \pm 0.006 \\
\hline 9.97 & 29.99 & 60.12 & 1.953 & 0.2191 & 19.17 & 16.78 & 7.93 & 55.24 & 6.12 & 3.42 & 27.601 \\
\hline \pm 0.08 & \pm 0.08 & \pm 0.08 & \pm 0.004 & \pm 0.0006 & \pm 0.05 & \pm 0.03 & \pm 0.05 & \pm 0.13 & \pm 0.15 & \pm 0.02 & \pm 0.006 \\
\hline 9.98 & 29.96 & 59.97 & 1.953 & 0.2355 & 19.32 & 14.11 & 8.01 & 55.62 & 14.2 & 3.62 & 29.536 \\
\hline \pm 0.08 & \pm 0.08 & \pm 0.08 & \pm 0.004 & \pm 0.0006 & \pm 0.05 & \pm 0.03 & \pm 0.05 & \pm 0.13 & \pm 0.2 & \pm 0.02 & \pm 0.007 \\
\hline 10.00 & 9.91 & & & & & & & 56.46 & & 3.78 & 31.142 \\
\hline \pm 0.08 & \pm 0.09 & \pm 0.08 & \pm 0.004 & \pm 0.0006 & \pm 0.05 & \pm 0.03 & \pm 0.05 & \pm 0.13 & \pm 0.2 & \pm 0.02 & \pm 0.008 \\
\hline 10.01 & 29.92 & 59.84 & 1.953 & 0.2524 & 19.94 & 11.21 & 8.18 & 57.12 & 25.5 & 3.79 & 31.555 \\
\hline \pm 0.08 & \pm 0.09 & \pm 0.09 & \pm 0.004 & \pm 0.0 & \pm 0.05 & \pm 0.03 & \pm 0.05 & \pm 0.13 & \pm 0.2 & \pm 0.02 & \pm 0.008 \\
\hline 10.00 & .93 & .92 & 953 & & 1.19 & 94 & 8.56 & 60.05 & 29.4 & 3.67 & 31.967 \\
\hline \pm 0.08 & \pm 0.09 & \pm 0.08 & \pm 0.004 & \pm 0.0006 & \pm 0.05 & \pm 0.03 & \pm 0.05 & \pm 0.12 & \pm 0.2 & \pm 0.02 & \pm 0.008 \\
\hline 10.00 & 30.10 & 60.22 & 1.952 & 0.2091 & 19.01 & 18.40 & 7.97 & 54.85 & 1.51 & 3.24 & 26.327 \\
\hline \pm 0.08 & \pm 0.08 & \pm 0.08 & \pm 0.004 & \pm 0.0006 & \pm 0.05 & \pm 0.03 & \pm 0.05 & \pm 0.13 & \pm 0.15 & \pm 0.02 & \pm 0.006 \\
\hline 9.91 & 30.02 & 59.95 & 1.951 & 0.22 & 19.13 & 15.65 & 8.02 & 55.15 & 9.2 & 3.46 & 28.261 \\
\hline \pm 0.08 & \pm 0.08 & \pm 0.08 & \pm 0.004 & \pm 0.0006 & \pm 0.05 & \pm 0.03 & \pm 0.05 & \pm 0.13 & \pm 0.2 & \pm 0.02 & \pm 0.006 \\
\hline 9.89 & 29.99 & 60.00 & 1.950 & 0.2442 & 19.53 & 12.13 & 8.14 & 56.13 & 21.2 & 3.70 & 30.640 \\
\hline \pm 0.08 & \pm 0.08 & \pm 0.08 & \pm 0.004 & \pm 0.0006 & \pm 0.05 & \pm 0.03 & \pm 0.05 & \pm 0.13 & \pm 0.2 & \pm 0.02 & \pm 0.007 \\
\hline 9.93 & 29.99 & 59.97 & 1.950 & 0.2498 & 20.05 & 11.13 & 8.29 & 57.38 & 26.1 & 3.71 & 31.305 \\
\hline \pm 0.08 & \pm 0.08 & \pm 0.09 & \pm 0.004 & \pm 0.0006 & \pm 0.05 & \pm 0.03 & \pm 0.05 & \pm 0.13 & \pm 0.2 & \pm 0.02 & \pm 0.008 \\
\hline 9.93 & 30.00 & 60.13 & 1.951 & 0.2532 & 22.14 & 10.94 & 8.92 & 62.20 & 31.6 & 3.52 & 31.882 \\
\hline \pm 0.08 & \pm 0.08 & \pm 0.08 & \pm 0.004 & \pm 0.0006 & \pm 0.05 & \pm 0.03 & \pm 0.05 & \pm 0.12 & \pm 0.2 & \pm 0.02 & \pm 0.008 \\
\hline 9.97 & 50.04 & 59.95 & 1.961 & 0.6263 & 21.07 & 20.51 & 8.48 & 59.78 & 1.29 & 3.00 & 25.95 \\
\hline \pm 0.08 & \pm 0.08 & \pm 0.08 & \pm 0.004 & \pm 0.0013 & \pm 0.05 & \pm 0.03 & \pm 0.05 & \pm 0.12 & \pm 0.14 & \pm 0.02 & \pm 0.03 \\
\hline 9.97 & 50.01 & 60.05 & 1.955 & 0.6359 & 21.18 & 19.55 & 8.54 & 60.03 & 3.77 & 3.07 & 26.71 \\
\hline \pm 0.08 & \pm 0.08 & \pm 0.08 & \pm 0.004 & \pm 0.0013 & \pm 0.05 & \pm 0.03 & \pm 0.05 & \pm 0.12 & \pm 0.14 & \pm 0.02 & \pm 0.03 \\
\hline
\end{tabular}




\begin{tabular}{|c|c|c|c|c|c|c|c|c|c|c|c|}
\hline $\begin{array}{l}T_{w, e i} \\
{\left[{ }^{\circ} \mathrm{C}\right]}\end{array}$ & $\begin{array}{l}T_{w, c i} \\
{\left[{ }^{\circ} \mathrm{C}\right]}\end{array}$ & $\begin{array}{l}T_{w, c o} \\
{\left[{ }^{\circ} \mathrm{C}\right]}\end{array}$ & $\begin{array}{c}\mathbf{m}_{\mathrm{w}, \mathrm{e}} \\
{[\mathrm{kg} / \mathrm{h}]}\end{array}$ & $\begin{array}{c}\mathbf{m}_{\mathrm{w}, \mathrm{c}} \\
{[\mathrm{kg} / \mathrm{h}]}\end{array}$ & $\begin{array}{c}\mathbf{p}_{\mathbf{c}} \\
\text { [bar] }\end{array}$ & $\begin{array}{c}\mathbf{p}_{\text {LR }} \\
\text { [bar] }\end{array}$ & $\begin{array}{c}\text { Wc } \\
{[\mathrm{kW}]}\end{array}$ & $\begin{array}{c}\text { Tc } \\
{\left[{ }^{\circ} \mathrm{C}\right]}\end{array}$ & $\begin{array}{c}\text { Sc } \\
{[K]}\end{array}$ & $\begin{array}{c}\mathrm{COP}_{h} \\
{[-]}\end{array}$ & $\begin{array}{c}\mathbf{Q}_{\mathrm{h}} \\
{[\mathrm{kW}]}\end{array}$ \\
\hline 9.97 & 49.96 & 60.14 & 1.955 & 0.6397 & 21.29 & 18.80 & 8.59 & 60.27 & 5.81 & 3.11 & 27.23 \\
\hline \pm 0.08 & \pm 0.08 & \pm 0.08 & \pm 0.004 & \pm 0.0013 & \pm 0.05 & \pm 0.03 & \pm 0.05 & \pm 0.12 & \pm 0.14 & \pm 0.02 & \pm 0.03 \\
\hline 9.99 & 49.95 & 60.06 & 1.954 & 0.6537 & 21.38 & 18.09 & 8.61 & 60.49 & 7.83 & 3.15 & 27.65 \\
\hline \pm 0.08 & \pm 0.08 & \pm 0.08 & \pm 0.004 & \pm 0.0014 & \pm 0.05 & \pm 0.03 & \pm 0.05 & \pm 0.12 & \pm 0.14 & \pm 0.02 & \pm 0.03 \\
\hline 9.99 & 49.98 & 60.11 & 1.954 & 0.6624 & 21.61 & 17.52 & 8.68 & 61.01 & 9.80 & 3.17 & 28.06 \\
\hline \pm 0.08 & \pm 0.08 & \pm 0.08 & \pm 0.004 & \pm 0.0014 & \pm 0.05 & \pm 0.03 & \pm 0.05 & \pm 0.12 & \pm 0.14 & \pm 0.02 & \pm 0.03 \\
\hline 9.99 & 49.96 & 60.02 & 1.954 & 0.6718 & 21.98 & 17.21 & 8.80 & 61.84 & 11.45 & 3.15 & 28.30 \\
\hline \pm 0.08 & \pm 0.08 & \pm 0.08 & \pm 0.004 & \pm 0.0014 & \pm 0.05 & \pm 0.03 & \pm 0.05 & \pm 0.12 & \pm 0.14 & \pm 0.02 & \pm 0.03 \\
\hline 9.93 & 50.12 & 60.02 & 1.951 & 0.6883 & 23.88 & 17.07 & 9.47 & 65.96 & 15.87 & 2.96 & 28.50 \\
\hline \pm 0.08 & \pm 0.08 & \pm 0.08 & \pm 0.004 & \pm 0.00 & \pm 0.05 & \pm 0.03 & \pm 0.05 & \pm 0.11 & \pm 0.13 & \pm 0.02 & \pm 0.03 \\
\hline 19.99 & 10.05 & 60.23 & 1.965 & 0.1670 & 18.17 & 17.20 & 8.02 & 52.73 & 2.5 & 4.29 & 35.021 \\
\hline \pm 0.08 & \pm 0.08 & \pm 0.09 & \pm 0.004 & \pm 0.0006 & \pm 0.05 & \pm 0.03 & \pm 0.05 & \pm 0.14 & \pm 0.2 & \pm 0.03 & \pm 0.009 \\
\hline 19.99 & 10.06 & 60.09 & 1.959 & 0.1979 & 18.76 & 10.45 & 8.18 & 54.23 & 25.5 & 4.97 & 41.381 \\
\hline \pm 0.08 & \pm 0.08 & \pm 0.09 & \pm 0.004 & \pm 0.00 & \pm 0.05 & \pm 0.03 & \pm 0.05 & \pm 0.13 & \pm 0.2 & \pm 0.03 & \pm 0.01 \\
\hline 20.08 & 9.98 & 60.05 & 1.921 & 0.2112 & 19.28 & 8.04 & 8.17 & 55.50 & 37.1 & 5.32 & 44.184 \\
\hline \pm 0.08 & \pm 0.08 & \pm 0.09 & \pm 0.004 & \pm 0.0006 & \pm 0.06 & \pm 0.03 & \pm 0.05 & \pm 0.14 & \pm 0.2 & \pm 0.03 & \pm 0.012 \\
\hline 20.03 & 10.01 & 60.05 & 1.942 & 0.2130 & 19.43 & 7.70 & 8.21 & 55.88 & 39.1 & 5.33 & 44.545 \\
\hline \pm 0.08 & \pm 0.08 & \pm 0.09 & \pm 0.004 & \pm 0.0006 & \pm 0.05 & \pm 0.03 & \pm 0.05 & \pm 0.13 & \pm 0.2 & \pm 0.03 & \pm 0.011 \\
\hline 19.99 & 10.08 & 59.95 & 1.936 & 0.2171 & 19.67 & 7.35 & 8.28 & 56.47 & 41.4 & 5.38 & 45.252 \\
\hline \pm 0.08 & \pm 0.08 & \pm 0.09 & \pm 0.004 & \pm 0.0006 & \pm 0.05 & \pm 0.03 & \pm 0.05 & \pm 0.13 & \pm 0.2 & \pm 0.03 & \pm 0.012 \\
\hline 20.07 & 9.98 & 60.00 & & & & & & & & 5.35 & 46.310 \\
\hline \pm 0.08 & \pm 0.08 & \pm 0.1 & \pm 0.004 & \pm 0.0006 & \pm 0.06 & \pm 0.03 & \pm 0.05 & \pm 0.13 & \pm 0.2 & \pm 0.03 & \pm 0.013 \\
\hline 20.09 & 10.00 & 60.00 & 1.959 & 0.2256 & 22.35 & 6.66 & 9.31 & 62.66 & 51.3 & 4.99 & 47.140 \\
\hline \pm 0.08 & \pm 0.08 & \pm 0.1 & \pm 0.004 & \pm 0.0006 & \pm 0.05 & \pm 0.03 & \pm 0.05 & \pm 0.12 & \pm 0.2 & \pm 0.03 & \pm 0.013 \\
\hline 19.88 & 9.88 & 0.21 & 1.945 & & 19.37 & 18.42 & 8.32 & 55.73 & 2.33 & 4.07 & 34.469 \\
\hline \pm 0.08 & \pm 0.09 & \pm 0.08 & \pm 0.004 & \pm 0.0007 & \pm 0.05 & \pm 0.03 & \pm 0.06 & \pm 0.13 & \pm 0.15 & \pm 0.03 & \pm 0.009 \\
\hline 19.87 & 29.96 & 59.84 & 1.944 & 0.2870 & 19.40 & 16.93 & 8.33 & 55.82 & 6.26 & 4.23 & 35.857 \\
\hline \pm 0.08 & \pm 0.08 & \pm 0.08 & \pm 0.004 & \pm 0.0008 & \pm 0.05 & \pm 0.03 & \pm 0.05 & \pm 0.13 & \pm 0.15 & \pm 0.03 & \pm 0.011 \\
\hline 19.93 & 29.99 & 60.24 & 1.942 & 0.3027 & 19.81 & 13.64 & 8.43 & 56.80 & 16.9 & 4.46 & 38.286 \\
\hline \pm 0.08 & \pm 0.09 & \pm 0.09 & \pm 0.004 & \pm 0.0008 & \pm 0.05 & \pm 0.03 & \pm 0.05 & \pm 0.13 & \pm 0.2 & \pm 0.03 & \pm 0.013 \\
\hline 20.08 & 30.06 & 60.15 & 1.937 & 0.3113 & 20.06 & 12.90 & 8.45 & 57.41 & 19.9 & 4.56 & 39.147 \\
\hline \pm 0.08 & \pm 0.09 & \pm 0.09 & \pm 0.004 & \pm 0.0008 & \pm 0.05 & \pm 0.03 & \pm 0.05 & \pm 0.13 & \pm 0.2 & \pm 0.03 & \pm 0.013 \\
\hline 20.08 & 30.07 & 59.98 & 1.936 & 0.3156 & 20.12 & 12.31 & 8.47 & 57.54 & 22.0 & 4.58 & 39.446 \\
\hline \pm 0.08 & \pm 0.08 & \pm 0.09 & \pm 0.004 & \pm 0.0008 & \pm 0.05 & \pm 0.03 & \pm 0.05 & \pm 0.13 & \pm 0.2 & \pm 0.03 & \pm 0.012 \\
\hline 20.02 & 30.25 & 60.50 & 1.933 & 0.3139 & 20.48 & 11.79 & 8.53 & 58.40 & 24.7 & 4.57 & 39.688 \\
\hline \pm 0.08 & \pm 0.08 & \pm 0.09 & \pm 0.004 & \pm 0.0008 & \pm 0.05 & \pm 0.03 & \pm 0.05 & \pm 0.13 & \pm 0.2 & \pm 0.03 & \pm 0.013 \\
\hline 19.93 & 30.00 & 59.89 & 1.940 & 0.3280 & 20.42 & 11.38 & 8.64 & 58.27 & 26.0 & 4.67 & 40.982 \\
\hline \pm 0.08 & \pm 0.08 & \pm 0.09 & \pm 0.004 & \pm 0.0008 & \pm 0.05 & \pm 0.03 & \pm 0.05 & \pm 0.13 & \pm 0.2 & \pm 0.03 & \pm 0.013 \\
\hline 19.88 & 29.97 & 59.88 & 1.951 & 0.3300 & 20.98 & 11.05 & 8.80 & 59.57 & 28.6 & 4.61 & 41.251 \\
\hline \pm 0.08 & \pm 0.08 & \pm 0.09 & \pm 0.004 & \pm 0.0008 & \pm 0.06 & \pm 0.03 & \pm 0.05 & \pm 0.13 & \pm 0.2 & \pm 0.03 & \pm 0.014 \\
\hline 19.89 & 30.01 & 59.87 & 1.951 & 0.3326 & 21.73 & 10.96 & 9.04 & 61.29 & 30.6 & 4.52 & 41.508 \\
\hline \pm 0.08 & \pm 0.08 & \pm 0.09 & \pm 0.004 & \pm 0.0008 & \pm 0.06 & \pm 0.03 & \pm 0.05 & \pm 0.13 & \pm 0.2 & \pm 0.03 & \pm 0.014 \\
\hline
\end{tabular}




\begin{tabular}{|c|c|c|c|c|c|c|c|c|c|c|c|}
\hline $\begin{array}{l}T_{w, e i} \\
{\left[{ }^{\circ} \mathrm{C}\right]}\end{array}$ & $\begin{array}{l}T_{w, c i} \\
{\left[{ }^{\circ} \mathrm{C}\right]}\end{array}$ & $\begin{array}{l}T_{w, c o} \\
{\left[{ }^{\circ} \mathrm{C}\right]}\end{array}$ & $\begin{array}{c}\mathbf{m}_{\mathrm{w}, \mathbf{e}} \\
{[\mathrm{kg} / \mathrm{h}]}\end{array}$ & $\begin{array}{c}\mathbf{m}_{\mathrm{w}, \mathrm{c}} \\
{[\mathrm{kg} / \mathrm{h}]}\end{array}$ & $\begin{array}{c}\mathbf{p}_{\mathbf{c}} \\
\text { [bar] }\end{array}$ & $\begin{array}{c}\mathbf{p}_{\text {LR }} \\
\text { [bar] }\end{array}$ & $\begin{array}{c}\text { Wc } \\
{[\mathrm{kW}]}\end{array}$ & $\begin{array}{c}\text { Tc } \\
{\left[{ }^{\circ} \mathrm{C}\right]}\end{array}$ & $\begin{array}{c}\text { Sc } \\
{[\mathrm{K}]}\end{array}$ & $\begin{array}{c}\mathrm{COP}_{\mathrm{h}} \\
{[-]}\end{array}$ & $\begin{array}{c}\mathbf{Q}_{\mathbf{h}} \\
{[\mathbf{k W}]}\end{array}$ \\
\hline 19.96 & 30.03 & 60.23 & 1.940 & 0.3333 & 23.61 & 10.92 & 9.61 & 65.39 & 34.8 & 4.31 & 42.078 \\
\hline \pm 0.08 & \pm 0.08 & \pm 0.09 & \pm 0.004 & \pm 0.0008 & \pm 0.06 & \pm 0.03 & \pm 0.05 & \pm 0.12 & \pm 0.2 & \pm 0.02 & \pm 0.014 \\
\hline 19.93 & 50.01 & 60.01 & 1.947 & 0.808 & 21.47 & 20.48 & 8.98 & 60.68 & 2.21 & 3.69 & 33.76 \\
\hline \pm 0.08 & \pm 0.08 & \pm 0.08 & \pm 0.004 & \pm 0.002 & \pm 0.05 & \pm 0.03 & \pm 0.06 & \pm 0.12 & \pm 0.13 & \pm 0.02 & \pm 0.05 \\
\hline 19.96 & 49.97 & 60.19 & 1.947 & 0.810 & 21.64 & 19.35 & 9.02 & 61.07 & 5.26 & 3.77 & 34.64 \\
\hline \pm 0.08 & \pm 0.08 & \pm 0.08 & \pm 0.004 & \pm 0.002 & \pm 0.05 & \pm 0.03 & \pm 0.06 & \pm 0.12 & \pm 0.14 & \pm 0.02 & \pm 0.05 \\
\hline 19.98 & 49.97 & 60.15 & 1.946 & 0.835 & 21.89 & 18.03 & 9.11 & 61.63 & 9.10 & 3.83 & 35.53 \\
\hline \pm 0.08 & \pm 0.08 & \pm 0.08 & \pm 0.004 & \pm 0.002 & \pm 0.05 & \pm 0.03 & \pm 0.06 & \pm 0.12 & \pm 0.14 & \pm 0.02 & \pm 0.05 \\
\hline 19.99 & 50.00 & 60.08 & 1.945 & 0.853 & 22.26 & 17.42 & 9.21 & 62.45 & 11.50 & 3.83 & 35.96 \\
\hline \pm 0.08 & \pm 0.08 & \pm 0.08 & \pm 0.004 & \pm 0.002 & \pm 0.05 & \pm 0.03 & \pm 0.05 & \pm 0.12 & \pm 0.14 & \pm 0.02 & \pm 0.05 \\
\hline 19.97 & 49.98 & 60.19 & 1.945 & 0.855 & 23.81 & 17.12 & 9.68 & 65.82 & 15.59 & 3.70 & 36.49 \\
\hline \pm 0.08 & \pm 0.08 & \pm 0.08 & \pm 0.004 & \pm 0.002 & \pm 0.05 & \pm 0.03 & \pm 0.05 & \pm 0.11 & \pm 0.13 & \pm 0.02 & \pm 0.05 \\
\hline 29.84 & 9.87 & 60.09 & 1.948 & 0.2162 & 18.40 & 16.97 & 8.44 & 53.31 & 3.7 & 5.29 & 45.371 \\
\hline \pm 0.08 & \pm 0.08 & \pm 0.08 & \pm 0.004 & \pm 0.0006 & \pm 0.05 & \pm 0.03 & \pm 0.05 & \pm 0.14 & \pm 0.2 & \pm 0.03 & \pm 0.011 \\
\hline 29.86 & 9.92 & 60.06 & 1.947 & 0.2170 & 18.37 & 16.75 & 8.47 & 53.24 & 4.2 & 5.28 & 45.462 \\
\hline \pm 0.08 & \pm 0.08 & \pm 0.09 & & \pm 0.0006 & \pm 0.05 & \pm 0.03 & \pm 0.05 & \pm 0.14 & \pm 0.2 & \pm 0.03 & \pm 0.012 \\
\hline 29.92 & 9.86 & 59.94 & 1.957 & 0.2193 & 18.34 & 16.66 & 8.47 & 53.17 & 4.4 & 5.33 & 45.908 \\
\hline \pm 0.08 & \pm 0.08 & \pm 0.09 & \pm 0.004 & \pm 0.0006 & \pm 0.05 & \pm 0.03 & \pm 0.05 & \pm 0.14 & \pm 0.2 & \pm 0.03 & \pm 0.012 \\
\hline 29.92 & 9.88 & 60.12 & 1.947 & 0.2441 & 18.94 & 11.50 & 8.61 & 54.67 & 22.0 & 5.85 & 51.26 \\
\hline \pm 0.08 & \pm 0.08 & \pm 0.11 & & & \pm 0.06 & \pm 0.03 & \pm 0.05 & \pm 0.14 & \pm 0.2 & \pm 0.04 & \pm 0.02 \\
\hline 29.87 & 9.77 & 59.93 & 1.971 & 0.2498 & 18.96 & 10.78 & 8.59 & 54.71 & 24.7 & 6.00 & 52.372 \\
\hline \pm 0.08 & \pm 0.08 & \pm 0.09 & \pm 0.004 & \pm 0.0007 & \pm 0.05 & \pm 0.03 & \pm 0.05 & \pm 0.13 & \pm 0.2 & \pm 0.04 & \pm 0.014 \\
\hline 29.90 & 9.88 & 59.86 & 1.944 & 0.2699 & 19.47 & 8.26 & 8.73 & 55.98 & 36.5 & 6.36 & 56.37 \\
\hline \pm 0.08 & \pm 0.08 & \pm 0.12 & \pm 0.004 & \pm 0.0007 & \pm 0.06 & \pm 0.03 & \pm 0.05 & \pm 0.15 & \pm 0.2 & \pm 0.04 & \pm 0.02 \\
\hline 29.84 & 9.81 & 60.23 & 1.965 & 0.2683 & 19.58 & 8.31 & 8.79 & 56.26 & 36.6 & 6.32 & 56.54 \\
\hline \pm 0.08 & \pm 0.08 & \pm 0.12 & \pm 0.004 & \pm 0.0007 & \pm 0.06 & \pm 0.03 & \pm 0.05 & \pm 0.15 & \pm 0.2 & \pm 0.04 & \pm 0.02 \\
\hline 29.83 & 9.83 & 59.90 & & & 19.30 & 7.70 & 8.61 & 55.57 & 38.8 & 6.12 & 53.55 \\
\hline \pm 0.08 & \pm 0.08 & \pm 0.11 & \pm 0.004 & \pm 0.0007 & \pm 0.06 & \pm 0.03 & \pm 0.05 & \pm 0.14 & \pm 0.2 & \pm 0.04 & \pm 0.02 \\
\hline 29.93 & 9.90 & 59.94 & 1.945 & 0.2523 & 19.35 & 7.54 & 8.63 & 55.68 & 39.7 & 6.02 & 52.76 \\
\hline \pm 0.08 & \pm 0.08 & \pm 0.11 & \pm 0.004 & \pm 0.0007 & \pm 0.06 & \pm 0.03 & \pm 0.05 & \pm 0.14 & \pm 0.2 & \pm 0.04 & \pm 0.02 \\
\hline 29.84 & 9.96 & 60.04 & 1.948 & 0.2337 & 20.04 & 6.79 & 8.72 & 57.37 & 45.2 & 5.52 & 48.908 \\
\hline \pm 0.08 & \pm 0.08 & \pm 0.1 & \pm 0.004 & \pm 0.0006 & \pm 0.05 & \pm 0.03 & \pm 0.05 & \pm 0.13 & \pm 0.2 & \pm 0.03 & \pm 0.014 \\
\hline 29.98 & 30.04 & 60.05 & 1.953 & 0.3597 & 19.68 & 18.08 & 8.82 & 56.48 & 3.91 & 5.03 & 45.129 \\
\hline \pm 0.08 & \pm 0.08 & \pm 0.08 & \pm 0.004 & \pm 0.0009 & \pm 0.05 & \pm 0.03 & \pm 0.05 & \pm 0.13 & \pm 0.14 & \pm 0.03 & \pm 0.014 \\
\hline 29.96 & 30.04 & 60.09 & 1.948 & 0.3997 & 20.20 & 13.63 & 8.96 & 57.75 & 17.83 & 5.51 & 50.21 \\
\hline \pm 0.08 & \pm 0.08 & \pm 0.08 & \pm 0.004 & \pm 0.0009 & \pm 0.05 & \pm 0.03 & \pm 0.05 & \pm 0.13 & \pm 0.15 & \pm 0.03 & \pm 0.02 \\
\hline 29.99 & 30.02 & 59.86 & 1.954 & 0.4214 & 20.78 & 11.53 & 9.16 & 59.11 & 26.3 & 5.65 & 52.55 \\
\hline \pm 0.08 & \pm 0.08 & \pm 0.08 & \pm 0.004 & \pm 0.0009 & \pm 0.05 & \pm 0.03 & \pm 0.05 & \pm 0.12 & \pm 0.2 & \pm 0.03 & \pm 0.02 \\
\hline 29.98 & 30.01 & 60.26 & 1.954 & 0.4220 & 21.74 & 11.12 & 9.46 & 61.30 & 30.0 & 5.55 & 53.37 \\
\hline \pm 0.08 & \pm 0.08 & \pm 0.08 & \pm 0.004 & \pm 0.001 & \pm 0.05 & \pm 0.03 & \pm 0.05 & \pm 0.12 & \pm 0.2 & \pm 0.03 & \pm 0.02 \\
\hline 30.00 & 30.00 & 60.13 & 1.954 & 0.4294 & 23.69 & 10.94 & 10.06 & 65.54 & 34.92 & 5.30 & 54.07 \\
\hline \pm 0.08 & \pm 0.08 & \pm 0.08 & \pm 0.004 & \pm 0.001 & \pm 0.05 & \pm 0.03 & \pm 0.05 & \pm 0.11 & \pm 0.15 & \pm 0.03 & \pm 0.02 \\
\hline
\end{tabular}




\begin{tabular}{|c|c|c|c|c|c|c|c|c|c|c|c|}
\hline $\begin{array}{c}\boldsymbol{T}_{w, e i} \\
{\left[{ }^{\circ} \mathbf{C}\right]}\end{array}$ & $\begin{array}{c}\boldsymbol{T}_{w, c i} \\
{\left[{ }^{\circ} \mathbf{C}\right]}\end{array}$ & $\begin{array}{c}\boldsymbol{T}_{w, c o} \\
{\left[{ }^{\circ} \mathbf{C}\right]}\end{array}$ & $\begin{array}{c}\mathbf{m}_{\mathrm{w}, \mathbf{e}} \\
{[\mathbf{k g} / \mathbf{h}]}\end{array}$ & $\begin{array}{c}\mathbf{m}_{\mathrm{w}, \mathbf{c}} \\
{[\mathbf{k g} / \mathbf{h}]}\end{array}$ & $\begin{array}{c}\mathbf{p}_{\mathbf{c}} \\
{[\mathbf{b a r}]}\end{array}$ & $\begin{array}{c}\mathbf{p}_{\mathbf{L R}} \\
{[\mathbf{b a r}]}\end{array}$ & $\begin{array}{c}\mathbf{W c} \\
{[\mathbf{k W}]}\end{array}$ & $\begin{array}{c}\mathbf{T c} \\
{\left[{ }^{\circ} \mathbf{C}\right]}\end{array}$ & $\begin{array}{c}\mathbf{S c} \\
{[\mathbf{K}]}\end{array}$ & $\begin{array}{c}\mathrm{COP}_{\mathrm{h}} \\
{[-]}\end{array}$ & $\begin{array}{c}\mathbf{Q}_{\mathbf{h}} \\
{[\mathbf{k W}]}\end{array}$ \\
\hline 29.98 & 50.27 & 59.94 & 1.956 & 1.081 & 21.80 & 20.22 & 9.48 & 61.45 & 3.56 & 4.51 & 43.76 \\
\pm 0.08 & \pm 0.08 & \pm 0.08 & \pm 0.004 & \pm 0.002 & \pm 0.05 & \pm 0.03 & \pm 0.05 & \pm 0.12 & \pm 0.13 & \pm 0.03 & \pm 0.08 \\
\hline 29.98 & 49.96 & 59.84 & 1.954 & 1.108 & 22.11 & 18.24 & 9.56 & 62.13 & 9.05 & 4.68 & 45.79 \\
\pm 0.08 & \pm 0.08 & \pm 0.08 & \pm 0.004 & \pm 0.002 & \pm 0.05 & \pm 0.03 & \pm 0.05 & \pm 0.12 & \pm 0.13 & \pm 0.03 & \pm 0.08 \\
\hline 29.97 & 49.95 & 60.01 & 1.954 & 1.108 & 22.91 & 17.32 & 9.80 & 63.88 & 13.16 & 4.65 & 46.63 \\
\pm 0.08 & \pm 0.08 & \pm 0.08 & \pm 0.004 & \pm 0.002 & \pm 0.05 & \pm 0.03 & \pm 0.05 & \pm 0.11 & \pm 0.13 & \pm 0.03 & \pm 0.08 \\
\hline
\end{tabular}




\section{B.4 Results for the SMS design}

Table B. 2: Experimental results and uncertainties for the SMS design

\begin{tabular}{|c|c|c|c|c|c|c|c|c|c|c|c|}
\hline $\begin{array}{l}T_{w, e i} \\
{\left[{ }^{\circ} \mathrm{C}\right]}\end{array}$ & $\begin{array}{l}T_{w, c i} \\
{\left[{ }^{\circ} \mathrm{C}\right]}\end{array}$ & $\begin{array}{l}T_{w, c o} \\
{\left[{ }^{\circ} \mathrm{C}\right]}\end{array}$ & $\begin{array}{c}\mathbf{m}_{\mathrm{w}, \mathrm{e}} \\
{[\mathrm{kg} / \mathrm{h}]}\end{array}$ & $\begin{array}{c}\mathbf{m}_{\mathrm{w}, \mathrm{c}} \\
{[\mathrm{kg} / \mathrm{h}]}\end{array}$ & $\begin{array}{c}\mathbf{p}_{\mathbf{c}} \\
\text { [bar] }\end{array}$ & $\begin{array}{c}\mathbf{p}_{\text {LR }} \\
\text { [bar] }\end{array}$ & $\begin{array}{c}\text { Wc } \\
{[\mathrm{kW}]}\end{array}$ & $\begin{array}{c}\text { Tc } \\
{\left[{ }^{\circ} \mathrm{C}\right]}\end{array}$ & $\begin{array}{l}\text { Sc } \\
{[\mathrm{K}]}\end{array}$ & $\begin{array}{c}\mathrm{COP}_{\mathrm{h}} \\
{[-]}\end{array}$ & $\begin{array}{c}\mathbf{Q}_{\mathrm{h}} \\
{[\mathrm{kW}]}\end{array}$ \\
\hline 10.00 & 9.01 & 65.33 & 1.937 & 0.1512 & 20.06 & 19.93 & 8.26 & 57.40 & 48 & 4.24 & 35.595 \\
\hline \pm 0.08 & \pm 0.08 & \pm 0.1 & \pm 0.004 & \pm 0.0005 & \pm 0.06 & \pm 0.03 & \pm 0.13 & \pm 0.13 & \pm 1 & \pm 0.06 & \pm 0.01 \\
\hline 9.84 & 9.95 & 54.77 & 1.937 & 0.1866 & 16.81 & 16.66 & 7.31 & 49.13 & 39 & 4.69 & 34.956 \\
\hline \pm 0.08 & \pm 0.08 & \pm 0.09 & \pm 0.004 & \pm 0.0006 & \pm 0.05 & \pm 0.03 & \pm 0.11 & \pm 0.15 & \pm 1 & \pm 0.07 & \pm 0.008 \\
\hline 9.90 & 9.94 & 59.88 & 1.937 & 0.1698 & 18.40 & 18.26 & 7.78 & 53.31 & 43 & 4.47 & 35.439 \\
\hline \pm 0.08 & \pm 0.08 & \pm 0.09 & \pm 0.004 & \pm 0.0006 & \pm 0.05 & \pm 0.03 & \pm 0.12 & \pm 0.14 & \pm 1 & \pm 0.07 & \pm 0.009 \\
\hline 9.94 & 19.99 & 59.84 & 1.938 & 0.2022 & 18.80 & 18.61 & 7.88 & 54.31 & 34 & 4.20 & 33.677 \\
\hline \pm 0.08 & \pm 0.08 & \pm 0.09 & \pm 0.004 & \pm 0.0006 & \pm 0.05 & \pm 0.03 & \pm 0.12 & \pm 0.13 & \pm 1 & \pm 0.06 & \pm 0.008 \\
\hline 10.00 & 29.87 & 60.04 & 1.937 & 0.2545 & 19.35 & 19.18 & 8.04 & 55.70 & 26 & 3.91 & 32.103 \\
\hline \pm 0.08 & \pm 0.08 & \pm 0.08 & \pm 0.004 & \pm 0.0006 & \pm 0.05 & \pm 0.03 & \pm 0.12 & \pm 0.13 & \pm 1 & \pm 0.06 & \pm 0.008 \\
\hline 9.98 & 39.92 & 60.02 & 1.937 & 0.3613 & 20.11 & 19.95 & 8.27 & 57.53 & 18 & 3.59 & 30.367 \\
\hline \pm 0.08 & \pm 0.08 & \pm 0.08 & \pm 0.004 & \pm 0.0009 & \pm 0.05 & \pm 0.03 & \pm 0.13 & \pm 0.13 & \pm 1 & \pm 0.05 & \pm 0.011 \\
\hline 9.87 & 50.03 & 59.95 & 1.937 & 0.6832 & 21.16 & 20.99 & 8.59 & 59.98 & 11 & 3.22 & 28.34 \\
\hline \pm 0.08 & \pm 0.08 & \pm 0.08 & \pm 0.004 & \pm 0.0014 & \pm 0.05 & \pm 0.03 & \pm 0.13 & \pm 0.12 & \pm 1 & \pm 0.05 & \pm 0.03 \\
\hline 9.97 & 54.91 & 60.06 & 1.939 & 1.256 & 21.92 & 21.76 & 8.80 & 61.70 & 8 & 2.99 & 27.10 \\
\hline \pm 0.08 & \pm 0.08 & \pm 0.08 & \pm 0.004 & \pm 0.002 & \pm 0.05 & \pm 0.03 & \pm 0.13 & \pm 0.12 & \pm 1 & \pm 0.05 & \pm 0.11 \\
\hline 19.97 & 9.97 & 54.94 & 1.940 & 0.2467 & 17.18 & 16.94 & 7.72 & 50.13 & 40 & 5.88 & 46.350 \\
\hline \pm 0.08 & \pm 0.08 & \pm 0.09 & \pm 0.004 & \pm 0.0006 & \pm 0.05 & \pm 0.03 & \pm 0.12 & \pm 0.14 & \pm 1 & \pm 0.09 & \pm 0.012 \\
\hline 19.99 & 10.07 & 60.23 & & & 18.92 & & & 54.63 & 44 & 5.61 & 47.083 \\
\hline \pm 0.08 & \pm 0.08 & \pm 0.09 & \pm 0.004 & \pm 0.0006 & \pm 0.05 & \pm 0.03 & \pm 0.13 & \pm 0.14 & \pm 1 & \pm 0.08 & \pm 0.012 \\
\hline 20.02 & 10.12 & 60.11 & 1.933 & 0.2267 & 18.96 & 18.73 & 8.24 & 54.71 & 44 & 5.65 & 47.372 \\
\hline \pm 0.08 & \pm 0.08 & \pm 0.09 & \pm 0.004 & \pm 0.0006 & \pm 0.05 & \pm 0.03 & \pm 0.13 & \pm 0.13 & \pm 1 & \pm 0.08 & \pm 0.012 \\
\hline 20.06 & .10 & 60.08 & 1.935 & 0.2644 & 19.31 & 19.10 & 8.36 & 55.59 & 35 & 5.19 & 44.185 \\
\hline \pm 0.08 & \pm 0.08 & \pm 0.08 & \pm 0.004 & \pm 0.0007 & \pm 0.05 & \pm 0.03 & \pm 0.13 & \pm 0.13 & \pm 1 & \pm 0.08 & \pm 0.01 \\
\hline 20.04 & 30.13 & 60.01 & 1.932 & 0.3295 & 19.74 & 19.54 & 8.47 & 56.64 & 27 & 4.76 & 41.143 \\
\hline \pm 0.08 & \pm 0.08 & \pm 0.08 & \pm 0.004 & \pm 0.0008 & \pm 0.05 & \pm 0.03 & \pm 0.13 & \pm 0.13 & \pm 1 & \pm 0.07 & \pm 0.012 \\
\hline 20.01 & 40.16 & 60.19 & 1.934 & 0.4637 & 20.48 & 20.29 & 8.71 & 58.40 & 19 & 4.36 & 38.84 \\
\hline \pm 0.08 & \pm 0.08 & \pm 0.08 & \pm 0.004 & \pm 0.001 & \pm 0.05 & \pm 0.03 & \pm 0.13 & \pm 0.13 & \pm 1 & \pm 0.07 & \pm 0.02 \\
\hline 20.16 & 50.05 & 60.22 & 1.939 & 0.855 & 21.53 & 21.34 & 9.03 & 60.82 & 12 & 3.92 & 36.37 \\
\hline \pm 0.09 & \pm 0.08 & \pm 0.08 & \pm 0.004 & \pm 0.002 & \pm 0.05 & \pm 0.03 & \pm 0.14 & \pm 0.12 & \pm 1 & \pm 0.06 & \pm 0.05 \\
\hline 20.27 & 55.12 & 59.82 & 1.940 & 1.844 & 22.22 & 22.02 & 9.25 & 62.36 & 8 & 3.76 & 36.2 \\
\hline \pm 0.09 & \pm 0.08 & \pm 0.08 & \pm 0.004 & \pm 0.004 & \pm 0.05 & \pm 0.03 & \pm 0.14 & \pm 0.12 & \pm 1 & \pm 0.06 & \pm 0.2 \\
\hline 20.14 & 55.26 & 59.97 & 1.977 & 1.774 & 22.43 & 22.24 & 9.28 & 62.83 & 9 & 3.63 & 34.9 \\
\hline \pm 0.08 & \pm 0.08 & \pm 0.08 & \pm 0.004 & \pm 0.003 & \pm 0.05 & \pm 0.03 & \pm 0.14 & \pm 0.12 & \pm 1 & \pm 0.06 & \pm 0.2 \\
\hline 19.98 & 55.01 & 65.11 & 1.942 & 0.853 & 23.71 & 23.51 & 9.69 & 65.59 & 11 & 3.63 & 36.07 \\
\hline \pm 0.08 & \pm 0.08 & \pm 0.08 & \pm 0.004 & \pm 0.002 & \pm 0.05 & \pm 0.03 & \pm 0.15 & \pm 0.11 & \pm 1 & \pm 0.05 & \pm 0.05 \\
\hline 24.86 & 9.83 & 54.88 & 1.942 & 0.2829 & 17.36 & 17.11 & 7.99 & 50.60 & 40 & 6.54 & 53.27 \\
\hline \pm 0.08 & \pm 0.09 & \pm 0.09 & \pm 0.004 & \pm 0.0008 & \pm 0.05 & \pm 0.03 & \pm 0.12 & \pm 0.15 & \pm 1 & \pm 0.1 & \pm 0.02 \\
\hline
\end{tabular}




\begin{tabular}{|c|c|c|c|c|c|c|c|c|c|c|c|}
\hline $\begin{array}{l}T_{w, e i} \\
{\left[{ }^{\circ} \mathrm{C}\right]}\end{array}$ & $\begin{array}{l}T_{w, c i} \\
{\left[{ }^{\circ} \mathrm{C}\right]}\end{array}$ & $\begin{array}{l}T_{w, c o} \\
{\left[{ }^{\circ} \mathrm{C}\right]}\end{array}$ & $\begin{array}{c}\mathbf{m}_{\mathrm{w}, \mathrm{e}} \\
{[\mathrm{kg} / \mathrm{h}]}\end{array}$ & $\begin{array}{c}\mathbf{m}_{\mathrm{w}, \mathrm{c}} \\
{[\mathrm{kg} / \mathrm{h}]}\end{array}$ & $\begin{array}{c}\mathbf{p}_{\mathbf{c}} \\
\text { [bar] }\end{array}$ & $\begin{array}{c}\mathbf{p}_{\text {LR }} \\
\text { [bar] }\end{array}$ & $\begin{array}{c}\text { Wc } \\
{[\mathrm{kW}]}\end{array}$ & $\begin{array}{c}\text { Tc } \\
{\left[{ }^{\circ} \mathrm{C}\right]}\end{array}$ & $\begin{array}{c}\text { Sc } \\
{[\mathrm{K}]}\end{array}$ & $\begin{array}{c}\mathrm{COP}_{\mathrm{h}} \\
{[-]}\end{array}$ & $\begin{array}{c}\mathbf{Q}_{\mathrm{h}} \\
{[\mathrm{kW}]}\end{array}$ \\
\hline 24.93 & 10.09 & 60.10 & 1.934 & 0.2524 & 18.99 & 18.74 & 8.42 & 54.79 & 44 & 6.15 & 52.755 \\
\hline \pm 0.08 & \pm 0.08 & \pm 0.09 & \pm 0.004 & \pm 0.0006 & \pm 0.05 & \pm 0.03 & \pm 0.13 & \pm 0.14 & \pm 1 & \pm 0.09 & \pm 0.014 \\
\hline 25.03 & 10.14 & 60.02 & 1.944 & 0.2550 & 19.00 & 18.74 & 8.46 & 54.82 & 44 & 6.17 & 53.150 \\
\hline \pm 0.08 & \pm 0.08 & \pm 0.09 & \pm 0.004 & \pm 0.0006 & \pm 0.05 & \pm 0.03 & \pm 0.13 & \pm 0.14 & \pm 1 & \pm 0.09 & \pm 0.014 \\
\hline 24.95 & 20.08 & 60.18 & 1.941 & 0.3018 & 19.43 & 19.19 & 8.58 & 55.89 & 36 & 5.79 & 50.58 \\
\hline \pm 0.08 & \pm 0.09 & \pm 0.09 & \pm 0.004 & \pm 0.0008 & \pm 0.05 & \pm 0.03 & \pm 0.13 & \pm 0.13 & \pm 1 & \pm 0.09 & \pm 0.02 \\
\hline 25.03 & 30.09 & 60.03 & 1.938 & 0.3798 & 19.93 & 19.67 & 8.71 & 57.10 & 27 & 5.35 & 47.55 \\
\hline \pm 0.08 & \pm 0.09 & \pm 0.09 & \pm 0.004 & \pm 0.0009 & \pm 0.05 & \pm 0.03 & \pm 0.13 & \pm 0.13 & \pm 1 & \pm 0.08 & \pm 0.02 \\
\hline 25.09 & 40.09 & 60.22 & 1.940 & 0.5214 & 20.58 & 20.36 & 8.92 & 58.64 & 19 & 4.81 & 43.91 \\
\hline \pm 0.08 & \pm 0.08 & \pm 0.08 & \pm 0.004 & \pm 0.0011 & \pm 0.05 & \pm 0.03 & \pm 0.14 & \pm 0.12 & \pm 1 & \pm 0.07 & \pm 0.02 \\
\hline 24.89 & 49.96 & 60.38 & 1.941 & 0.934 & 21.66 & 21.44 & 9.24 & 61.13 & 12 & 4.28 & 40.69 \\
\hline \pm 0.08 & \pm 0.08 & \pm 0.08 & \pm 0.004 & \pm 0.002 & \pm 0.05 & \pm 0.03 & \pm 0.14 & \pm 0.12 & \pm 1 & \pm 0.06 & \pm 0.06 \\
\hline 25.00 & 55.04 & 60.08 & 1.940 & 1.858 & 22.33 & 22.12 & 9.43 & 62.62 & 9 & 3.99 & 39.2 \\
\hline \pm 0.08 & \pm 0.08 & \pm 0.08 & \pm 0.004 & \pm 0.004 & \pm 0.05 & \pm 0.03 & \pm 0.14 & \pm 0.12 & \pm 1 & \pm 0.06 & \pm 0.2 \\
\hline 25.00 & 55.07 & 65.17 & 1.940 & 0.934 & 23.81 & 23.61 & 9.9 & 65.80 & 12 & 3.90 & 39.49 \\
\hline \pm 0.08 & \pm 0.08 & \pm 0.08 & \pm 0.004 & \pm 0.002 & \pm 0.05 & \pm 0.03 & \pm 0.2 & \pm 0.11 & \pm 1 & \pm 0.06 & \pm 0.07 \\
\hline 29.93 & 9.90 & 59.86 & 1.945 & 0.2820 & 19.02 & 18.73 & 8.66 & 54.87 & 44 & 6.67 & 58.87 \\
\hline \pm 0.08 & \pm 0.08 & \pm 0.09 & \pm 0.004 & \pm 0.0008 & \pm 0.05 & \pm 0.03 & \pm 0.05 & \pm 0.13 & \pm 1 & \pm 0.04 & \pm 0.02 \\
\hline 29.96 & 29.88 & 59.83 & 1.954 & 0.4268 & 19.98 & 19.67 & 8.94 & 57.21 & 27 & 5.85 & 53.42 \\
\hline \pm 0.08 & \pm 0.08 & \pm 0.08 & \pm 0.004 & & \pm 0.05 & \pm 0.03 & \pm 0.05 & \pm 0.12 & \pm 1 & \pm 0.03 & \pm 0.03 \\
\hline 29.79 & 50.04 & 59.82 & 1.949 & 1.143 & 21.74 & 21.46 & 9.50 & 61.30 & 12 & 4.78 & 46.8 \\
\hline \pm 0.08 & \pm 0.08 & \pm 0.08 & \pm 0.004 & \pm 0.004 & \pm 0.05 & \pm 0.03 & \pm 0.05 & \pm 0.12 & \pm 1 & \pm 0.04 & \pm 0.3 \\
\hline 29.93 & 55.13 & 1.99 & & & 24.00 & 23.72 & 10.16 & 66.20 & 12 & 4.33 & 45.13 \\
\hline \pm 0.09 & \pm 0.08 & \pm 0.11 & \pm 0.004 & \pm 0.0008 & \pm 0.06 & \pm 0.04 & \pm 0.05 & \pm 0.14 & \pm 1 & \pm 0.04 & \pm 0.02 \\
\hline 34.87 & 19.98 & 60.01 & 1.935 & 0.3786 & 19.60 & 19.27 & 9.07 & 56.30 & 36 & 6.85 & 63.34 \\
\hline \pm 0.08 & \pm 0.08 & \pm 0.08 & \pm 0.004 & \pm 0.001 & \pm 0.05 & \pm 0.03 & \pm 0.05 & \pm 0.12 & \pm 1 & \pm 0.04 & \pm 0.02 \\
\hline 34.95 & 40.31 & 60.12 & 1.940 & 0.675 & 20.90 & 20.53 & 9.43 & 59.39 & 18 & 5.83 & 55.92 \\
\hline \pm 0.08 & \pm 0.08 & \pm 0.08 & \pm 0.004 & \pm 0.002 & \pm 0.05 & \pm 0.03 & \pm 0.05 & \pm 0.12 & \pm 1 & \pm 0.03 & \pm 0.11 \\
\hline 34.93 & 54.98 & 60.33 & 1.951 & 2.287 & 22.72 & 22.39 & 9.97 & 63.48 & 9 & 4.88 & 51.27 \\
\hline \pm 0.08 & \pm 0.08 & \pm 0.08 & \pm 0.004 & \pm 0.002 & \pm 0.05 & \pm 0.03 & \pm 0.05 & \pm 0.11 & \pm 1 & \pm 0.03 & \pm 0.1 \\
\hline 19.77 & 9.78 & 59.89 & 1.942 & 0.1673 & 18.08 & 17.90 & 8.07 & 52.02 & 1 & 4.27 & 35.043 \\
\hline \pm 0.08 & \pm 0.09 & \pm 0.11 & \pm 0.004 & \pm 0.0006 & \pm 0.06 & \pm 0.03 & \pm 0.12 & \pm 0.09 & \pm 1 & \pm 0.06 & \pm 0.01 \\
\hline 19.94 & 30.03 & 59.84 & 1.943 & 0.2732 & 19.22 & 19.02 & 8.39 & 54.88 & 1 & 3.99 & 34.047 \\
\hline \pm 0.08 & \pm 0.1 & \pm 0.1 & \pm 0.004 & \pm 0.0007 & \pm 0.06 & \pm 0.03 & \pm 0.13 & \pm 0.08 & \pm 1 & \pm 0.06 & \pm 0.011 \\
\hline 19.97 & 50.18 & 60.22 & 1.934 & 0.784 & 21.42 & 21.22 & 9.05 & 60.11 & 1 & 3.57 & 32.90 \\
\hline \pm 0.08 & \pm 0.08 & \pm 0.08 & \pm 0.004 & \pm 0.002 & \pm 0.05 & \pm 0.03 & \pm 0.14 & \pm 0.06 & \pm 1 & \pm 0.05 & \pm 0.05 \\
\hline 19.92 & 55.22 & 60.31 & 1.935 & 1.523 & 22.28 & 22.09 & 9.27 & 62.08 & 1 & 3.40 & 32.4 \\
\hline \pm 0.08 & \pm 0.08 & \pm 0.08 & \pm 0.004 & \pm 0.003 & \pm 0.05 & \pm 0.03 & \pm 0.14 & \pm 0.06 & \pm 1 & \pm 0.05 & \pm 0.2 \\
\hline 19.77 & 9.78 & 59.89 & 1.942 & 0.1673 & 18.08 & 17.90 & 8.07 & 52.02 & 1 & 4.27 & 35.043 \\
\hline \pm 0.08 & \pm 0.09 & \pm 0.11 & \pm 0.004 & \pm 0.0006 & \pm 0.06 & \pm 0.03 & \pm 0.12 & \pm 0.09 & \pm 1 & \pm 0.06 & \pm 0.01 \\
\hline
\end{tabular}

